\title{
Anabolic management in patients with COPD
}

Citation for published version (APA):

Creutzberg, E. C. (2000). Anabolic management in patients with COPD. [Doctoral Thesis, Maastricht University]. Universitaire Pers Maastricht. https://doi.org/10.26481/dis.20001027ec

Document status and date:

Published: 01/01/2000

DOI:

$10.26481 /$ dis.20001027ec

Document Version:

Publisher's PDF, also known as Version of record

\section{Please check the document version of this publication:}

- A submitted manuscript is the version of the article upon submission and before peer-review. There can be important differences between the submitted version and the official published version of record.

People interested in the research are advised to contact the author for the final version of the publication, or visit the DOI to the publisher's website.

- The final author version and the galley proof are versions of the publication after peer review.

- The final published version features the final layout of the paper including the volume, issue and page numbers.

Link to publication

\footnotetext{
General rights rights.

- You may freely distribute the URL identifying the publication in the public portal. please follow below link for the End User Agreement:

www.umlib.nl/taverne-license

Take down policy

If you believe that this document breaches copyright please contact us at:

repository@maastrichtuniversity.nl

providing details and we will investigate your claim.
}

Copyright and moral rights for the publications made accessible in the public portal are retained by the authors and/or other copyright owners and it is a condition of accessing publications that users recognise and abide by the legal requirements associated with these

- Users may download and print one copy of any publication from the public portal for the purpose of private study or research.

- You may not further distribute the material or use it for any profit-making activity or commercial gain

If the publication is distributed under the terms of Article $25 \mathrm{fa}$ of the Dutch Copyright Act, indicated by the "Taverne" license above, 
Anabolic management in patients with COPD

Eva Charlotte Creutzberg 
(C) Eva Charlotte Creutzberg, Maastricht 2000

Omslagillustratie: Johanna Creutzberg-Eskes

Druk: Datawyse / Universitaire Pers Maastricht

ISBN: 90-9014105-7

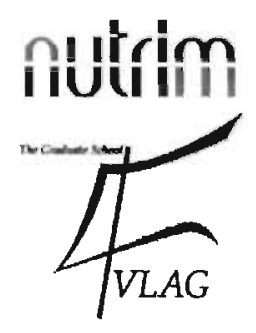

The study presented in this thesis was performed at the Nutrition and Toxicology Research Institute Maastricht (NUTRIM) which participates in the Graduate School VLAG (Food Technology, Agrobiotechnology, Nutrition and Health Sciences), accredited by the Royal Netherlands Academy of Arts and Sciences. 


\section{Anabolic management in patients with COPD}

\section{PROEFSCHRIFT}

ter verkrijging van de graad van doctor aan de Universiteit Maastricht, op gezag van de Rector Magnificus Prof. dr. A. C. Nieuwenhuijzen

Kruseman, volgens het besluit van het College van Decanen, in het openbaar te verdedigen op vrijdag 27 oktober 2000 om 12.00 uur door

Eva Charlotte Creutzberg 


\section{Promotor}

Prof. dr. E. F. M. Wouters

\section{Co-promotor}

Dr. ir. A. M. W. J. Schols

\section{Beoordelingscommissie}

Prof. dr. R. W. Stockbrügger (voorzitter)

Prof. dr. P. M. A. Calverley (University Hospital Aintree, Liverpool, UK)

Prof. dr. G. Ramsay

Prof. dr. H. P. Sauerwein (Universiteit van Amsterdam)

Prof. dr. K. R. Westerterp 
Ter nagedachtenis aan mijn vader Aan mijn moeder 

Contents 


\section{Chapter 1}

General introduction

\section{Chapter 2}

Prevalence of an elevated resting energy expenditure in patients with chronic obstructive pulmonary disease in relation to body composition and lung function

\section{Chapter 3}

Acute effects of nebulized salbutamol on resting energy expenditure in patients with chronic obstructive pulmonary disease and in healthy subjects

\section{Chapter 4}

Plasma leptin is related to proinflammatory status and dietary intake in patients with chronic obstructive pulmonary disease

\section{Chapter 5}

Disturbances in leptin metabolism are related to energy imbalance during acute exacerbations of chronic obstructive pulmonary disease

\section{Chapter 6}

Efficacy of nutritional supplementation therapy implemented in a pulmonary rehabilitation program in depleted patients with COPD

\section{Chapter 7}

Characterization of nonresponse to high caloric oral nutritional therapy in depleted patients with chronic obstructive pulmonary disease

\section{Chapter 8}

Anabolic steroids

\section{Chapter 9}

A role for anabolic steroids in the rehabilitation of patients with chronic obstructive pulmonary disease? A double-blind, placebo-controlled, randomized trial

\section{Chapter 10}

General Discussion

\section{Chapter 11}

Summary 
Chapter 12

Samenvatting

p. 163

Abbreviations

ค. 167

Naschrift

p. 171

Publications

p. 175

Curriculum vitae

p. 177 


\title{
Chapter 1
}

\author{
General introduction
}




\section{Chronic obstructive pulmonary disease}

\section{Prevalence and health care costs}

Chronic obstructive pulmonary disease (COPD) represents a major problem for health care, since it is one of commonest causes of death and the only cause of death which is increasing at this time (1). It represents the fourth cause of death in the Netherlands and will be the third leading cause of death worldwide in 2020 , with an expected mortality of 4.7 million persons each year. In the Netherlands, approximately 73 per 1000 subjects are diagnosed as having COPD. Persistently decreased lung function or a rapid decline in lung function, as clinical characteristics of COPD, are observed in approximately $20 \%$ of the general adult population in the Netherlands (2).

COPD is a major burden for health care. In 1993, the COPD-related medical costs. including costs for physicians, hospital care, nursing and medication, were $1.3 \%$ of the total Dutch health care budget. When assuming constant treatment patterns and care, the prevalence of COPD in the Netherlands will increase to 31 per 1000 inhabitants in 2010 , relative to 20 per 1000 inhabitants in 1993 . Ageing of the population is the main cause of this predicted increase in prevalence. As a result, the total COPD-related costs will be increased with $60 \%$ in 2010 . Future scenarios that include feasible or optimistic smoking reduction effects, predict a cost reduction to a $56 \%$ and a $46 \%$ increase respectively. In the long run, the impact of smoking cessation on medical costs will nevertheless rise (3).

\section{Definitions, causes and pathology}

COPD is defined as a disorder indicated by tests of abnormal expiratory airflow, that do not change markedly over periods of several months (4). The chronic airflow limitation progresses slowly over time and the disease is, by definition, largely irteversible (5). In clinical practice, the forced expiratory volume in one second $\left(F E V_{1}\right)$, as a measure of airflow obstruction, is used to separate the different stages of COPD from mild (stage I) via moderate (stage II) to severe (stage III) $(4,5)$. Long-term tobacco smoking is currently a causal factor in more than $90 \%$ of the patients in westernized societies (1). Other factors influencing the prevalence and incidence of COPD are sex, race, ambient air pollution, occupational factors (4) and socioeconomic status (6). In addition, genetic variations may predispose to COPD. Subjects who have a genetic deficiency in the anti-protease $\alpha_{1}$ antitrypsin have a very high risk of developing emphysema at an early age (7). In the future, more information will come available on other genetic risk factors for COPD, like polymorphisms of genes coding for other proteases and antiproteases, immunoglobulines, vitamins (1), inflammatory cytokines (8) and oxidative and antioxidative mediators (9). COPD comprises the subtypes emphysema and chronic bronchitis. Chronic bronchitis is defined as the presence of chronic productive cough for three months in each of two successive years, while other causes of chronic cough have been excluded. Emphysema is defined as abnormal permanent enlargement of the airspaces distal to the terminal bronchioles, accompanied by destuction of their walls and without obvious fibrosis. The pathology of chronic bronchitis primarily includes large airway mucus gland hyperplasia and inflammation. Emphysema is related with a decreased diffusing capacity and a reduced lung parenchymal density on high-resolution computerized tomography (4). In a substantial part of the patients, the two subtypes of COPD are present together, their respective attribution varying from patient to patient. 
The most important complaint of patients with COPD is dyspnea at exertion and in later stages also at rest (10). Dyspnea however poorly correlates with routine spirometry measurements (11). In contrast, lung hyperinflation is a major contributor to the intersubject variability in the perception of dyspnea or breathlessness for a given ventilation (12). Lung hyperinflation is defined as an abnormal increase in functional residual capacity, i.e. lung volume at the end of tidal expiration. Hyperinflation results from changes in the elastic properties of the lungs and chest wall and is therefore predominantly present in patients with the emphysematous type of COPD (13). Lung hyperinflation increases the rib cage contribution to chest wall motion, whilst it reduces the abdominal contribution. These changes are likely the results of the fact that the mechanical advantage of the diaphragm is severely reduced (14). The chronic rise in respiratory load and lung volume due to increasing lung hyperinflation result in new functional requirements of the diaphragm (15). The diaphragm adapts to the chronically hyperinflated state of the lung by flattening. This adaptation to chronic foreshortening is caused by a dropout of sarcomeres in series along the muscle fibers. It in part restores the force-generating capacity of the muscle, but it reduces the capacity of the muscle to undergo length changes (14).

Hyperinflation may worsen during exercise; the so-called dynamic hyperinflation is the result of the onset of inspiration before lung volumes has fallen to the relaxation volume of the respiratory system (air-trapping). Dynamic hyperinflation increases the mechanical load on the inspiratory muscles and the oxygen cost of breathing at exertion (13).

\section{Determinants of impaired physical functioning}

Several studies indicate that functional capacity is impaired in patients with COPD. The $\mathrm{FEV}_{1}$, which has been shown to be an accurate predictor of prognosis, is the most widely used measure of the severity of COPD. However, the $\mathrm{FEV}_{1}$ and measures of oxygenation, like $\mathrm{PaO}_{2}$ and $\mathrm{SaO}_{2}$, are only weakly associated with physical functioning (16). Therefore other factors must be responsible for the impaired physical functioning in COPD.

In order to examine the factors responsible for the decreased function in COPD, it was found that peripheral skeletal muscle strength, independently of disease severity, was an important contributor to both symptom intensity (fatigue and dyspnea) and work capacity (17). A subsequent study revealed that the intensity of symptoms was significantly associated with power output at submaximal and maximal exercise in health as well as in cardiorespiratory disease. Leg fatigue and dyspnea were the predominant subjective exercise-limiting factors (18). In patients with COPD, subjective physical fatigue, but not $\mathrm{FEV}_{1}$, was significantly, inversely correlated with peripheral skeletal muscle force (19).

In addition, fat-free mass (FFM), as an indirect measure of muscle mass, is an important determinant of physical capacity. Depletion of FFM commonly occurs in COPD, its prevalence amounting up from $20 \%$ in clinically stable outpatients (20) up to $35 \%$ in patients eligible for pulmonary rehabilitation (21).

It was a long-held misconception that nutritional depletion was an inevitable and adaptive mechanism to increased metabolism and that during undernutrition the respiratory muscles were spared. It is now known that loss of body weight and FFM adversely affects respiratory as well as peripheral muscle function $(20,22)$ and exercise capacity $(21)$, 
independently of disease severity. Body weight loss was furthermore identified as a predictor of increasing mortality in patients with COPD, independently of lung function, arterial blood gases and smoking behavior $(23,24)$.

Besides overall loss of muscle mass, intrinsic muscle abnormalities are reported in COPD. Concerning the respiratory muscles, there is evidence that the diaphragm of patients with severe COPD has undergone adaptations resulting in relative resistance to fatigue. The physiological alterations were accompanied by increases in fiber type I proportions and in slow isoforms of myofibrillar proteins (25). In contrast, in the peripheral muscles, a decrease in the proportion of type I fibers corresponding with a relative increase in type II fibers was seen, indicating a shift in function from endurance towards more strength $(26,27)$. These morphological alterations can be accompanied by disturbances in peripheral muscle oxidative enzyme capacity. Patients with COPD exhibiting chronic respiratory failure showed increased activity of the mitochondrial enzyme cytochrome oxidase in skeletal muscle compared with healthy control subjects (28). In addition, elevated concentrations of inosine monophosphate, which is thought to reflect an imbalance between resynthesis and utilization of adenosine triphosphate, were found in the peripheral muscle tissue of stable patients with COPD (29).

Furthermore, the COPD population comprises merely elderly subjects. Aging per se is already accompanied by a decline in the size of muscle fibers and thereby in muscle function, which is an important determinant of physical performance (30). Furthermore, many patients with COPD reduce their level of exercise dramatically in response to exertional dyspnea. The resulting sedentary lifestyle leads to muscle deconditioning and ultimately to inactivity and disability (31).

\section{Determinants of impaired health status}

Health status is reported to be impaired in patients with COPD. Health status is defined as to signify the gap, specifically due to the disease, between that which is desired and that which is achievable. Impaiment in health status in COPD is related with factors like distress because of respiratory symptoms, disturbance of physical activity and the impact of the disease on daily life and well-being (32).

Health status was found to be only weakly associated with disease severity on base of the $\mathrm{FEV}_{1}(16)$. In elderly patients with COPD, activities of daily living and emotional status were predictors of health status but not the severity of the disease (33). Another study also revealed that when patients were classified according to the disease stage on base of the $\mathrm{FEV}_{1}$, no or a weak association was found with health status. In contrast, when patients were classified according to the level of dyspnea, a significant, inverse association with health status was revealed (34).

Furthermore, a reduced health status in COPD is associated with nutritional depletion. Patients suffering from lean mass depletion exhibited significantly greater impairment in symptom, activity, impact and overall SGRQ scores. The effects of tissue depletion on health status appeared however to be mediated through increased levels of dyspnea (35). In contrast, Mostert et al. revealed that the relation between tissue depletion and health status was independently of dyspnea, but instead mediated by a decreased exercise performance (36). 
In addition, depression, anxiety and emotional dysfunction play a prominent role in COPD. It is suggested that the degree of psychosocial limitation may not be as strongly influenced by disease severity once some threshold of COPD is reached. Measures of exercise tolerance as well as dyspnea correlate better with psychosocial limitation than $F E V_{1}$ or oxygenation measures (16). A recent study revealed that depression scores, as well as exercise performance and health status, were not correlated with $\mathrm{FEV}_{1}$, but instead with dyspnea (37).

\section{Determinants of weighi loss and muscle wasting}

Energy balance

Disturbances in the energy balance are the result of an imbalance between energy expenditure and dietary intake. An energy imbalance is reported in patients with stable COPD (38) and to a worse extent in patients suffering from an acute disease exacerbation (39).

In general, the dietary intake of patients with COPD does not differ from the recommended daily allowances (40). Weight-losing patients exhibited however a lower dietary intake compared with weight-stable patients (38). During an acute exacerbation of COPD, a substantial decrease in appetite and dietary intake was reported, associated with increased subjective sensations of dyspnea and fatigue (39).

Limited data are however available on the underlying disturbances in the (dys-) regulation of appetite and dietary intake relative to energy expenditure. Previous experimental and clinical research indicate the involvement of leptin in energy balance and body weight homeostasis. Leptin is a hormone produced by the adipose tissue and its circulating concentrations are proportional to the amount of fat mass (FM). It regulates the energy balance in a feedback mechanism in which the hypothalamus is involved (41). In animals, administration of leptin results in a reduction in food intake (42) as well as in an increase in energy expenditure (43). It is unknown if possible disturbances in the normal feedback mechanism of leptin are responsible for the decreased dietary intake reported in COPD. At the other end of the energy balance, an elevated resting energy expenditure (REE) is often seen in patients with COPD (44). The increase in REE was however found to be unrelated to the increased total daily energy expenditure $(45,46)$. Furthermore, in contrast to the earlier opinion, hypermetabolism at rest is not the result of an increased oxygen cost of breathing (12). In a recent study, plasma TNF $\alpha$ concentrations were positively correlated with REE in patients with COPD, suggesting a causal relationship between the systemic inflammatory response and hypermetabolism at rest (47). Some bronchodilators, like the $B_{2}$-sympathicomimetic drug salbutamol, have thermogenic properties. Reports in younger healthy subjects and in patients with COPD found dose-dependent increases in REE after administration of a single dose of salbutamol $(48,49)$. The effects of salbutamol on REE in patients with COPD in comparison with younger and elderly healthy subjects are however unknown. Furthermore, the prevalence of an elevated REE in relation with body composition and lung function is still to be investigated.

\section{Protein balance}

Besides an overall energy imbalance, there are also indications for disturbances in the protein balance in a subgroup of patients with COPD. Since selective wasting of FFM 
despite relative preservation of FM is reported (50), a disturbed protein balance can also be present without accompaniment of overall body weight loss. At first, the daily protein intake is reported to be decreased compared to the recommended allowances, especially during the first days of an acute exacerbation of COPD (39). Secondly, as one mechanism of muscle wasting, a decreased protein synthesis was seen in underweight patients with emphysema (51).

An enhanced systemic inflammatory response is described as one of the possible causes of a selectively disturbed protein balance. In patients with an elevated REE and an increased $\mathrm{C}$-reactive protein, FFM was decreased together with elevated concentrations of the inflammatory mediators LPS-binding protein (LBP), interleukin-8 and soluble TNFreceptors 55 and 75 compared with those with normal CRP concentrations (52). In addition, an inverse correlation coefficient between elevated plasma LBP concentrations and the of total sum of plasma amino acids was reported (53).

Furthermore, decreased levels of anabolic hormones might aggravate the failure of generating an anabolic response needed for muscle anabolism. Indeed low levels of testosterone are reported in COPD, which were even more pronounced in patients on oral glucocorticosteroid (GC) therapy (54). Long-term, low-dose systemic glucocorticosteroids are prescribed as maintenance antiinflammatory medication in a substantial number of patients. Chronic use of oral glucocorticosteroids further contributes to weakness of both the respiratory and peripheral muscles in patients with COPD (55).

\section{Therapy}

Because of the deleterious effects of body weight loss and muscle wasting on morbidity and mortality in COPD, it is important to take the implementation of appropriate therapies under investigation. Several attempts have been made to reverse weight loss and muscle wasting by instituting oral nutritional repletion therapy (56-60). The outcome of these interventions were however not unambiguously positive. The fact that the designs of the different studies varied substantially, could be (one of the) explanations for these nonuniform results. It is very important to optimize the study design in order to exclude failure of the intervention as a factor responsible for nonresponse to nutritional supplementation therapy.

It can be deduced from the above described evidence on protein balance disturbances in COPD, that nutritional supplementation must consist of enough dietary protein, as well as of a sufficient amount of calories given for a reasonable time span. Furthermore, the intervention has to be combined with an anabolic stimulus, like exercise training, to enhance improvements in muscle mass and physical function. In other words, the intervention design has to be optimized before improvements in clinical outcome can be achieved. Then it can be studied if patients with COPD are indeed able to generate an anabolic response after nutritional supplementation therapy comparable with healthy, elderly subjects. In addition, the effects on physical performance and health status are to be precisely defined, since the available nutritional interventions have mainly focused on body composition and respiratory muscle function only.

It is described that a substantial number of patients fails to respond to nutritional supplementation therapy in terms of body weight gain. The clinical relevance of 
nonresponse to nutritional therapy was emphasized by a recent survival analysis that revealed weight gain as a significant, independent predictor of survival in patients with COPD (23). The underlying causes of nonresponse to nutritional therapy are unknown. Nonresponse may be due to factors such as noncompliance to the therapy, an inadequate energy intake relative to energy requirements or the inability of the patient to ingest the extra calories. It is unknown to what extent nonresponse can be explained by underlying disease-specific problems leading to an inadequate metabolic handling. Furthermore, maintenance treatment with oral glucocorticosteroids is suggested as one of the possible explanations for the problem why patients with COPD are not able to generate an anabolic response on nutritional therapy.

Anabolic stimuli such as anabolic steroids might be an additional mode of intervention for the treatment of muscle wasting in COPD. Only few controlled studies on anabolic steroid supplementation are performed in COPD. Previously we investigated the effects of nandrolone decanoate combined with nutritional supplementation versus nutrition alone or placebo, as integrated part of an eight-weeks pulmonary rehabilitation program. In the depleted patients, both treatment regimens resulted in improvements in body weight, FFM and maximal inspiratory mouth pressure (PI-max). However, only in the group treated with nandrolone decanoate, the rises in FFM and PI-max differed significantly from the control group. (60). Besides this short-term study, others have evaluated the effects of oral stanozolol treatment during six months in male depleted patients with COPD with a low PI-max. The treatment was combined with inspiratory muscle training and cycling. Body weight, lean body mass as well as arm muscle and thigh circumference increased. However, the changes in PI-max, the six minutes walking distance and maximal exercise capacity were not different from the control group (61).

These previous studies with anabolic steroids have predominantly evaluated their efficacy in the treatment of weight loss. However, imposement of anabolic stimuli might be indicated for the improvement of muscle mass in COPD, irrespectively of weight loss. Furthermore, the effects on physical performance and health status are to be defined.

\section{Aims of the thesis}

The aims of the thesis were:

1. To investigate the prevalence of and the contributing factors to an increased REE in patients with COPD

2. To investigate the role of leptin in the energy (im-)balance in patients with stable COPD and during acute disease exacerbations.

3. To investigate the efficacy of nutritional supplementation and anabolic steroid therapy implemented in a pulmonary rehabilitation program in patients with COPD. In addition, determinants of nonresponse to anabolic management are studied.

\section{Outline of the thesis}

In chapter 2, the prevalence of an elevated REE in patients with COPD in relation with body compositional and lung functional characteristics is studied. As one of the possible contributors of hypermetabolism at rest, in chapter 3 the acute effects of a single dose of 
nebulized salbutamol on REE is investigated in patients with COPD compared with a group of younger and elderly healthy subjects.

In chapter 4 , the role of leptin in the energy balance of patients with stable COPD is studied, as well as the possible regulators of systernic leptin concentrations. In chapter 5 , the role of leptin in the energy balance of patients with COPD during hospitalization for an acute disease exacerbation of COPD is investigated, as well as the possible regulators of systemic leptin concentrations.

In chapter 6, the efficacy of nutritional supplementation therapy implemented in a pulmonary rehabilitation program with respect to body composition, physical functioning and health status in depleted patients with COPD is evaluated. The potential causes of nonresponse to nutritional supplementation therapy in depleted patients with COPD are analyzed in chapter 7 . Chapter 8 reviews the ayailable information on the effects of anabolic steroids in acute and chronic disease, together with their supposed mechanisms of action. The efficacy of anabolic steroids in the rehabilitation of patients with COPD is studied in chapter 9 .

Chapter 10 comprises the general discussion of the thesis and gives implications for future investigations.

\section{References}

1. Barnes P.J. Genetics and pulmonary medicine - 9-Molecular geneties of chronic obstructive pulmonary disease. Thorax 1999,54 (3) $245-252$

2. van den Boom G., van Schayck C.P., van Mollen M.P., Tirimanna P.R., den Otter J.J., van Gnunsven P.M. Buitendijk M.J., van Herwaarden C.L., van Weel C. Active detection of chronic obstructive pulmonary disease and asthma in the general population. Results and economic. consequences of the DIMCA program. Am J Respir Crit Core Med 1998:158:1730-1738.

3. Rutten-van Molken M.P., Postma M.J., Joore M.A., Van Genugten M.L., Leidl R., Jager J.C. Current and future medical costs of asthma and chronic obstructive pulmonary disease in The Netherlands. Respir Med 1999:93:779-787.

4. ATS. Standards for the diagnosis and care of patients with chronic obstructive pulmonary disease Am J Respir Crit Care Med 1995:152 (suppl.):S77-121.

5. Siafakas N.M., Vermeire P., Pride N.B., Paoletti P., Gibson J., Howard P., Yernault J.C., Decramer M. Higenbottam T. Postma D.S., et al. Optimal assessment and management of chronic obstructive pulmonary disease (COPD). The European Respiratory Society Task Force /see cormments] Eur Respir J 1995:8:1398-1420.

6. Prescott E., Vestbo J. Sociocconomic status and chronic obstructive pulmonary discase. Thorax 1999:54:737-741.

7. Sandford A.J., Weir T.D., Spinelli J.J., Pare P.D. Z and S mutations of the alpha( ()-antitrypsin gene and the risk of chronic obstructive pulmonary disease. Am J Respir Crit Cell Mol Biolol 1999:20:287-291.

8. Huang S.L., Su C.H., Chang S.C. Tumor necrosis factor-alpha gene polymorphism in chronic bronchitis. Am J Respir Crit Care Med 1997:156 (5): 1436-1439.

9. Ishii T., Matsuse T., Teramoto S., Matsui H., Miyao M., Hosoi T., Takahashi H., Fukuchi Y.. Ouchi Y. Glutathione S-transferase P1 (GSTPI) polymorphism in patients with chronic obstructive pulmonary disease. Thorax 1999:54:693-696.

10. Mock P.M., Schwartzstein R.M., Adams L., Altose M.D., Breslin E.H.. Carrieri Kohlman V., Gift A.. Hanley M.V. Harver A. Jones P.W. Killian K. Knebel A., Lareau S.C. Mahler D. A.. D O.D. Steele B. Stuhlbarg M. Titler M. Dyspnea - Mechanisms, assessment, and managernent: A consensus statement. Am.J Respir (rit Care Med 1999:159 (1):321-340.

11. Wolkove N., Dajczman E., Colacone A., Kreisman H. The relationship between pulmonary 
function and dyspnea in obstructive lung disease. Chest 1989;96:1247-1251.

O. Donnell D., Webb K.A. Exertional breathlessness in patients with chronic airflow limitation. The role of lung hyperinflation. Am Rev Respir Dis 1993;148:1351-1357.

13. Gibson G.J. Pulmonary hyperinflation a clinical overview. Eur Respir J 1996;9:2640-2649.

14. Decramer M. Hyperinflation and respiratory muscle interaction. Eur Respir J 1997; 10:934-941

15. Mercadier J.J., Schwartz K., Schiaffino S., Wisnewsky C., Ausoni S., Heimburger M., Marrash R., Pariente R., Aubier M. Myosin heavy chain gene expression changes in the diaphragm of patients with chronic lung hyperinflation. Am J Physiol 1998:274:L527-534.

16. Curtis J.R., Deyo R.A., Hudson L.D. Pulmonary rehabilitation in chronic respiratory insufficiency.

7. Health-related quality of life among patients with chronic obstructive pulmonary disease. Thorax 1994:49:162-170

17. Hamilton A.L., Killian K.J., Summers E., Jones N.L. Muscle strength, symptom intensity, and exercise capacity in patients with cardiorespiratory disorders. Am J Respir Crit Care Med 1995; 152:2021-2031.

18. Hamilton A.L., Killian K.J., Summers E., Jones N.L. Symptom intensity and subjective limitation to exercise in patients with cardiorespiratory disorders. Chest 1996;110:1255-1263.

19. Breukink S.O., Strijbos J.H., Koom M., Koeter G.H., Breslin E.H., van der Schans C.P. Relationship between subjective fatigue and physiological variables in patients with chronic obstructive pulmonary disease. Respir Med 1998;92:676-682.

20. Engelen M.P.K.J., Schols A.M.W.J., Baken W.C., Wesseling G.J., Wouters E.F.M. Nutritional depletion in relation to respiratory and peripheral skeletal muscle function in out-patients with COPD. Eur Respir J 1994:7: 1793-1797.

21. Schols A.M.W.J., Soeters P.B., Dingemans A.M., Mostert R., Frantzen P.J., Wouters E.F.M. Prevalence and characteristics of nutritional depletion in patients with stable COPD eligible for pulmonary rehabilitation. Am Rev Respir Dis 1993;147:1151-1156.

22. Nishimura Y., Tsutsumi M., Nakata H., Tsunenari T., Maeda H., Yokoyama M. Relationship between respiratory muscle strength and lean body mass in men with COPD. Chest 1995; 107:1232-1236.

23. Schols A.M.W.J.. Slangen J.. Volovics L., Wouters E.F.M. Weight loss is a reversible factor in the prognosis of chronic obstructive pulmonary disease Am J Respir Crit Care Med 1998;157 (6): $1791-1797$

24. Landbo C.. Prescott E., Lange P., Vestbo J., Almdal T.P. Prognostic value of nutritional status in chronic obstructive pulmonary disease. Am J Respir Cril Care Med 1999;160:1856-1861.

25. Levine S.. Kaiser L., Leferovich J., Tikunov B. Cellular adaptations in the diaphragm in chronic obstructive pulmonary disease. N Engl J Med 1997:337:1799-1806.

26. Whittom F., Jobin J., Simard P.M., Leblanc P., Simard C., Bernard S., Belleau R., Maltais F. Histochemical and morphological characteristics of the vastus lateralis muscle in patients with chronic obstructive pulmonary disease. Med Sci Sports Exercise 1998;30 (10):1467-1474.

27. Satta A.. Migliori G.B. Spanevello A., Neri M. Bottinelli R. Canepari M., Pellegrino M.A., Reggiani C. Fibre types in skeletal muscles of chronic obstructive pulmonary disease patients related to respiratory function and exercise tolerance. Eur Respir $J$ 1997; 10:2853-2860.

28 Sauleda J., Garcia Palmer F., Wiesner R.J., Tarraga S., Harting I., Tomas P., Gomez C., Saus C., Palou A. Agusti A.G. Cytochrome oxidase activity and mitochondrial gene expression in skeletal muscle of patients with chronic obstructive pulmonary disease. Am $J$ Respir Crit Care Med 1998:157:1413-1417.

29. Pouw E.M. Schols A.M.W.J, vanderVusse G.J. Wouters E.F.M. Elevated inosine monophosphate levels in resting muscle of patients with stable chronic obstructive pulmonary disease. Am J Respir ('rit Care Med 1998:157 (2):453-457.

30. Klitgaard H. Mantoni M.. Schiaffino S., Ausoni S., Gorza L., Laurent-Winter C., Schnohr P., Saltin B. Function. morphology and protein expression of ageing skeletal muscle: a cross-sectional study of elderly men with different training backgrounds. Acta Physiol Scand 1990;140:41-54.

31. Casaburi R. Anabolic therapies in chronic obstructive pulmonary disease. Monaldi Arch Chest Dis 


\section{$1998 ; 53: 454-459$}

32. Jones P.W. Issues concerning health-related quality of life in COPD. Chest 1995;107: 187S-193S.

33. Yohannes A.M., Roomi J., Waters K., Connolly M.J. Quality of life in elderly patients with COPD: measurement and predictive factors. Respir Med 1998;92 (10):1231-1236.

34. Hajiro T., Nishimura K., Tsukino M., Ikeda A., Oga T., Izumi T. A comparison of the level of dyspnea vs disease severity in indicating the health-related quality of life of patients with COPD. Chest 1999; 116:1632-1637.

35. Shoup R., Dalsky G., Wamer S., Davies M., Connors M., Khan M., Khan F., ZuWallack R. Body composition and health-related quality of life in patients with obstructive airways disease. Eur Respir J 1997;10:1575-1580.

36. Mostert R., Goris A., Weling-Scheepers C.A.P.M., Wouters E.F.M., Schols A.M.W.J. Tissue depletion and health related quality of life in patients with chronic obstructive pulmonary disease. Respir Med. 2000 (in press).

37. Bestall J.C., Paul E.A., Garrod R., Garnham R., Jones P.W., Wedzicha J.A. Usefulness of the Medical Research Council (MRC) dyspnoea scale as a measure of disability in patients with chronic obstructive pulmonary disease. Thorax 1999;54:581-586.

38. Schols A.M.W.J., Socters P.B., Mostert R., Saris W.H., Wouters E.F.M. Energy balance in chronic obstructive pulmonary disease. Am Rev Respir Dis 1991;143:1248-1252.

39. Vermeeren M.A.P., Schols A.M.W.J., Wouters E.F.M. Effects of an Acute Exacerbation On Nutritional and Metabolic Profile of Patients With COPD. Eur Respir J 1997;10 (10):2264-2269.

40. Hunter A.M., Carey M.A., Larsh H.W. The nutritional status of patients with chronic obstructive pulmonary disease. Am Rev Respir Dis 1981:124:376-381.

41. Campfield L.A., Smith F.J., Burn P. The OB protein (leptin) pathway--a link between adipose tissue mass and central neural networks. Horm Metab Res 1996:28:619-632.

42. Seeley R.J., van Dijk G., Campfield L.A., Smith F.J., Burn P., Nelligan J.A., Bell S.M., Baskin D.G., Woods S.C., Schwartz M.W. Intraventricular leptin reduces food intake and body weight of lean rats but not obese Zucker rats. Horm Metab Res 1996;28:664-668.

Hwa J.J., Ghibaudi L., Compton D.. Fawzi A.B. Strader C.D. Intracerebroventricular injection of leptin increases thermogenesis and mobilizes fat metabolism in ob/ob mice. Horm Metah Res 1996:28:659-663.

44. Schols A.M.W.J., Fredrix E.W., Soeters P.B. Westerterp K. R. Wouters E.F.M. Rusting encrgy expenditure in patients with chronic obstructive pulmonary discasc. Am J Clin Nutr 1991:54:98:987.

45. Baarends E.M., Schols A.M.W. J., Pannemans D.L., Westurterp K. R., Wouters E. F.M. Total free living energy expenditure in patients with severe chronic obstructive pulmonary disease. $A m, J$ Respir Crit Care Med 1997;155:549-554

46. Baarends E.M., Schols A.M.W.J., Westerterp K.R., Wouters E.F.M. Total daily energy expenditure relative to resting energy expenditure in clinically stable patients with COPD. Thorax 1997:52 (9): 780-785.

47. Nguyen L.T., Bedu M., Caillaud D., Beaufrere B., Beaujon G., Vasson M. Coudert J., Ritz P. Increased resting energy expenditure is related to plasma TNF-alpha concentration in stable COPD patients. Clin Nutr 1999:18:269-274.

48. Amoroso P., Wilson S.R., Moxham J., Ponte J. Acute effects of inhaled salbutamol on the metabolic rate of normal subjects. Thorax 1093,48:882-885.

49. Burdet L., de Muralt B., Schutz Y., Fitting J.W. Thermogenic effect of bronchodilators in patients with chronic obstructive pulmonary discase. Thorax 1997:52:130-135.

50. Engelen M., Schols A., Lamers R.J.S., Wouters E.F.M. Different patterns of chronic tissue wasting among patients with chronic obstructive pulmonary disease. Clin Nutr 1999;18:275-280.

51. Morrison W.L. Gibson J.N.. Scrimgeour C.. Rennie M.J. Muscle wasting in emphysema. Clin Sci $1988: 75: 415-420$

52. Schols A.M.W.J., Buurman W.A., Staal van den Brekel A.J., Dentener M.A., Wouters E.F.M Evidence for a relation between metabolic derangements and increased levels of inflammatory 
mediators in a subgroup of patients with chronic obstructive pulmonary disease. Thorax 1996:51:819-824.

53. Pouw E.M., Schols A.M.W.J., Deutz N.E., Wouters E.F.M. Plasma and muscle amino acid levels in relation to resting energy expenditure and inflammation in stable chronic obstructive pulmonary disease. Am J Respir Crit Care Med 1998;158:797-801.

54. Kamischke A., Kemper D.E., Castel M.A., Luthke M., Rolf C., Behre H.M., Magnussen H., Nieschlag E. Testosterone levels in men with chronic obstructive pulmonary disease with or without glucocorticoid therapy. Eur Respir J 1998;11:41-45.

55. Decramer M., Lacquet L.M., Fagard R., Rogiers P. Corticosteroids contribute to muscle weakness in chronic airflow obstruction. Am J Respir Crit Care Med 1994;150:11-16.

56. Rogers R.M., Donahoe M., Costantino J. Physiologic effects of oral supplemental feeding in malnourished patients with chronic obstructive pulmonary disease. A randomized control study. Am Rev Respir Dis 1992;146:1511-1517.

57. Efthimiou J., Fleming J., Gomes C., Spiro S.G. The effect of supplementary oral nutrition in poorly nourished patients with chronic obstructive pulmonary disease. Am Rev Respir Dis 1988;137:10751082.

58. Lewis M.I., Belman M.J., Dorr Uyemura L. Nutritional supplementation in ambulatory patients with chronic obstructive pulmonary disease. Am Rev Respir Dis 1987;135:1062-1068.

59. Otte K.E., Ahlburg P., F D.A., Stellfeld M. Nutritional repletion in malnourished patients with emphysema. JParenter Enteral Nutr 1989;13:152-156.

60. Schols A.M.W.J., Soeters P.B., Mostert R., Pluymers R.J., Wouters E.F.M. Physiologic effects of nutritional support and anabolic steroids in patients with chronic obstructive pulmonary disease. A placebo-controlled randomized trial. Am J Respir Crit Care Med 1995;152:1268-1274.

6l. Ferreira I.M., Verreschi I.T., Nery L.E., Goldstein R.S., Zamel N., Brooks D., Jardim J.R. The influence of 6 months of oral anabolic steroids on body mass and respiratory muscles in undernourished COPD patients. Chest 1998;114:19-28 


\section{Chapter 2}

\section{Prevalence of an elevated resting energy expenditure in patients with chronic obstructive pulmonary disease in relation to body composition and lung function}

E. C. Creutzberg, A. M. W. J. Schols, F. C. M. Bothmer-Quaedvlieg, E. F. M. Wouters

Department of Pulmonology, University Hospital Maastricht, The Netherlands

Europeun Journal of Clinical Nutrition 1998; 52: 396-401 


\section{Abstract \\ Objective This study describes the prevalence and characteristics of an elevated resting energy expenditure (REE) in patients with chronic obstructive pulmonary disease (COPD).}

Design \& Setting Patients were measured consecutively admitted to an in-patient pulmonary rehabilitation centre.

Subjects The study group consisted of 172 clinically stable patients with COPD (1230, age mean (SD) 64 (10) years).

interventions REE was assessed by indirect calorimetry (ventilated hood) and adjusted for the influence of fat-free mass (FFM; measured by bioelectrical impedance analysis) using the linear regression equations of REE on FFM generated in 92 healthy agematched subjects (58\%, age 67 (8) years) for men and women separately. The predicted REE adjusted for FFM (REEFFM) was obtained by using the FFM of each individual patient in the linear regression equation of REE on FFM generated in the healthy control group.

Results $26 \%$ of the patients were hypermetabolic (REE $>110 \%$ REEFFM), characterized by a lower age (60 (10) vs 65 (9) years) and a lower total lung capacity (TLC; 122 (27) vs 139 (28) \%pred) compared to normometabolic patients $(\mathbf{p}<0.001)$. The prevalence of FFM-depletion was equal among normo- and hypermetabolic patients: $36 \%$ vs $33 \%$ respectively. Depleted patients expressed however a significantly higher residual volume/TLC ratio and a lower maximal inspiratory mouth pressure independently of hypermetabolism $(p<0.05)$. In contrast, on base of the Harris\&Benedict (HB) prediction equations, which do not take body composition into account, $54 \%$ of the patients were hypermetabolic (REE $110 \%$ REEHB), characterized by a higher age and a lower body mass and FFM $(p<0.05)$

Conc/usions Hypermetabolism commonly occurs in COPD, characterized by less hyperinflation at rest, in contrast to the suggested contribution of an elevated oxygen cost of breathing (OCB) to hypermetabolism in COPD. The higher hyperinflation at rest in FFM-depleted patients independently of hypermetabolism suggest a higher OCB during activities, contributing to the elevated total daily energy expenditure previously reported in COPD. The HB-equations overestimate the prevalence of hypermetabolism and link hypermetabolism incorrectly to aging and depletion.

\section{Introduction}

Weight loss is a common problem in patients with chronic obstructive pulmonary disease (COPD) (1), compromising fat mass (FM) and fat-free mass (FFM) (2). The clinical importance of weight loss, particularly loss of FFM, has been demonstrated in its adverse effects on physical performance and on respiratory muscle function (3). Furthermore, weight loss and a low body mass are unfavourable prognostic factors for survival (4).

In general, weight loss is considered as the result of an imbalance between energy intake and energy expenditure. Metabolic derangements seem to be a major cause of the disturbed energy balance leading to weight loss. Furthermore metabolic changes can lead to selective depletion of FFM despite relative preservation of FM in COPD. Several studies have reported an increased resting energy expenditure (REE) in 
patients with COPD (5-9), but the prevalence and the determining factors of hypermetabolism are yet unknown.

The aim of the present study was to describe the prevalence of hypermetabolism in 172 clinically stable patients with COPD in relation to body composition and lung function. On the one hand, hypermetabolism was defined based on the classically used Harris and Benedict (HB-) equations (10). On the other hand, hypermetabolism was based on adjustment for FFM in an age-matched healthy control group, since we hypothesized that the HB-equations may not correctly predict REE in patients with COPD due to body compositional changes after weight loss. Furthermore, the relative contribution of hypermetabolism to the prevalence and characteristics of depletion of FFM in patients with COPD was studied.

\section{Methods}

\section{Patients}

The patient group consisted of patients with COPD consecutively admitted to an inpatient pulmonary rehabilitation centre. According to the ATS guidelines (11), patients exhibiting an increase in forced expiratory volume in one second $\left(\mathrm{FEV}_{1}\right)$ greater than $10 \%$ of baseline after inhalation of a $B_{2}$-agonist were excluded from the study. Also patients with confounding disorders such as cancer, unstable cardiac condition, active gastrointestinal abnormalities, recent surgery, endocrine disorders like diabetes mellitus and hyper-/hypothyroidy were excluded from the study. To avoid a possible confounding effect of acute infectious exacerbations of the disease on REE (12), only patients in a stable pulmonary condition were studied: none of the patients had clinical signs of edema, was suffering from a respiratory tract infection as based on a negative bacteriologic sputum analysis, had fever or showed an increase in symptoms. The final study group consisted of $172\left(1230^{\circ}\right)$ stable patients with moderate to severe COPD.

\section{Conirols}

The control group consisted of $92\left(58 \sigma^{\circ}\right)$ healthy, age-matched subjects. Volunteers with disorders which might affect metabolic rate (cancer, unstable cardiac condition, gastrointestinal diseases, recent surgery, endocrine disorders and diseases of the respiratory tract) were excluded from the study.

\section{Resting energy expenditure}

REE was measured by an open circuit indirect calorimetry system using a ventilated hood (Oxycon Beta ${ }^{k}$ : Mijnhardt, Bunnik, the Netherlands). The system was calibrated daily at the start of the experiment. The accuracy of the system was regularly assessed using a methanol combustion test. Measurements were started in the early morning $(8.30 \mathrm{a} . \mathrm{m}$.). Patients and control subjects were in a fasting state for at least 10 hours and had a period of at least 30 minutes bed rest prior to the measurement during which subjects were comfortably lying on a bed in supine position. Patients received their maintenance inhalation medication 2 hours before measurements started. After stabilization, REE was recorded during a period of $20 \mathrm{~min}$. and calculated from oxygen consumption and carbon dioxide production using the abbreviated Weir formula (13). 


\section{Body composition}

Body height was determined to the nearest $0.5 \mathrm{~cm}$ (Lameris, WM 715, Breukelen, The Netherlands) while subjects standing barefoot. Body mass was assessed with a beam scale to the nearest $0.1 \mathrm{~kg}$ (SECA, FRG) while subjects standing barefoot and in light clothing. In 26 controls FFM was calculated from total body water assessment using the deuterium dilution technique described in the Maastricht protocol (14). In the other 66 controls as well as in the patient group FFM was measured using single frequency $(50 \mathrm{kHz})$ bioelectrical impedance analysis (BIA; Xitron technologies, San Diego, USA). Resistance was measured while subjects in supine position. FFM was assessed using the equations of Lukaski et al. (15) for the control subjects and the equation of Schols et al. (16) for the patients with COPD. FM was calculated by subtracting FFM from body mass. Previously it was established that FFM assessed with BIA was highly correlated with FFM assessed with the deuterium dilution technique in clinically stable patients with COPD (16).

\section{Lung function}

$\mathrm{FEV}_{1}$ was calculated from the flow-volume curve using spirometry and total lung capacity (TLC) and residual volume (RV) were measured plethysmographically (Masterlab ${ }^{\circledR}$, Jaeger, Würzburg, Germany). Diffusing capacity for carbon monoxide (DLCO) was determined using the single breath method (Masterlab ${ }^{\star}$, Jaeger, Würzburg, Germany). Lung function parameters were expressed as percentage of reference value (17). Arterial blood was drawn by puncture of the brachial artery while patients were at rest and breathing room air; arterial oxygen tension $\left(\mathrm{PaO}_{2}\right)$ and carbon dioxide tension $\left(\mathrm{PaCO}_{2}\right)$ were analysed on a blood gas analyser (Radiometer, $\mathrm{ABL}$ 330 , Copenhagen, Denmark). Respiratory muscle strength was assessed by measuring maximal inspiratory (PI-max) and expiratory (PE-max) mouth pressures according to the method of Black and Hyatt (18). PI-max values were noted as positive values.

The study was approved by the medical ethical committee of the University Hospital Maastricht and all subjects gave their informed consent.

\section{Statistics}

Analysis of variance was performed to investigate if REE differs between patients and healthy subjects after conrection for the covariates sex, age, FFM and FM. Stepwise regression analysis was performed with the independent variables sex, age, FFM and FM in the control group and sex, age, FFM, FM, $\mathrm{PaO}_{2}, \mathrm{PaCO}_{2}, \mathrm{FEV}$, TLC and DLCO in the patient group to reveal which parameters could explain the variation in absolute REE.

A linear regression equation of REE on FFM was generated in the healthy agematched control group to adjust REE for the influence of FFM. Different equations for men and women were generated, because the regression equations were significantly different between the sexes. The predicted REE adjusted for FFM (REEFFM) for patients was obtained by using the FFM of each individual patient in the linear regression equation of REE on FFM generated in the healthy control group. as earlier described by Schols et al. (5). Patients were considered hypermetabolic when 
measured REE as percentage of the FFM-based REE (REE/REEFFM) exceeded $110 \%$.

Using the HB-equations for the prediction of REE, patients and controls were considered hypermetabolic when measured REE expressed as percentage of the HBequations (REE/REEHB) exceeded $110 \%$.

For comparing parameters between groups the Student's t-test was used for parametric data and the Mann-Whitney $U$ test for non-parametric data (19). Data were analysed with the computer program 'Statistical Package for the Social Sciences' (SPSS).

\section{Results}

On analysis of variance, REE was significantly higher in the patients with COPD compared to the healthy age-matched control subjects $(p=0.013)$ after correction for the covariates sex, age, FFM and FM (table 1).

Table 1: Resting energy expenditure is significantly higher in patients with COPD compared to healthy age-matched subjects after correction for the significant influence of sex, age, fatfree mass and fat mass.

\begin{tabular}{llr}
\hline & F & p-value \\
\hline Covariates & 16.1 & $<0.001$ \\
Sex & 30.3 & $<0.001$ \\
Age & 135.2 & $<0.001$ \\
Fat-free mass & 21.8 & $<0.001$ \\
Fat mass & & \\
Main effect & 6.3 & 0.013 \\
COPD & 87.9 & $<0.001$ \\
Explained & &
\end{tabular}

\section{Controls}

The healthy age-matched control group was characterized as follows: age mean (SD) $67(8)$ years, body mass index (BMI; body mass $/$ height ${ }^{2}$ ) 26.0 (3.5) kg/m $\mathrm{m}^{2}$, FFM-index (FFMl; FFM/height ${ }^{2}$ ) $18.2(2.2) \mathrm{kg} / \mathrm{m}^{2}$.

Stepwise regression analysis revealed that FFM significantly explained $65^{\circ} \%$ of the variation in REE in the control group. In addition, sex, FM and age were selected as significant, independent contributors to a total variation in REE of $77 \%$ (table 2 ).

Based on the HB-equations, $24 \%$ of the controls were hypermetabolic. Using the linear regression equation of REE/REEHB on REE/REEFFM, a REE/RFEFFM of $110 \%$ corresponded with a REE/REEHB of $111 \%$.

\section{Patients}

In the patient group (age 64 (10) years, BMI $23.7(4.9) \mathrm{kg} / \mathrm{m}^{2}$ ), stepwise regression analysis revealed that FFM significantly explained $51 \%$ of the variation in REF. In addition, age and FM were selected as significant, independent contributors to a total variation in REE of $60 \%$, while lung function was excluded from the model (table 2).

Using the FFM-based REE generated in the healthy age-matched control group, $26 \%$ of the patients were considered hypermetabolic. Hypermetabolic patients were characterized by a significantly lower age and a lower TLC compared to normometabolic patients (table 3 ). 
Table 2: Stepwise regression analysis to reveal which variables explain the variation in resting energy expenditure in the healthy control group and the patient group respectively.

\begin{tabular}{llll}
\hline Prediction variables & Cumulative $\mathbf{R}^{2}$ & SE & p-value \\
\hline Controls & & & \\
Fat-free mass & 0.65 & 139.4 & $<0.001$ \\
Sex & 0.71 & 126.7 & $<0.001$ \\
Fat mass & 0.76 & 117.4 & $<0.001$ \\
Age & 0.77 & 114.3 & $<0.05$ \\
Patients & & & \\
Fat-free mass & 0.51 & 165.4 & $<0.001$ \\
Age & 0.57 & 155.7 & $<0.001$ \\
Fat mass & 0.60 & 150.3 & $<0.01$ \\
\hline
\end{tabular}

Table 3: Differences between normo- and hypermetabolic patients with COPD: hypermetabolism defined on base of the fat-free mass-based resting energy expenditure (REE).

\begin{tabular}{|c|c|c|c|c|c|}
\hline \multirow{3}{*}{$\mathrm{n}$} & \multirow{3}{*}{$(\mathrm{m} / \mathrm{f})$} & \multicolumn{2}{|c|}{ Normo } & \multicolumn{2}{|c|}{ Hyper } \\
\hline & & 127 & $(105 / 22)$ & 45 & $(18 / 27)$ \\
\hline & & mear & $(S D)$ & mean & $(S D)$ \\
\hline$\overline{\text { Age }}$ & (yrs) & 65 & (9) & 60 & $(10)^{* * *}$ \\
\hline Body mass index & $\left(\mathrm{kg} / \mathrm{m}^{2}\right)$ & 23.2 & (4.3) & 24.9 & (6.3) \\
\hline Fat-free mass index & $\left(\mathrm{kg} / \mathrm{m}^{2}\right)$ & 17.0 & (2.5) & 17.0 & $(3.0)$ \\
\hline Fat mass index & $\left(\mathrm{kg} / \mathrm{m}^{2}\right)$ & 6.2 & $(2.5)$ & 8.0 & (3.7) \\
\hline REF/Harris\&Benedict-based REE & $(\%)$ & 107 & $(12)$ & 121 & $(10)^{* * *}$ \\
\hline REE/fat-free mass-based REE & $(\%)$ & 97 & (9) & 119 & $(8)^{* * *}$ \\
\hline Arterial $\mathrm{O}_{2}$ tension & $(\mathrm{kPa})$ & 9.2 & $(1.5)$ & 9.8 & $(1.8)$ \\
\hline Arterial $\mathrm{CO}_{2}$ tension & $(\mathrm{kPa})$ & 5.3 & $(0.7)$ & 5.3 & $(0.9)$ \\
\hline Forced exp. volume in $1 \mathrm{~s}$. & (\%pred) & 40 & (13) & 43 & (14) \\
\hline Total lung capacity & (\%pred) & 139 & $(28)$ & 122 & $(27)^{* * *}$ \\
\hline Diffusing capacity & (\%pred) & 72 & (27) & 75 & $(26)$ \\
\hline Max. insp. mouth pressure & $\left(\mathrm{cm} \mathrm{H}_{2} \mathrm{O}\right)$ & 66 & (23) & 66 & (31) \\
\hline Max exp. mouth pressure & $\left(\mathrm{cm} \mathrm{H} \mathrm{H}_{2} \mathrm{O}\right)$ & 81 & $(25)$ & 77 & (23) \\
\hline
\end{tabular}

*** $p<0.001$.

Differences in body composition were eliminated after correction for sex and age. Maintenance medication use of the patients did not differ between hypermetabolic and normometabolic patients (theophyllines: $64 \%$ vs $68 \%, B_{2}$-sympathicomimetics: $96 \%$ vs $98 \%$, ipratropium bromide: $84 \%$ vs $87 \%$, oral corticosteroids: $56 \%$ vs $53 \%$ and inhalation corticosteroids: $73 \%$ vs $79 \%$ of the patients respectively). Data concerning the duration of oral corticosteroid use until the measurement of REE were not available, but it may generally be assumed that the patients who were receiving oral corticosteroids at the time of measurement were chronic users; exacerbations of lung failure are commonly treated with short courses of oral corticosteroids, but the patients in the present study were all in a stable clinical condition. The proportion patients who were smoking cigarettes was $40 \%$ in the hypermetabolic patient group and $20 \%$ in the normometabolic patient group (NS).

Using the HB-equations. $54 \%$ of the patients were considered hypermetabolic. Using the linear regression equation of REE/REEHB on REE/REEFFM, a REE/REEFFM of $110^{\circ} .0$ corresponded with a REF/REEHB of $116 \%$. When looking at the differences 
between patients who were normometabolic on base of both definitions of hypermetabolism versus the group that was normometabolic based on REE/REEFFM but hypermetabolic based on REE/REEHB, the latter group was, after correction for sex and age, characterized by a higher age, a lower BMI, a lower FFMI and a lower FM-index (FMI) (table 4).

Table 4: Characteristics of normometabolic patients (on base of the fat-free mass (FFM)-based resting energy expenditure (REE)) stratified by hypermetabolism on base of the Harris and Benedict-equations (HB).

\begin{tabular}{|c|c|c|c|c|}
\hline \multirow[b]{2}{*}{$\mathrm{n}$} & \multirow[b]{2}{*}{$(\mathrm{m} / \mathrm{f})$} & $\begin{array}{l}\text { Normo FFM } \\
\text { Normo HB }\end{array}$ & \multicolumn{2}{|c|}{$\begin{array}{l}\text { Normo FFM } \\
\text { Hyper HB }\end{array}$} \\
\hline & & $\begin{array}{l}72 \quad(54 / 18) \\
\text { mean }(S D)\end{array}$ & $\begin{array}{l}55 \\
\text { mean }\end{array}$ & $\begin{array}{l}(51 / 4) \\
(S D)\end{array}$ \\
\hline$\overline{\text { Age }}$ & (yrs) & $63 \quad(11)$ & 67 & $(6)^{* *}$ \\
\hline Body mass index & $\left(\mathrm{kg} / \mathrm{m}^{2}\right)$ & $24.4 \quad(4.4)$ & 21.7 & $(3.6)^{* * *}$ \\
\hline Fat-free mass index & $\left(\mathrm{kg} / \mathrm{m}^{2}\right)$ & $17.2(2.6)$ & 16.7 & $(2.5)^{*}$ \\
\hline Fat mass index & $\left(\mathrm{kg} / \mathrm{m}^{2}\right)$ & $7.1 \quad(2.5)$ & 5.1 & $(2.1)^{* * *}$ \\
\hline REE/Harris\&Benedict-based REE & $(\%)$ & (8) & 119 & $(7)^{* * *}$ \\
\hline REE/fat-free mass-based REE & $(\%)$ & $(10)$ & 102 & $(7)^{* * *}$ \\
\hline Arterial $\mathrm{O}_{2}$ tension & $(\mathrm{kPa})$ & $(1.6)$ & 9.0 & $(1.2)$ \\
\hline Arterial $\mathrm{CO}_{2}$ tension & $(\mathrm{kPa})$ & $(0.7)$ & 5.4 & $(0.8)$ \\
\hline Forced exp. volume in $1 \mathrm{~s}$. & (\%pred) & (14) & 40 & (11) \\
\hline Total lung capacity & (\%pred) & $136 \quad(28)$ & 142 & (26) \\
\hline Diffusing capacity & (\%pred) & (28) & 70 & $(25)$ \\
\hline Max insp. mouth pressure & $\left(\mathrm{cm} \mathrm{H}_{2} \mathrm{O}\right)$ & (24) & 63 & $(21)$ \\
\hline Max exp. mouth pressure & $\left(\mathrm{cm} \mathrm{H}_{2} \mathrm{O}\right)$ & (27) & 80 & $(22)$ \\
\hline
\end{tabular}

${ }^{*} p<0.05,{ }^{* *} p<0.01,{ }^{* * *} p<0.001$.

The prevalence of depletion of FFM, defined as FFMIs $15(\%) / 16\left(\sigma^{r}\right) \mathrm{kg} / \mathrm{m}^{2}$, was not significantly different between normo- and hypermetabolic patients with COPD (36\% vs $33 \%$ respectively; using the FFM-based definition of hypermetabolism). Depleted patients expressed, independently of the presence of hypermetabolism, a significantly higher RV/TLC ratio (figure la) and a lower PI-max (figure lb) compared to nondepleted patients. 

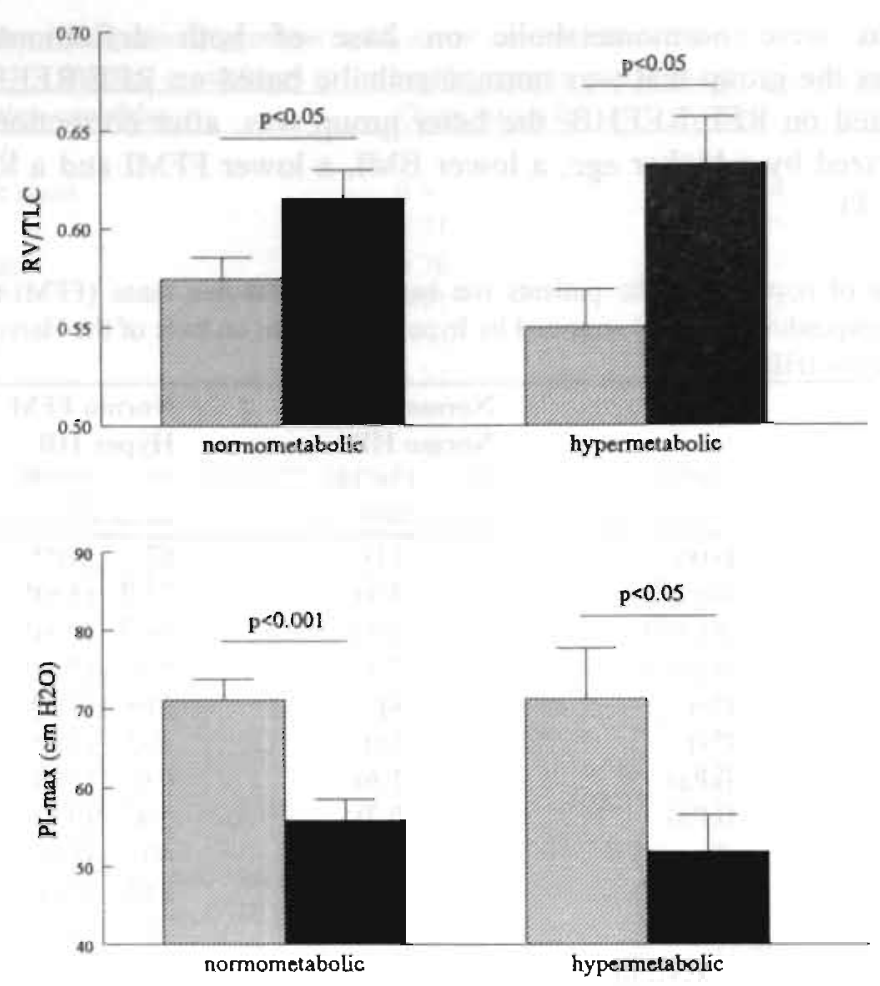

Figure 1: Differences in residual volume/total lung capacity (la; upper panel) and maximal inspiratory mouth pressure ( $1 \mathrm{~b}$; bottom panel) between non-depleted (striped bar) and depleted (fat-free mass index $\leq 15(q) / 16\left(0^{\circ}\right) \mathrm{kg} / \mathrm{m}^{2}$; solid bar) patients with COPD, stratified by hypermetabolism (on base of the fat-free mass-based resting energy expenditure). Data are expressed as mean (SEM).

\section{Discussion}

This paper is the first study describing hypermetabolism in such a large group of stable patients with COPD in relation to body composition and lung function. The prevalence of hypermetabolism based on adjustment for FFM amounted up to $26 \%$ in the patients with COPD. This prevalence was surprisingly lower than might be expected on base of earlier studies (6-9).

The most common approach to predict REE for an individual in clinical practice is to apply the HB-equations (10), which are based on sex, age, height and body mass. Different studies have investigated hypermetabolism in stable patients with COPD on base of the HB-equations, most studies revealing an increased REE compared to the HB-equations or to a control group (6-9), some not (20,21). The disadvantage of all these studiss however, is that they described hypermetabolism in relatively small groups of patients ( $0-19$ patients), so that the prevalence of hypermetabolism could not be established. 
The difference in REE expressed as percentage of the HB-equations between the healthy control group and patients with COPD may in part be caused by differences in the relative amount of FFM between patients and controls, since FFM is the most important determinant of REE. The HB-equations do not take body composition into account, nor do the COPD-specific prediction equations of Moore (22), which were derived on base of body mass in a group of 43 stable patients with COPD. Considering FFM seems furthermore important in COPD since body compositional changes occur after weight loss. Besides, depletion of FFM despite a normal body mass has been described in patients with COPD (23). In the present study, FFM explained the variation in REE for $65 \%$ in healthy subjects, in agreement with the meta-analyses of Cunningham (24) and Weinsier et al. (25), which both revealed FFM as the best single predictor for $R E E\left(R^{2}=0.65-0.90, R^{2}=0.92\right.$ respectively). Also in our patient group, FFM was identified as the most important predictor of REE $(51 \%)$. The studies of Green and Muers (9) and Fitting et al. (7), which took muscle mass calculated from skinfold thickness into account, found a higher REE divided by muscle mass in patients with COPD compared to healthy subjects. However, by dividing REE by FFM, depleted subjects are incorrectly considered more hypermetabolic than nondepleted subjects, because the intercept in the equation of REE on FFM is not equal to zero. Therefore we adjusted REE for FFM in an age-matched healthy control group as earlier described by Schols et al. (5), and applied the derived equations for men and women on the patient group to predict REE.

The prevalence rate of hypermetabolism was shown to be higher in patients with COPD compared to healthy controls. Furthermore, on analysis of variance REE was higher in the patient group compared to the control group after correction for sex, age, FFM and FM. Besides FFM, age was also a significant explaining parameter for the variation in REE in controls and patients. It is known that REE decreases when age increases, which can be predominantly explained by the decline in FFM due to reduced physical activity in elderly people $(26,27)$. This decrease in FFM is possibly accompanied with an alteration in tissue metabolism with age and/or an adaptation in REE due to a lower daily caloric intake (28) and a decline in physical activity in the elderly (29). Furthermore, although the HB-equations adjust REE for age, it is known that they overestimate hypermetabolism in men over 64 years $(30)$, which was also seen in our elderly control group

The fact that patients who were hypermetabolic on base of the HB-equations hut normometabolic on base of FFM were characterized by a higher age, a lower BMI, FFMI and FMI, brings up the statement that the HB-equations -incorrcctly- link hypermetabolism to depletion and aging in patients with COPD, in agrcement with several other studies that found a higher REE/REEHB in malnourished patients with COPD compared to adequately nourished patients (8.31.32). Also elderly depleted patients with various diseases were found to have a higher REE divided by body mass than subjects who were not depleted (33).

The finding that REE remained significantly higher in the patient group compared to the healthy control group after analysis of variance with the covariates sex, age. FIM and FM, suggests that other factors influence RFE in patients with (COPD. 
Cigarette smoking is considered to have an increasing effect on REE in healthy subjects by the effects of nicotine (34), but we did not see any effect of smoking on REE in our patient population.

The suggested increase in oxygen cost of breathing (OCB) is assumed to be one of the main explanations for the elevated REE seen in patients with COPD contributing to weight loss. Several studies have investigated the OCB in patients with COPD and all found a higher OCB in patients compared to healthy controls $(8,20,35-39)$. However, the artefact of these studies is that OCB was measured by augmenting the ventilation or ventilatory effort and not in rest. O'Donnell postulated recently that increasing the ventilation demands much more energy in patients with COPD than it does in healthy subjects because patients may suffer from dynamic hyperinflation (40). Dynamic hyperinflation will therefore substantially compromise patients with COPD during exercise by elevating the $\mathrm{OCB}$, and as a result total daily energy expenditure (TDEE) may be increased. Indeed, a recent study of Baarends et al. (41) revealed an elevated TDEE in stable patients with COPD compared to healthy subjects, in contrast to the findings of Hugli et al. (42) which could not establish an increased TDEE in patients with COPD. The fact that patients with COPD do not show an elevated ventilation in rest makes it however improbable that the OCB is of great impact on REE (40). This is further emphasized by the results of several studies in which the efficiency of breathing in rest was measured by imposing resistance $(34,36,43,44)$. In all but one (34) study, no difference in breathing efficiency in rest was seen between patients with COPD and healthy subjects. In the present study we also found no evidence for a higher OCB in hypermetabolic patients compared to normometabolic patients with COPD; instead a tendency towards the opposite direction was seen: the significantly lower TLC found in the hypermetabolic patients indicate that they might be suffering from less air trapping and therefore from less static hyperinflation compared to the normometabolic patient group.

The latter finding brings up the suggestion that the presence of hypermetabolism may be different for the COPD-subtypes emphysema and chronic bronchitis. On base of the established differences in TLC, the hypermetabolic patients seem to express the more bronchitic form of COPD and the normometabolic patients the emphysematous form. No differences in DLCO, which is the parameter commonly used in clinical practice to distinct emphysema and chronic bronchitis, were however seen between the normoand hypermetabolic patients. Nevertheless, patients expressing a diminished DLCO are in general characterized by more hyperinflation. Green and Muers (45) actually discriminated emphysema and chronic bronchitis on base of $\mathrm{PaCO}_{2}$ and found that measured REE in patients with the postulated bronchitic subtype of COPD $\left(\mathrm{PaCO}_{2}>6 \mathrm{kPa}\right)$ was higher than the predicted $\mathrm{REE}$, while in patients with the suggested emphysematous subtype of $\mathrm{COPD}\left(\mathrm{PaCO}_{2}<5 \mathrm{kPa}\right)$ it was not. The $\mathrm{PaCO}_{2}$ is however absolutely no good criterium for discriminating between emphysema and chronic bronchitis; Biemacki et al. (46) investigated the extent of emphysema by measuring lung density using computed tomography scanning and found no relationship between emphysema and $\mathrm{PaCO}_{2}$ or $\mathrm{PaO}_{2}$. Therefore the findings of Green and Muers are disputable, and emphysema and chronic bronchitis must first be adequately differentiated as by use of high resolution computed tomography (HRCT) before 
drawing preliminary conclusions.

Another possible explanation for the elevated REE seen in patients with COPD may be a thermogenetic effect of bronchodilating agents such as theophyllines and $B_{2}$ sympathicomimetics, which are given in general as an essential part of the pharmacological maintenance treatment approach in patients with COPD. In recent studies both drugs showed an elevating effect on REE in younger healthy subjects $(47,48)$. In a previous study we also found a significant increase in REE of $11 \%$ after nebulization of $5 \mathrm{mg}$ of the $B_{2}$-sympathicomimetic drug salbutamol in younger subjects, but the increase in REE in patients with COPD was only $4 \%$ and did not differ from an age-matched control group (6\%) (49), in line with the rise in REE of 5\% found in a comparable study in patients with COPD (50). Together, these slight effects of salbutamol on REE cannot fully explain the elevated REE in patients with COPD. Furthermore, in the present study the proportion of patients using $\beta_{2}$ sympathicomimetics or theophyllines was not significantly different between hypermetabolic and normometabolic patients with COPD.

Weight loss has also been related to the presence of a systemic inflammatory response. Increased serum concentrations of the inflammatory mediator tumour necrosis factor alpha $(\mathrm{TNF} \alpha)$ were found in patients with COPD who had involuntarily lost weight (51). Furthermore, the LPS-induced production of TNF $\alpha$ by monocytes was higher in weight-losing versus weight-stable patients (52). In an earlier study of our group, elevated levels of the acute phase reactant proteins C-reactive protein (CRP) and LPSbinding protein were reported in hyper- versus normometabolic patients (53). Also the increased REE found in elderly patients who had undergone recent surgery was related to elevated levels of CRP (33). Together, these studies suggest a relationship between hypermetabolism and hepatic acute phase response in a part of the patients with COPD.

In order to investigate the relative contribution of hypermetabolism to depletion of FFM in COPD, we determined the prevalence of depletion stratified by hypermetabolism (hypermetabolism based on FFM-adjustment), and found a similar prevalence among normo- and hypermetabolic patients. Because no difference was seen in the prevalence of depletion between normo- and hypermetabolic patients, an elevated REE cannot be the sole reason for weight loss and/or loss of FFM in COPD. The fact that FFM-depleted patients were suffering from more hyperinflation (on base of a higher RV/TLC ratio) and showed a lower PI-max, brings up the suggestion that depleted patients, independently of the presence of hypermetabolism, will express a higher $O C B$ during activities due to more air-trapping and therefore a higher dynamic hyperinflation, which may contribute to the elevated TDEE previously described in patients with COPD compared to healthy age-matched controls independently of REE (41). This higher TDEE will lead to loss of body mass and of FFM when not adequately met by an increase in energy intake, and will ultimately compromise functional perfornance.

The last finding implies that analysis of resting energy metabolism alone is not enough for the interpretation of energy balance and body composition in patients with COPD. The eventually enhanced TDEE or energy expenditure for activities should be taken 
into account when assessing the energy requirements of individual patients in clinical practice.

\section{References}

1. Wilson DO, Rogers RM, Wright E (1989). Body weight in chronic obstructive pulmonary disease. Am. Rev. Respir. Dis. 139, 1435-1438.

2. Schols AMWJ, Soeters PB, Dingemans AMC, Mostert R, Frantzen PJ, Wouters EFM (1993). Prevalence and characteristics of nutritional depletion in patients with stable COPD eligible for pulmonary rehabilitation. Am. J. Respir. Dis. 147, 1151-1156.

3. Fiaccadori E, Del Canale S, Coffrini E, Vitali P, Antonucci C, Cacciani G, Mazzola I, Guariglia A (1988). Hypercapnic-hypoxemic chronic obstructive pulmonary disease (COPD): influence of severity of COPD on nutritional status. Am. J. Clin. Nutr. 48, 680-685.

4. Schols AMWJ, de Vries G, Slangen J, Wouters EFM (1995). The predictive value of a low body mass index on survival in COPD patients. Eur. Respir. $J .8$, suppl. 19, 166s (abstract).

5. Schols AMWJ, Fredrix EWHM, Soeters PB, Westerterp KR, Wouters EFM (1991). Resting energy expenditure in patients with chronic obstructive pulmonary disease. Am. J. Clin. Nutr. 54 , 983-987.

6. Hugli O, Frascarolo P, Schutz Y, Jéquier E, Leuenberger P, Fitting JW (1993). Diet-induced thermogenesis in chronic obstructive pulmonary disease. Am. Rev. Respir. Dis. 148, 1479-1483.

7. Fitting JW, Frascarolo P, Jéquier E, Leuenberger P (1989). Energy expenditure and rib cageabdominal motion in chronic obstructive pulmonary disease. Eur. Respir. J. 2, 840-845.

8. Donahoe M, Rogers RM, Wilson DO, Pennock BE (1989). Oxygen consumption of the respiratory muscles in normal and in malnourished patients with chronic obstructive pulmonary disease. Am. Rev. Respir. Dis. 140, 385-391.

9. Green JH, Muers MF (1991). The thermic effects of food in underweight patients with emphysematous chronic obstructive pulmonary disease. Eur. Respir. J. 4, 813-819.

10. Harris JA, Benedict EG (1919). A Biometric Study of Basal Metabolism. Washington: Carnegie Institution of Washington.

11. ATS (1995). Standards for the diagnosis and care of patients with chronic obstructive pulmonary disease. Am. J. Respir. Crit. Care Med. 152, s78-s 121 .

12. Vermeeren MAP, Schols AMWJ, Quaedvlieg FCM, Wouters EFM (1994). The influence of an acute disease exacerbation on the metabolic profile of patients with chronic obstructive pulmonary disease. Clinical Nutrition 13, suppl. 1, 38-39 (abstract).

13. Weir JB (1949). New methods for calculating metabolic rate with special reference to protein metabolism. I. Phys. 109. 1-9.

14. Westerterp KR, Wouters L, Marken Lichtenbelt WD (1995). The Maastricht protocol for the measurement of body composition and energy expenditure with labeled water. Obesity Research 3, suppl. 1, 49-57.

15. Lukaski HC, Bolonchuk WW. Hall CB, Siders WA (1986). Validation of tetrapolar bioclectrical impedance method to assess human body composition. J. Appl. Physiol. 60, 1327-1332.

16. Schols AMWJ, Wouters EFM, Soeters PB, Westerterp KR (1991). Body composition by bioelectrical impedance analysis compared to deuterium dilution and skinfold anthropometry in patients with chronic obstructive pulmonary disease. Am. J. Clin. Nuir. 53, 421-424.

17. Quanjer PH, ed. (1993). Standardised lung function testing. Eur. Respir. J. 6, suppl. 16, 1-52.

18. Black LF, Hyatt RE (1969). Maximal respiratory pressures: normal values and relationship to age and sex. Am. Rev. Respir. Dis. 99, 696-702.

19. Altman DG, Gore SM, Gardner MJ, Pocock SJ (1983). Statistical guidelines for contributors to medical joumals. British Med J 286, 1489-1493.

20. Sridhar MK, Carter R, Lean MEJ, Banham SW (1994). Resting energy expenditure and nutritional state of patients with increased oxygen cost of breathing due to emphysema, scoliosis and thoracoplasty. Thorax $49,781-785$. 
21. Ryan CF, Road JD, Buckley PA, Ross C, Whittaker JS (1993). Energy balance in stable malnourished patients with chronic obstructive pulmonary disease. Chest 103, 1038-1044.

22. Moore JA, Angelillo VA (1988). Equations for the prediction of resting energy expenditure in chronic obstructive lung disease. Chest 94, 1260-1263.

23. Engelen MPKJ, Schols AMWJ, Baken WC, Wesseling GJ, Wouters EFM (1994). Nutritional depletion in relation to respiratory and peripheral skeletal muscle function in out-patients with COPD. Eur. Respir. J. 7, 1793-1797.

24. Cunningham JJ (1991). Body composition as a determinant of energy expenditure: a synthetic review and a proposed general prediction equation. Am. J. Clin. Nutr. 54, 963-969.

25. Weinsier RL, Schutz Y, Bracco D (1992). Reexamination of the relationship of resting metabolic rate to fat-free mass and to the metabolically active components of fat-free mass in humans. $\mathrm{Am}$. J. Clin. Nutr. 55, 790-794.

26. Vaughan L, Zurlo F, Ravussin E (1991). Aging and energy expenditure. Am. J. Clin. Nutr. 53, 821-825.

27. Prentice AM (1992). Energy expenditure in the elderly. Eur. J. Clin. Nutr. 46, suppl. 3, s21-s28.

28. Fukagawa NK, Bandini LG, Young JB (1990). Effect of age on body composition and resting metabolic rate. Am. J. Physiol. 259, E233-E238

29. Poehlman ET (1992). Energy expenditure and requirements in aging humans. J. Nutr. 122, 20572065

30. Owen OE, Holup JL, D'Alessio DA, Craig ES, Polansky M, Smalley KJ, Kavle EC, Bushman MC. Owen LR, Mozzoli MA, Kendrick ZV, Boden GH (1987). A reappraisal of the caloric requirements of men. Am. J. Clin. Nutr. 46: 875-885.

31. Wilson DO. Donahoe M, Rogers RM, Pennock BE (1990). Metabolic rate and weight loss in chronic obstructive pulmonary disease. JPEN 14, 7-11.

32. Schols AMWJ, Mostert R, Soeters PB, Saris WHM, Wouters EFM (1991). Energy balance in patients with chronic obstructive pulmonary disease. Am. Rev. Respir. Dis. 143, 1248-1252.

33. Campillo B, Bories PN, Devanlay M, Pormin B, Le Parco JC, Gaye-Bareyt E, Fouet E (1992). Aging. energy expenditure and nutritional status: evidence for denutrition-related hypermetabolism. Ann. Nutr. Metab. 36, 265-272.

34. Collins LC, Cornelius MF, Vogel RL, Walker JF, Stamford BA (1994). Effect of caffeine and/or cigarette smoking on resting energy expenditure. Int. J. Obes. Relal. Metab. Disord. 18, 551 556.

35. Cherniack RM (1958). The oxygen consumption and efficiency of the respiratory muscles in health and cmphysema. $J$ Clin. Invest. 38, 494-499.

36. Shindoh C. Hida W, Kikuchi Y, Taguchi O. Miki H, Takishima T, Shirato K (1994). Oxygen consumption of respiratory muscles in patients with COPD. Chest 105, 790-797.

37. McGrigor M. Becklake MR (196I). The relationship of oxygen cost of breathing to respiratory michanical work and respiratory force. J. Clin. Invest. 40, 971-980.

38. Mannix ET. Manfredi F. Palange P. Dowdeswell IRG, Farber MO (1992). Oxygen may lower the $\mathrm{O}_{2}$ cost of ventilation in chronic obstructive lung disease. Chest 101, 910-915.

39. Levison H. Cherniack RM (1968). Ventilatory cost of exercise in chronic obstructive pulmonary disease. J. Appl. Physiol. 25: 21-27.

40. O'Donnell DE, Webb KA (1993). Exertional breathlessness in patients with chronic airflow limitation. The role of lung hyperinflation. Am. Rev. Respir. Dis. 148. 1351-1357.

41. Baarends EM. Schols AMWJ, Pannemans DLE, Westerterp KR, Wouters EFM (1997). Total free living encrgy expenditure in patients with severe chronic obstructive pulmonary disease. $\mathrm{Am}$. J. Respir. Crit. Care Med. 155, 549-554

42. Hugli O, Schutz Y. Fitting J-W (1996). The daily encrgy expenditure in stable chronic obstructive pulmonary disease. Am. J. Respir. Crit. (ar' Mt'd. 153, 294-300.

43. Fritts HW, Filler J, Fishman AP, Coumand A (1959). The efficiency of ventilation during voluntary hyperpnea: studies in normal subjects and in dyspneic patients with either chronic pulmonary emphysema or obesity. J. Clin. Invest. 38, 1339-1348. 
44. Gosselink RAAM, Wagenaar RC, Rijswijk H, Sargeant AJ, Decramer MLA (1995). Diaphragmatic breathing reduces efficiency of breathing in patients with chronic obstructive pulmonary disease. Am. J. Respir. Crit. Care Med. 151, 1136-1142.

45. Green JH, Muers MF (1992). Comparisons between basal metabolic rate and diet-induced thermogenesis in different types of chronic obstructive pulmonary disease. Clin. Sci. 83, 109-116.

46. Biernacki W, Gould GA, Whyte KF, Flenley DC (1989). Pulmonary hemodynamics, gas exchange, and the severity of emphysema as assessed by quantitative CT scan in chronic bronchitis and emphysema. Am. Rev. Respir. Dis. 139, 1509-1515.

47. Dash A, Agrawal A, Venkat N, Moxham J, Ponte J (1994). Effect of oral theophylline on resting energy expenditure in normal volunteers. Thorax 49, $1116-1120$

48. Amoroso P, Wilson SR, Moxham J, Ponte J (1993). Acute effects of inhaled salbutamol on the metabolic rate of normal subjects. Thorax $48,882-885$.

49. Creutzberg EC, Schols AMWJ, Wesseling G, Wouters EFM (1994). Acute effects of inhaled salbutamol on lung function and energy metabolism in COPD patients and normal subjects. Eur. Respir. J. 7, suppl. 18, 466s (abstract).

50. Burdet L, Muralt B de, Schutz Y, Fitting J-W (1997). Thermogenic effect of bronchodilators in patients with chronic obstructive pulmonary disease. Thorax 52, 130-135.

51. Francia M di, Barbier D, Mege JL, Orehek J (1994). Tumor Necrosis Factor alpha levels and weight loss in chronic obstructive pulmonary disease. Am. J. Resp. Crit. Care Med. 150. 14531455 .

52. Godoy I de, Donahoe M, Calhoun WJ, Mancino J, Rogers RM (1996). Elevated TNF $\alpha$ production by peripheral blood monocytes of weight-losing COPD patients. Am. J. Respir. Crit. Care Med. 153, 633-637.

53. Schols AMWJ, Buurman WA, Staal-Brekel AJ van den, Dentener MA, Wouters EFM (1996) Evidence for a relation between metabolic derangements and increased levels of inflammatory mediators in a subgroup of patients with chronic obstructive pulmonary disease. Thorax 51,819 24. 


\section{Chapter 3}

Acute effects of nebulized salbutamol on resting energy expenditure in patients with chronic obstructive pulmonary disease and in healthy subjects

E. C. Creutzberg, A. M. W. J. Schols, F. C. M. Bothmer-Quaedvlieg, G. Wesseling, E. F. M. Wouters

Department of Pulmonology, University Hospital Maastricht, The Netherlands

Respiration 1998; 65: 375-380 


\section{Abstract}

This study investigated the contribution of a single dose of salbutamol by nebulizer to the increased resting energy expenditure (REE) frequently found in patients with chronic obstructive pulmonary disease (COPD) $(n=22)$, in comparison with a younger $(n=15)$ and an older healthy $(n=10)$ control group. The rise in REE after nebulization of $5 \mathrm{mg}$ salbutamol was significantly higher in younger $(11.4 \%)$ compared to older healthy subjects $(5.7 \%)$ and patients with COPD $(4.2 \%)(p<0.05)$, which also accounted for the increase in heart rate and the drop in respiratory quotient. No differences in metabolic effects were found between older control subjects and patients with COPD. In conclusion, despite significant improvements in $\mathrm{FEV}_{1}$ and Raw, a significant rise in REE was observed in patients with COPD after nebulization of salbutamol. The metabolic effects of salbutamol were however not sufficient to explain totally the elevated REE seen in these patients.

\section{Summary}

Aim This study investigated the contribution of a usual dose of salbutamol (a bronchodilating $B_{2}$-agonist) administered by nebulization to the increased resting energy expenditure (REE) frequently found in patients with chronic obstructive pulmonary disease (COPD).

Subjects and methods In 15 younger healthy subjects (age 29 years, body mass index (BMI; weight/height ${ }^{2}$ ) $22.7 \mathrm{~kg} / \mathrm{m}^{2}$ ), 10 older healthy subjects (64 years, $24.4 \mathrm{~kg} / \mathrm{m}^{2}$ ) and 22 patients with COPD ( 66 years, $24.1 \mathrm{~kg} / \mathrm{m}^{2}$ ) REE by open canopy indirect calorimetry, heart rate, flow volume curve and body plethysmography were assessed before and after nebulization of $5 \mathrm{mg}$ of salbutamol.

Results Baseline REE was significantly increased in patients with COPD (116\% of predicted). The rise in REE after salbutamol was significantly higher in younger subjects (mean (SEM) $11.4(1.4) \%$ ) compared to older subjects $(5.7(2.3) \%, \mathrm{p}<0.05)$ and patients $(4.2(1.1) \%, \mathrm{p}<0.001)$, which also accounted for the increase in heart rate $(13.4(2.1) \%$; $3.9(3.4) \%, p<0.05 ; 4.9(1.7) \%, p<0.01$ respectively) and the drop in respiratory quotient $(-10.2(1.4) \% ;-7.3(1.7) \% ;-3.9(0.5) \%, p<0.001$ respectively). The metabolic effects were not different between older healthy subjects and patients with COPD.

Conclusions A single dose of nebulized salbutamol produced significant effects on REE and heart rate in healthy subjects and in patients with COPD, despite significant improvements in $\mathrm{FEV}_{1}$ and Raw. The metabolic effects were significantly more pronounced in younger compared to older healthy subjects and to the patients. The significant rise in REE of $4 \%$ due to salbutamol was nevertheless not sufficient to explain totally the elevated REE seen in patients with COPD.

\section{Introduction}

Weight loss is a common problem in patients with chronic obstructive pulmonary disease (COPD) (1), comprising loss of fat mass and fat-free mass (FFM) and adversely affecting functional performance and survival $(2,3)$. Weight loss is primarily the result of a disturbed energy balance. 
In a substantial proportion of patients with COPD resting energy expenditure (REE) is increased up to $15-20 \%$ above predicted values (4). The cause of the elevated REE seen in these patients has not yet been elucidated. Several studies have suggested that hypermetabolism in patients with COPD is the result of an increased oxygen cost of breathing $(\mathrm{OCB})$, but convincing evidence has not yet been provided $(5,6)$.

Weight loss has also been related to the presence of systemic inflammation. Elevated serum concentrations of the inflammatory mediator tumor necrosis factor $\alpha$ (TNF $\alpha$ ) were found in patients with COPD suffering from involuntary weight loss (7), and in another study increased levels of acute phase reactant proteins and soluble TNF-receptors were reported in a subset of hypermetabolic patients with COPD, whereas in all normometabolic patients these levels were within a normal range (8).

Another possible explanation for the elevated REE in patients with COPD might be a stimulating effect of pharmacological treatment such as the bronchodilating agents theophyllines and $B_{2}$-sympathicomimetics, which are in general an essential part of the pharmacological maintenance treatment approach in patients with COPD. Theophylline and salbutamol (a short-acting, bronchodilating $B_{2}$-sympathicomimetic drug) have been shown to effect an acute elevation of REE in younger healthy subjects $(9,10)$. Furthermore, in contrast to ipratropium bromide, salbutamol has recently been reported to cause an acute elevation of REE in patients with COPD (11), while theophylline did not (12). In addition Hugli, in a group of 14 stable patients with COPD, found no relationship between plasma theophylline level and total daily energy expenditure (TDEE), but a significant, positive correlation between the daily dose of inhaled $B_{2}$ agonists and TDEE, although this effect could be explained predominantly by three patients with a high TDEE who were using a high daily dose of $\beta_{2}$-sympathicomimetics (13). $\beta_{2}$-Agonists are commonly given to patients with COPD as treatment for exacerbations of their lung failure, during which REE has been shown to increase temporarily (14). All together, different studies have shown that $\beta_{2}$-sympathicomimetics exert an acute increasing effect on REE in younger healthy subjects and in patients with COPD, but it is unclear whether the metabolic effects of $B$-agonists are comparable for patients with COPD, younger healthy subjects and age-matched healthy subjects.

The aim of the present study was to investigate the acute effects of a single dose of nebulized salbutamol on REE, respiratory quotient (RQ), heart rate and lung function in patients with COPD in comparison with a younger and an age-matched healthy control group.

\section{Subjects and methods}

Subjects

The study group consisted of 22 patients with COPD and 25 healthy control subjects; the latter group was stratified by age into two subgroups $(n=15<48$ years and $n=10>48$ years), on the one hand to allow a comparison with the available data about younger volunteers reported in the literature and on the other hand to match for the (elderly) patient group. In the patient group measurements were done at least 6 days after admission to the hospital while they were recovering from an acute exacerbation of their lung failure, which was treated with a standard protocol of medication (nebulized short-acting $B_{2}$ - 
sympathicomimetics ( $>20 \mathrm{mg} / 24 \mathrm{~h}$ ), inhaled anticholinergics, intravenously administered theophylline and prednisolone $(0.5-1.0 \mathrm{mg} / \mathrm{kg} / 24 \mathrm{~h})$, the latter given in decreasing doses). The plasma theophylline levels of all patients fell within the therapeutic range (8.0-16.7 $\mathrm{mg} / \mathrm{l})$ and none of the patients had fever at the time of measurement.

The study was approved by the medical ethical committee of the University Hospital Maastricht and all subjects gave their informed consent.

\section{Resting energy expenditure and heart rate}

REE, the most prominent part of TDEE, can be described as the amount of energy necessary for basal functioning of the body (breathing, circulation, homoeostasis) under non-sleeping conditions. REE was measured by an open circuit indirect calorimetry system using a ventilated hood (Oxycon Beta ${ }^{\$}$; Mijnhardt, Bunnik, the Netherlands). The system was calibrated daily at the start of the experiment, while the accuracy was regularly assessed using a methanol combustion test. Patients and controls were in a fasting state for at least 10 hours and had a period of at least 30 minutes bed rest prior to the measurements started. In addition, patients abstained from their regular bronchodilator medications for at least eight hours prior to the start of the experiment. During the measurement of REE, subjects were comfortably lying on a bed in supine position allowing them to watch television or listen to the radio. REE was calculated from oxygen consumption $\left(\mathrm{V}^{\prime} \mathrm{O}_{2}\right)$, which accounts for the most prominent part of REE, and carbon dioxide production $\left(\mathrm{V}^{\prime} \mathrm{CO}_{2}\right)$ using the abbreviated Weir formula (15). Measured REE was compared with the prediction equations of Harris and Benedict (16). The heart rate was recorded continuously during measurement of REE (Hewlett-Packard, Böblingen, Germany).

\section{Body composition}

Body weight was assessed to the nearest $0.1 \mathrm{~kg}$, while subjects wore light clothing and no shoes. FFM was measured using single frenquency $(50 \mathrm{kHz})$ bioelectrical impedance analysis (Xitron technologies, San Diego, USA) with subjects in supine position. FFM was calculated using the equation of Schols (17) for the patients with COPD and the equation of Deurenberg (18) for the healthy control subjects.

\section{I.ung, function}

Forced expiratory volume in one second $\left(\mathrm{FEV}_{1}\right)$ and inspiratory vital capacity (IVC) were calculated from the flow-volume curve using a spirometer (Masterlab ${ }^{\$}$, Jaeger, Würzburg, Germany). Airway resistance (Raw) was measured using a whole body plethysmograph (Masterlab**, Jaeger, Würzburg, Germany). Lung function was expressed as percentage of reference value (19).

\section{Treatment}

A solution containing $1 \mathrm{ml}$ of salbutamol hemisulphate $0.5 \%$ (Centrafarm, Etten-Leur, the Netherlands) and $1 \mathrm{ml}$ sodium chloride $0.9 \%$ (Baxter, Utrecht, the Netherlands) was administered by a handheld nebulizer (Hudson. Temecula, Mexico) to the patients and control subjects. Totally, a dose of $5 \mathrm{mg}$ salbutamol was given at each administration, which is the standard dose used in our hospital 


\section{Study design}

Measurements were started in the early morning $(8.30 \mathrm{a} . \mathrm{m}$.). At first, body weight and FFM were assesed. Then REE was measured during 20 minutes, after which lung function was assessed. After the baseline measurements, patients and healthy subjects received 5 mg nebulized salbutamol. Directly after nebulization, REE measurement was continued for 45 minutes. Finally, the second lung function test was performed.

\section{Statistics}

The baseline measurements of $\mathrm{REE}, \mathrm{RQ}$ (ratio $\mathrm{V}^{\prime} \mathrm{CO}_{2} / \mathrm{V}^{\prime} \mathrm{O}_{2}$ ) and heart rate were integrated over $0-20 \mathrm{~min}$. The response curves of REE, RQ and heart rate after salbutamol nebulization were integrated over 0-5, 5-10, 10-20, 20-30 and 30-45 min. For comparison within the individual before and after treatment, a paired $t$-test was used. The differences in response at each time interval and the mean differences between the groups were assessed with an independent $t$-test. For the latter purpose we integrated the metabolic changes over 10-45 min to avoid the initial peak value. Stepwise regression analysis was performed to determine the factors contributing to the variation in REE change due to the treatment. Data were analysed with the computer program 'Statistical Package for the Social Sciences' (SPSS) using the guidelines of Altman (20).

\section{Results}

Baseline characteristics of the patient group and of the two control groups are shown in table 1. Patients with COPD showed a significantly elevated baseline REE and heart rate compared to age-matched healthy subjects. The variation in REE was not influenced by plasma theophylline in the patients. Lung function was, as expected, severely impaired in the patient group. Raw was significantly higher in the older compared to the younger healthy control group.

Table 1: Baselinc characteristics of the study groups.

\begin{tabular}{|c|c|c|c|c|c|c|c|}
\hline \multirow{3}{*}{$\mathrm{n}$} & \multirow{3}{*}{$(\mathrm{m} / \mathrm{f})$} & \multicolumn{2}{|c|}{ Controls $<48 y$} & \multicolumn{2}{|c|}{ Controls $>48 y$} & \multicolumn{2}{|c|}{ Patients with COPD } \\
\hline & & 15 & $(6 / 9)$ & 10 & $(4 / 6)$ & & $(16 / 6)$ \\
\hline & & mean & $(S D)$ & mean & $(S D)$ & mean & $(S D)$ \\
\hline Age & (yrs) & 28.9 & (6.2) & 63.9 & $(11.8)^{* * *}$ & 66.1 & $(9.0)^{* * *}$ \\
\hline BMI & $\left(\mathrm{kg} / \mathrm{m}^{2}\right)$ & 22.7 & (2.4) & 24.4 & (3.7) & 24.1 & $(7.0)$ \\
\hline Fat-free mass & (kg) & 50.3 & $(110)$ & 45.3 & $(8.3)$ & 48.7 & $(10.8)$ \\
\hline REE & (\%pred) & 98.2 & $(6.5)$ & 104.6 & $(12.5)$ & 116.1 & $(9.0)^{* * * * H}$ \\
\hline \multicolumn{2}{|c|}{ Respiratory quotient } & 0.84 & $(0.04)$ & 0.84 & $(0.05)$ & 0.85 & $(0.05)$ \\
\hline Heart rate & (b/min) & 63.2 & $(8.7)$ & 61.0 & $(7.3)$ & 81.2 & $(13.0)^{* * * \# \# H}$ \\
\hline IVC & (\%pred) & 107.5 & $(13.0)$ & 104.8 & $(17.2)$ & 82.0 & 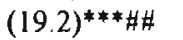 \\
\hline $\mathrm{FEV}_{1}$ & (\%pred) & 105.2 & $(10.1)$ & 97.4 & $(19.4)$ & 36.6 & $(11.7)^{* * *} \# \# \#$ \\
\hline Raw & (\%pred) & 70.9 & $(28.8)$ & 112.7 & $(49.9)^{*}$ & 282.0 & 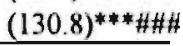 \\
\hline
\end{tabular}

BML: body mass index

REE: resting energy expenditure

${ }^{*} p<0.05,{ }^{* * *} p<0.001$ compared to controls $<48 y$.

$\#$ p $<0.01$, \#\#\# $<<0.001$ compared to controls $248 y$ 
Figure 1 shows the time course of REE, RQ and heart rate after salbutamol administration expressed as percentage of baseline values. Significant effects on mean REE, RQ and heart rate integrated over 10 to 45 minutes were seen after salbutamol nebulization in all groups, except for heart rate in the older healthy control group. The rise in mean (SEM) REE expressed as percentage of baseline value was significantly higher in younger healthy subjects $(11.4(1.4) \%)$ compared to older healthy subjects $(5.7(2.3) \%, \mathrm{p}<0.05)$ and patients with COPD $(4.2(1.1) \%, \mathrm{p}<0.001)$, which also accounted for the increase in heart rate $(13.4(2.1) \%$ vs $3.9(3.4) \%$, p $<0.05$ vs $4.9(1.7) \%, p<0.01$ respectively). The drop in RQ was more pronounced in the younger healthy subjects $(-10.2(1.4) \%)$ compared to the older healthy subjects $(-7.3(1.7) \%)$ and the patients $(-3.9(0.5) \%$, $p<0.001)$. There were no significant differences in metabolic effects between older healthy subjects and patients with COPD.

Salbutamol had a significant effect on IVC expressed as percentage of baseline value (SD) in patients with COPD $(9.3(9.4) \%, p<0.001)$. Significant improvements in $F E V_{1}$ and Raw were seen in the younger control group $\left(\mathrm{FEV}_{1} 6.5(3.3) \%, \mathrm{p}<0.001\right.$; Raw $-27.3(22.7) \%$, $\mathrm{p}<0.001$ ), in the older control group ( $\mathrm{FEV}_{1} 4.6(1.8) \%$, $\mathrm{p}<0.001$; Raw $-17.1(11.5) \%$, $\mathrm{p}<0.01)$ and in the patient group $\left(\mathrm{FEV}_{1} 19.3(16.2) \%\right.$, $\mathrm{p}<0.001$; Raw $-23.7(22.3) \%$, $p<0.001)$ after nebulization. The effects of salbutamol on lung function were not different between younger and older healthy subjects, whereas patients with COPD showed a significantly higher increase in IVC and $\mathrm{FEV}_{1}$ compared to the healthy controls.

To gain more insight into possible determinants of the variation in REE change after nebulization of salbutamol in healthy subjects, we performed a stepwise regression analysis with age, FFM, change in IVC, change in FEV ${ }_{1}$ and change in Raw as independent variables, and the change in REE as the dependent variable. On stepwise regression analysis, age $(p=0.004)$ and $F F M(p=0.03)$ were identified as significant contributors to the variation in REE change after salbutamol nebulization $\left(R^{2}=0.53\right)$. The degree of lung function change did not influence the change in REE. The variation in REE change in the patients with COPD was lower than in the healthy controls and none of the five variables could be identified as significant contributor to the variation in REE change. 

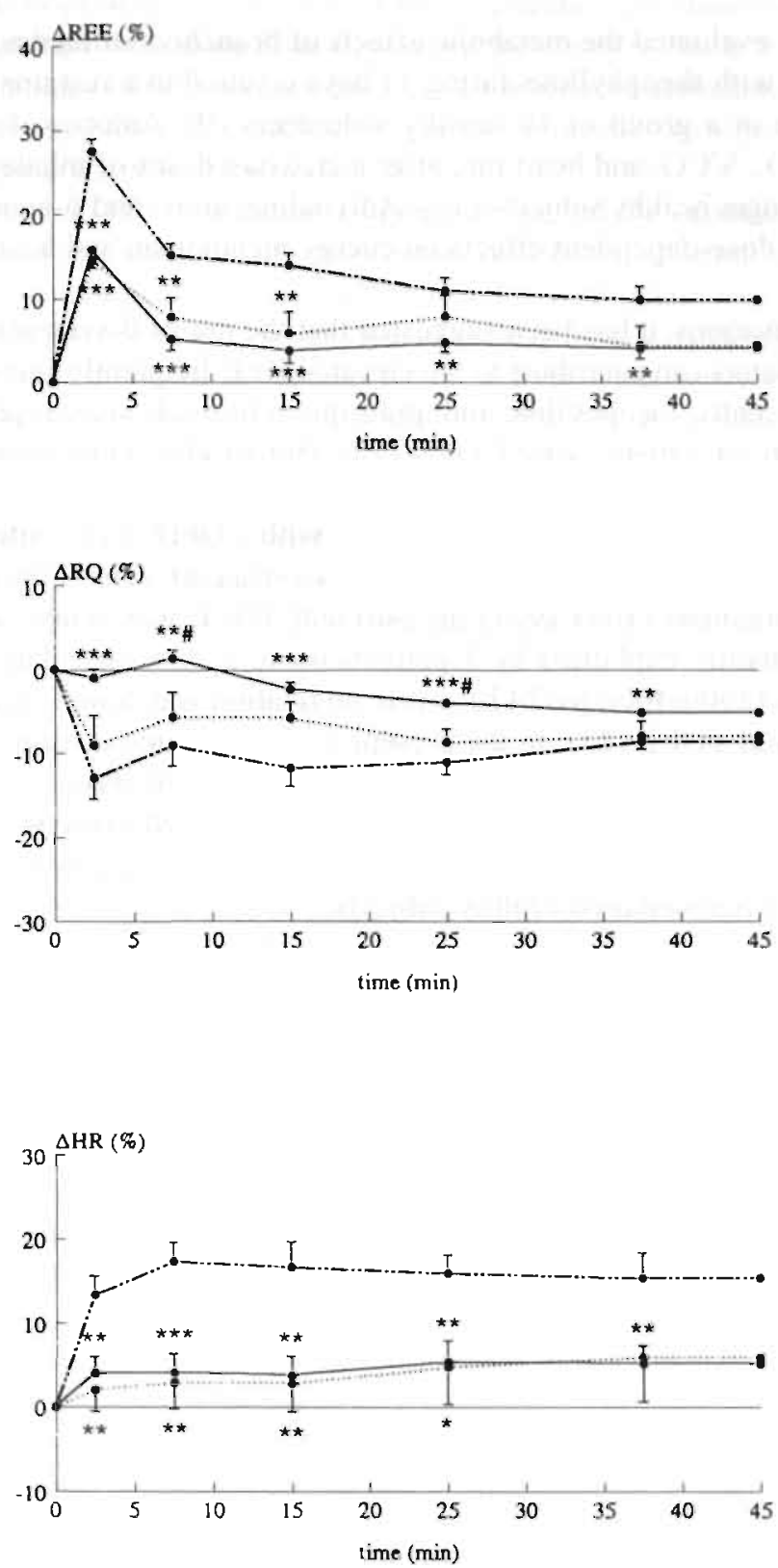

Figure 1: Time course of the changes in REE (top panel), RQ (middle panel) and heart rate (bottom panel) after nebulization of $5 \mathrm{mg}$ salbutamol in younger healthy subjccts (dashed/dotted line), older healthy subjects (dashed line) and patients with COPD (solid line), data are expressed as percentage of baseline value (SEM). Significances $" p<0.05, " p<0.01$, $\cdots p<0.001$ compared to controls $<48 \mathrm{y}$; $\mathrm{p}<0.05$ compared to controls $\geqslant 48 \mathrm{y}$. 


\section{Discussion}

Several studies have evaluated the metabolic effects of bronchodilating drugs in healthy subjects. Treatment with theophylline during 11 days resulted in a sustained increase in $\mathrm{V}^{\prime} \mathrm{O}_{2}$ and heart rate in a group of 10 healthy volunteers (9). Amoroso found a dosedependent rise in $\mathrm{V}^{\prime} \mathrm{O}_{2}, \mathrm{~V}^{\prime} \mathrm{CO}_{2}$ and heart rate after increasing doses of inhaled salbutamol vs placebo in 10 younger healthy subjects (10). Adrenaline, an $\alpha$ - and B-agonist, has also been found to exert dose-dependent effects on energy metabolism and heart rate (21).

Based on these observations, it has been suggested that the use of $B$-sympathicomimetics and other bronchodilators can contribute to the elevated REE frequently found in patients with COPD (10). Recently, theophylline and ipratropium bromide were reported to exert no effect on REE in 14 patients with COPD (12). Burdet elucidated however that, in contrast to ipratropium bromide, $5 \mathrm{mg}$ salbutamol by nebulizer induced an acute elevating effect on REE (4.8\%) and heart rate in 13 patients with COPD (11). Furthermore, in a group of 14 stable patients with COPD a significant, positive correlation between the daily dose of inhaled $B_{2}$-agonists (1061 (973) $\mu \mathrm{g} / 24 \mathrm{~h}$ ) and TDEE was found, although this effect was predominantly explained by 3 patients using a very high daily dose of $B_{2}$ sympathicomimetics $(1500-4000 \mu \mathrm{g} / 24 \mathrm{~h}$ ), while no relation was found between plasma theophylline level and TDEE (13). In the present study we found a similar, significant increase in REE in patients with COPD $(4.2 \%)$ as in the study of Burdet. The metabolic changes were however significantly lower in the patients compared to the younger healthy subjects. Furthermore, no significant difference in metabolic response was observed between patients and age-matched healthy subjects.

Although the rise in metabolism was similar, there was a discrepancy in the effect of salbutamol on RQ between the findings of Amoroso (10) and the present study; while Amoroso found an initial peak in RQ at 5 minutes after salbutamol inhalation followed by a fall benciath baseline, we observed an initial decrease in $R Q$ after salbutamol nebulization. The fall in $R Q$ probably reflects a rise in lipolysis and use of free fatty acids (FFA). Several other studies have investigated the effect of $\beta_{2}$-sympathicomimetics on RQ in healthy subjects. In a study in 7 healthy younger male volunteers no change in RQ was found after salbutamol infusion, while infusion with the non-selective B-agonist isoprenalinc resulted in a significant rise in arterial blood glycerol and FFA and in an increased uptake and oxidation of FFA in muscle tissue, which suggests an elevation in cellular oxygen uptake, lipolysis, glycogenolysis and gluconeogenesis (22). Similarly, another study showed an initial transient increase in respiratory exchange ratio together with a rise in blood glucose. glycerol and lactate during adrenaline infusion (21).

The metabolic effects of nebulized salbutamol were significantly more pronounced in younger compared to older healthy subjects, and by stepwise regression analysis age indeed explained a significant part of the variation in REE change in healthy control subjects. A decreasing effect of salbutamol could be caused by a reduction in the $\beta_{2}$ adrenoceptor number and/or sensitivity in peripheral (muscle) tissue with age. However, reported data are in favour of the hypothesis that $B_{2}$-receptor functioning is maintained in the elderly, although one study reported a decrease in the chronotropic cardiovascular 
response to isoprenaline in healthy elderly subjects (23). However, two other placebocontrolled studies, evaluating dose-dependent increases in finger tremor and heart rate in younger and older subjects to cumulative doses of inhaled salbutamol following pre-treatment with propanolol (a $\beta_{1}$ - and $\beta_{2}$-antagonist), showed no evidence for a decrease in $\beta_{2}$ adrenoceptor activity in the elderly $(24,25)$.

In addition to age, FFM explained a significant part of the variation in REE change after nebulization of salbutamol in healthy control subjects, suggesting that salbutamol mainly affects the metabolically active cell mass. After stimulation of the $\beta_{2}$-adrenoceptors located on the fibres and muscle spindles of skeletal muscle by $\$_{2}$-agonists, the membrane$B_{2}$-adrenoceptor complex is formed which activates adenylate cyclase, which in turn catalyses the conversion of ATP to cyclic 3,5-AMP by activating the membrane-bound $\mathrm{Na}^{+} / \mathrm{K}^{+}$-ATPase linked to the $\mathrm{B}_{2}$-adrenoceptor on the cell (26). The $\mathrm{Na}^{+} / \mathrm{K}^{-}$-pump is a major energy source of the cell activating several protein kinases. Glycogenolysis, lipolysis and release of renin, insulin, glucagon, parathyroid and antidiuretic hormones are stimulated, resulting in elevated levels of glucose, insulin, FFA, glycerol, lactate, pyruvate, ketone bodies and high density lipoprotein cholesterol (27).

In the present study no differences in the metabolic effects of salbutamol were seen between patients and age-matched healthy subjects, although different factors could have attenuated the increase in REE in patients with COPD.

At first, the already elevated baseline REE in the patient group could have blunted the metabolic effects of salbutamol as seen in the younger healthy control group.

Secondly, patients with COPD could have build up tolerance after long-term treatment with salbutamol due to a reduced receptor sensitivity and/or to down regulation of Breceptors (28). Large differences in susceptibility to tachyphylaxis between different tissues are however reported: muscle tissue seems to demonstrate more tolerance after long-term use than lung tissue (27). Indeed, prolonged treatment with inhaled salbutamol could not cause a sustained increase in REE in younger healthy volunteers and completely blunted the acute thermogenic response to a single high dose of salbutamol $(29,30)$. The patient group in the present study showed however the same metabolic response on $5 \mathrm{mg}$ nebulized salbutamol as the age-matched healthy control group, although all patients were regularly using $\beta_{2}$-agonists. This finding argues against tachyphylaxis to the metabolic effects of $B_{2}$-sympathicomimetics in patients with COPD.

A third explanation for the attenuated response of REE in the patient group could be a reduction in oxygen cost of breathing (OCB) due to salbutamol. The significant effects of salbutamol on $F E V_{1}$, Raw and IVC reflect a decrease in the resistive and elastic load of the respiratory system. Therefore a resulting decrease in REE could be hypothesized after salbutamol administration due to a decrease in OCB. Otherwise, no differences in metabolic effects were seen between the patients and the older healthy control subjects, suggesting that, as supported by the study of Shridhar (6), this supposed influence of the OCB on REE is not of great impact in COPD.

In conclusion, a single dose of nebulized salbutamol induced significant effects on REF, RQ and heart rate in healthy subjects and in patients with COPD. These effects were significantly higher in younger compared to older healthy subjects and to patients. Regular 
use of $B_{2}$-agonists by the patients did not totally blunt the systemic effects of the single dose of salbutamol. Age and FFM explained 53\% of the variation in REE change after salbutamol administration in healthy subjects. Despite significant improvements in $\mathrm{FEV}_{1}$ and Raw, probably reflecting a decrease in OCB, a significant rise in REE was observed in the patients with COPD. The acute metabolic effects of salbutamol did however not appear to be sufficient to explain the total elevation in REE seen in patients with COPD.

\section{References}

1. Schols AMWJ, Soeters PB, Dingemans AMC, Mostert R, Frantzen PJ, Wouters EFM. Prevalence and characteristics of nutritional depletion in patients with stable COPD eligible for pulmonary rehabilitation. Am. J. Resp. Dis. 1993; 147: 1151-6.

2. Wilson DO, Rogers RM, Wright E. Body weight in chronic obstructive pulmonary disease. Am. Rev. Resp. Dis. 1989; 139: 1435-8.

3. Fiaccadori E, Del Canale S, Coffrini E et al. Hypercapnic-hypoxemic chronic obstructive pulmonary disease (COPD): influence of severity of COPD on nutritional status. Am. J. Clin. Nutr. $1988 ; 48: 680-5$.

4. Schols AMWJ, Fredrix EWHM, Soeters PB, Westerterp KR, Wouters EFM (1991). Resting energy expenditure in patients with chronic obstructive pulmonary disease. Am. J. Clin. Nutr. 54, 983-987.

5. Donahoe M, Rogers RM. Wilson DO. Pennock BE. Oxygen consumption of the respiratory muscles in normal and in malnourished patients with chronic obstructive pulmonary discase. Am. Rev. Resp. Dis. 1989; 140: 385-91.

6. Sridhar MK. Carter R, Lean MEJ. Banham SW. Resting energy cxpenditure and nutritional state of paticnts with increased oxygen cost of breathing due to emphysema, scoliosis and thoracoplasty. Thorax 1994; 49: 781-5.

7. Francia M di, Barbier D, Mege JL, Orehek J. Tumor Necrosis Factor-alpha levels and weight loss in chronic obstructive pulmonary disease. Am. J. Resp. Crit. Care Med. 1994; 150: 1453-5.

8. Schols AMWJ, Buurman WA, Staal-Brekel AJ van den, Dentener MA, Wouters EFM. Evidence for a relation between metabolic derangements and increased levels of inflammatory mediators in a subgroup of patients with chronic obstructive pulmonary disease. Thorax 1996; 51: 819-24.

9. Dash A, Agrawal A, Venkat N, Moxham J, Ponte J. Effect of oral theophylline on resting energy expenditure in normal volunteers. Thorax 1994; 49: 1116-20.

10. Amoroso P, Wilson SR, Moxham J, Ponte J. Acute effects of inhaled salbutamol on the metabolic rate of normal subjects. Thorax 1993; 48: 882-5.

11. Burdet L, Muralt B de, Schutz Y, Fitting J-W. Thermogenic effect of brochodilators in patients with chronic obstructive pulmonary disease. Thorax 1997; 52: 130-135.

12. Mosier K, Renvall MJ, Ramsdell JW, Spindler AA. The effects of theophylline on metabolic rate in chronic obstructive lung disease patients. J. Am. Coll. Nutr. 1996: 15:403-407.

13. Hugli O, Schutz Y, Fitting JW. The daily energy expenditure in stable chronic obstructive pulmonary disease. Am. J. Respir. Crit. Care Med. 1996; 153: 294-300.

14. Vermeeren MAP, Schols AMWJ, Quaedvlieg FCM, Wouters EFM. The influence of an acute disease exacerbation on the metabolic profile of patients with chronic obstructive pulmonary disease. Clin. Nutr. 1994: 13 suppl. 1: 38-9 (abstract).

15. Weir JB. New methods for calculating metabolic rate with special reference to protein metabolism. J. Physiol. 1949; 109: 1-9.

16. Harris JA, Benedict EG. A Biometric Study of Basal Metabolism. Washington: Camegie Institution of Washington, 1919.

17. Schols AMWJ, Wouters EFM, Soeters PB, Westerterp KR. Body composition by bioelectrical impedance analysis compared to deuterium dilution and skinfold anthropomatry in patients with chronic obstructive pulnionary discase. Am. J. Clin. Nutr. 1991: 53: 421-4.

18. Deurenberg P, Kooy K van der, Leenen R, Weststrate JA, Seidell JC. Sex and age specific 
prediction formulas for estimating body composition from bioelectrical impedance: a crossvalidation study. Int. J. Obes. 1991; 15; 17-25.

19. Quanjer PH, ed. Standardised lung function testing. Eur. Respir. J. 1993; 6 (suppl. 16): 1-52.

20. Altman DG, Gore SM, Gardner MJ, Pocock SJ. Statistical guidelines for contributors to medical journals. British Med J. 1983; 286: 1489-93.

21. Fellows IW, Bennett T, Macdonald IA. The effect of adrenaline upon cardiovascular and metabolic functions in man. Clin. Sci. 1985; 69: 215-22.

22. Blaak EE. The Sympathetic Nervous System and Human Energy Metabolism in Relation to Obesity (thesis). Maastricht: University Press Maastricht, 1993.

23. Johansson SR, Hjalmarson A. Age and sex differences in cardiovascular reactivity to adrenergic agonists, mental stress and isometric exercise in normal subjects. Scand. J. Clin. Lab. Inves. 1988, 48: $183-91$

24. Lipworth BJ, Tregaskis BF, McDevitt DG. B-Adrenoceptor responses to inhaled salbutamol in the elderly. Br. J. Clin. Pharmacol. 1989; 28: 725-9.

25. Lipworth BJ, Tregaskis BF, McDevitt DG. Comparison of hypokalaemic, electrocardiographic and haemodynamic responses to inhaled isoprenaline and salbutamol in young and elderly subjects. $J$. Clin. Pharmacol. 1991: 40: 255-60.

26. Olsson OAT, Swanberg E, Svedinger I, Waldeck B. Effects of B-adrenoceptor agonists on ainway smooth muscle and on slow-contracting skeletal muscle: in vitro and in vivo results compared. Acta Pharmacol. Toxicol. 1979; 44: 272-6.

27. Tattersfield AE, Britton JR. B-Adrenoreceptor agonists. In: Barnes PJ, Roger JW, Thomson NC, eds. Asthma: Basic Mechanisms and Clinical Management. London: London Academic Press, 1988: $563-90$.

28. Tattersfield AE, Wilding P. B-Agonists and ventilation. Thorax 1993; 48: 877-8.

29. Wilson SR, Amoroso P, Moxham J, Ponte J. Modification of the thermogenic effect of acutely inhaled salbutamol by chronic inhalation in normal subjects. Thorax 1993; 48: 886-9.

30. Holgate ST, Stubbs WA, Wood PJ, McCaughey ES, Alberti KGMM, Tattersfield AE. Airway and metabolic resistance to intravenous salbutamol: a study in normal man. Clin. Sci. 1980; 59 ; 15561 . 


\section{Chapter 4}

Plasma leptin is related to proinflammatory status and dietary intake in patients with chronic obstructive pulmonary disease
A. M. W. J. Schols', E. C. Creutzberg', W. A. Buurman², L. A. Campfield $^{3}$, W. H. M. Saris ${ }^{4}$, E. F. M. Wouters ${ }^{1}$

Departments of ${ }^{1}$ Pulmonology, ${ }^{2}$ Surgery and ${ }^{4}$ Human Biology, University Hospital Maastricht, The Netherlands; ${ }^{3}$ Hoffman-La Roche Inc., Nutley, NJ, U.S.A.

American Journal of Respiratory and Critical Care Medicine 1999; 160: $1220-1226$ 


\section{Abstract}

Chronic obstructive pulmonary disease (COPD) is a syndrome of chronic wasting, in part associated with a chronic inflammatory response. Aim of this study was to investigate cross-sectionally and prospectively the potential role of leptin in relation to systemic inflammation in the regulation of the energy balance in COPD. Body composition by deuterium dilution, resting energy expenditure (REE) by indirect calorimetry and plasma concentrations of leptin and soluble TNF-receptors (sTNFR-) 55 and 75 by ELISA were measured in 27 male patients with emphysema and 15 male patients with chronic bronchitis (disease-subtype defined by high resolution computed tomography). Emphysematous patients were characterized by a lower body mass index due to a lower fat mass (FM) $(\mathrm{p}=0.001)$ and by lower mean (detectable) leptin concentrations $(\mathrm{p}=0.020)$ compared to bronchitic patients. Leptin was exponentially related to FM in emphysema $(r=0.74, p<0.001)$ and in chronic bronchitis $(r=0.80, p=0.001)$. Furthermore, a significant partial correlation coefficient between leptin and sTNF-R55 adjusted for FM and oral corticosteroid use was seen in emphysema $(r=0.81, p<0.001)$ but not in chronic bronchitis. In 17 predominantly emphysematous depleted male patients with COPD baseline plasma leptin divided by FM was in addition logarithmically inversely related to baseline dietary intake $(r=-0.50, p=0.047)$ and to the degree of weight change after eight weeks of nutritional support $(r=-0.60, p=0.017)$. This proposed cytokine-leptin link in pulmonary cachexia may explain the poor response to nutritional support in part of the cachectic patients with COPD and may open a novel approach in combating this significant comorbidity in COPD.

\section{Introduction}

Recent studies suggest that leptin, a protein synthesized by adipose tissue and encoded by the ob gene (1) plays an important role in the energy balance. Leptin is postulated to represent the afferent hormonal signal to the brain including the hypothalamus in a feedback mechanism regulating the fat mass (FM). Leptin binds to the leptin receptor (2) in the hypothalamus (3), the brain nucleus that plays a central role in the regulation of feeding behavior and energy balance. In animal models, the result of this interaction is a decrease in food intake (4). There is now evidence that the effects of leptin on food intake are mediated by two limbs of the weight control system: the appetite stimulating peptide, neuropeptide $\mathrm{Y}$, and the satiety stimulating melanocyte-stimulating hormone (5). Furthermore, leptin may mediate energy expenditure by both increasing physical activity and activity-independent thermogenesis, which in part appears to involve activation of brown adipose tissue $(6)$.

In obesity. a central insensitivity ('resistance') to leptin has been shown (7). On the opposite of obesity, tissue wasting ultimately leading to cachexia is commonly seen in chronic discases such as chronic obstructive pulmonary disease (COPD). Different patterns of chronic wasting. from massive loss of FM to disproportionate wasting of body cell mass, can be distinguished (8). These differences indicate the involvement of different regulatory mechanisms for the (disturbances in) energy and protein balance in COPD. In view of the fact that both anorexia and hypermetabolism play a role in the wasting associated with chronic pulmonary disease $(9,10)$, underlying abnormalities in the leptin feed-back mechanism might also be involved. In particular, elevated concentrations of 
circulating leptin or, on the contrary, a hypothalamic insensitivity to a fall in leptin concentrations might be present. The observed link between inflammatory cytokines and leptin in two experimental animal studies $(11,12)$ led to the hypothesis that adipose tissue gene expression is regulated by inflammatory cytokines, which in turn could induce anorexia in acute or chronic inflammation. Two recent reports have furthermore shown an enhanced production of tumor necrosis factor $\alpha(\mathrm{TNF}-\alpha)$ in patients with COPD suffering from weight loss $(13,14)$. Clinical data regarding the possible involvement of leptin in the pathophysiology of inflammation-associated chronic wasting are however lacking.

The present study was undertaken to investigate cross-sectionally the relationship between plasma leptin concentrations and soluble TNF-receptor (sTNF-R) 55 and 75 concentrations, as a reflection of an enhanced inflammatory status, in patients with COPD stratified into emphysema and chronic bronchitis. Furthermore, in a group of depleted patients with COPD it was prospectively studied if leptin was a determining factor of dietary intake, resting energy expenditure (REE) and the response to nutritional therapy.

\section{Subjects and methods}

\section{Patients}

\section{Cross-sectional study}

A random group of patients with COPD, consecutively admitted to a pulmonary rehabilitation center, were included in the study when they fulfilled the following criteria: 1) COPD according to the ATS guidelines (15) and chronic airflow obstruction defined as a measured forced expiratory volume in one second $\left(\mathrm{FEV}_{1}\right)$ less than $70 \%$ of the reference value; 2 ) irreversible obstructive airway disease, i.e. $<10 \%$ improvement in FEV , expressed as percentage of predicted after inhalation of a $\boldsymbol{B}_{2}$-agonist; 3 ) in clinically stable condition. not suffering from a respiratory tract infection; 4) no concomitant confounding diseases, such as malignant disease, gastrointestinal disorders, severe endocrine disorders or recent surgery; 5) no suspected abnormal fluid balance as manifested by the presence of edema or regular use of diuretics. In order to increase homogeneity of the study population, only male subjects were included.

\section{Prospective study}

The second group consisted of male patients with COPD fulfilling the same inclusion criteria as indicated in the cross-sectional study, and suffering from below normal body weight (body mass index (BMI; body weight/height") $\leq 23 \mathrm{~kg} / \mathrm{m}^{2}$ ) and/or depletion of fatfree mass (fat-free mass index (FFMI; FFM/height ${ }^{2}$ ) $\leq 16 \mathrm{~kg} / \mathrm{m}^{2}$ ). These patients received standardized nutritional therapy consisting of $500-750 \mathrm{kcal} /$ day given as three liquid supplements of $200 \mathrm{ml}$ each, as integrated part of an in-patient pulmonary rehabilitation program. Response to nutritional therapy was defined as the weight change reached after eight weeks of treatment.

The study was approved by the medical ethical committee of the University Hospital of Maastricht. Informed consent was obtained from all subjects. All measurements were performed during the first two weeks after admission to the center, and in the prospective study in addition after eight weeks of nutritional treatment. 


\section{Body composition}

Body height was determined to the nearest $0.5 \mathrm{~cm}$ (Lameris WM 715, Breukelen, The Netherlands) with subjects standing barefoot. Body weight was measured with a beam scale to the nearest $0.1 \mathrm{~kg}$ (SECA, FRG, Germany) with subjects barefoot and in light clothing. Recent weight loss was defined as body weight loss in the last three months. To measure total body water (TBW) each patient received a weighed $(1 \mathrm{~g} / 1$ estimated TBW) oral dose of deuterium labeled water $\left(\mathrm{D}_{2} \mathrm{O} ; 99.84\right.$ atom percentage excess) mixed into $70 \mathrm{ml}$ water in the late evening around $10 \mathrm{p} . \mathrm{m}$. Just before and approximately 10 hours later, after complete emptying of the bladder, an urine sample was obtained. Urine was analyzed for deuterium with an isotope ratio mass spectrometer (16). Deuterium dilution space was calculated from the quantity of administered $\mathrm{D}_{2} \mathrm{O}$ and the urine $\mathrm{D}_{2} \mathrm{O}$ concentrations following complete distribution. TBW was calculated from these values by applying a conversion factor of 1.04 . This correction accounts for the exchange of labile hydrogen which occurs in humans during the equilibrium period. FFM was calculated assuming a hydration factor of 0.73 . FM was calculated by subtracting FFM from body weight.

In order to assess possible disturbances in body fat distribution in the cross-sectional study group, subregional PM was assessed by dual-energy $\mathrm{x}$-ray absorptiometry (DXA), which is a direct method of assessing bone mineral content and the soft tissue surrounding the bone (FFM and FM). Each patient, lying in supine position on a scan table for approximately 15 minutes, was scanned by a DPX-L Bone Densitometer ${ }^{8}$ (Lunar Radiation Corporation, Madison, WI; voltage $76.0 \mathrm{kVp}$, current $150 \mu \mathrm{A}$, collination 1.68 $\mathrm{mm}$ ). Multiple fast speed transverse scans from head to toes with $1 \mathrm{~cm}$ intervals were performed, with a scan area of $576^{*} 1968 \mathrm{~mm}$ and a sample interval of $1 / 32$. A rectilinear scanner was used to detect density differences as the two concentrations of photon energy were projected through the subject. The scanner used a constant potential $\mathrm{x}$-ray source at $78 \mathrm{kV}$ and a K-edge filter to achieve a congruent beam of stable dual-energy radiation with effective energies of 38 and $70 \mathrm{keV}$. Data were collected in maximal 205 scan lines* 120 sample points (pixel size $4.8 * 9.6 \mathrm{~mm}$ ). Entrance radiation dose was minimal $(<0.02 \mathrm{mSv} / \mathrm{scan})(17)$. Total and subregional FM were derived according to computer algorhythms (Lunar software version 1.3) provided by the manufacturer.

\section{Resting energy expenditure}

REE was measured by an open circuit indirect calorimetry system using a ventilated hood (Oxycon Beta ${ }^{\star}$, Jaeger, Würzburg, Germany) (18). Measurements were started in the early moming $(8.30 \mathrm{a} . \mathrm{m}$.). Patients were in a fasting state for at least 10 hours and had a period of at least 30 minutes bed rest prior to the measurement during which subjects were comfortably lying on a bed in supine position. After stabilization, REF: was recorded during a period of $20 \mathrm{~min}$. and calculated from oxygen consumption and carbon dioxide production using the abbreviated Weir formula.

\section{Dietary intake}

In the cross-sectional study dietary intake was assessed using the dietary history method with cross check. In the prospective study, food intake was recorded during four days before the start of the nutritional intervention and the mean intake of the four days was 
taken for analysis. The information was coded for computer nutrient analysis by the same trained dietician. The nutrient data base was derived from the Dutch food composition tables (19).

\section{Lung function}

Lung function testing included spirometry ( $\mathrm{FEV}$, and forced vital capacity (FVC)), thoracic gas volumes (total lung capacity (TLC)) and diffusing capacity for carbon monoxide (DLco) (Masterlab ${ }^{*}$, Jaeger, Wurzburg, FRG). Lung function values were expressed as a percentage of predicted (20). Blood was drawn from the brachial artery at rest while breathing room air. Arterial pressures of oxygen and carbon dioxide $\left(\mathrm{PaO}_{2}\right.$, $\mathrm{PaCO}_{2}$ ) were analyzed on a blood gas analyzer (Radiometer, ABL 330, Copenhagen).

\section{Assessment of emphysema}

Evaluation of the presence and severity of emphysema was performed by high resolution computed tomography (HRCT) using a commercial scanner (Somaton Plus ${ }^{\star} ;$ Siemens, Erlangen, FRG; voltage: $137 \mathrm{kVp}$, current: $220 \mathrm{~mA}$, collimation: $1.0 \mathrm{~mm}$, scanning time: $1.0 \mathrm{sec}$ ). Five thin-section CT scans were obtained with the patient supine during breath hold at end-expiration: 2 scans of the upper and two scans of the lower lung zones at 3 and $6 \mathrm{~cm}$ above and below the carina and 1 scan at the carina. Images were made at a concentration of $-800 \mathrm{HU}$ and window width of $1600 \mathrm{HU}$, which is appropriate for lung detail. The severity and extent of emphysema of each scan was visually scored at a fourpoint scale independently by two observers according to the direct observational method of Sakai (21). For each of the lung sections, the score for the severity of emphysema was multiplied by the score for the extent; the resultant scores were subsequently summed to give a total HRCT-score. Visual scores ranged from 0 (no emphysema) to 120 (severe emphysema). Patients with a visual score $<30$ were sub-typed as chronic bronchitis and patients with a visual score $>30$ were sub-typed as emphysema (22).

High resolution computed tomography (HRCT) is a sensitive technique for the evaluation of the presence and severity of emphysema; in patients with emphysema the densitometric parameters substantially differ from the corresponding values in patients with chronic bronchitis and healthy controls, regardless the level of inspiration (23).

\section{Collection and analysis of plasma samples}

From all patients blood was obtained in the fasting state by venipuncture at $9 \mathrm{pm}$. Blood was collected in evacuated blood collection tubes (Sherwood Medical, St Louis, MO) containing EDTA. Plasma was separated from blood cells by centrifugation at $1000 \mathrm{G}$ for 10 minutes at $4{ }^{\circ} \mathrm{C}$ within 1 hour after collection. Plasma samples were stored at $-70^{\circ} \mathrm{C}$ until analysis.

STNF-R55 and -R75 were measured using specific sandwich ELISA described elsewhere (24). In short, MAbs MR1-1 and MR2-2 were coated on immuno-assay plates (NuncImmuno Plate Maxisorp, Roskilde, Denmark). The standards used were recombinant human sTNF-R55 and sTNF-R75. Specific biotin-labeled polyclonal rabbit anti humansTNF-R $\operatorname{lgG}$ were used as detector reagents followed by streptavidin-peroxidase conjugate (Dako, Glostrup, Denmark). Photospectrometry $(450 \mathrm{~nm})$ was performed using a micro ELISA autoreader. The detection limit of both assays was $100 \mathrm{pg} / \mathrm{ml}$. Leptin 
concentrations were measured using a double antibody sandwich ELISA assay using a monoclonal antibody specific for human leptin. The lower concentration of detection was $0.25 \mathrm{ng} / \mathrm{ml}$ and the upper limit $50 \mathrm{ng} / \mathrm{ml}$. The intra- and inter- assay variation were $9 \%$ and $12 \%$ respectively. The leptin concentrations of normal-weight healthy subjects range from 1 to $12 \mathrm{ng} / \mathrm{ml}$.

Fasting serum concentration of glucose was determined by spectrophotometric analysis (Cobas Mira ; Hoffmann-La Roche, Basel, Switzerland).

\section{Statistical analysis}

Results are given as mean (SD). Differences between groups were statistically analyzed using an unpaired Student's t-test. In the patients with leptin values below the detection limit $(0.25 \mathrm{ng} / \mathrm{ml})$, the value $0.25 \mathrm{ng} / \mathrm{ml}$ is used in the analysis. After curve estimation, linear, exponential or logarithmic Pearson product moment correlation coefficients were calculated. The relationship between leptin and the sTNF-receptors were adjusted for FM and oral corticosteroid use using partial correlation analysis. Following the simple correlations a regression model was fitted to the data to enable the variables that contributed to the explained variation in plasma leptin concentration. Significance was determined at the $5 \%$ level. Data were analyzed according to the guidelines of Altman et al. (25), using SPSS (Statistical Package for the Social Sciences, version 6.0 for Windows, SPSS Inc., Chicago, IL, U.S.A.).

\section{Results}

\section{Cross-sectional study}

Characteristics of the study group stratified into the COPD sub-types (27 patients with emphysema, 15 patients with chronic bronchitis) are given in table 1 . The total group was characterized by severe lung function impairment. Patients with emphysema were characterized by a significantly lower $\mathrm{FEV}_{1}$, Dlco and $\mathrm{PaO}_{2}$ compared to those with chronic bronchitis. Emphysematous patients expressed also a significantly lower BMI due to a significantly lower FM (mean difference $7.8 \mathrm{~kg} ; 95 \% \mathrm{Cl}: 3.2-12.4 \mathrm{~kg}$ ), whereas the groups were not different in FFM and in the prevalence of recent weight loss (emphysema: $14 / 27$ vs chronic bronchitis: $6 / 15, p=0.340$ ). Dietary intake was nearly significantly higher in the patients with the emphysematous subtype of COPD compared to the patients with the bronchitic sub-type ( $\mathrm{p}=0.055$ ), while no difference was seen in REE.

Maintenance medication in the majority of patients consisted of theophylline, (inhaled) $B_{2}$-agonists and inhaled corticosteroids. Furthermore, $11 / 27$ patients with emphysema versus $8 / 15$ patients with chronic bronchitis were on low dose systemic corticosteroids (prednisone $\leq 10 \mathrm{mg} /$ day; $\mathrm{p}=0.322$ ). No differences were seen in senum glucose between the patients with emphysema and chronic bronchitis (table 1). On DXA-analysis, visceral FM estimated by trunk FM expressed as percentage of total FM was higher in patients with emphysema compared to chronic bronchitis (52.1 (5.4)\% vs $47.2(6.7) \%, p=0.023)$. However, no influence of oral corticosteroid use on the distribution of body fat could be established. 
Table 1: Patient characteristics.

\begin{tabular}{|c|c|c|c|c|c|c|}
\hline \multirow[t]{2}{*}{$\mathrm{n}$} & & \multicolumn{2}{|c|}{$\begin{array}{l}\text { Emphysema } \\
27\end{array}$} & \multicolumn{3}{|c|}{$\begin{array}{l}\text { Chronic bronchitis } \\
15\end{array}$} \\
\hline & & mean & (SD) & mean & (SD) & p-value \\
\hline$\overline{\text { Age }}$ & (yrs) & 67 & (8) & 67 & (5) & 0.855 \\
\hline Body mass index & $\left(\mathrm{kg} / \mathrm{m}^{2}\right)$ & 21.6 & $(3.0)$ & 25.1 & (3.3) & 0.001 \\
\hline Fat-free mass & (kg) & 47.0 & $(6.7)$ & 48.7 & (7.1) & 0.440 \\
\hline Fat mass & $(\mathrm{kg})$ & 15.7 & $(6.4)$ & 23.5 & $(7.6)$ & 0.001 \\
\hline Dietary intake & $(\mathrm{kcal} / 24 \mathrm{~h})$ & 2144 & $(536)$ & 1803 & (533) & 0.055 \\
\hline REE & $(\mathrm{kcal} / 24 \mathrm{~h})$ & 1494 & (194) & 1588 & (232) & 0.169 \\
\hline FVC & (\%pred) & 86 & (14) & 83 & (15) & 0.434 \\
\hline $\mathrm{FEV}_{1}$ & (\%pred) & 33 & $(10)$ & 43 & (14) & 0.016 \\
\hline TLC & (\%pred) & 120 & (19) & 118 & (17) & 0.663 \\
\hline Diffusing capacity & (\%pred) & 45 & (17) & 71 & (19) & $<0.001$ \\
\hline $\mathrm{PaO}_{2}$ & $(\mathrm{kPa})$ & 9.4 & (1.4) & 10.5 & $(0.9)$ & 0.012 \\
\hline $\mathrm{PaCO}_{2}$ & $(\mathrm{kPa})$ & 5.8 & $(0.7)$ & 5.6 & $(1.0)$ & 0.354 \\
\hline sTNF-receptor 55 & (ng/ml) & 0.65 & $(0.32)$ & 0.65 & $(0.30)$ & 0.992 \\
\hline sTNF-receptor 75 & $(\mathrm{ng} / \mathrm{ml})$ & 1.57 & $(0.39)$ & 1.66 & $(0.46)$ & 0.512 \\
\hline Glucose & $(\mathrm{mmol} / \mathrm{l})$ & 5.9 & $(0.9)$ & 6.5 & $(1.5)$ & 0.121 \\
\hline Leptin' & $(\mathrm{ng} / \mathrm{ml})$ & 2.6 & $(2.7)$ & 5.1 & $(3.0)$ & 0.020 \\
\hline
\end{tabular}

REE: resting energy expenditure; FVC: forced vital capacity; $\mathrm{FEV}_{1}$ : forced expiratory volume in 1 second: TLC: total lung capacity.

'Mean value of detcetable leptin concentrations: $n=19$ (emphysema) and $n=13$ (bronchitis).

Lower detection limit of the assay: $0.25 \mathrm{ng} / \mathrm{ml}$.

As expected based on the lower FM, mean detectable plasma leptin was significantly lower in the patients with emphysema compared to patients with chronic bronchitis (table 1). Non-detectable concentrations (below $0.25 \mathrm{ng} / \mathrm{ml}$ ) were found in 8 out of 27 patients with emphysema relative to 2 out of 15 patients with chronic bronchitis. A large interindividual variation was seen, which is illustrated by the distribution of FM among the patients with leptin concentrations below the detection limit (figure 1). The curvilinear correlation coefficient between leptin and FM was $0.74(p<0.001)$ in the patients with emphysema (figure $1 \mathrm{a})$ and $0.80(\mathrm{p}=0.001)$ in the patients with chronic bronchitis (figure 1b). In addition, significant correlation coefficients between leptin and visceral FM expressed as percentage of total FM were revealed in the emphysematous patients $(r=0.45$, $\mathrm{p}=0.030)$ and in the bronchitic patients $(\mathrm{r}=0.77, \mathrm{p}=0.003)$. The relation between leptin and FM or proportion visceral FM was not affected by oral corticosteroid use.

After adjustment for FM and oral corticosteroid use as possible confounders, a significant partial correlation coefficient was found in the total group between leptin and sTNF-R55 $(r=0.59, p=0.001)$ but not between leptin and sTNF-R75 $(r=-0.08, p=0.633)$. Figure 2 shows a striking difference in the relationship between STNF-R55 and leptin concentration between the COPD sub-types. While in the patients with emphysema a highly significant partial correlation coefficient was found between STNF-R55 and leptin after adjustment for FM and oral corticosteroid use $(r=0.81, p<0.001$; figure $2 a)$, such a relationship was not found in chronic bronchitis ( $r=0.29, p=0.369$; figure $2 b$ ). 


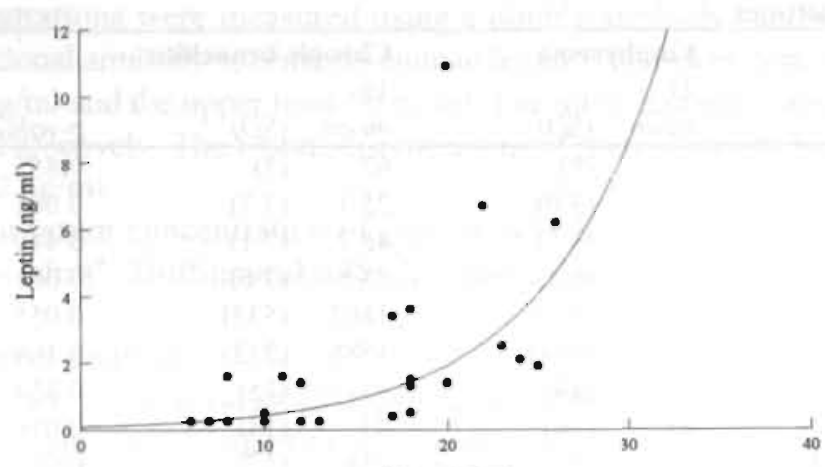

Fat mass (kg)

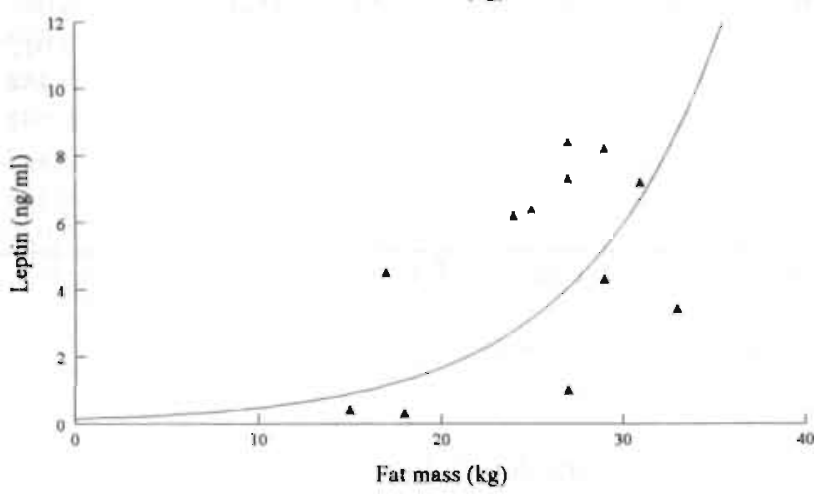

Figure 1: Relationship betwcen leptin concentration and fat mass in patients with emphysema (figure la: upper pancl: $r=0.74, p<0.001$ ) and in patients with chronic bronchitis (figure $1 b$; lower panel; $r=0.80, p=0.001$ ).

There are minor discrepancies in the number of subjects in figures $1 \mathrm{a}$ and $2 \mathrm{a}$ and $\mathrm{lb}$ and $2 b$. These discrepancies can be explained by the fact that in $2 / 27$ patients with emphysema and in $1 / 15$ patients with chronic bronchitis FM was not measured.

On stepwise regression analysis, FM and sTNF-R55 significantly explained $64 \%$ of the variation in plasma leptin concentration $(p<0.001)$. HRCT-score as a measure of the extent of emphysema, FFMI as a measure of functional tissue depletion and oral corticosteroid use were excluded from the model (table 2).

Table 2: Independent contributors to the explained variation in plasma leptin concentration on stepwise regression analysis.

\begin{tabular}{lllr}
\hline & & Cumulative $\mathbf{R}^{2}$ & p-value \\
\hline Fat mass & $(\mathrm{kg})$ & 0.46 & $<0.001$ \\
sTNF-receptor 55 & $(\mathrm{ng} / \mathrm{ml})$ & 0.64 & $<0.001$ \\
HRCT-score & $(0-120)$ & & 0.728 \\
Fat-free mass index & $\left(\mathrm{kg} / \mathrm{m}^{2}\right)$ & & 0.717 \\
Oral corticosteroid use & $($ no/yes) & & 0.432 \\
\hline
\end{tabular}

$\mathrm{R}^{2}$ coefficient of determination. 

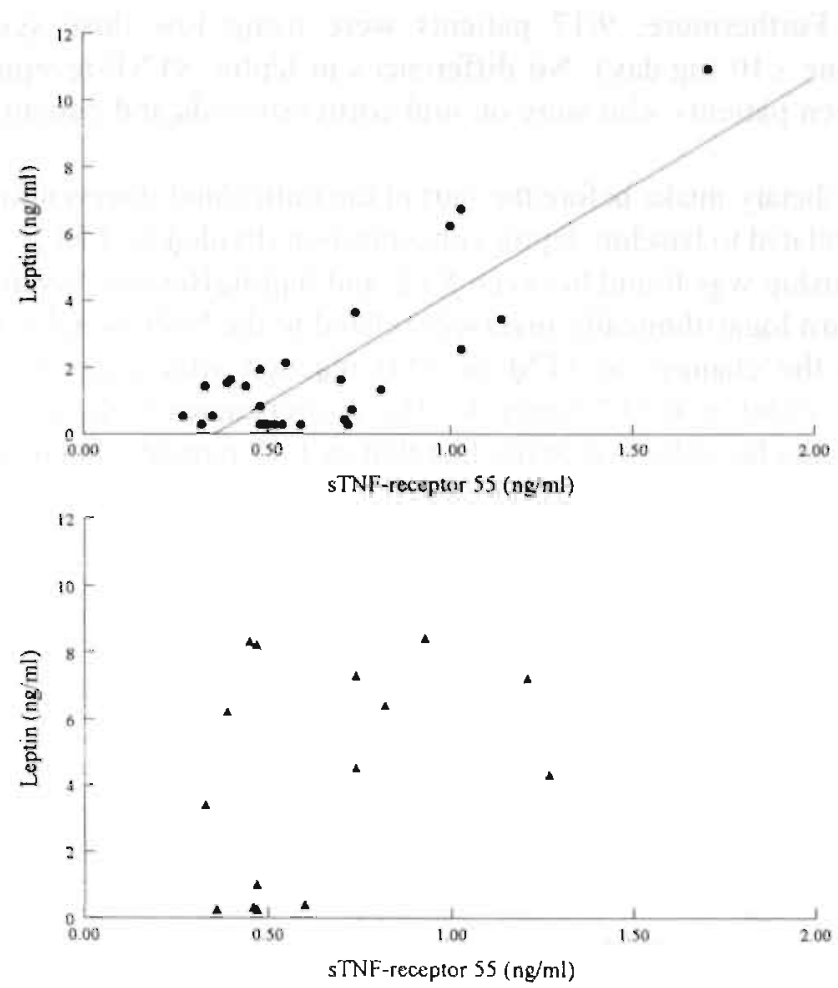

Figure 2: After adjustment for fat mass and oral corticosteroid use, leptin concentration is significantly related to soluble TNF-receptor 55 in emphysema (figure 2a: upper panel: $\mathrm{r}=0.8 \mathrm{I}, \mathrm{p}<0.00 \mathrm{l}$ ), but not in chronic bronchitis (figure $2 \mathrm{~b}$; lower pancl; $\mathrm{r}=0.29, \mathrm{p}=0.369$ ).

\section{Prospective study}

Prospectively, 17 male patients with COPD suffering from depletion of body weight and/or FFM were studied. In this group, mean (SD) age amounted to 65 (7) years, BMI $19.4(2.1) \mathrm{kg} / \mathrm{m}^{2}$, FFM 44.5 (5.0) kg, FM 13.9 (6.5) kg, FEV, 30 (10) \%pred and DLco 37 (14) \%pred. In these patients the DLco, as a less precise measure of the extent of emphysema, was comparable to the DLco of the patients with emphysema described in the cross-sectional study and significantly lower than in the bronchitic patients $(p-0.05)$. It is known that HRCT assessment of emphysema highly correlates with the DL.co. In the study of Lamers et al., (1998) a high prevalence (93\%) of HRCT-scored emphysema was observed in patients with a DLco $<50 \%$ of predicted and a low prevalence $(19 \%)$ in patients with a DLco $\geq 50 \%$ of predicted. Furthermore, DLco ( $\%$ of predicted) significantly inversely correlated with the HRCT emphysema score (26). Mean weight gain after eight weeks of nutritional supplementation was $2.9(2.7) \mathrm{kg}$, consisting of 1.6 (2.0) kg FFM.

In most patients (10/17) leptin concentrations were undetectable. Serum glucose amounted up to mean (SD) $6.2(1.0) \mathrm{mmol} / \mathrm{l}$. Similar to the cross-sectional study, maintenance medication in the majority of patients consisted of theophylline, (inhaled) $B_{2}$-agonists and 
inhaled corticosteroids. Furthermore, 9/17 patients were using low dose systemic corticosteroids (prednisone $\leq 10 \mathrm{mg} /$ day). No differences in leptin, sTNF-receptors or glucose were seen between patients who were on oral corticosteroids and patients who were not.

Figure 3 shows that mean dietary intake before the start of the nutritional intervention was logarithmically inversely related to baseline leptin concentration divided by FM $(\mathrm{r}=-0.50$. $\mathrm{p}=0.047$ ) while no relationship was found between REE and leptin. Baseline leptin, also divided by FM, was in turn logarithmically inversely related to the body weight change (but not specifically to the changes in FFM or FM) reached after eight weeks of nutritional intervention $(r=-0.60, p=0.017$; figure 4$)$. The discrepancies in the number of subjects in figures 3 and $4 \mathrm{can}$ be addressed to the fact that in $1 / 17$ patients dietary intake was not assessed and in $2 / 17$ patients the change in body weight was not measured.

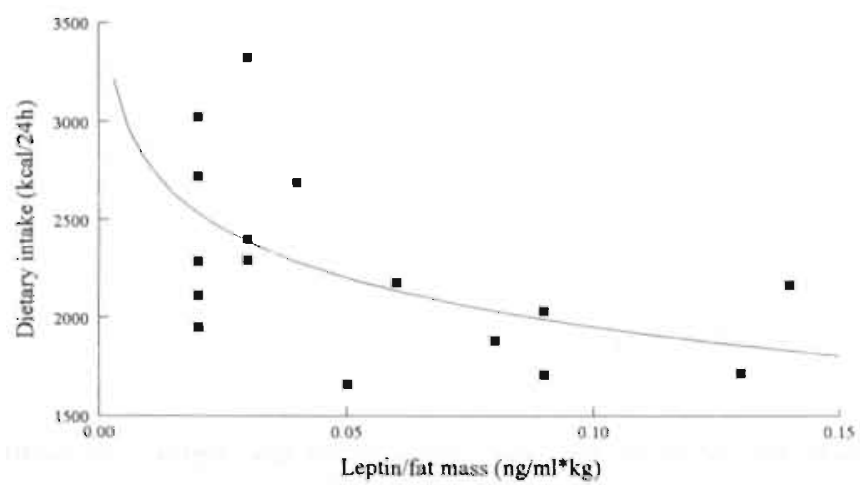

Figure 3: Inverse relationship between dietary intake before nutritional therapy and baseline plasma leptin concentration divided by fat mass in depleted patients with COPD $(r=-0.50$. $\mathrm{p}=0.047$ )

\section{Discussion}

This is the first clinical study showing that enhanced concentrations of leptin are related to pro-inflammatory status in patients with COPD. A significant relationship between plasma concentrations of leptin and sTNF-R55 adjusted for fat mass and oral corticosteroid use was found, particularly in the emphysematous sub-type. Subsequently in a group of depleted emphysematous patients with COPD, baseline leptin concentration was in turn inversely related to baseline dietary intake as well as to the weight change after eight weeks of nutritional intervention. 


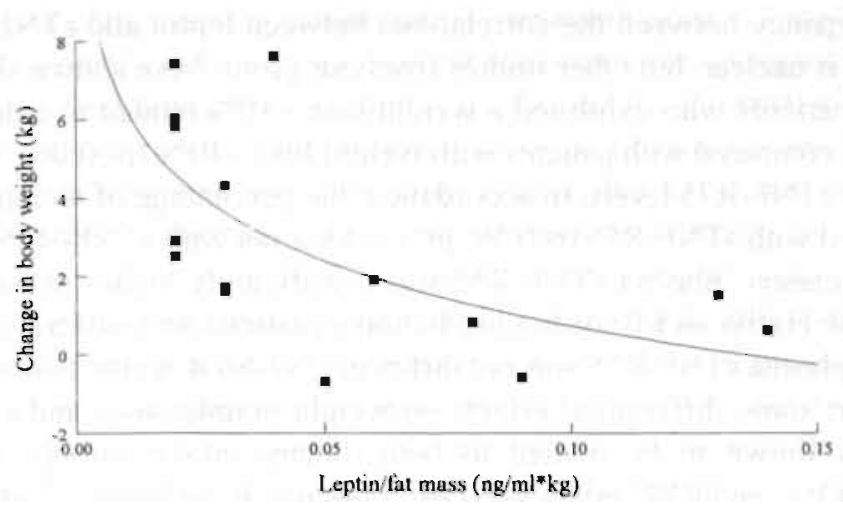

Figure 4: Inverse relationship between the change in body weight after 8 weeks of nutritional therapy and baseline plasma leptin concentration divided by fat mass in depleted patients with COPD $(r=-0.60, p=0.017)$.

Leptin was found to be associated with FM in line with the reported feed-back mechanism involved in the regulation of FM. Since plasma leptin was unrelated to FFMI (as a measure of functional tissue depletion), it appears that this feed-back mechanism does not consider global body composition in patients with COPD. We were however not able to compare leptin levels in COPD with normal leptin levels, since we did not include a healthy age-matched control group. The difference in plasma leptin between emphysema and chronic bronchitis was expected because of significant differences in FM. The lower leptin levels in emphysema could be related to the higher dietary intake revealed in this sub-group, according to the normal feed-back mechanism of fat mass by leptin. The fact that dietary intake was increased in the patients with emphysema, despite a similar REE and prevalence of recent weight loss compared to the patients with chronic bronchitis, could be explained by an increased 'wasting' of energy related to a -previously reportedincreased activity-related energy expenditure (27).

The fact that FM could only partly explain the variation in leptin concentrations suggests that other factors might be involved. In this study we identified a significant relationship between leptin and STNF-R55 concentrations in patients with COPD after adjustment for FM and oral corticosteroid use. Further indications for involvement of inflammation in the pathogenesis of weight loss in COPD are given by observations of others. I ssing an immuno-radiometric assay, di Francia et al. demonstrated elevated TNF- $\alpha$ concentrations in serum of patients with C.OPD suffering from weight loss compared to weight-stable patients (13). In contrast de Godoy, using an ELISA assay which measured only biologically active TNF- $\alpha$, did not find differences in TNF- $\alpha$ serum concentrations between weight-losing and weight-stable patients with COPD (14). The TNF- $\alpha$ production of peripheral monocytes of patients with recent weight loss was however enhanced after stimulation with lipopolysaccharide (LPS) when compared to weight-stable patients with COPD and control subjects (14). 
The reason for the discrepancy between the correlations between leptin and sTNF-R55 and leptin and STNF-R75 is unclear, but other studies from our group have shown similar results. In lung cancer, patients who exhibited a weight loss $\geq 10 \%$ tended to exhibit a higher level of sTNF-R55 compared with patients with weight loss $<10 \%(\mathrm{p}=0.06)$, while there was no difference in STNF-R75 levels. In accordance, the percentage of weight loss was significantly correlated with STNF-R55 $(\mathrm{r}=0.59, \mathrm{p}=0.02)$ but not with $\mathrm{sTNF}-\mathrm{R} 75(28)$. In another study in lung cancer, plasma sTNF-R55 was significantly higher in patients with a REE $\geq 110 \%$ of the Harris and Benedict prediction equations and suffering from recent weight loss, while plasma sTNF-R75 was not different (29). So it seems that sTNFR55 and sTNF-R75 exert some differential effects on weight maintenance and energy balance; sTNF-R55 has shown to be related to both dietary intake and metabolic parameters such as weight loss and REE, while sTNF-R75 has not. In addition, sTNF-R55 may be more sensitive to metabolic changes than STNF-R75.

Experimental animal studies have provided evidence for a link between pro-inflammatory cytokines and leptin. Cytokine treatment (TNF- $\alpha$, IL-1) of fasted hamsters increased concentrations of leptin in the circulation and leptin mRNA in adipose tissue. The increase in circulating leptin concentrations correlated with a decrease in food intake (11). The hypothesis that cytokine induction of leptin may play a significant role in the anorexia and cachexia of inflammatory diseases was further illustrated by Sarraf showing that administration of the pro-inflammatory cytokines TNF- $\alpha$, IL- 1 and to a lesser extent leukemia inhibitory factor produced a prompt and dose-dependent increase in serum leptin and leptin mRNA expression in the adipose tissue of mice. In contrast, the cytokines IL10. IL-4 and ciliary neurotrophic factor, not known to induce anorexia or a decrease in intake, did not affect leptin gene expression or serum leptin concentrations (12). No data are available yet on leptin mRNA expression in FM of patients suffering from cachexia. Furthermore it should be pointed out that leptin gene expression may be different between rodents and humans

On the opposite end of the energy balance spectrum, recent data have suggested a key role for TNF- $\alpha$ in the insulin resistance of obesity and of non-insulin dependent diabetes mellitus (NIDDM) (30). In humans, a strong positive correlation was found between the degree of obesity based on the BMI, hyperinsulinemia and relative TNF- $\alpha$ mRNA concentrations in adipose tissue (31). The results of another recent study did however not reveal a significant relationship between individual insulin sensitivity on the one hand and circulating concentrations of TNF- $\alpha$ and leptin on the other in patients with offspring NIDDM (32). No significant relationship was found between leptin and TNF- $\alpha$ in these patients in contrast to the findings of our group. Based on the present study, we can not exclude an influence of alterations in insulin sensitivity, possibly induced by oral corticosteroid therapy, on the observed relationship between sTNF-receptors and leptin in patients with COPD. Jacobsson et al. reported nevertheless that insulin resistance was not exhibited by patients with advanced COPD compared to healthy subjects (33).

A substantial proportion of patients used oral corticosteroids as maintenance medication. Reports concerning the effects of oral corticosteroid use on leptin are contradictory. Two 
days of oral corticosteroid administration (dexamethasone; $1.5 \mathrm{mg} /$ day) in healthy subjects resulted in significantly increased serum concentrations of leptin, due to enhanced leptin messenger RNA concentrations, and of insulin, but not of serum glucose (34). In addition, another study reported that administration of dexamethasone during four days ( 2.5 $\mathrm{mg} /$ day) to healthy lean and obese subjects induced a significant increase in plasma leptin concentrations. Furthermore, significant correlations between the change in plasma leptin on the one hand and BMI, baseline plasma leptin and plasma dexamethasone concentrations on the other were revealed (35). In lean healthy male volunteers, Tataranni investigated whether acute intravenous administration of glucocorticosteroids (methylprednisolone; $125 \mathrm{mg}$ ) or prolonged oral treatment ( $40 \mathrm{mg} / \mathrm{d}$ during 4 days) affected plasma leptin concentrations. Acute administration had no effects on insulin, free fatty acids (FFA) or leptin concentrations as compared to placebo, while prolonged administration significantly increased fasting concentrations of insulin, but not of glucose, FFA or leptin (36). In the cross-sectional part of this study we found no influence of prolonged oral corticosteroid use on the relation of leptin with FM c.q. STNF-R55. Also concentrations of leptin and sTNF-receptors were comparable between patients using prednisone or not. In the prospective study, no differences in leptin, sTNF-receptors or glucose were seen between patients who were on oral corticosteroids and patients who were not.

Another well-known effect of chronic use of glucocorticoids is shifting in body fat distribution towards a higher visceral fat compartment. Visceral adiposity has furthermore been associated with increased serum leptin concentrations in healthy male subjects, in contrast to females (37). In the cross-sectional study indeed a significant, positive relationship was established between the proportion visceral fat and leptin, but no influence of chronic oral corticosteroid use on fat distribution was seen.

Overall, on base of the present study, the impact of the presumed effects of oral corticosteroids on leptin metabolism and the relationship between leptin and sTNFreceptors appear marginal

The etiology of the systemic inflammation in patients with COPD is unknown. In our study group the relation between leptin and sTNF-R55 was stronger in the patients with emphysema compared to those with chronic bronchitis. This difference could be related to a larger proportion of depleted patients or to other factors in the pathophysiology of the disease such as chronic or intermittent hypoxemia. Ghezzi and co-workers previously demonstrated that LPS-stimulated human monocytes increased their release of TNF- $\alpha$ and IL-1 during hypoxia (38). More recently, Hempel showed that hypoxia also caused significant changes in the LPS-stimulated release of the cytokines TNF- $\alpha$ and IL-1 $\beta$ by the human alveolar macrophage. These changes could be mediated by an altered synthesis of anti-inflammatory prostaglandins (PG), i.e. PG- $E_{2}$, or by a direct effect of hypoxemia on gene regulation due to changes in cell oxidant tone (39). In addition, in patients with chronic bronchitis, the FM was significantly higher than in emphysema, so in this subgroup of patients the relation between FM, leptin and dietary intake is probably less disturbed by the presence of a systemic inflammatory response. We recognize however that the relationship between leptin and systemic inflammation may also be related to the nutritional status which was better in the bronchitic than in the emphysematous patients. 
The results of this study may have important therapeutic implications. Despite an overall positive effect of nutritional support on body composition and functional performance in depleted patients with COPD, we and others have reported that a proportion of the patients did not respond to this treatment (40). Based on the present findings it may be argued whether oral nutritional support alone is an appropriate treatment strategy in part of the depleted patients with COPD suffering from anorexia due to the presence of a systemic inflammatory response. In line with this hypothesis we showed in a sub-group of predominantly emphysematous depleted patients with COPD that baseline plasma leptin concentrations were inversely related to baseline dietary intake and to the change in body weight after eight weeks of nutritional therapy. Further longitudinal studies are indicated to confirm this proposed cytokine-leptin hypothesis in pulmonary cachexia which may then open a novel approach to combat this significant co-morbidity in COPD.

\section{References}

1. Zhang Y, R Proenca, M Maffei, M Barone, L Leopold, JM Friedman. 1994. Positional cloning of the mouse obese gene and its human homologue. Nature 372: 425-432.

2. Tartaglia LA, M Dembski, X Weng, N Deng, J Culpepper, R Devos, GJ Richards, LA Campfield, FT Clark, J Deeds et al. 1995. Identification and expression cloning of a leptin receptor, OB-R. Cell 83: 1263-1271.

3. Chen H, O Charlat, LA Tartaglia, EA Woolf, X Weng, SJ Ellis, ND Lakey, J Culpepper, KJ Moore, RE Breitbart, GM Duyk, RI Tepper, JP Morgenstern. 1996. Evidence that the diabetes gene encodes the leptin receptor: identification of a mutation in the leptin receptor gene in $\mathrm{db} / \mathrm{db}$ mice. Cell 84: 491-495.

4. Halaas JL, KS Gajiwala, M Maffei, SL Cohen, BT Chait, D Rabinowitz, RL Lallone, SK Burley, JM Friedman. 1995. Weight-reducing effects of the plasma protein encoded by the obese gene. Science 269: 543-546.

5. Friedman JM. 1997. The alphabet of weight control. Nature 385: 119-120.

6. Collins S, CM Kuhn, AE Petro, AG Swick, BA Chrunyk, RS Surwit. 1996. Role of leptin in fat regulation. Nature 380:677.

7. Considine RV, MK Sinha, ML Heiman, A Kriauciunas, TW Stephens, MR Nyce, JP Ohannesian. CC Marco, LJ McKee, TL Bauer, et al. 1995. Serum immunoreactive leptin concentrations in normal-weight and obese humans. New Engl. J. Med. 334: 292-295

8. Engelen MPKJ, AMWJ Schols, WC Baken, GJ Wesseling, EFM Wouters. 1994. Nutritional depletion in relation to respiratory and peripheral skeletal muscle function in out-patients with COPD. Eur Respir. J. 7: 1793-1797.

9. Schols AMWJ, PB Soeters, R Mostert, WHM Saris, EFM Wouters. 1991. Energy balance in COPD. Am. Rev. Respir. Dis. 143: 1248-1252.

10. Schols AMWJ, EWHM Fredrix, PB Soeters, KR Westerterp, EFM Wouters. 1991. Resting energy expenditure in patients with chronic obstructive pulmonary disease. Am. J. Clin. Nutr. 54: 983-987.

11. Grunfeld C, C Zhao, J Fuller, A Pollock. A Moser, J Friedman, KR Feingold. 1996. Endotoxin and cytokines induce expression of leptin, the $o b$ gene product, in hamsters. $J$. Clin Invest 9 : 2152-2!57.

12. Sarraf P, RC Frederich, EM Turner, G Ma, NT Jaskowiak, DJ Rivet, JS Flier, BB Lowell, DL Fraker, HR Alexander. 1997. Multiple cytokines and acute inflammation raise mouse leptin levels potential role in inflammatory anorexia. $J$. Experimental. Med. 1: 171-175.

13. Di Francia M, D Barbier, JL Mege, J Orehek. 1994. Tumor necrosis factor alpha levels and weight loss in chronic obstructive pulmonary disease. Am. J. Respir. Crit. Care Med 150: 1453-1455.

14. Godoy I de, M Donahoe, WJ Calhoun, J Mancino, RM Rogers. 1996. Elevated TNF- $\alpha$ production by peripheral blood monocytes of weight-losing COPD patients. Am. J. Respir. Crit Care Med. 153: 633-637. 
15. American Thoracic Society. 1995. Standards for the diagnosis and care of patients with chronic obstructive pulmonary disease. Am. I. Respir. Crit. Care Med. 152: s77-s120.

16. Westerterp KR. L Wouters, WD van Marken Lichtenbelt. 1995. The Maastricht Protocol for the measurement of body composition and energy expenditure with labeled water. Obesity Research 3: $49-57$.

17. Mazess RB, H Barden, JP Bisek, J Hanson. 1990. Dual-energy x-ray absorptiometry for total body and regional bone-mineral, and soft tissue composition. Am. J. Clin. Nutr. 51: 1106-1112.

18. Schols AMWJ, PF Schoffelen, H Ceulemans, EFM Wouters, WH Saris. 1992. Measurement of resting energy expenditure in patients with COPD in a clinical setting. JPEN 16:364-368

19. Stichting Nederlands Voedingsstoffenbestand. 1996. NEVO tabel. Den Haag: Voorlichtingsbureau voor de Voeding.

20. Quanjer PH. (ed.) 1993. Standardized lung function testing. Eur. Respir. J. 6 (suppl. 16): 1-52.

21. Sakai F, G Gamsu, JG Im, CS Ray. 1987. Pulmonary function abnormalities in patients with CTdetermined emphysema. J. Comp. Assist. Tomogr. 11: 963-968.

22. Engelen MPKJ, AMWJ Schols, RJL Lamers, GAK Heidendal, EFM Wouters. 1996. Influence of alveolar wall destruction on body composition and physiological function in patients with chronic obstructive pulmonary disease. Am. J. Respir. Crit. Care Med. 53: A454 (abstract).

Lamers RJ, Thelissen GR, Kessels AG, Wouters EF, van Engelshoven JM. Chronic obstructive pulmonary disease: evaluation with spirometrically controlled CT lung densitometry. Radiology 1994; 193 (1): 109-113

24. Leeuwenberg JFM, GMMA Jeunhomme, WA Buurman. 1994. Slow release of soluble TNFreceptors by monocytes in vitro. J. Immunol. 152: 4036-4043.

25. Altman DG, SM Gore, MJ Gardner, SJ Pocock. 1983. Statistical guidelines for contributors to medical joumals. Br. Med. J. 286 (Clin. Res. Ed.): 1489-1493.

26. Lamers, RJS. 1998. Quantitative CT of the lungs. Technical aspects and clinical studies (thesis). Datawyse boekproducties, Maastricht.

27. Baarends EM, AMWJ Schols, DLE Pannemans, KR Westerterp, EFM Wouters. 1997. Total free living energy expenditure in patients with severe chronic obstructive pulmonary disease. $A \mathrm{~m} . J$. Respir. Crit. Care Med. 155: 549-554.

28. Simons, JPFHA. 1997. Cancer cachexia (thesis). Datawyse boekproducties, Maastricht.

29. Staal-van den Brekel AJ, Dentener MA, Schols AMWJ, Buurman WA, Wouters EFM. Increased resting energy expenditure and weight loss are related to a systemic inflammatory response in lung cancer patients. J Clin Oncol 1995: 13: 2600-2605

30. Hotamisligil GS, B Spiegelman. 1994. Tumor necrosis factor $\alpha$ : a key component of the obesitydiabutes link. Diabets's 43: 1271-1278.

31. Kern PA, M Saghizadeh. JM Ong. RJ Bosch, R Deem. RB Simsolo. 1995. The expression of tumor necrosis factor in human adipose tissue. J. Clin. Invest. 95: 2.111-2119.

32. Kellırır M. K Rıtt. IV Renn. L Groop. HU Häring. 1995. Circulating TNF-alpha and leptin levels in offspring of NIDDM patients do not correlate to individual insulin sensitivity. Horm. Metah. Res. 28: 737-743

33. Jakobsson P. L Jorfeldt. H Von Schenck. 1995. Insulin resistance is not exhibited by advanced chronic obstructive pulmonary disease patients. Clin. physiol. 15:547-555

34. Papaspyrourao S. SH Schneider. RN Petersen. SK Fried. 1997. Dexamethasone increases leptin expression in humans in vivo. JCEM 82: $1635-1637$.

35. DagogoJack S, G Selke. AK Melson. JW Newcomer. 1997. Robust leptin secretory responses to dexamethasone in obese subjects. JCEM 82: 3230-3233.

36. Tataranni PA, R Pratley, M Maffei, E Ravussin. 1997. Acute and prolonged administration of glucocorticoids (methylprednisolone) does not affect plasma leptin concentration in humans. Int. J. Obesity 21: 327-330.

37. Ronnemaa T, SL Karonen, A Rissanen, M Koskenvuo, VA Koivisto. 1997. Relation between plasma leptin levels and measures of body fat in identical twins discordant for obesity. Ann. Int. Med. 126:26-31. 
38. Ghezzi P, CA Dinarello, M Bianchi, E Rosandich, JE Repine, CW White. 1991. Hypoxia increases production of interleukin-1 and tumor necrosis factor by human mononuclear cells. Cylokine 3 : 189-194.

39. Hempel SL, MM Monick, GW Hunninghake. 1996. Effect of hypoxia on release of IL-1 and TNF by human-alveolar macrophages. Am. J. Respir. Cell. Mol. Biol. 14: 170-176.

40. Schols AMWJ, PB Soeters, R Mostert, RJ Pluymers, EFM Wouters. 1995. Physiological effects of nutritional support and anabolic steroids in COPD patients. Am. J. Respir. Crit. Care Med. 152: 1268-1274. 


\section{Chapter 5}

\section{Disturbances in leptin metabolism are related to energy imbalance during acute exacerbations of COPD}

E. C. Creutzberg' ${ }^{1}$, E. F. M. Wouters ${ }^{1}$, I. M. L. Vanderhoven-Augustin ${ }^{2}$, M. A. Dentener ${ }^{1}$, A. M. W. J. Schols ${ }^{1}$

'Department of Pulmonology, ${ }^{2}$ Heart and Lung Function Laboratory, University Hospital Maastricht, The Netherlands

American Journal of Respiratory and Critical Care Medicine, 2000, in press

The study was supported by Numico Research BV, The Netherlands 


\section{Abstract}

Previously we reported an impaired energy balance in patients with COPD during an acute disease exacerbation, but limited data are available on the underlying mechanisms. Experimental and clinical research supports the hypothesis of involvement of the hormone leptin in body weight and energy balance homeostasis. The aim of this study was to investigate the course of the energy balance in relation to leptin and the soluble TNF-receptors (sTNF-R) 55 and 75, plasma glucose and serum insulin in patients with severe COPD during the first seven days of hospitalization for an acute exacerbation ( $\mathrm{n}=17,11$ men, age mean (SD) $66(10)$ y, FEV $36(12) \%$ pred). For reference values of the laboratory parameters, blood was collected from 23 ( 16 men) healthy, elderly subjects. On admission, the dietary intake/REE ratio was severely depressed $(1.28(0.57))$, but gradually restored till day seven $(1.65(0.45)$, $\mathrm{p}=0.005$ vs. day one). Glucose and insulin concentrations were elevated on admission, but on day seven only plasma glucose was decreased. The sTNF-Rs were not different from healthy subjects and did not change. Plasma leptin, adjusted for fat mass expressed as \% of body weight ( $\% \mathrm{FM})$, was elevated on day one compared to healthy subjects $(1.82(3.85)$ vs. $0.32(0.72) \mathrm{ng} * \% / \mathrm{ml}, \mathrm{p}=0.008)$, but decreased significantly till day seven ( $1.46(3.77) \mathrm{ng} \% \% / \mathrm{ml}, \mathrm{p}=0.015$ vs. day one). On day seven, sTNF-R55 was, independently of $\% \mathrm{FM}$, correlated with the natural logarithm (LN) of leptin ( $\mathrm{r}=0.65$, $\mathrm{p}=0.041)$ and with plasma glucose $(\mathrm{r}=0.81, \mathrm{p}=0.015)$. In addition, the dietary intake/REE ratio was not only inversely related with $L N$ leptin $(-0.74, p=0.037)$, but also with sTNF-R55 $(r=-0.93, p=0.001)$ on day seven. In conclusion, temporary disturbances in the energy balance were seen during an acute exacerbation of COPD, related to increased leptin concentrations as well as to the systemic inflammatory response. Evidence was found that the elevated leptin concentrations were in tum under control of the systemic inflammatory response. and, presumably, the high-dose systemic glucocorticosteroid treatment.

\section{Introduction}

The frequent occurrence of weight loss and subsequent tissue depletion in patients with chronic obstructive pulmonary disease (COPD) is associated with an increased morbidity and even mortality (1). In addition, several reports have provided evidence that weight loss negatively affects the prevalence and outcome of acute disease exacerbations of COPD. The risk of being hospitalized for an acute exacerbation was increased in patients with a low body mass index ( $\mathrm{BMl}$; body weight/height ${ }^{2}$ ) (2). A low $\mathrm{BMl}$ and weight loss were reported as an unfavorable index of outcome during an exacerbation of (COPD. i.c., predicting the need for mechanical ventilation ( 3 ). Furthermore, the survival time following a disease exacerbation was found to be independently related to the $\mathrm{BMl}(4)$.

In a subgroup of patients, weight loss is suggested to follow a stepwise pattern related to acutc disease exacerbations. Previously we reported an impaired energy balance in pittients with C(OPD during the first days of an acute exacerbation of their disease, predominantly duc to a severely depressed dietary intake and. to a lesser extent, due to an incriased resting energy expenditure (REE) (5). Limited data are however available 
on the underlying disturbances in the (dis-)regulation of the energy balance during an acute exacerbation of COPD.

Previous experimental and clinical research indicate the involvement of leptin in body weight homeostasis. Leptin is a hormone produced by the adipose tissue and its circulating concentrations are proportional to amount of fat mass (FM). Leptin regulates the energy balance in a feedback mechanism in which the hypothalamus is involved (6). In animals, administration of leptin results in a reduction in food intake (7) as well as in an increase in energy expenditure (8). In stable depleted patients with COPD, dietary intake as well as weight gain after nutritional therapy were inversely related to plasma leptin (9).

The normal leptin feedback mechanism can be disturbed by several factors. In animals, administration of endotoxin, tumor necrosis factor- $\alpha$ (TNF- $\alpha$ ) or interleukin-1 (IL-1), inflammatory cytokines known for their anorectic effects, resulted dose-dependently in an upregulation of leptin mRNA in fat cells and in an increase in circulating leptin concentrations $(10,11)$. In stable patients with emphysema, leptin was found to be positively related to plasma soluble TNF-receptor 55 (9). During an acute exacerbation of COPD, the involvement of the systemic inflammatory response may even be more pronounced than in stable patients (12).

Glucocorticosteroids are also reported to stimulate leptin production. They can act on leptin metabolism in a direct manner (13) or via the induction of insulin resistance, since glucose and insulin are also able to induce leptin expression $(14,15)$. The influence of glucocorticosteroids on leptin metabolism may be of special interest during acute exacerbations of COPD. Under these conditions, intravenous treatment with high-dose prednisolone is still part of the medical therapy of the patients, despite the moderate effects on clinical outcome (16).

For these reasons we hypothesize that disturbances in leptin metabolism underlie the impaired energy balance during an acute exacerbation of COPD. These disturbances might be induced by the systemic inflammatory response as well as by the glucocorticosteroid treatment. The aim of this study was to investigate the course of the energy balance in relation to leptin and glucose metabolism and the systemic inflammatory response in patients with COPD hospitalized for an acule exacerbation of their lung failure.

\section{Subjects and methods \\ Study population}

The patient group consisted of subjects consecutively admitted to the hospital sulfering from an acute exacerbation of COPD. An exacerbation was defined as a recent increase in dyspnea, cough and sputum production of sufficient severity to warrant admission to the hospital. The presence of an exacerbation was determined by an independent chest physician. COPD was defined according to the criteria of the American Thoracic Society (ATS) (17). Patients were excluded when they were suffering from concomitant diseases and when their stay in the hospital was less than seven days. The final study group consisted of 17 patients $(11 \mathrm{men})$. Duration time of 
admission to the hospital was mean (SD) 13 (6) days. 14/17 Patients were current or ex-smokers. The patients were treated with a standard protocol of medication consisting of nebulized short-acting $B_{2}$-sympathicomimetics (salbutamol $>20 \mathrm{mg} / 24 \mathrm{~h}$ ), inhaled anticholinergics (ipratropium bromide) and intravenously administered theophylline and prednisolone. Prednisolone was given in decreasing doses throughout the exacerbation. The patients received, depending on body weight, 50 or $75 \mathrm{mg} / 24 \mathrm{~h}$ during the first four days of the exacerbation. From day four till day seven, the initial dose was halved. The plasma theophylline concentrations of the patients fell within the therapeutic range (mean (SD) $10.7(4.5) \mathrm{mg} / \mathrm{ml}$ ). In case of a bacterial infection which was confirmed by a sputum culture (12/17 patients), specific antibiotic therapy was given. Only one patient had fever on the first day after admisssion to the hospital. During hospitalization, 11 of the 17 patients were on additional oxygen therapy.

The measurements were performed in the early morning ( $8.30 \mathrm{a.m}$.), when patients were in the fasting state for at least ten hours. The measurements were done at day one, three, five and seven after hospitalization. The patients received their bronchodilating medication two to three hours before the measurements started. The study was approved by the medical ethics committee of the University Hospital Maastricht and all subjects gave their informed consent.

For reference values of the laboratory parameters, fasting blood was collected from 23 (16 men) healthy, elderly volunteers. They were not exhibiting any acute or chronic disease nor taking medication that could influence energy or glucose metabolism.

\section{Lung function}

Forced expiratory volume in one second $\left(\mathrm{FEV}_{1}\right)$, inspiratory vital capacity (IVC) and peak expiratory flow (PEF) were calculated from the flow-volume curve using a portable spirometer (Jaeger, Würzburg, Germany). Lung function was expressed as percentage of reference value (18). Blood was drawn from the brachial artery and arterial oxygen tension $\left(\mathrm{PaO}_{2}\right)$ and carbon dioxide tension $\left(\mathrm{PaCO}_{2}\right)$ were analyzed on a blood gas analyzer (Radiometer, ABL 330, Copenhagen, Denmark).

\section{Body composition}

Body height was determined to the nearest $0.5 \mathrm{~cm}$ (Lameris. WM 715, Breukelen. The Netherlands) with subjects standing barefoot. Body weight was assessed to the nearest $0.1 \mathrm{~kg}$ using a digital weighing chair while subjects wore light clothing and no shoes. Body composition was estimated using single frequency $(50 \mathrm{kHz})$ bio-electrical impedance analysis (Xitron technologies Inc., San Diego, CA, USA) while subjects were in supine position. FFM was calculated using the disease-specific equation of Schols et al. (19). In the healthy volunteers, FFM was calculated from total body water assessment using the deuterium dilution technique described in the Maastricht protocol (20). Previously it was established that, in healthy subjects as well as in patients with COPD, FFM assessed with BIA did not significantly differ from FFM assessed with the deuterium dilution technique (21). FM was calculated by subtracting FFM from body weight. 


\section{Energy balance}

Habitual dietary intake was evaluated using the diet history method with cross-check. All interviews were performed by the same trained dietician. On the day of admission to the hospital (day zero) and during hospitalization, dietary intake was registered by use of dietary records and an automated food distribution system. The patients had the opportunity to choose their menus. The daily $500 \mathrm{ml}$ infusion solution contained $5 \%$ glucose which is equivalent to $100 \mathrm{kcal} /$ day. This amount of energy was incorporated in the calculations of the daily dietary intake in the hospital. The food composition data were coded for computer energy and nutrient analysis. The database was derived from the Dutch food composition tables (22).

REE was measured by an open circuit indirect calorimetry system using a ventilated hood (Oxycon Beta; Jaeger, Würzburg, Germany). The system was calibrated daily at the start of the experiment, while the accuracy was regularly assessed using a methanol combustion test. Patients had a period of at least 30 minutes bed rest prior to the measurements started. When patients were on additional oxygen during the hospitalization, the oxygen was temporarily withdrawn 30 minutes before and during the measuring of REE. The patients were comfortably lying on a bed in supine position allowing them to watch television. REE was calculated from oxygen consumption $\left(\mathrm{V}^{\prime} \mathrm{O}_{2}\right)$ and carbon dioxide production $\left(\mathrm{V}^{\prime} \mathrm{CO}_{2}\right)$ using the abbreviated Weir formula (23). REE was compared with the reference values (24).

\section{Collection and analysis of laboratory and inflammatory parameters}

For the measurement of glucose, blood was collected in an evacuated blood collection tube containing heparin and centrifuged by $4000 \mathrm{rpm}$ for 5 minutes at $4{ }^{\circ} \mathrm{C}$. After separation from the blood cells, tri-chloride acetic acid was added to the plasma. The suspension was vortexed and stored at $-70^{\circ} \mathrm{C}$ until analysis by enzymatic, fluorimetric spectrophotometry (Cobas Mira ${ }^{\infty}$; Hoffmann-La Roche, Basel, Switzerland). To assess insulin, blood was collected in an evacuated coagulation tube and centrifuged for 15 minutes at $3000 \mathrm{rpm}$. Serum was collected and stored until assessment using a radioimmuno assay.

An evacuated tube containing EDTA (Sherwood Medical, St Louis, Missouri, USA) was used to collect blood for the measurements of the inflammatory parameters and leptin. Plasma was separated from blood cells by centrifugation at $1000 \mathrm{G}$ for 10 minutes within $2 \mathrm{~h}$ after collection. Separated plasma was again centrifuged at $1000 \mathrm{G}$ for 10 minutes. Plasma samples were stored at $-70^{\circ} \mathrm{C}$ until analysis. $\mathrm{C}$-reactive protein (CRP), sTNF-R55. sTNF-R75 and interleukin-6 (IL-6) were measured using sandwich enzyme-linked immunosorbent assay (ELISA) as described previously (25). Plasma IL6 concentrations were measured using the murine anti-human IL- 6 antibody 5E1 (developed in our laboratory). Diluted plasma samples ( $1 / 1)$ and the standard titration curve with recombinant IL-6 were added to the immunoassay plates (Nunc-Immuno Plate Maxisorp, Roskilde, Denmark). The amount of IL- 6 bound to the wells was quantified by sequential incubation with a polyclonal rabbit anti-IL-6 antibody, followed by adding peroxidase conjugated goat anti-rabbit $\operatorname{lgG}$ and substrate. The lower detection limit of [L-6 was $0.01 \mathrm{ng} / \mathrm{ml}$. IL- 6 was not measured in the plasma of the healthy volunteers. Plasma leptin was measured with a double antibody sandwich 
ELISA (BioVendor Laboratory Medicine Inc., Brno, Czech Republic). The wells were pre-coated with anti-human leptin antibody. After a thorough wash, anti-human leptin antibody labeled with horseradish peroxidase (HRP) was added to the wells and incubated with the immobilized antibody-leptin complex. Following washing, the remaining HRP-conjugated antibody was allowed to react with the substrate tetramethylbenzidine. The reaction was stopped by adding an acidic solution. Absorbency was measured spectrophotometrically at $450 \mathrm{~nm}$ using a micro ELISA autoreader. The lower and upper limits of detection were respectively 0.2 and 50 $\mathrm{ng} / \mathrm{ml}$. The intra- and inter-assay variation was $6 \%$ and $9 \%$ respectively.

\section{Statistics}

For comparisons within the individual between day one, three, five and seven of the exacerbation, the paired t-test was used. The Bonferroni correction was applied to correct for the multiple comparisons that were performed. Since per time point three comparisons were done, significance was determined at a p-value of $0.017(=0.050 / 3)$. For dietary intake, five comparisons per time point were done, so significance was determined at a p-value of $0.010(=0.050 / 5)$. Differences between healthy volunteers and patients with COPD on day one and seven of the exacerbation respectively were compared using a Student's t-test for independent samples, if the data were normally distributed and equal variances could be assumed. Otherwise, non-parametric analysis (Mann-Whitney U test) was performed. Significance was determined at a p-value of 0.05 . Plasma leptin was logarithmically transformed by calculating its natural logarithm (LN leptin) for use in correlation and regression analysis. Pearson's product moment correlation coefficients on the metabolic and inflammatory parameters were calculated on day one and day seven respectively. In order to adjust for sex, age and, when appropriate, FM expressed as percentage of body weight (\%FM), partial correlation analysis was performed. In order to investigate which factor(s) could significantly explain the variation in dietary intake/REE ratio on day one and on day seven of the exacerbation, linear stepwise regression analysis was done. Data were expressed as mean (SD) in the text and tables and as mean (SEM) in the graphs. Data were analyzed according to the guidelines of Altman et al. (26) using SPSS/PC+ (Statistical Package for the Social Sciences, version 7.5 for Windows, SPSS Inc., Chicago, IL, U.S.A.).

\section{Results}

Study group

The characteristics of the patients with COPD on day one after admission to the hospital for an acute exacerbation are shown in table 1. Although mean BMl was normal, the FFM-index (FFMI; FFM/height ${ }^{2}$ ) was just above the minimum normal value. Lung function was significantly impaired; on base of the $\mathrm{FEV}_{1}$, the patients could be considered as having severe COPD. While $\mathrm{PaO}_{2}$ was decreased compared with normal, no signs of hypercapnia were seen. 
Table 1: Characteristics of the study group on the day after admission to the hospital for an acute exacerbation of COPD.

\begin{tabular}{llll}
\hline II & $(\mathrm{m} / \mathrm{f})$ & 17 & $(\mathrm{Il} / 6)$ \\
& & mean & $S D$ \\
\hline Age & $(\mathrm{yrs})$ & 66 & $(10)$ \\
Body mass index & $\left(\mathrm{kg} / \mathrm{m}^{2}\right)$ & 24.3 & $(4.4)$ \\
Fat-free mass index & $\left(\mathrm{kg} / \mathrm{m}^{2}\right)$ & 16.0 & $(2.5)$ \\
Fat mass & $(\%$ body weight $)$ & 33.6 & $(6.9)$ \\
$\mathrm{FEV}$ & $(\%$ pred $)$ & 36 & $(12)$ \\
IVC & $(\% p r e d)$ & 70 & $(24)$ \\
$\mathrm{PEF}$ & $(\% p r e d)$ & 41 & $(14)$ \\
$\mathrm{PaO}_{2}$ & $(\mathrm{kPa})$ & 8.6 & $(1.4)$ \\
$\mathrm{PaCO}_{2}$ & $(\mathrm{kPa})$ & 5.9 & $(0.8)$ \\
\hline
\end{tabular}

Course of the parameters during the exucerbation

\section{Energy balance}

Figure 1 shows the habitual dietary intake and the course of dietary intake and REE during the exacerbation. Dietary intake at the day of admission (day zero) was severely decreased when compared with the habitual intake of the patients, but gradually increased during the course exacerbation. At day seven it was even higher than the habitual dietary intake. REE decreased from day one to day seven, but in absolute terms the drop was not significant. Also when expressed as percentage of predicted, the decrease in REE from day one till day seven of the exacerbation was not significant and the patients remained hypermetabolic (115 (11) vs. 109 (12)\%pred, NS). Mean dietary intake/REE ratio increased from $1.28(0.57)$ at day one to 1.65 $(0.45)$ at day seven $(\mathrm{p}=0.005)$.

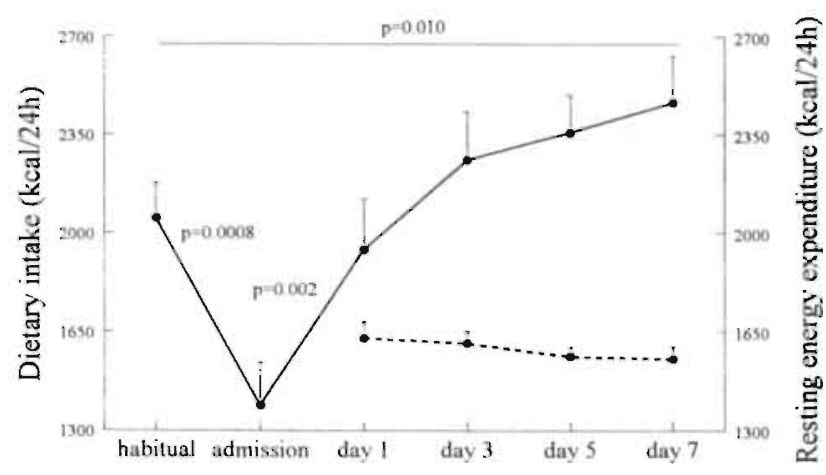

Figure 1: Habitual dietary intake and the course of dietary intake (solid line) and resting energy cxpenditure (dashed line) during the first seven days of an acute exacerbation of COPD. Data are expressed as mean (SEM). 


\section{Glucose and insulin}

Plasma glucose at day one of the exacerbation was significant higher than in the healthy subjects $(p<0.001)$. Thereafter, it gradually decreased in such a way that on day seven it was lower than on day one and the difference with the healthy subjects group was eliminated (figure 2). The pattern of serum insulin during the exacerbation was similar to that of plasma glucose; however, no significances in the drop in insulin could be achieved. On day one as well as one day seven serum insulin was elevated compared with the healthy subjects ( $\mathrm{p}<0.001$ ) (figure 2 ).

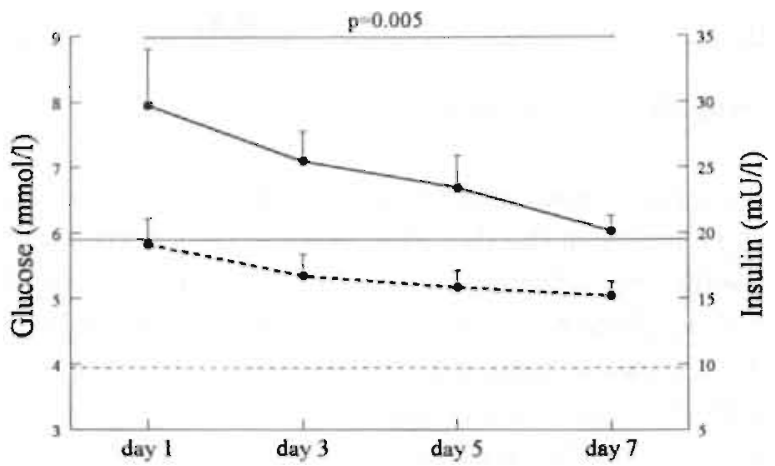

Figure 2: $\quad$ Course of plasma glucose (solid line) and serum insulin (dashed line) during the first seven days of an acute exacerbation of COPD. Data are expressed as mean (SEM). Horizontal lines: mean plasma glucose (solid line) and mean serum insulin (dashed line) in healthy, elderly subjects.

\section{Inflammatory parameters and leptin}

A temporary increased acute phase protein response (APPR) was seen during the exacerbation. At day one of the exacerbation, plasma CRP was elevated compared with the healthy subjects $(33.3(25.9) \mu \mathrm{g} / \mathrm{ml} \mathrm{vs.} 9.0(16.0) \mu \mathrm{g} / \mathrm{ml}, \mathrm{p}<0.001)$. Already on day three, CRP was dropped to $15.3(17.6) \mu \mathrm{g} / \mathrm{ml}(\mathrm{p}=0.010$ vs. day one) and did no longer differ from healthy subjects. CRP on day seven amounted up to 11.7 (15.9) $\mu \mathrm{g} / \mathrm{rnl}$ ( $\mathrm{p}=0.016$ vs day one).

No differences were seen in the concentrations of sTNF-R55 and R75 between patients with COPD on day one and seven compared with the healthy subjects. The TNFreceptors did not drop during the exacerbation. Instead, sTNF-R55 showed a temporary rise from day one to day three, that already was eliminated at day five (figure 3). IL-6 concentrations were low in the patient group and no changes were seen throughout the exacerbation (day one: $0.28(0.54)$ vs. day seven: $0.11(0.11) \mathrm{ng} / \mathrm{ml}$, NS). 


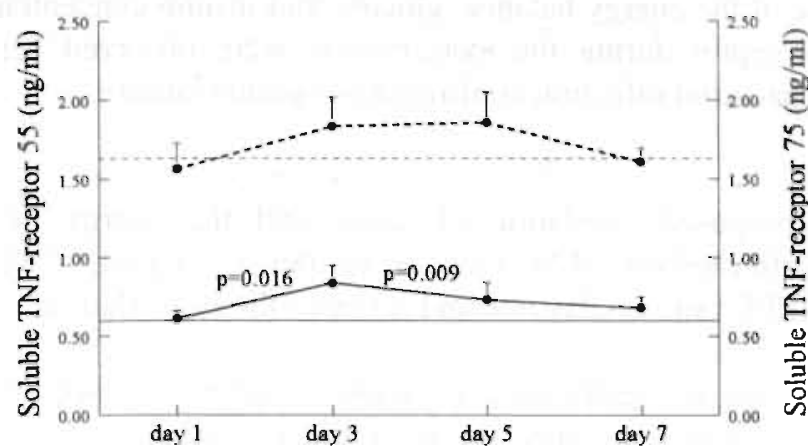

Figure 3: $\quad$ Course of plasma soluble TNF-receptor 55 (solid line) and 75 (dashed line) during the first seven days of an acute exacerbation of COPD. Data are expressed as mean (SEM). Horizontal lines: mean plasina soluble TNF-receptor 55 (solid line) and 75 (dashed line) in healthy. elderly subjects.

Compared with its concentration in the healthy subjects $(12.5(33.8) \mathrm{ng} / \mathrm{ml})$, plasma leptin was significantly higher in the patients with COPD on day one and still on day seven of hospitalization $(76.8(190.5) \mathrm{ng} / \mathrm{ml}, \mathrm{p}=0.006$ and $62.2(180.8) \mathrm{ng} / \mathrm{ml}, \mathrm{p}=0.017$ respectively vs. healthy subjects). Leptin decreased gradually throughout the exacerbation. After dividing leptin by \%FM, the same pattern was seen (figure 4). Leptin $\%$ FM was significantly elevated on day one and nearly significantly increased on day seven compared to the healthy subjects ( $\mathrm{p}=0.008$ and $\mathrm{p}=0.018$ respectively).

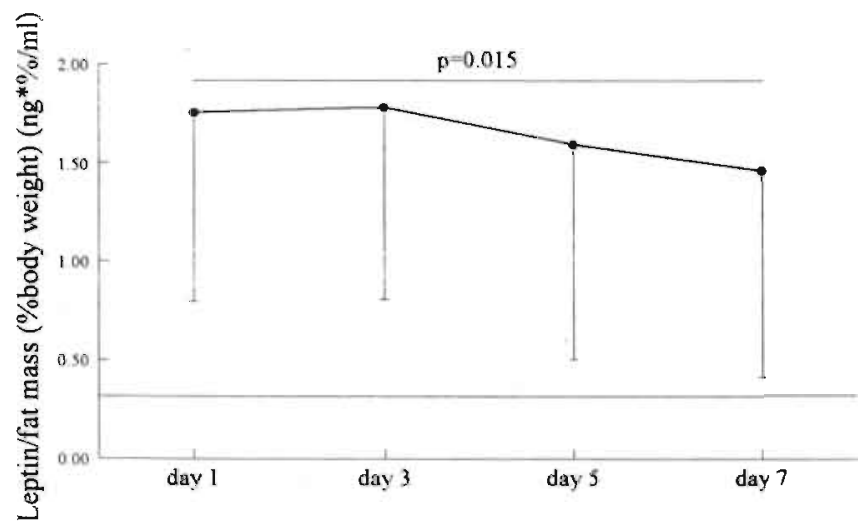

Figure 4: Course of plasma leptin divided by fat mass (as $\%$ of body weight) during the first seven days of an acute exacerbation of COPD. Data are expressed as mean (SEM). Horizontal line: mean plasma leptin divided by fat mass (as $\%$ of body weight) in healthy, elderly subjects. 
No differences in the course of the energy balance, glucose and insulin concentrations, inflammatory mediators or leptin during the exacerbation were observed between patients with and without a bacterial infection confirmed by sputum culture.

\section{Correlation analyses}

To further elucidate the proposed regulation of leptin and the energy balance, correlation analysis was performed on $\% \mathrm{FM}$, glucose, insulin, LN leptin, sTNF-R55 and R75 and dietary intake/REE ratio on day one and seven of the exacerbation.

On day one of the exacerbation, no significant correlations could be revealed between any of the parameters. In contrast, on day seven of the exacerbation, LN leptin positively correlated with \%FM after correcting for the influences of sex and age (table 2). In addition, LN leptin was found to be positively correlated with STNF-R55, but not R75, after correction for sex, age and \%FM (table 2).

Furthermore, a significant correlation coefficient was revealed between plasma glucose and \%FM, after correction for sex and age, at day seven of the exacerbation of COPD (table 2). Plasma glucose was also correlated with sTNF-R55 on day seven after adjusting for the influences of sex, age and \%FM (table 2).

Table 2: $\quad$ Correlation analysis to elucidate the regulation of leptin and glucose metabolism on day seven of an acute exacerbation of COPD

\begin{tabular}{lllll}
\hline & $\begin{array}{l}\text { Natural logarithm } \\
\text { of leptin }\end{array}$ & Glucose & & Insulin \\
\hline Fat mass (\% body weight) & $\mathrm{r}=0.73, \mathrm{p}=0.010$ & $\mathrm{r}=0.71, \mathrm{p}=0.022$ & & NS \\
Glucose & $\mathrm{NS}$ & - & $\mathrm{NS}$ \\
Insulin & $\mathrm{NS}$ & $\mathrm{NS}$ & - \\
Soluble TNF-receptor 55 & $\mathrm{r}=0.65, \mathrm{p}=0.041$ & $\mathrm{r}=0.81, \mathrm{p}=0.015$ & $\mathrm{NS}$ \\
Soluble TNF-receptor 75 & $\mathrm{NS}$ & $\mathrm{NS}$ & $\mathrm{NS}$ \\
\hline
\end{tabular}

Correlation coefficients are given after correction for the influences of sex, age and. when appropriate. fat mass (as \% of body weight) by partial correlation analysis. No significant correlation coefficients between the parameters were found on day one of the exacerbation.

On day seven of the acute exacerbation of COPD, the dietary intake/REE ratio was found to be inversely correlated with the natural logarithm of plasma leptin on the one hand and with the plasma concentration of the STNF-receptor 55 on the other after correcting for sex, age and \%FM. The respective scatter plots are shown in figure 5a and $5 b$. Since both LN leptin and sTNF-R55 were correlated with dietary intake/REE ratio, we performed a stepwise regression analysis with sex, age, \%FM, glucose, insulin. IN leptin. STNF-R55 and sTNF-R75. This elucidated that sTNF-R55 significantly explained $66 \%$ of the variation in energy balance on day seven of the exacerbation $(p=0.009)$, while the other parameters were excluded from the model. 

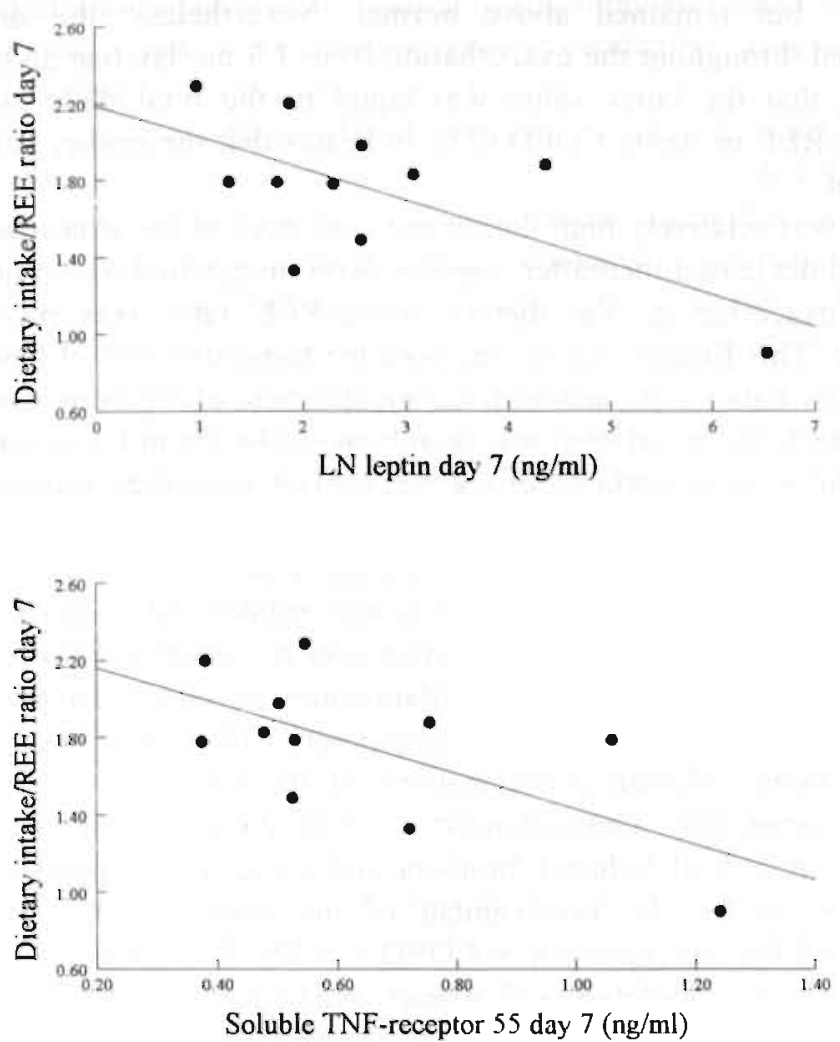

Figure 5: Scatter plot of the dietary intake/resting energy expenditure ratio against the natural logarithm of plasma leptin (5a; upper panel) and against plasma soluble TNF-receptor 55 (5b: lower panel) at day scven of an acute exacerbation of COPD. Respective correlation coefficients after adjusting for the influences of sex, age and fat mass (as \% of body weight) $-0.74(p=0.037)$ and $-0.93(p=0.001)$.

\section{Discussion}

Until now, little is known about the mechanisms underlying the energy imbalance in patients with COPD. The present study was performed in order to make a first attempt to unravel the factors contributing to the disturbed energy balance in patients with COPD suffering from an exacerbation. Therefore, the course of the energy balance in relation to leptin and glucose metabolism and the systemic inflammatory response were investigated during the first seven days of hospitalization for an acute exacerbation of COPD.

According to the study by Vermeeren et al. (5), the patients exhibited a severely depressed dietary intake compared with habitual on the day of admission to the hospital. Intake gradually restored during the course of the exacerbation. The elevated 
REE decreased slightly, but remained above normal. Nevertheless, the dietary intake/REE ratio increased throughout the exacerbation from 1.3 on day one up to 1.7 on day seven. The fact that the latter value was equal to the total daily energy expenditure corrected for REE in stable COPD (27), indicates that the energy balance was restored on day seven.

Leptin divided by \%FM was relatively high during the first days of the exacerbation, when intake was low, and decreased thereafter, together with the gradual rise in intake. On day seven of the exacerbation, the dietary intake/REE ratio was inversely correlated with LN leptin. This finding was in line with the suggested role of leptin in the regulation of the energy balance (6) and with the involvement of leptin in anorexia in stable COPD (9). The fact that no relation was seen between leptin and intake at day one, may indicate that the normal leptin feedback mechanism regulating food intake was completely disturbed during the first days of the exacerbation.

In addition to the inverse relationship between LN leptin and intake, we also revealed a significant, inverse correlation coefficient between dietary intake and STNF-R55 on day seven, the latter as a measure of the systemic inflammatory response. This finding provided further evidence for the involvement of inflammation in anorexia and was in line with our recent report in which stable, depleted patients with COPD with a low caloric intake exhibited higher plasma concentrations of the sTNF-receptors (28). Animal studies have reported that administration of inflammatory mediators like endotoxin, TNF- $\alpha$ or IL- $1 \alpha$ indeed induced anorexia and cachexia in animals (29). Furthermore, evidence exists for the involvement of the systemic inflammatory response in weight loss and hypermetabolism in COPD (30-32). Since both LN leptin and STNF-R55 were inversely correlated with dietary intake/REE ratio, a stepwise regression analysis was performed. the finding that sTNF-R55 significantly explained $66 \%$ of the variation in energy balance on day seven of the exacerbation, while LN leptin was excluded, may indicate that the influence of leptin on energy balance was under control of the systemic inflammatory response.

In accordance with the nomal mechanism of leptin regulation (6), LN leptin was found to be conclated with \%FM on day seven of the exacerbation. The fact that no such relation was seen at day one of the exacerbation probably indicated a temporary dissociation, related to the exacerbation, of the normal feedback regulation of leptin by FM. Mean leptin corrected for \%FM significantly decreased throughout the exacerbation. However, its plasma concentration was not only at day one, but until day seven, elevated compared with the healthy, elderly subjects.

The elevated leptin concentrations during the exacerbation likely represented an upregulation of leptin mRNA resulting in an enhanced leptin production, which could have been be induced by several factors. Independently of \%FM, a positive correlation between LN leptin and the plasma concentration of STNF-R55 was seen in patients with COPD on day seven of the exacerbation. This finding gives further evidence for an inflammation-related disturbance in leptin metabolism in COPD. Previously we also reported in clinically stable patients with emphysema, in a cross-sectional study design, a positive correlation between leptin and STNF-R55 (9). In patients with solid tumors, infusion of TNF- $\alpha$ resulted in a transient increase in serum leptin 
concentration (33). Administration of recombinant human IL-1 $\alpha$ to cancer patients also increased leptin concentration dose-dependently, accompanied by a decrease in appetite in the majority of the patients (34).

Controversial results on the relationship between IL-6 and leptin in acute illness are reported in the literature. We revealed very low IL-6 concentrations in the present study, unrelated with leptin and not changing during the exacerbation. Bornstein et al. revealed that IL- 6 and leptin concentrations were dramatically elevated in critically ill patients suffering from acute sepsis compared to healthy subjects (35). In the study of Torpy et al., also elevated leptin and IL-6 concentrations were seen in critically ill patients suffering from sepsis. However, leptin inversely correlated with IL-6, suggesting that the leptin hypersecretion was not under the influence of IL-6 (36). This was confirmed by a study of Faggioni, in which turpentine was able to increase leptin in IL-6-non-deficient mice, but also in IL-6-deficient mice. Oppositely, leptin could not be induced in IL-1-deficient mice, but only in IL-1-non-deficient mice (37). In two other investigations from our laboratory, using the same measurement techniques and plasma handling as in our study, elevated IL-6 concentrations were reported in acute disease (sepsis and hemorrhagic shock syndrome after surgery respectively) $(38,39)$. So the low lL-6 concentrations found in the present study could not be attributed to inappropriate measurement techniques, but probably to the disease severity; an acute exacerbation of COPD was likely not able to induce prompt increases in IL-6, oppositely to sepsis and shock. Taking together the available studies in the literature with our own finding of very low IL-6 concentrations, unrelated to leptin, in patients suffering from an acute exacerbation of COPD, Il-6 does not seem to exert a great role in the enhancement of leptin secretion, opposite to IL-1.

A second reason for the high leptin concentrations might have been the high dose glucocorticosteroid treatment. The course of plasma leptin seemed to mimic the scheme of prednisolone administration. The first days, during which the patients received the highest dose of prednisolone, leptin was high. Thereafter, lower leptin concentrations were seen, together with the tapering off of the glucocorticosteroid treatment. Glucocorticosteroids in high doses are indeed reported to stimulate leptin production. Two days of oral dexamethasone administration to healthy volunteers increased serum leptin as well as the presence of leptin mRNA in abdominal and gluteal adipose tissues (13).

Glucocorticosteroids in therapeutic doses have a stimulating effict on leptin concentrations via the induction of insulin resistance (40), since glucose and insulin are also able to induce leptin expression. In lean mice. glucose injection resulted in an increase in plasma glucose and in an upregulation of leptin mRNA, independently of age, nutritional state and plasma insulin (14). Also injection of insulin in fasted rats induced leptin gene expression (41). At the level of adipose tissue and muscle, glucocorticosteroids antagonize insulin-mediated uptake and utilization of glucose and also exert a permissive effect on lipolysis by promoting the activation of the cAMPdependent hormone-sensitive lipase, a key enzyme inhibited by insulin (42). Insulin resistance seemed indeed to be present during the exacerbation, predominantly based on the high insulin concentrations and to a lesser extent on base of the temporary 
increased glucose concentrations. It is therefore plausible that the kinetics of glucose and insulin during the exacerbation were (partly) related to the tapering off of the systemic prednisolone treatment.

Other medications that were prescribed to our patients during an acute exacerbation of COPD might also have affected leptin metabolism. Little is reported about the effect of theophyllines on leptin; only one study suggests that leptin release is attenuated by theophylline-like substances (43). More is known about the effects of adrenergic stimulation on leptin metabolism. However, no studies have been performed with specific $B_{2}$-adrenergic stimulants like salbutamol, but only with non-selective $B$ agonists. Intravenous infusion of isoprenaline (a $B_{1,2}$-agonist) in young, lean, healthy volunteers resulted in a maximal suppression of plasma leptin of $20 \%$ of baseline values after $2 \mathrm{~h}$. In the recovery period of $1 \mathrm{~h}$, leptin concentrations rapidly returned to baseline values (44). It must be noted that in the present study, the patients received salbutamol by nebulizer and not intravenously. So, probably relatively little active substance might have reached the systemic circulation. With respect to the very high leptin concentrations, it is likely that other factors, like an inflammatory response and/or the high dose oral glucocorticosteroid treatment, overruled the influence of treatment with $\mathrm{B}_{2}$-sympathicomimetics and/or theophyllines on leptin metabolism.

Besides the influence of glucocorticosteroids on glucose metabolism, also TNF- $\alpha$ is known for its role in insulin resistance (45). The concentration of glucose at day one of the exacerbation was significant higher than in the healthy subjects and gradually decreased thereafter. In contrast, the elevated insulin concentration did not significantly decrease. On day seven of the exacerbation, sTNF-R55 was positively correlated with plasma glucose, independently of the amount of FM. TNF- $\alpha$, which is produced in fat and muscle tissue, is known as a potent regulator of glucose metabolism, decreasing the expression of the glucose transporter Glut4. Expression of TNF- $\alpha$ in the $m$. vastus lateralis was found to be fourfold higher in patients with insulin resistance or non-insulin-dependent diabetes mellitus (NIDDM) than in insulinsensitive subjects (46). The correlation between glucose and sTNF-R55 in patients with $C O P D$ on day seven might have been a reflection of disease-specific metabolic disturbances related to the systemic inflammatory response.

During the first day of the exacerbation an increased APPR was seen: CRP, which is commonly used in daily clinical practice as a marker of acute inflammation, was elevated on day one of the exacerbation, but rapidly dropped thereafter. This was confirmed in another recent study in which CRP, irrespective of the presence of a proven bacterial or viral infection, could be identified as a marker of acute exacerbation of COPD, showing a rapid decline after 4-5 days of treatment (47).

In contrast to CRP, plasma sTNF-R55 and R75 were not different between patients and healthy subjects and did not decrease during the exacerbation. The latter phenomenon may be due to a lack in response to the high-dose glucocorticosteroid treatment (48) or to relatively slow kinetics of the TNF-receptors (49). The TNFreceptors have been suggested to represent a buffer system that prolongs the biological effects of TNF- $\alpha$ by forming a 'slow-release reservoir'. Compared with circulating 
TNF- $\alpha$, which was not measured in the present study, the sTNF-receptor concentrations remain elevated for longer periods of time and are probably of more value for monitoring pro-inflammatory responses (50).

In the present study, no correlations were revealed between sTNF-R75 and any of the metabolic parameters. This might be explained by the fact that sTNF-R 55 represents the major soluble form of the TNF-receptor and, although sTNF-R75 may have a permissive role, it appears that STNF-R55 has the primary role in controlling the cytotoxic effects of TNF- $\alpha(50)$.

Besides its function in weight homeostasis, leptin may also play a protective role in severe stress states. In leptin-defective mice, in which the T-cell mediated immunity is decreased for unknown reasons, administration of leptin resulted in a complete reversion of the immunosuppressive effects of acute starvation. This might be explained by the fact that leptin, which is low during starvation, can induce proliferation, differentiation and functional activation of hematopoietic cells and enhances the production and phagocytic activity of macrophages (51). This protective effect of leptin was confirmed in two studies in acute sepsis, in which surviving patients were characterized by higher leptin concentrations than non-survivors ( 35 , 36).

Furthermore, a role for leptin in the regulation of respiration has been suggested. The respiratory depression of which leptin-deficient, obese mice were suffering from, was easily restored by administration of leptin (52). Whether these two additional functions of leptin play a role during an acute exacerbation of COPD, is yet unknown, but deserves further attention.

In conclusion, temporary disturbances in the energy balance were seen during an acute exacerbation of COPD, related to increased leptin concentrations as well as to the systemic inflammatory response. Evidence was found that the elevated leptin concentrations were in turn under control of the systemic inflammatory response, and, presumably, the high-dose systemic glucocorticosteroid treatment.

\section{Acknowledgment}

The authors are grateful to M. A. P. Vermeeren ${ }^{3}$ for her technical assistance and to F. van Dielen ${ }^{4}$ for the analysis of leptin.

Departments of ${ }^{3}$ Dietetics and ${ }^{4}$ Surgery. University Hospital Maastricht. The Netherlands.

\section{References}

1. Schols. A.M.W.J., J. Slangen, L. Volovics, and E.F.M. Wouters. 1998 Weight loss is a reversible factor in the prognosis of chronic obstructive pulmonary discase. Am. J Respir. Crit. Carc Med 157 (6): 1791-1797.

2. Kessler. R., M. Faller. G. Fourgaut. B. Mennecier, and E. Weitzenblum. 1999. Predictive factors of hospitalization for acute exacerbation in a series of 64 patients with chronic obstructive pulmonary disease. Am. J. Respir. Crit. Care Mea. 159 (1):158-164

3. Vitacca, M., E. Clini, R. Porta, K. Foglio, and N. Ambrosino. 1996. Acute exacerbations in patients with COPD: predictors of need for mechanical ventilation. Eur. Respir. J. 9:14871493.

4. Connors, A.F., Jr.. N.V. Dawson, C. Thomas, F.E. Harrell, Jr, N. Dusbiuns. W.J. Fulkerson, 
P. Kussin, P. Bellamy, L. Goldman, and W.A. Knaus. 1996. Outcomes following acute exacerbation of severe chronic obstructive lung disease. The SUPPORT investigators (Study to Understand Prognoses and Preferences for Outcomes and Risks of Treatments). Am. J. Respir. Crit. Care Med. 154:959-967.

5. Vermeeren, M.A.P., A.M.W.J. Schols, and E.F.M. Wouters. 1997. Effects of an Acute Exacerbation On Nutritional and Metabolic Profile of Patients With COPD. Eur. Respir. J. 10 (10):2264-2269.

6. Campfield, L.A., F.J. Smith, and P. Bum. 1996. The OB protein (leptin) pathway--a link between adipose tissue mass and central neural networks. Horm. Metab. Res. 28:619-632.

7. Seeley, R.J., G. van Dijk, L.A. Campfield, F.J. Smith, P. Bum, J.A. Nelligan, S.M. Bell, D.G. Baskin, S.C. Woods, and M.W. Schwartz. 1996. Intraventricular leptin reduces food intake and body weight of lean rats but not obese Zucker rats. Horm. Metab. Res. 28:664-668.

8. Hwa, J.J., L. Ghibaudi, D. Compton, A.B. Fawzi, and C.D. Strader. 1996. Intracerebroventricular injection of leptin increases thermogenesis and mobilizes fat metabolism in ob/ob mice. Horm. Metab. Res. 28:659-663.

9. Schols, A., E.C. Creutzberg, W.A. Buurman, L.A. Campfield, W.H.M. Saris, and E.F.M. Wouters. 1999. Plasma leptin is related to proinflammatory status and dietary intake in patients with chronic obstructive pulmonary disease. Am. J. Respir. Crit. Care Med. 160:1220-1226.

10. Grunfeld, C., C. Zhao, J. Fuller, A. Pollack, A. Moser, J. Friedman, and K.R. Feingold. 1996. Endotoxin and cytokines induce expression of leptin, the ob gene product, in hamsters. J. Clin. Invest. 97:2152-2157.

11. Sarraf, P., R.C. Frederich, E.M. Tumer, G. Ma, N.T. Jaskowiak. D.J. Rivct. 3rd, J.S. Flicr. B.B. Lowell. D.L. Fraker, and H.R. Alexander. 1997. Multiple cytokines and acute inflammation raise mouse leptin levels: potential role in inflammatory anorcxia. J. Exp. Mcd. 185:171-175.

12. Saetta, M., A Di Stefano, P. Maestrelli, G. Turato, M.P. Ruggieri, A. Roggeri, P. Calcagni, C.E. Mapp, A. Ciaccia, and L.M. Fabbri. 1994. Airway eosinophilia in chronic bronchitis during exacerbations [see comments]. Am. J. Respir. Cril. Care Med. 150:1646-1652.

13. Dagogo Jack, S., G. Selke, A.K. Melson. and J.W. Newcomer. 1997. Robust leptin secretory responses to dexamethasone in obese subjects. J. Clin. Endocrinol. Metab. 82:3230-3233.

14. Mizuno, T., H. Bergen, S. Kleopoulos, W.A. Bauman, and C.V. Mobbs. 1996. Effects of nutritional status and aging on leptin gene expression in mice: importance of glucose. Horm. Metab. Res. 28:679-684.

15. Bodkin, N.L., M. Nicolson, H.K. Ortmeyer, and B.C. Hansen. 1996. Hyperleptinemia: relationship to adiposity and insulin resistance in the spontaneously obese rhesus monkey. Horm. Metab. Res. 28:674-678.

16. Niewoehner. D.E. M.L. Erbland, R.H. Deupree. D. Collins, N.J. Gross, R.W. Light, P. Anderson, and M A Morgan. 1999. Effect of systemic glucocorticoids on exacerbations of chronic obstructive pulmonary disease. N. Engl. J. Med. 340: 1941-1947.

17. ATS 1995. Standards for the diagnosis and care of patients with chronic obstructive pulmonary discase. Am. J. Respir. Crit. Care Med. 152 (suppl.) S77-12I.

18. Quanjer, P.H.e. 1493. Standardized lung function testing. Official statement of the European Respiratory Society [see comments]. Eur. Respir. J. 6 (suppl. 16): 1-100.

19. Schols. A.M.W.J., E.F.M Wouters, P.B. Soeters, and K.R. Westerterp. 1991. Body composition by bioelectrical-impedance analysis compared with deuterium dilution and skinfold anthroponetry in patients with chronic obstructive pulmonary disease. Am. J. Clin. Nuir. $53: 421-424$

20. Westerterp, K.R., L. Wouters, and W.D. van Marken Lichtenbelt. 1995. The Maastricht protocol for the measurement of body composition and energy expenditure with labeled water. Obes. Res. 3 Suppl 1:49-57.

21. Baarends, E.M., W.D.V. Lichtenbelt, E.F.M. Wouters, and A.M.W.J. Schols. 1998. Bodywater compartments measured by bio-electrical impedance spectroscopy in patients with 
chronic obstructive pulmonary disease. Clin. Nutr. 17 (1):15-22.

22. Stichting Nederlands Voedingsstoffenbestand. 1996. NEVO tabel. Voorlichtingsbureau voor de voeding, Den Haag.

23. Weir, J.B. 1949. New methods for calculating metabolic rate with special reference to protein metabolism. J. Phys. 109:1-9

24. Creutzberg, E.C., A.M.W.J. Schols, F.C.M. Bothmer-Quaedvlieg, and E.F.M. Wouters. 1998. Prevalence of an elevated resting energy expenditure in patients with chronic obstructive pulmonary disease in relation to body composition and lung function. Eur. J. Clin. Nutr. 52 (6):396-401.

25. Leeuwenberg, J.F., T.M. Jeunhomme, and W.A. Buuman. 1994. Slow release of soluble TNF receptors by monocytes in vitro. $J$. Immunol. 152:4036-4043.

26. Altman, D.G., S.M. Gore, M.J. Gardner, and S.J. Pocock. 1983. Statistical guidelines for contributors to medical journals. Br. Med. J. Clin. Res. Ed. 286:1489-1493.

27. Baarends, E.M., A.M.W.J. Schols, D.L. Pannemans, K.R. Westerterp, and E.F.M. Wouters. 1997. Total free living energy expenditure in patients with severe chronic obstructive pulmonary disease. Am. J. Respir. Crit. Care Med. 155:549-554.

28. Creutzberg E.C. A.M.W.J. Schols, C.A.P.M. Weling-Scheepers, W.A. Buurman, E.F.M. Wouters. 2000. Characterization of non-response to high-caloric oral nutritional therapy in depleted patients with chronic obstructive pulmonary disease. Am. J. Respir. Crit. Care Med. 161:745-752

29. Fong, Y., L.L. Moldawer, M. Marano, H. Wei, A. Barber, K. Manogue, K.J. Tracey, G. Kuo, D.A. Fischman. A. Cerami. and et al. 1989. Cachectin/TNF or IL-I alpha induces cachexia with redistribution of body proteins. Am. J. Phisiol. 256:R659-665.

30. De Godoy, I.. M. Donahoc. W. J. Calhoun, J Mancino, and R.M. Rogers. 1996. Elevated TNFalpha production by peripheral blood monocytes of weight-losing COPD patients. Am. J. Respir. Crit. Care Med. 153:633-637.

31. Di Francia, M. D. Barbicr. J.L. Megu, and J. Orchck 1994. Tumor necrosis factor-alpha levels and weight loss in chronic obstructive pulmonary disease. Am. J. Respir. Crit. Care Med. 150:1453-1455.

32. Schols, A.M.W.J., W.A. Buurman. A.J. Staal van den Brekel, M.A. Dentener, and E.F.M. Wouters. 1996. Evidence for a relation between metabolic derangements and increased levels of inflammatory mediators in a subgroup of patients with chronic obstructive pulmonary disease. Thorax 51:819-824.

33. Zumbach, M.S., M.W. Boehme. P. Wahl, W. Stremmel, R. Ziegler, and P.P. Nawroth. 1997. Tumor necrosis factor increases serum leptin levels in humans. J. Clin. Endocrinol. Merab. 82.4080-4082

34. Janik, J.E., B.D. Curti. R.V. Considine, H.C. Rager, G.C. Powers. W.G. Alvord, J.W. Smith, 2nd. B.L. Gausc. and W.C. Kopp. 1997. Interleukin I alpha increases serum leptin concentrations in humans. J. Clin. Endocrinol. Metab. 82:3084-3086.

35. Bornstein, S.R. J. Licinio, R. Tauchnitz, L. Engelmann, A.B. Negrao, P. Gold, and G.P. Chrousos. 1998. Plasma leptin levels are increased in survivors of acute sepsis: associated loss of diumal rhythm, in cortisol and leptin secretion. J. Clin. Endocrinol. Metab. 83:280-283.

36. Torpy. D.J.. S.R. Bornstein, and G.P. Chrousos. 1998. Leptin and interleukin-6 in sepsis. Horm. Melab. Res. 30 (12):726-729.

37. Faggioni. R. G. Fantuzzi, J. Fuller. C.A. Dinarcllo, K. R. Feingold, and C. Grunfeld. 1998. ILI beta mediates leptin induction during inflammation. Am. J. Physiol. 274:R204-208.

38. Froon. A.H. M.H. Bemelmans. J.W. Greve. C.J. van der Linden, and W. A. Buurman. 1994. Increased plasma concentrations of soluble tumor necrosis factor receptors in sepsis syndrome: correlation with plasma creatinine values. Crit. Care Med. 22:803-809.

39. Froon. A.H. J.W. Greve. C.J. Van der Linden, and W.A. Buurman 1996. Increased concentrations of cytokines and adhesion molecules in patients after repair of abdominal aortic aneurysm. Eur. J. Surg. 162:287-296 
40. Tataranin, PA. P Pratley, M. Maffei, and E Ravuegin 1947. Acute and prolonged adminiafration of glucocorticoids (mothylprednisolone) does not affect plasma leptin Goncentration is humans. Int f. Obes. Relat. Metab. Disord. 21 327-330.

41. Saladin, R, B Staels, J. Auwerk, and M. Briggs. 1996. Regulation of ob gene expression in redents and hermans Horm Metab. Fes. 28.638-641.

42. Folli, $F_{w}, M J$ Sand, and CR. Kahn. 1996 . Insulin reeptor/IRS-1/PI 3-kinase signaing system. in conticosteroid-induced insulin resistance. Acta Drabetol. 33.185-192.

43. Cheng IT, IM Liu, TE Chi, KS Shinozuka, FH Lu, TJ Wu, CS Chang. 2000. Role of adenosine in insulin-stimulated relcase of leptin from isolated white adipocytes of Wistar rate. Diabetes 49 (1) $20-24$.

44. Pinkney JH, SW Coppack, V Mohamed-Ali, 1998. Effect of isoprenaline on plasma leptin and lipolysisin humans. Chn Endocrinol 48 (4), 407-411.

45. Hotamighgi, G.S. P. Ancr, If. Cara, R. A. Atkinson, and B.M. Spiegelman. 1995. Increased. adipose lisete expression of tumor necrosis factor-alpha in human obesity and insulin resistance $J$ Clin invest. 95.2409-2415.

46. Saghizadef, M, JM. Ong, W.T. Garvey, R. W. Henry, and F. A. Kern. I996. The expression of TNF alpha by human muscle, 洯elationship to insulin resistance. $J$ Clin. Invest. 97:1111-1116.

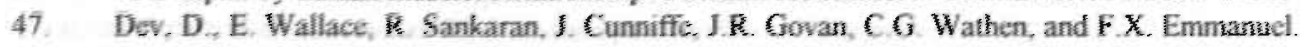
1998. Elalue of C-reative protein measurements in exacerbations of chronic obstnctive puimonary discase. Respir. Med 92:664-667.

48. Keatngs, V.M. A Jatakanon, Y.M. Worsdell, and P.J. Bames. 1997. Effects of inhaled and oral glucocorticoide on inflammotry indices in asthma and COPD. Am. J. Respir. Crit. Care Med 155:542-548.

49. Curtis, G.E. C.A. McAtear, L. Fomela, A. Walsi, and A Shenkin. 1995. The effect of nutritional stafus on the cytokine and acute phase protein responses to elective surgery. Cytokine 7,39:5=388.

50. Mantzoros, C. S. S. Moschos, I. Avramopoulos, V. Kaklamani, A. Liolios, D.E. Doulgerakis, 1. Griveas, N. Katsilambros, and J.S. Flier. 1997. Leptin concentrations in relation to body mass index and the tumor necrosis factor-alpha system in humans. J. Clin. Endocrinol. Metab. $82: 3468$ 8 -3413 .

51. Lord, G.M., G. Matarese, L.K. Howard, R.J. Baker, S.R. Bloom, and R.1. Lechler. 1998. Leptin modulates the $\mathrm{T}$-cell immune response and reverses starvation-induced immunosuppression. Nature 394 (6696):897-901.

52. O. Donnell, C.P., C.D. Schaub, A.S. Haines, D.E. Berkowitz, C.G. Tankersley, A.R. Schwartz, and P.L. Smith. 1999. Leptin prevents respiratory depression in obesity. Am. J. Respir. Cril. Care Med. 159:1477-1484. 


\section{Chapter 6}

Efficacy of nutritional supplementation therapy implemented in a pulmonary rehabilitation program in depleted patients with chronic obstructive pulmonary disease

E. C. Creutzberg' ${ }^{1}$, E. F. M. Wouters ${ }^{1}$, R. Mostert ${ }^{2}$, C. A. P. M. WelingScheepers ${ }^{2}$, A. M. W. J. Schols ${ }^{1}$

${ }^{1}$ Department of Pulmonology, University Hospital Maastricht; ${ }^{2}$ Asthma Center Hornerheide, Horn; The Netherlands

\section{Submitted}

The study was supported by Numico Research BV and NV Organon, The Netherlands 


\section{Abstract}

Weight loss and muscle wasting in COPD adversely affect morbidity and mortality. The aim of the study was to investigate the efficacy of oral nutritional supplementation therapy (mean (SD) $672(125) \mathrm{kcal} / 24 \mathrm{~h}$ ) incorporated in an eight-weeks inpatient pulmonary rehabilitation program in 64 (49 men) depleted or weight-losing, but otherwise clinically stable, patients with severe COPD (age 65 (9) years, FEV 35 (14) \%pred). Overall, increases in body weight $(2.1(2.1) \mathrm{kg}, \mathrm{p}<0.001)$, fat-free mass $(1.1(2.0) \mathrm{kg}, \mathrm{p}<0.001)$ and serum protein $(2.8(5.0) \mathrm{g} / 1, \mathrm{p}<0.001)$ were seen. Furthermore, maximal inspiratory mouth pressure $\left(4(10) \mathrm{cm} \mathrm{H}_{2} \mathrm{O}, \mathrm{p}=0.001\right)$, handgrip strength $(1.2(3.1) \mathrm{kg}, \mathrm{p}=0.004)$ and peak work load on an incremental bicycle ergometry test $(7$ (11) W, $\mathrm{p}=0.001$ ) significantly improved. Clinically significant improvements in health status, as assessed by the St. George's Respiratory Questionnaire, on the items symptoms $(9$ (16) points, $\mathrm{p}<0.001)$ and impact ( 4 (15) points, $\mathrm{p}=0.043$ ) were revealed. $48 \%$ Of the patients was on long-term treatment with low-dose oral glucocorticosteroids as maintenance medication (dose: 7.6 (2.5) $\mathrm{mg} / 24 \mathrm{~h}$ ). Oral glucocorticosteroid treatment significantly impaired the response to nutritional supplementation therapy with respect to maximal inspiratory mouth pressure, exercise capacity (peak work load as well as peak lactate/peak work load ratio) and health status. In conclusion, nutritional supplementation therapy implemented in a pulmonary rehabilitation program in depleted or weight-losing patients with COPD is effective. Oral glucocorticosteroid treatment however attenuated the anabolic response.

\section{Introduction}

The commonly occurring weight loss and muscle wasting in patients with chronic obstructive pulmonary disease (COPD) adversely affect respiratory and peripheral muscle function (1,2), exercise capacity (3), health status (4) and even survival rates (5), independently of aifflow obstruction. Several factors might be responsible for this involuntary weight loss and muscle wasting in COPD.

Weight loss can simply be the result of an increased energy expenditure unbalanced by an adequate dietary intake. In general, the dietary intake of patients with COPD does not differ from the recommended daily allowances (6). Weight-losing patients exhibited however a lower dietary intake compared with weight-stable patients with COPD (7). Also during an acute exacerbation of COPD, a temporary decrease in appetite and dietary intake was reported, associated with increased subjective sensations of dyspnea and fatigue (8). In addition, evidence for a relation between an enhanced systemic inflammatory response on the one hand and relative anorexia on the other was revealed in patients with $\operatorname{COPD}(9,10)$.

In 26\% of the patients with COPD, an increased resting energy expenditure (REE) adjusted for fat-free mass (FFM) was reported (11). In contrast to the earlier opinion, an increased REE is not solely the result of an increased oxygen cost of breathing at rest (12). Other factors have been implicated, such as bronchodilating medication like salbutamol (13) and an enhanced systemic inflammatory state (14). Besides an increased REE, also an elevated total daily energy expenditure (TDEE) is reported in patients with COPD compared with healthy age-matched subjects (15). The variation in TDEE appeared to reflect differences in the energy expenditure for activities and not in REE, since TDEE did not differ between patients with a normal REE and those with an increased REE (16). 
Besides a disturbed energy balance, there are also indications for disturbances in the protein balance. Since selective wasting of FFM despite relative preservation of fat mass (FM) is reported in COPD (17), a disturbed protein balance can also be present disproportionately to overall weight loss. At first, it is reported that the daily protein intake is decreased, especially during the first days of an acute exacerbation of COPD (8). Secondly, as one mechanism of muscle wasting, a decreased protein synthesis was reported in underweight patients with emphysema (18). Recently, in normal-weight patients with stable COPD, in addition an increased protein turnover was found (19).

An enhanced systemic inflammatory response is described as one of the possible causes of a selectively disturbed protein balance. In patients with COPD with an elevated REE and an increased $\mathrm{C}$-reactive protein (CRP). FFM, but not body weight, was decreased together with elevated concentrations of the inflammatory mediators LPS-binding protein, interleukin 8 and soluble TNF-receptors 55 and 75 compared with those with normal CRP concentrations (20). Decreased concentrations of anabolic hormones might further aggravate the failure to generate the stimulus needed for an anabolic response, i.e. muscle anabolism. Indeed low levels of testosterone are reported in COPD, which were even more pronounced in patients on oral glucocorticosteroid (GC) therapy (21). Long-term, low-dose systemic GCs are still prescribed as maintenance anti-inflammatory medication in a substantial number of patients with COPD. Chronic use of oral GCs can further contribute to weakness and wasting of both the respiratory and peripheral muscles in patients with severe COPD (22).

Several attempts have been made to reverse weight loss and muscle wasting in patients with COPD by instituting oral nutritional therapy. A recent meta-analysis by Ferreira et al. concluded however that nutritional supplementation therapy had no effect on improving anthropometric measures, lung function or functional exercise capacity among stable patients (23). It can be deduced from the above described evidence on protein balance disturbances, that nutritional therapy in COPD must consist of enough dietary protein. Furthermore, it has to be combined with an anabolic stimulus, like exercise training, to enhance improvements in muscle mass and physiological function. The first aim of the present study was to investigate the effects of oral nutritional supplementation therapy incorporated in an eight-weeks inpatient pulmonary rehabilitation program on body composition, muscle function, exercise capacity and health status in depleted or weight-losing patients with COPD.

No information is available yet whether patients with COPD are indeed able to generate an anabolic response after nutritional supplementation therapy compared with healthy, elderly subjects. The second aim of our study was therefore to compare the actual changes in body weight and FFM during nutritional supplementation with the body weight and FFM responses that are to be expected in health. For this purpose, we used a computer simulation model that is build up from large sets of data on body composition, energy intake and energy expenditure derived from healthy men and women in a large range of age (24).

Thirdly, we set out to investigate oral maintenance GC treatment as one of the possible explanations for the problem why patients with COPD are not able to generate an anabolic response on nutritional therapy. In order to do this, the patients were post-stratified by 
maintenance oral GC use and the efficacy of treatment was compared between users and non-users of long-term, low-dose oral GCs.

\section{Patients and methods}

\section{Patients}

The study group consisted of patients with COPD eligible for nutritional therapy consecutively admitted to a pulmonary rehabilitation center (Asthma Center Hornerheide, Horn, The Netherlands). The patients were included if they fulfilled the criteria for COPD according to the ATS guidelines (25). The FEV 1 had to be less than $70 \%$ of the reference value and the increase in $\mathrm{FEV}_{1}$ after inhalation of a $B_{2}$-agonist less than $10 \%$ of the reference value. Patients with concomitant confounding diseases such as malignant disorders, gastrointestinal abnormalities, recent surgery or severe endocrine disorders were excluded. Only patients in a clinical stable condition (not suffering from a recent respiratory tract infection) were included in the study. Eligibility for nutritional supplementation was defined as:

1. Body mass index (BMI; body weight/height $\left.{ }^{2}\right) \leq 21 \mathrm{~kg} / \mathrm{m}^{2}$ and $/$ or

2. FFM-index (FFMI; FFM/height $\left.{ }^{2}\right) \leq 15(\%) / \leq 16\left(\sigma^{7}\right) \mathrm{kg} / \mathrm{m}^{2}$ and $/$ or

3. $\mathrm{BMI} \leq 25 \mathrm{~kg} / \mathrm{m}^{2}$ and weight loss $\geq 5 \%$ in one month or $\geq 10 \%$ in six months prior admission to the pulmonary rehabilitation center.

The first criterion was based on the fact that BMI $\leq 21 \mathrm{~kg} / \mathrm{m}^{2}$ is a generally accepted limit below which subjects are considered as being underweight. Patients were in addition selected on the base of a low FFMI, because it has been well established as a limiting factor for functional performance (3). The third criterion was based on a COPD survival analysis by Schols et al. in which a BMI threshold value of $25 \mathrm{~kg} / \mathrm{m}^{2}$ was identified below which the mortality risk was clearly increased (5). These results were confirmed by the study of Landbo et al. She also found an increased mortality risk in patients with a BMI $.25 \mathrm{~kg} / \mathrm{m}^{2}$. especially when their COPD was severe (FEV $<50 \%$ pred) (26). Since the patients in our study were characterized by severe COPD and weight-losing patients per se have a poorer prognosis because they are prone to depletion, patients with a BMI $\leq 25$ $\mathrm{kg} / \mathrm{m}^{2}$ suffering from weight loss received in addition nutritional supplementation. The final study group consisted of 64 patients (49 men; age mean (SD) 65 (9) years) with severe COPD (forced expiratory volume in one second; $\mathrm{FEV}_{1}: 35$ (14) \% of predicted). The study was approved by the medical ethical committee of the University Hospital Maastricht and all subjects gave their informed consent.

Almost all patients were ex- or current smokers (97\%). A substantial proportion of the study group suffered from chronic hypoxia $\left(\mathrm{PaO}_{2}<7.3 \mathrm{kPa} ; 19 \%\right.$ of the patients), oxygen desaturation during exercise $\left(47^{\circ} \%\right.$ ) and/or at night (31\%). Most of the patients were using one or more respiratory medications: inhaled/oral short- and long-term B2sympathicomimetics $(97 \%)$, oral theophyllines $\left(67^{\circ} \%\right)$, inhaled ipratropium bromide $(91 \%)$ and inhaled glucocorticosteroids $(86 \%)$. About half of the patients was on long-term, low dose oral GCs as maintenance anti-inflammatory medication (table 1).

\section{Assessments}

\section{Lung function}

At baseline, FEV, and inspiratory vital capacity (IVC) were calculated from the flow 
volume curve using a spirometer (Masterlab" Jaeger, Würzburg, Germany). Diffusing capacity for carbon monoxide was determined using the single breath method (Masterlab ${ }^{*}$, Jaeger, Würzburg, Germany) and corrected for alveolar volume (Kco). Lung functional parameters were expressed as percentage of reference values (27). Blood was drawn from the brachial artery while the patients were breathing room air. Arterial oxygen tension $\left(\mathrm{PaO}_{2}\right)$ and carbon dioxide tension $\left(\mathrm{PaCO}_{2}\right)$ were analyzed on a blood gas analyzer (Radiometer, ABL 330, Copenhagen, Denmark).

The following measurements were performed before and after eight weeks of nutritional intervention.

\section{Energy balance}

REE was measured in the early morning $(8.30$ a.m.) by an open circuit indirect calorimetry system using a ventilated hood (Oxycon Beta ${ }^{\infty}$, Jaeger, Würzburg, Germany). The system was calibrated daily before the start of the experiment. The accuracy of the system was regularly assessed using a methanol combustion test. Patients were in a fasting state for at least 10 hours and had a period of at least 30 minutes bed rest prior to the measurements. Patients received their maintenance medication two hours before measurements started. REE was measured when subjects were comfortably lying on a bed in supine position. REE was calculated from oxygen consumption $\left(\mathrm{V}^{\prime} \mathrm{O}_{2}\right)$ and carbon dioxide production $\left(\mathrm{V}^{\top} \mathrm{CO}_{2}\right)$ using the abbreviated Weir formula (28).

Habitual dietary intake was assessed using the dietary history method with cross check. All interviews were performed by the same trained dietician. In addition, before and in the last week of the nutritional therapy, a subgroup of patients $(n=48)$ were asked to register their food intake during four consecutive days. Dietary intake was calculated by taking the average intake over four days. The use of dietary records gives a good representation of the actual consumption of calories because the food intake is averaged over four consecutive days so day-tot-day variations are largely discarded. The obtained information from the dietary history and dietary records was coded for computer nutrient analysis. The nutrient data base was derived from the Dutch food composition tables (29). The dietary intake/REE ratio was calculated by dividing dietary intake by REE. Total protein, carbohydrate and fat intake were presented as proportions of total energy intake (energy $\%$ ). Total protein intake was also expressed as $\mathrm{g} / \mathrm{kg}$ body weight $/ 24 \mathrm{~h}$.

\section{Body composition}

Body height was determined to the nearest $0.5 \mathrm{~cm}$ (WM 715, Lameris, Breukelen, The Netherlands) with subjects standing barefoot. Body weight was assessed with a beam scale to the nearest $0.1 \mathrm{~kg}$ (SECA, Hamburg, Germany) with subjects standing barefoot and in light clothing. Body weight was, in addition to before and after eight weeks of nutritional intervention, also measured at week two, four and six. Circumference of the upper arm was taken with a flexible measuring tape. Skinfold thickness at four sites (bicipital, tricipital, subscapular and suprailiac) were measured with a skinfold caliper (Harpenden, Holtain Ltd., Crymych, UK). \%FM was estimated from the sum of the skinfolds using the Durnin tables (30). 
FFM was estimated using single frequency $(50 \mathrm{kHz})$ bioelectrical impedance analysis (BIA; Xitron technologies, San Diego, U.S.A.). Resistance was measured with subjects in supine position. FFM was calculated using the disease-specific equation of Schols (31). For validation of $B I A$, in a subgroup of patients $(n=47)$, FFM was also assessed using the deuterium dilution method (32), described in detail elsewhere (10). In short, deuterium dilution space was calculated from the amount of orally administered deuterium-labeled water and the urine concentrations before and after complete, overnight distribution. FFM was calculated assuming a hydration factor of 0.73 . At baseline, FFM by BIA was equal to FFM by deuterium dilution (43.6 (6.4) vs. 42.7 (6.6) $\mathrm{kg}$ respectively, NS). Also the change in FFM after nutritional intervention was similar for the two techniques $(0.9$ (2.0) vs. 0.4 (1.8) kg respectively, NS). On Bland and Altman plots, no significant trends in the difference between the two measurement techniques were revealed.

\section{Collection and analysis of laboratory parameters}

Blood was collected in the early morning when patients were in the fasting state for at least 10 hours. Biochemistry included measurements of serum protein, albumin, glucose and CRP by spectrophotometric analysis (Cobas Mira ; Hoffmann-La Roche, Basel, Switzerland).

\section{Respiratory and peripheral muscle function}

Respiratory muscle function was assessed by measuring maximal inspiratory mouth pressure (PI-max) according to the method of Black and Hyatt (33). The best of three attempts was taken for analysis. PI-max values were noted as positive values. Skeletal muscle function of the upper extremities was assessed with use of a Harpenden handgrip dynamometer (Yamar ${ }^{\otimes}$, Preston, Jackson, MI, U.S.A.). The isometric grasp was determined by measuring the maximally developed strength of the flexors of the fingers of the right and left hand respectively. The highest value of three maneuvers was used. The average of the maximal left and right handgrip strength was taken for analysis. The muscle function tests were performed twice at baseline; the second measurement was taken for analysis to exclude possible learning effects. During all muscle function tests, the patients were encouraged to perform as optimum as they could.

\section{Fxercise performance}

I'n measure exercise performance. the patients performed an indoor corridor walk during 12 minutes. The distance walked in 12 minutes ( $12 \mathrm{MWD}$ ) was used in the analysis. The patients were not encouraged during the walk.

In addition, in a subgroup of patients not suffering from chronic hypoxia $\left(n=38, \mathrm{PaO}_{2}\right.$ $\geq 7.3 \mathrm{kPa}$ ), an incremental bicycle ergometry test was performed on an electromagnetic brakes ergometer (Corival $400^{x}$, Lode. Groningen. The Netherlands) to investigate maximal leg exercise capacity. After a two minute resting period and one minute unloaded cycling, power was increased every minute by $10 \mathrm{~W}$. The work load cycled was unknown to the patients who were encouraged to cycle for as long as possible. Peak work load was compared to the predicted values (34). During the exercise test, heart rate was monitored (Sport-tester ${ }^{*}$, Polar electro $\mathrm{Cy}$, Kempele, Finland). Oxygen consumption ( $\mathrm{V}^{\circ} \mathrm{O}_{2}$ ) was measured and calculated from breath by breath analysis using a breathing mask (Oxycon 
Beta $^{\star}$, Jaeger, Würzburg, Germany). The equipment was calibrated before the tests and the accuracy of the system was regularly assessed using a methanol combustion test. Immediately before and two minutes after reaching the peak work load, a venous blood sample was taken to measure the concentration lactate. The blood samples were stored on ice $\left(4^{\circ} \mathrm{C}\right.$ ) and centrifuged for 5 minutes at $3000 \mathrm{rpm}$ (Sigma 2-15 ${ }^{\circ}$, Lameris, Breukelen, The Netherlands). Plasma lactate was determined enzymatically using an automated system (Cobas Mira ${ }^{\text {}}$, Roche, Basel, Switzerland). Peak work load, the ratio between peak lactate and peak work load, peak $\mathrm{V}^{\prime} \mathrm{O}_{2}$ and the ratio between peak $\mathrm{V}^{\prime} \mathrm{O}_{2}$ and peak heart rate (peak oxygen pulse) were used in the analyses.

\section{Health status}

Health status is defined as to signify the gap, specifically due to the disease, between that which is desired and that which is achievable. Health status was measured, before and after eight weeks of treatment, by the St. George's Respiratory Questionnaire (SGRQ), a standardized, sensitive and reproducible questionnaire specific for patients with lung diseases. The SGRQ consists of 76 items and is designed to allow direct comparisons of the health gain to be obtained with different types of interventions. After it was filled out by the patients themselves, subscores ranging from 0 to 100 points for the categories symptoms (distress due to respiratory symptoms), activity (disturbance of physical activity) and impact (overall impact on daily life and well-being) were calculated, as well as an total score (mean of the three scores). A high score means greater impairment in health status. The Cronbach $\alpha$ (a measure of homogeneity of the items within each category) is 0.60 for symptoms, 0.82 for activity and 0.71 for impact. A change from baseline score of four points or more after treatment is considered as clinically significant. This was based on a multivariate model in which the SGRQ score was related to clinically appropriate changes in a range of disease-related variables. In addition, minimum subjective efficacy of therapy corresponded with a change in SGRQ of four points (35). In addition, the patients had to score on a visual analogue scale (VAS), ranging from 0 to $100 \mathrm{~mm}$, how healthy or unhealthy they regard themselves (score $=100 \mathrm{~mm}$ : perfect health; score $=0 \mathrm{~mm}$ : dead). The score was filled in after answering six questions to draw attention to the different dimensions of health (performing daily activities, worrying about the disease and the prognosis, pain or other complaints, side-effects of medication and spending spare time)

\section{Nutritional intervention}

After baseline screening, the patients were treated with nutritional therapy consisting of 2.7 (SD 0.5; range: 1-3.5) supplements per $24 \mathrm{~h}$ containing 672 (SD 125; range: $250-875$ ) $\mathrm{kcal}$ in total. Patients were allowed to choose from an assortment of products with variable consistency and flavor (Nutridrink ${ }^{\infty}$, Fortimel ${ }^{\infty}$, Ensini ${ }^{\infty}$, Fortipudding ${ }^{k}$ ). The supplementation consisted for 61 energy percent of carbohydrates, for 19 energy percent of fat and for 20 energy percent of protein. The supplements were labeled with the name of each individual patient and handed out once to thrice daily in order to have a stringent control on their intake. Patients were, in addition to taking the supplements, encouraged to continue the consumption of their regular meal portions as well. Due to the inpatient setting, the regular diet that was offered to the patients was standardized. The total protein 
content of the supplements together with that of the consumed regular meals was more than enough to ensure the amount of protein needed for optimum protein synthesis (1.6 (0.4) g protein $/ \mathrm{kg}$ body weight $/ 24 \mathrm{~h}$; see table 2 ). This was based on the available data in the literature that protein synthesis is optimally stimulated during administration of $1.5 \mathrm{~g}$ $\mathrm{protein} / \mathrm{kg}$ body weight $/ 24 \mathrm{~h}(36)$.

The intervention was embedded in an eight-weeks, standardized inpatient pulmonary rehabilitation program, consisting of general physical training with particular attention to exercise in relation to daily activities, cycle ergometry (work load depending on the peak work load during an incremental bicycle ergometry test), treadmill walking, swimming, sports and games. In addition, an educational program about the disease and medication use was implemented. When appropriate, psychologic or occupational therapy was given. The metabolic cost of the exercise program was tried to be kept at the same level for all patients by adjusting the exercise activities to the physical performance state of each individual patient. Because the exercise program was offered in an inpatient setting, there was a thorough control on the compliance of the patients to the different aspects of the program. Furthermore, since the patients in general trained together, they exerted an additional control on the compliance of each other.

\section{Statistical analysis}

A computer simulation model taking into account the patient's sex, age, height, body composition and dietary intake (24) was used for the estimation of the weight and FFM response after nutritional therapy. The changes in body weight and FFM were predicted on the base of the actual, net rise in dietary intake after nutritional therapy. Calculations were done for men and women separately and the weighed mean was taken for analysis. The actual change in FFM after eight weeks was compared with the predicted change in FFM. The course of body weight was predicted every two weeks and compared with actual body weight at week two, four, six and eight of nutritional intervention.

Changes within the groups between baseline and week eight were tested by applying the Student's paired t-test for dependent samples. Since body weight was measured at baseline and at week two, four, six and eight, the Bonferroni correction was applied to correct for the multiple comparisons. Since per time point four comparisons were done, significance was determined at a p-value of $0.0125(=0.050 / 4)$. For the other tests, significance was determined at the level of $5 \%$. Differences in baseline parameters between users and non-users of oral GCs were analyzed with the Student's t-test for independent samples when variables were normally distributed. The Mann-Whitney $U$ test was applied for not normally distributed variables. Differences in the response to nutritional supplementation between users and non-users of oral GCs were tested using analysis of variance (ANOVA). Oral GC-use was taken as fixed factor and the baseline value was included in the model as covariant to exclude possible influences of baseline differences. ANOVA was also performed with age and maintenance use of theophyllines and ipratropium bromide as covariants included in the model, since these parameters significantly differed between users and non-users of oral GCs. Data are expressed as mean (SD) in the text and as mean (SEM) in the bar graphs. Data were analy $z$ ed according to the guidelines of Altman et al. (37), using SPSS/PC+ (statistical package for the social sciences, version 9.0 for Windows, SPSS Inc., Chicago, IL, U.S.A.). 


\section{Results}

\section{Baseline}

In table 1, the baseline parameters of the study group are presented. On the base of the $F E V_{1}$, the patients were suffering from severe COPD. Kco was decreased. Mean arterial blood gases were in the normal range. Exercise capacity was impaired when compared with the predicted values. The habitual dietary intake expressed as percentage of REE was lower than the TDEE reported in weight-stable patients with COPD measured in the same pulmonary rehabilitation setting, amounting up to 1.7 (15). Also habitual protein intake was lower than the recommended values (36). Since the registration of food intake and the incremental bicycle ergometry test were performed in (different) subgroups of the total study group, we tested whether the baseline parameters of these groups were different from those of the total study group. On statistical analysis, there were no baseline differences between the total study group and the subgroups in which food intake and bicycle ergometry were assessed.

Table 1: Baseline characteristics of the study group

\begin{tabular}{|c|c|c|c|}
\hline \multicolumn{2}{|l|}{$\overline{n(m / f)}$} & \multirow{2}{*}{$\begin{array}{l}64 \\
\text { mean } \\
65\end{array}$} & \multirow{2}{*}{$\begin{array}{l}(49 /[5) \\
(S D)) \\
(9)\end{array}$} \\
\hline$\overline{\text { Age }}$ & (yrs) & & \\
\hline Forced expiratory volume in $1 \mathrm{sec}$. & (\%pred) & 35 & (14) \\
\hline Inspiratory vital capacity & (\%pred) & 81 & (19) \\
\hline Diffusing capacity/alviolar volume & (\%pred) & 53 & (23) \\
\hline Arterial $\mathrm{O}_{2}$ pressure & $(\mathrm{kPa})$ & 9.3 & $(1.2)$ \\
\hline Arterial $\mathrm{CO}_{2}$ pressure & $(\mathrm{kPa})$ & 5.7 & $(0.8)$ \\
\hline Body mass index & $\left(\mathrm{kg} / \mathrm{m}^{2}\right)$ & 20.2 & $(1.7)$ \\
\hline Fat-free mass index & $\left(\mathrm{kg} / \mathrm{m}^{2}\right)$ & 15.3 & $(1.4)$ \\
\hline Puak work load & (\%pred) & 41 & $(18)$ \\
\hline Habitual dietary intake & $(\mathrm{kcal} / 24 \mathrm{~h})$ & 2106 & $(668)$ \\
\hline \multicolumn{2}{|c|}{ Habitual dietary intake/resting energy expenditure } & 1.5 & $(0,6)$ \\
\hline Habitual protein intake & ( $\mathrm{g} / \mathrm{kg}$ body weight $24 \mathrm{~h}$ ) & 1.4 & $(0.5)$ \\
\hline Habitual protein intake & (energy $\%$ ) & 15 & (3) \\
\hline Habitual carbohydrate intake & (energy $\%$ ) & 46 & (7) \\
\hline Habitual fat intake & (energy $\%)$ & 36 & (6) \\
\hline Oral glucocorticosteroids ${ }^{1}$ & $(\mathrm{mg} / 24 \mathrm{~h})$ & 7.6 & $(2.5)$ \\
\hline
\end{tabular}

Mean of patients using oral glucocorticosteroids as maintenance medication: $31 / 64$ (48\%).

Efficacy of oral nutritional supplementation therapy implemented in an inpatient pulmonary rehabilitation program

Energy balance

Dietary intake as well as dietary intake/REE ratio were significantly increased after nutritional therapy. There was nevertheless an adaptation in the intake of the regular meals, since net change in dietary intake amounted up to $438 \mathrm{kcal} / 24 \mathrm{~h}$, which was $6.5 \%$ of the expected $672 \mathrm{kcal} / 24 \mathrm{~h}$ (table 2). REE did not change (data not shown). When looking at the change in macronutrient intake, both protein and carbohydrate were increased after eight weeks. while fat intake did not change (data not shown). Also expressed as $\mathrm{g} / \mathrm{kg}$ body weight, an increase in protein intake was seen. Protein and carbohydrate intake, expressed as percentage of total energy intake, increased, while percentage fat intake decreased after treatment (table 2). 


\section{Body composition and serum proteins}

Body weight, FFM, \%FM by skinfolds and midarm circumference were significantly increased after eight weeks of nutritional supplementation therapy (table 2). The change in body weight was not correlated to the initial body weight. The course of body weight per two weeks is depicted in figure 1. Already after two weeks, a rise in body weight was seen. Body weight further increased from week two till week four and from week four till week eight. The finally achieved rise in body weight after eight weeks of intervention was however lower than the predicted value ( $2.1 \mathrm{vs.} 2.6 \mathrm{~kg}$; figure 1), because of an attenuated rise from week four till week six. The actual gain in FFM after eight weeks was similar to the predicted gain $(1.1$ vs. $0.9 \mathrm{~kg}$ ). Total serum protein, but not serum albumin, increased after eight weeks of treatment (table 2).

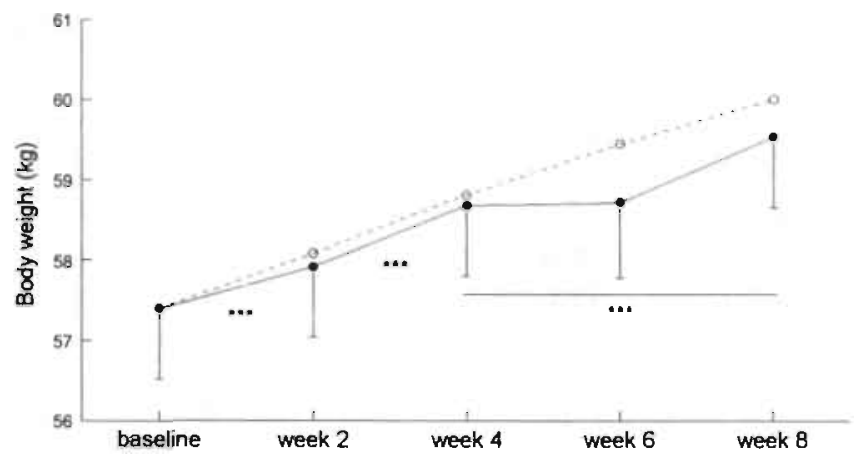

Figure 1: Course of body weight per two weeks during nutritional therapy incorporated in an eight-wecks pulmonary rehabilitation program. Data are presented as mean (SEM). Solid line with closed circles: actual body weight. Dashed line with open circles: predicted body weight on the base of the rise in dietary intake. ${ }^{* * *} \mathrm{p}<0.001$

\section{Respiratory and peripheral muscle function and exercise capacity}

PI-max, handgrip strength and the $12 \mathrm{MWD}$ increased significantly from baseline till week eight (table 2). In addition, peak work load, peak lactate'peak work load, peak oxygen consumption and peak oxygen pulse during the incremental bicycle ergometry test improved (table 2).

\section{Health status}

Health status, as assessed by the St. George's Respiratory Questionnaire, improved on the items symptoms and impact. The change in total score was nearly significant. Activity score did not change. The VAS score on subjective health perception increased significantly (table 2 ). 
Table 2: Efficacy of nutritional supplementation therapy implemented in an eight-weeks pulmonary rehabilitation program.

\begin{tabular}{|c|c|c|c|c|c|c|}
\hline & & \multicolumn{2}{|l|}{ Baseline } & \multicolumn{2}{|c|}{ Week eight } & \multirow{2}{*}{$\begin{array}{l}\text { Pre-post } \\
\text { p-value }\end{array}$} \\
\hline & & mean & (SD) & mean & (SD) & \\
\hline \multicolumn{7}{|l|}{ Energy balance } \\
\hline Dietary intake & $(\mathrm{kcal} / 24 \mathrm{~h})$ & 2316 & $(522)$ & 2754 & $(557)$ & $<0,001$ \\
\hline \multicolumn{2}{|c|}{ Dietary intake/resting energy expenditure } & 1.6 & $(0.4)$ & 1.9 & $(0.3)$ & $<0.001$ \\
\hline Protein intake & $(\mathrm{g} / \mathrm{kg} / 24 \mathrm{~h})$ & 1.6 & $(0.4)$ & 1.9 & $(0.4)$ & $<0.001$ \\
\hline Protein intake & (energy \%) & 16 & (2) & 17 & (2) & 0.013 \\
\hline Carbohydrate intake & (energy \%) & 45 & (6) & 49 & (5) & $<0.00 \mathrm{i}$ \\
\hline Fat intake & (energy \%) & 39 & (5) & 35 & (4) & $<0.001$ \\
\hline \multicolumn{7}{|c|}{ Body composition and serum proteins } \\
\hline Body weight & $(\mathrm{kg})$ & 57.4 & $(7.0)$ & 59.5 & (7.1) & $<0.001$ \\
\hline Fat-free mass & $(\mathrm{kg})$ & 43.6 & $(6.0)$ & 44.7 & $(6.0)$ & $<0.001$ \\
\hline Fat mass skinfolds & $(\%)$ & 13.7 & $(6.9)$ & 14.8 & $(7.6)$ & 0.010 \\
\hline Midarm circumference & $(\mathrm{cm})$ & 24.1 & $(1.7)$ & 24.8 & $(1.8)$ & $<0.001$ \\
\hline Serum protein & $(\mathrm{g} / \mathrm{l})$ & 63.2 & $(5.8)$ & 66.0 & $(5.2)$ & $<0.001$ \\
\hline Serum albumin & $(g / l)$ & 43.9 & $(3.8)$ & 44.8 & (3.1) & NS \\
\hline \multicolumn{7}{|c|}{ Muscle function and exercise performance } \\
\hline Max. inspiratory mouth pressure & $\left(\mathrm{cm} \mathrm{H}_{2} \mathrm{O}\right)$ & 70 & $(19)$ & 74 & $(18)$ & 0.001 \\
\hline Handgrip strength & $(\mathrm{kg})$ & 31.9 & $(7.8)$ & 33. $]$ & $(8.2)$ & 0.004 \\
\hline $12 \mathrm{~min}$. walking distance & $(\mathrm{m})$ & 708 & $(181)$ & 840 & (204) & $<0.001$ \\
\hline Peak work load & (W) & 53 & $(20)$ & 59 & $(24)$ & 0.001 \\
\hline Peak lactate/peak work load & $\left(\mathrm{mmol} / \mathrm{W}^{*} \mathrm{l}\right)$ & 0.07 & $(0.03)$ & 0.06 & $(0.02)$ & 0.037 \\
\hline Peak oxygen consumption & $(\mathrm{ml} / \mathrm{min})$ & 833 & $(195)$ & 884 & (257) & 0.041 \\
\hline Peak oxygen pulse & $(\mathrm{ml})$ & 7.0 & $(1.8)$ & 7.5 & $(2.2)$ & 0.020 \\
\hline \multicolumn{7}{|l|}{ Hiallh stams } \\
\hline Symptom score - SGRQ & (points) & 55 & $(20)$ & 46 & (21) & $<0.001$ \\
\hline Activity score - SGRQ & (points) & 65 & (22) & 66 & (20) & NS \\
\hline Impact score - SGRQ & (points) & 41 & (19) & 37 & (17) & 0.043 \\
\hline Total score - SGRQ & (points) & 50 & (17) & 47 & (16) & NS \\
\hline Subjective health perception & $(\mathrm{mm})$ & 53 & (17) & 58 & (16) & 0.033 \\
\hline
\end{tabular}

SGRQ: St. George's Respiratory Questionnaire. Subjective health perception was measured by a visual analogue scale (score $=100 \mathrm{~mm}$ : perfect health; score $=0 \mathrm{mum}$ : dead).

Influence of maintenance oral glucocorticosteroid use on efficacy of nutritional supplementation therapy

Baseline differences between users and non-users of oral glucocorticosteroids

Differences in baseline parameters between patients to whom oral GCs were prescribed as maintenance medication and to whom not are presented in table 3. A higher proportion of patients in the oral GC treated group compared to the subgroup not treated with oral GCs was using ipratropium bromide and theophylline. Patients using oral GCs were characterized by a higher age and habitual protein intake compared to non-users of oral GCs. Lung function, arterial blood gases, sex, smoking habits and habitual and baseline dietary intake were similar in patients treated compared with patients not treated with oral GCs. Also no differences were seen in users and non-users of oral GCs with respect to serum glucose and serum CRP. In addition, the prevalence of other respiratory medication use and recent weight loss was similar. Regarding the efficacy parameters, no differences were seen in baseline body composition, serum proteins, muscle function or excrcisc 
capacity between patients using oral GCs compared with non-users of oral GCs. Impact and total score of the SGRQ were however worse in GC users compared to GC non-users.

Table 3: Baseline characteristics of non-users and users of long-term, low-dose oral glucocorticosteroids.

\begin{tabular}{|c|c|c|c|c|c|c|}
\hline & \multicolumn{2}{|c|}{$\begin{array}{l}\text { No oral GCs } \\
n=33\end{array}$} & \multicolumn{2}{|c|}{$\begin{array}{l}\text { Oral GCs } \\
n=31\end{array}$} & \multirow[b]{2}{*}{ p-value } \\
\hline & & $n$ & $(\%)$ & $n$ & $(\%)$ & \\
\hline $\mathrm{m} / \mathrm{f}$ & & $24 / 9$ & & $25 / 6$ & & NS \\
\hline Use of ipratropium bromide & & 27 & (81) & 31 & $(100)$ & 0.012 \\
\hline \multirow[t]{2}{*}{ Use of theophyllines } & & 17 & $(50)$ & 26 & (84) & 0.005 \\
\hline & & mean & (SD) & mean & (SD) & p-value \\
\hline$\overline{\text { Age }}$ & (yrs) & 62 & $(10)$ & 67 & (6) & 0.040 \\
\hline Forced expiratory volume in $1 \mathrm{sec}$. & (\%pred) & 37 & (18) & 33 & (8) & NS \\
\hline Inspiratory vital capacity & (\%pred) & 85 & (22) & 77 & (16) & NS \\
\hline Diffusing capacity/alveolar volume & (\%pred) & 51 & (22) & 55 & (23) & NS \\
\hline Arterial $\mathrm{O}_{2}$ pressure & $(\mathrm{kPa})$ & 9.3 & (1.4) & 9.2 & (1.1) & NS \\
\hline Arterial $\mathrm{CO}_{2}$ pressure & $(\mathrm{kPa})$ & 5.6 & $(0.7)$ & 5.8 & $(0.8)$ & NS \\
\hline Body mass index & $\left(\mathrm{kg} / \mathrm{m}^{2}\right)$ & 20.1 & (1.6) & 20.2 & (1.8) & NS \\
\hline Fat-free mass index & $\left(\mathrm{kg} / \mathrm{m}^{2}\right)$ & 15.2 & (1.5) & 15.5 & (1.2) & NS \\
\hline Pcak work load & (\%pred) & 42 & (22) & 40 & (11) & NS \\
\hline Habitual dietary intake/resting energ. & sy expenditure & 1.6 & $(0.6)$ & 1.5 & $(0.5)$ & NS \\
\hline Habitual protein intake & (energy \%) & 14 & (3) & 17 & (3) & 0.001 \\
\hline Serum protein & $(g / l)$ & 64 & (5) & 62 & (6) & NS \\
\hline Serum albumin & $(\mathrm{g} / \mathrm{l})$ & 43 & (5) & 43 & (4) & NS \\
\hline Serum glucose & $(\mathrm{mmol} / \mathrm{l})$ & 5.6 & $(0.5)$ & 5.5 & (1.3) & NS \\
\hline Serum C-reactive protein & $(\mu \mathrm{g} / \mathrm{l})$ & 9.5 & (18.6) & 4.5 & $(10.7)$ & NS \\
\hline Symptom score - SGRQ & (points) & 51 & (20) & 58 & (19) & NS \\
\hline Activity score - SGRQ & (points) & 60 & (22) & 70 & (21) & NS \\
\hline Impact score - SGRQ & (points) & 36 & (17) & 46 & (19) & 0.042 \\
\hline Total score - SGRQ & (points) & 46 & (15) & 55 & (17) & 0.028 \\
\hline
\end{tabular}

GCs: glucocorticosteroids. SGRQ: St. George`s Respiratory Questionnaire.

Differences in treatment efficacy between users and non-users of oral glucocorticosteroids PI-max improved to a higher extent after nutritional therapy in patients not treated with oral GCs compared to those treated by oral GCs (figure 2). As measures of exercise capacity, the improvements in peak work load (figure 3 ) and peak lactate/peak work load ratio (figure 4) were significantly impaired in patients to whom oral GCs were prescribed compared to patients to whom not. Finally, patients not on oral GCs exhibited a greater improvement in the symptom score of the SGRQ (figure 5).

Since age was significantly higher in patients treated with oral GCs. ANOVA was also performed with age as additional covariant. As a result. the difference in the change in Plmax was abolished $(\mathrm{p}=0.103)$, because age was a significant determinant of the difference in Pl-max change after nutritional therapy between users and non-users of oral GCs $(\mathrm{p}=0.010)$. Age did however not affect the difference in treatment response regarding peak work load, peak lactate/peak work load and symptom score. The prevalence of theophylline and ipratropium bromide use was excluded from the model. since they exerted no effect on the difference in response to nutritional therapy between users and non-users of oral GCs. No difference in treatment response was seen between patients to 
whom oral GCs were prescribed as maintenance medication and to whom not with regard to energy balance, body composition, serum proteins, peripheral muscle function and the 12 MWD (data not shown).

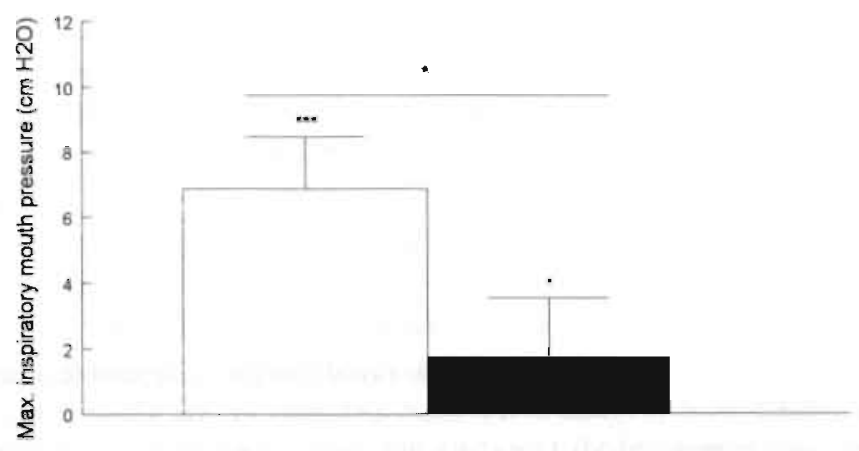

Figure 2: Change in maximal inspiratory mouth pressure after nutritional therapy incorporated in an eightweeks pulmonary rehabilitation program in non-users and users of oral glucocorticosteroids (GCs). Data are presented as mean (SEM). Open bars: non-users of oral GCs; Closed bars: users of oral GCs. ${ }^{*} \mathrm{p}<0.05,{ }^{* * *} \mathrm{p}<0.001$.

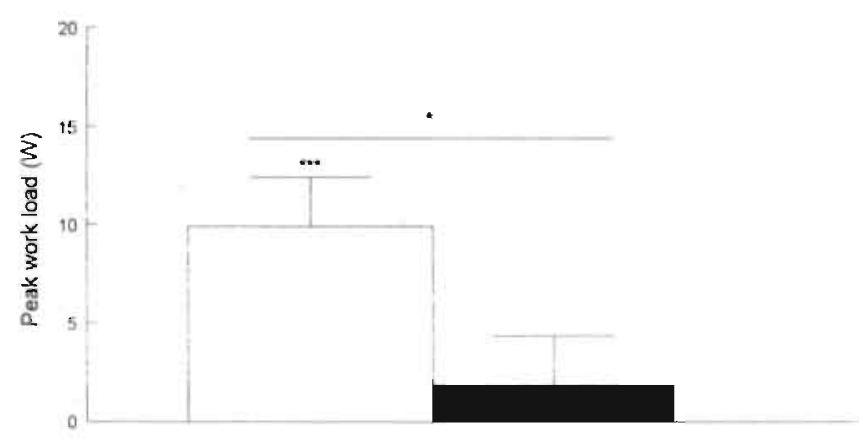

Figure 3: Change in peak work load after nutritional therapy incorporated in an eight-weeks pulmonary rehabilitation program in non-users and users of oral glucocorticosteroids (GCs). Data are presented as mean (SEM). Open bars: non-users of oral GCs: closed bars: users of oral GCs. ${ }^{*} \mathrm{p}<0.05,{ }^{* * *} \mathrm{p}<0.001$. 


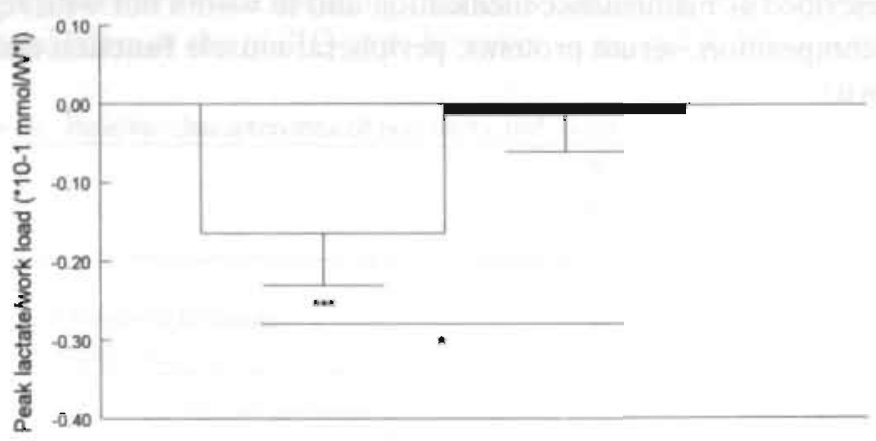

Figure 4: Change in peak lactate/peak work load ratio after nutritional therapy incorporated in an eightwceks pulmonary rehabilitation program in non-users and users of oral glucocorticosteroids (GCs). Data are presented as mean (SEM). Open bars: non-users of oral GCs: closed bars: users of oral GCs. ${ }^{*} p<0.05,{ }^{* * *} p<0.001$.

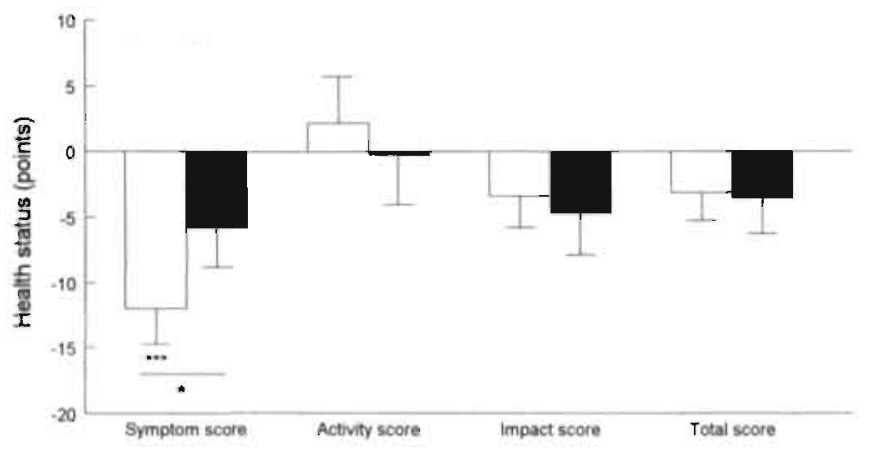

Figure 5: Change in health status as assessed by the St. George's Respiratory Questionnaire after nutritional therapy incorporated in an eight-weeks pulmonary rehabilitation program in non-users and users of oral glucocorticosteroids (GCs). Data are presented as mean (SEM). Open bars: non-users of oral GCs; closed bars: users of oral GCs. ${ }^{*} p<0.05,{ }^{* * *} p<0.001$ versus baseline

\section{Discussion}

The present study reveals that nutritional supplementation therapy embedded in a pulmonary rehabilitation program leads to increases in body composition and serum protein in patients with COPD. In addition, improvements in respiratory and peripheral muscle function, exercise capacity and health status were achieved. On the base of the actual change in dietary intake, the rise in FFM was as high as predicted. Body weight increase was attenuated compared to the predicted weight response due to a lower than 
expected rise in FM. The use of long-term, low-dose oral GCs as maintenance antiinflammatory medication significantly impaired the response to nutritional therapy with respect to respiratory muscle function, exercise capacity and health status.

Because of the deleterious effects of loss of body weight and muscle wasting on morbidity and mortality in COPD, the rationale for nutritional repletion therapy is well established. Ferreira et al. however concluded in their recent meta-analysis that nutritional supplementation therapy had no effect on improving anthropometric measures, lung function or functional exercise capacity in patients with stable COPD (23). Some remarks however must be placed with the conclusions of this meta-analysis. Firstly, interventions studies with a duration of two or more weeks were included. It is likely that two weeks of nutritional supplementation are probably too short to achieve substantial changes in physiological function.

Secondly, most of the nutritional intervention trials were not combined with exercise training. It can be expected that nutritional supplementation without an anabolic stimulus will only result in an expansion of FM (38). Physiological function will likewise not improve on nutrition alone, since FFM is an important determinant of functional performance. Furthermore, body weight gain consisting of FFM is a much more energy efficient process than expansion of FM, because for the gain of $1 \mathrm{~kg}$ of FM an energy intake of $9000 \mathrm{kcal}$ is required, relatively to $4000 \mathrm{kcal}$ for the gain of $1 \mathrm{~kg}$ of FFM.

Thirdly, in several studies, the offered nutritional supplementation therapy consisted of an inadequate energy intake, relative to energy requirements, needed for body weight gain. Nonresponse can furthermore be due to noncompliance to the therapy or to the inability of the patient to ingest the extra calories. So the possibility exists that the nutritional interventions themselves were not of sufficient magnitude to sort an effect. In other words, the failure of intervention instead of the failure to intervene might have been responsible for the nonresponse found in several intervention trials. In addition, underlying diseasespecific problems leading to inadequate metabolic handling could be present. Indeed, we recently revealed that patients not responding to nutritional therapy in terms of weight gain, were characterized by an elevated systemic inflammatory response, besides a higher age and relative anorexia. Baseline dietary intake was furthermore inversely correlated with soluble ICAM concentrations (10).

The results of our study were contradictive to the conclusions of Ferreira et al. (23). Body weight increased with $2.1 \mathrm{~kg}$ compared with the common effect in the meta-analysis of $1.65 \mathrm{~kg}$ and PI-max improved with $4 \mathrm{~cm} \mathrm{H}_{2} \mathrm{O}$ instead of $0.1 \mathrm{~cm} \mathrm{H} \mathrm{H}_{2} \mathrm{O}$. The rise in FFM of $1.1 \mathrm{~kg}$ in the present study was quite likely the result of the combined effects of nutrition with an adequate protein intake ( $1.9 \mathrm{~g} / \mathrm{kg}$ body weight $/ 24 \mathrm{~h})$ and training. Because the relative increases in respiratory muscle function and exercise capacity were higher than the relative increases in body composition, the nutritional intervention might have induced intracellular alterations. For instance, an increase in mitochondria in muscle fibers might favor oxidative capacity, thereby improving physiological function.

The net increase in dietary intake amounted up to $438 \mathrm{kcal} / 24 \mathrm{~h}$, which was $65 \%$ of the offered average $672 \mathrm{kcal} / 24 \mathrm{~h}$. The compliance to the nutritional supplementation was however set at a maximum, since there was a thorough control on the consumption of the 
supplements. They were labeled with the narne of the respective patient and handed out under supervision. Therefore the difference between the offered and the consumed amount of calories has to be the result of an adaptation in the intake of the regular meals.

The changes in body weight and FFM were predicted by a computer simulation model (24) on the base of the actual, net change in dietary intake, thereby taking into account the adaptation in the consuming of the regular meals. The increase in FFM was as high as expected, but the rise in body weight was attenuated with $0.5 \mathrm{~kg}$ due to a lower than expected increase in FM. The discrepancy between the predicted and actual body weight change might be explained by the assumption of the simulation model that other factors like REE and activity level remained at a constant level. Indeed REE did not change during the intervention, but the activity level of the patients was presumably increased compared to their situation at home, owing to the pulmonary rehabilitation program.

A methodological remark must be made about the design of the present study. We realize that the nutritional supplementation therapy was not performed in a placebo-controlled fashion. However, in the earlier nutritional intervention study of our group, it was established that pulmonary rehabilitation without nutritional supplementation therapy did not result in functional improvements in depleted patients with COPD (39). Therefore, it was regarded as unethical to restrain a part of our patients from nutritional supplementation.

The nutritional supplements were handed out three times daily: one between breakfast and lunch, one between lunch and dinner and one in the evening. In this way, overall dietary intake was spread over the day and excessive loading with nutrients was prevented. In the present study, carbohydrate-rich supplements were used. This was reflected in a relative increase in carbohydrate intake and a relative decrease in fat intake. The general belief about the use of carbohydrate-rich supplements in COPD is that they adversely affect the ventilatory system by increasing the ventilatory drive to a higher extent than fat-rich supplements (40). In contrast, our group previously observed that transcutaneous oxygen desaturation and dyspnea were more pronounced after a moderate fat compared with a carbohydrate-rich meal in patients with COPD (41). This might be explained by the longer gastric emptying after a high-fat compared to a moderate-fat meal (42). Furthermore, the temporarily decreased appetite and dietary intake during an acute exacerbation of COPD were particulary reflected in a low fat intake (8).

In addition, a recent investigation of our group found no adverse effects of a single energy load up to $500 \mathrm{kcal}$ on symptoms and functional capacity, except in a small subgroup of very cachectic patients (43). Also no differences were seen in energy metabolism or exercise capacity after a carbohydrate-rich compared with a fat-rich supplement at the most optimal caloric load $(250 \mathrm{kcal})$. Surprisingly, the pre-postprandial increase in shortness of breath was lower after the carbohydrate-rich compared to the fat-rich drink (43). The studies reviewed above yielded evidence for the preferability of carbohydraterich supplements for the repletion of depleted or weight-losing patients with COPD, especially because the patients were participating in a pulmonary rehabilitation program.

Nutritional depletion in COPD is associated with a reduced health status. Patients suffering from lean mass depletion exhibited significantly greater impairment in symptom, 
activity, impact and total SGRQ scores. The effects of tissue depletion on health status appeared however to be mediated through increased levels of dyspnea (4). In contrast, Mostert et al. revealed that the relation between tissue depletion and health status was independently of dyspnea, but instead mediated by a decreased exercise performance (44). In the present study, clinically significant improvements in symptom and impact score of the SGRQ were achieved after eight weeks of nutritional therapy. So the adverse effects of tissue depletion c.q. weight loss on health status were (in part) overcome by nutritional supplementation, probably mediated by the improvements in functional performance.

Remarkable differences in baseline characteristics were seen between patients using and not using oral GCs. At present, oral GCs are often prescribed as maintenance antiinflammatory medication in patients with COPD, despite insufficient evidence regarding their efficacy at this time. In the present study, the patients to whom oral GC were prescribed as maintenance medication were characterized by a higher age, an increased prevalence of theophylline and ipratropium bromide prescription and, interestingly, an impaired health status compared with patients to whom oral GCs were not prescribed. The patients on oral GCs did not differ from patients not using oral GCs with regard to baseline lung function or blood gases. Also no difference in baseline CRP, as a measure of the systemic inflammatory response, was revealed. In addition, although glucocorticosteroids are known to affect glycemic homeostasis (45), we found no evidence for a disturbed glucose metabolism due to oral GC use.

Overall, the disease severity, on the base of lung functional parameters, was not worse in oral GC users, so in fact there was no objective indication for oral GC prescription. However, no information was available about the indication for prescription of oral GCs in our patients, since treatment was started long before admission to the pulmonary rehabilitation center. Theoretically, the effect of oral GC administration on treatment outcome might reflect an indication bias. Nevertheless the question is raised whether the indication for systemic GC prescription was on the base of objective criteria or on the base of the subjective sensation of impaired health. Possibly the latter argumentation might have lead to an increase in the prescription of respiratory medication, including oral GCs.

In this report, despite of similar rises in dietary intake and body composition, use of oral GCs significantly attenuated the improvements in physiological function after nutritional therapy with respect to respiratory muscle function, exercise capacity and health status. Clinical evidence exists for adverse effects of systemic GC administration. Decramer et al. reported an inverse correlation coefficient between the average daily dose of oral GCs and respiratory and peripheral muscle strength in patients with COPD or asthma (22). There are no clear indications that systemic GCs induce a loss in overall muscle mass. In addition. Pouw et al. revealed that muscle energy metabolism was comparable in nonusers and long-term users of systemic GCs (46). In contrast, a worse qualitative muscle morphology was reported in patients with steroid-induced myopathy, indicated by an increased variation in diameter of fibers, several angular atrophic fibers and diffuse necrotic and basophilic fibers. In addition, an increased amount of connective tissue in between fibers was present (47). Whether chronically systemic GC administration is able 
to induce disturbances in protein balance, deserves further attention.

The fact that the functional improvements in the patients treated with oral GCs were impaired compared with patients not using oral GCs, despite of similar increases in body composition, might be explained by intrinsic abnormalities in muscle tissue due to GCs, that could not easily be overcome by nutrition alone. Firstly, muscle weakness and wasting induced by administration of systemic GCs significantly differs from the wasting effects induced by nutritional deprivation per se, the latter characterized by general atrophy of all fiber types (48). Experimental studies indicate that especially the glycolytic, type II fibers are susceptible for the deleterious effects of GCs (49). Secondly, fiber type shifts are reported in COPD. In the peripheral muscles, a decrease in the proportion of type I fibers corresponding with a relative increase in type II fibers was seen, indicating a shift from endurance towards a more strength function $(50,51)$. Concerning the respiratory muscles, there is evidence that the diaphragm of patients with severe COPD has undergone adaptations resulting in relative resistance to fatigue. The physiological alterations were accompanied by increases in fiber type I proportions and in slow isoforms of myofibrillar proteins (52). These adaptations, reflecting the new functional requirements of the diaphragm, are probably the result of the chronic rise in respiratory load and lung volume due to increasing lung hyperinflation (53).

Taken together, because GCs mainly affect type II fibers, the already compromised diaphragmatic function in COPD might be more sensitive, relative to the peripheral muscles, for the deleterious effects of long-term systemic GS use. This might explain why the improvement in PI-max after nutritional supplementation therapy was significantly attenuated by long-term, low-dose GC use and peripheral muscle function not. The higher improvements in peak work load and peak lactate/peak work load ratio in the patients not using oral GCs compared with patients long-term treated with oral GCs, might be a reflection of an increase in oxidative capacity. Hypothetically, the lower improvement in SGRQ symptom score in users of oral GCs was the result of the lower increase in PI-max and exercise capacity compared to non-users of oral GCs.

For the patients long-term treated with systemic GCs, other strategies are warranted in order to achieve functional improvements after nutritional therapy. For instance, anabolic steroids are able to neutralize the deleterious effects of endogenous and exogenous GCs by binding competition on the GC receptor (54). Experimental animal studies have shown that anabolic steroids can reverse the diaphragmatic muscle wasting and weakness specifically induced by systemically administered GCs, without respect to the underlying disease $(55,56)$.

In conclusion, nutritional supplementation therapy embedded in an eight-weeks, inpatient pulmonary rehabilitation program is an effective treatment strategy for depleted or weightlosing patients with COPD. The use of long-term, low-dose oral GCs as maintenance antiinflammatory medication however significantly impaired the response to nutritional supplementation with respect to respiratory muscle function, exercise capacity and health status. For this subgroup of patients, additional modes of interventions such as anabolic steroids must be evaluated. Since this study provided further evidence for the adverse side effects of systemic $G($ 's. clinicians should nevertheless carefully consider the prescription of ural $(\mathrm{i} C \mathrm{~S}$ as maintenance medication in COPD. 


\section{References}

1. Nishimura. Y., M. Tsutsumi, H. Nakata, T. Tsunenari, H. Maeda, and M. Yokoyama. 1995. Relationship between respiratory muscle strength and lean body mass in men with COPD. Chest 107:1232-1236.

2. Engelen, M.P.K.J., A.M.W.J. Schols, W.C. Baken, G.J. Wesseling, and E.F.M. Wouters. 1994. Nutritional depletion in relation to respiratory and peripheral skeletal muscle function in out-patients with COPD. Eur. Respir. J. 7:1793-1797.

3. Schols, A.M.W.J., P.B. Soeters, A.M. Dingemans, R. Mostert, P.J. Frantzen, and E.F.M. Wouters. 1993. Prevalence and characteristics of nutritional depletion in patients with stable COPD eligible for pulmonary rehabilitation. Am. Rev. Respir. Dis. 147:1151-1156.

4. Shoup, R., G. Dalsky, S. Warner, M. Davies, M. Connors, M. Khan, F. Khan, and R. ZuWallack. 1997. Body composition and health-related quality of life in patients with obstructive airways disease. Eur. Respir. J. 10:1575-1580.

5. Schols, A.M.W.J., J. Slangen, L. Volovics, and E.F.M. Wouters. 1998. Weight loss is a reversible factor in the prognosis of chronic obstructive pulmonary disease. Am. J. Respir. Crit. Care Med. 157 (6): 1791-1797.

6. Hunter, A.M., M.A. Carey, and H.W. Larsh. 1981. The nutritional status of patients with chronic obstructive pulmonary disease. Am. Rev. Respir. Dis. 124:376-381.

7. Schols, A.M.W.J., P.B. Soeters, R. Mostert, W.H. Saris, and E.F.M. Wouters. 1991. Energy balance in chronic obstructive pulmonary disease. Am. Rev. Respir. Dis. 143:1248-1252.

8. Vermeeren, M.A.P., A.M.W.J. Schols, and E.F.M. Wouters. 1997. Effects of an acute exacerbation on nutritional and metabolic profile of patients with COPD. Eur. Respir. J. 10 (10):2264-2269.

9. Schols, A.M.W.J., E.C. Creutzberg, W.A. Buurman, L.A. Campfield, W.H.M. Saris, and E.F.M. Wouters. 1999. Plasma leptin is related to proinflammatory status and dietary intake in patients with chronic obstructive pulmonary disease. Am. J. Respir. Crit. Care Med. 160:1220-1226.

10. Creutzberg. E.C., A.M.W.J. Schols. C.A.P.M. Weling-Scheepers, W.A. Buurman, and E.F.M. Wouters. 2000. Characterization of nonresponse to high caloric oral nutritional therapy in depleted patients with chronic obstructive pulmonary disease. Am. J. Respir. Crit. Care Med. 161:745-752.

11. Creutzberg. E.C.. A.M.W.J. Schols. F.C.M. Bothmer-Quaedvlieg, and E.F.M. Wouters. 1998. Prevalence of an elevated resting energy expenditure in patients with chronic obstructive pulmonary disease in relation to body composition and lung function. Eur. J. Clin. Nutr. 52 (6):396-401.

12. O. Donnell, D. and K.A. Webb. 1993. Exertional breathlessness in patients with chronic airflow limitation. The role of lung hyperinflation. Am. Rev. Respir. Dis. 148:1351-1357.

13. Creutzberg. E.C. A.M.W.J. Schols. F.C.M. Bothmer-Quaedvlieg. G. Wesseling, and E.F.M. Wouters. 1998. Acute effects of nebulized salbutamol on resting energy expenditure in patients with chronic obstructive pulmonary disease and in healthy subjects. Respiration 65 (5):375-380.

14. Nguyen. L.T., M. Bedu. D. Caillaud, B. Beaufrere, G. Beaujon. M. Vasson, J. Coudert, and P. Ritz. 1999. Increased resting energy expenditure is related to plasma TNF-alpha concentration in stable COPD patients. Clin. Nurr. 18:269-274

15. Baarends. E.M. A.M.W.J. Schols, D.L. Pannemans, K.R. Westerterp, and E.F.M. Wouters. 1997. Total free living energy expenditure in patients with severe chronic obstructive pulmonary disease $A m$. J. Respir Crit Carc Med 155:549-554

16. Baarends. E.M. A.M.W.J. Schols. K.R. Westerterp. and E.F.M. Wouters. 1997. Total daily energy expunditure relative to resting encrgy expenditure in clinically stable patients with COPD. Thorax 52 (9):780-785

17. Engelen, M.P.K.J. A.M.W.J. Schols. R.J.S. Lamers, and E.F.M. Wouters. 1999. Different patterns of chronic tissue wasting among patients with chronic obstructive pulmonary disease. Clin. Nutr. 18:275-280.

18. Morrison. W.L. J.N. Gibson. C. Scrimgeour, and M.J. Rennie. 1988. Muscle wasting in emphysema. Clin. Sci. $75: 415-420$.

19. Engelen M.P.K.J., N.E.P. Deutz, E.F.M. Wouters. A.M.W.J. Schols. 2000. Enhanced levels of whole body tumover in patients with chronic obstnuctive pulmonary disease. Am. J Respir. Crit. Care Med. 
(in press).

20. Schols, A.M.W.J., W.A. Buurman, A.J. Staal van den Brekel, M.A. Dentener, and E.F.M. Wouters. 1996. Evidence for a relation between metabolic derangements and increased levels of inflammatory mediators in a subgroup of patients with chronic obstructive pulmonary disease. Thorax 51:819-824

21. Kamischke, A, D.E. Kemper, M.A. Castel, M. Luthke, C. Rolf, H.M. Behre, H. Magnussen, and E. Nieschlag. 1998. Testosterone levels in men with chronic obstructive pulmonary disease with or without glucocorticoid therapy. Eur. Respir. J. 11:41-45.

22. Decramer, M., L.M. Lacquet, R. Fagard, and P. Rogiers. 1994. Corticosteroids contribute to muscle weakness in chronic airflow obstruction. Am. J. Respir. Crit. Care Med. 150:11-16.

23. Ferreira, I.M., D. Brooks, Y. Lacasse, and R.S. Goldstein. 2000. Nutritional Support for Individuals With COPD: A Meta-analysis. Chest 117:672-678.

24. Westerterp, K.R, J.H. Donkers, E.W. Fredrix, and P. Boekhoudt. 1995. Energy intake, physical activity and body weight: a simulation model. Br. J. Nutr. 73:337-347.

25. Americam thoracic society. 1995. Standards for the diagnosis and care of patients with chronic obstructive pulmonary disease. Am. J. Respir. Crit. Care Med. 152 (suppl.):S77-121

26. Landbo, C., E. Prescott, P. Lange, J. Vestbo, and T.P. Almdal. 1999. Prognostic value of nutritional status in chronic obstructive pulmonary disease. Am. J. Respir. Crit. Care Med. 160:1856-1861.

27. Quanjer, P.H. (ed.) 1993. Standardized lung function testing. Official statement of the European Respiratory Society. Eur. Respir. $J .6$ (suppl 16): 1-100.

28. Weir, J.B. 1949. New methods for calculating metabolic rate with special reference to protein metabolism. J. Phys. 109:1-9.

29. Stichting Nederlands Voedingsstoffenbestand. 1996. NEVO tabel, Voorlichtingsbureau voor de voeding, Den Haag.

30. Dumin, J.V., and J. Womersley. 1974. Body fat assessed from total body density and its estimation from skinfold thickness: measurements on 481 men and women aged from 16 to 72 years. Br. J. Nutr. 32:77-97.

31. Schols, A.M.W.J., E.F.M. Wouters, P.B. Soeters, and K.R. Westerterp. 1991. Body composition by bioelectrical-impedance analysis compared with deuterium dilution and skinfold anthropometry in patients with chronic obstructive pulmonary disease. Am. J. Clin. Nutr 53:421-424.

32. Westerterp, K.R., L. Wouters, and W.D. van Marken Lichtenbelt. 1995. The Maastricht protocol for the measurement of body composition and energy expenditure with labeled water. Obes. Res. 3 Suppl 1:49-57.

33. Black. L.F., and R.E. Hyatt. 1969. Maximal respiratory pressures: normal values and relationship to age and sex. Am. Rev. Respir. Dis. 99:696-702.

34. Jones, N.L. 1988. In Clinical exercise testing, 3rd edition ed. Saunders. Philadelphia. 158-185.

35. Jones, P.W. 1995. Issues concerning health-related quality of life in COPD. Che'st 107:187S-193S

36. Sauerwein, H.P., and J.A. Romijn. 1999. More consideration to dietary protein in the nutrition of chronically ill adults with tendency to weight loss. Ned. Tijdschr. Geneeskd. 143:886-889.

37. Altman, D.G., S.M. Gore, M.J. Gardner, and S.J. Pocock. 1983. Statistical guidelines for contributors to medical joumals. Br. Med. J. (Clin. Res. Ed.) 286:1489-1493.

38. Donahoe M., J. Mancino, J. Constantino, et al. 1994. The effect of an aggresive nutritional support regimen on body composition in patients with severe COPD and weight loss (abstract). Am. J. Respir. Crit. Care Med. 1994; 149: A313

39. Schols, A.M.W J., P.B. Soeters, R. Mostert, R.J. Pluymers, and E.F.M. Wouters. 1995. Physiologic effects of nutritional support and anabolic steroids in patients with chronic obstructive pulmonary disease. A placebo-controlled randomized trial Am. J. Respir. Crit. Care Med. 152:1268-1274.

40. Efthimiou, J., P.J. Mounsey, D.N. Benson, R. Madgwick, S.J. Coles, and M.K. Benson. 1992. Effect of carbohydrate rich versus fat rich loads on gas exchange and walking performance in patients with chronic obstructive lung disease. Thorax 47:451-456.

41. Schols, A.M.W J., R. Mostert, N. Cobben, P. Soeters, and E. F.M. Wouters. 1991. Transcutancous oxygen saturation and carbon dioxide tension during meals in paticnts with chronic obstructive pulmonary disease. Chest 100:1287-1292. 
42. Akrabawi, S.S., S. Mobarhan, R.R. Stoltz, and P.W. Ferguson. 1996. Gastric emptying, pulmonary function, gas exchange, and respiratory quotient after feeding a moderate versus high fat enteral formula meal in chronic obstructive pulmonary disease patients. Nutrition 12:260-265.

43. Vermeeren M.A.P., L.H. Nelissen, A van Lier, Z. Hofman, E.F.M. Wouters, A.M.W.J. Schols. 2000. Acute effects of different nutritional supplements on symptoms and functional capacity in patients with chronic obstructive pulmonary disease Am. J. Clin. Nutr. (in press).

44. Mostert R., A. Goris, C.A.P.M. Weling-Scheepers, E.F.M. Wouters, A.M.W.J. Schols. 2000. Tissue depletion and health related quality of life in patients with chronic obstructive pulmonary disease. Respir. Med. (in press).

45. Tataranni, P.A., R. Pratley, M. Maffei, and E. Ravussin. 1997. Acute and prolonged administration of glucocorticoids (methylprednisolone) does not affect plasma leptin concentration in humans. Int. J. Obes. Relat. Metab. Disord. 21:327-330.

46. Pouw E.M., E. Koerts-de Lang, H.R. Gosker, G. Freling. G.J. Vusse van der, E.F.M. Wouters, A.M.W.J. Schols. 2000. Muscle metabolic status in patients with severe COPD with and without longterm prednisolone Eur. Respir. J (in press).

47. Decramer, M., V. de Bock, and R. Dom. 1996. Functional and histologic picture of steroid-induced myopathy in chronic obstructive pulmonary disease. Am. J. Respir. Crit. Care Med. 153:1958-1964.

48. Koerts De Lang, E., A.M.W.J. Schols, E.F.M. Wouters, G. Gayan Ramirez, and M. Decramer. 1998. Contractile propertics and histochemical characteristics of the rat diaphragm after prolonged triamcinolone treatment and nutritional deprivation. J. Muscle Res. Cell. Motil. 19:549-555.

49. Wang. Y.M., T. Zintel, A. Vasquez, and C.G. Gallagher. 1991. Corticosteroid therapy and respiratory musclc function in humans. Am. Rev. Respir. Dis. 144:108-112.

50. Whittom. F., J. Jobin. P.M. Simard, P. Leblanc, C. Simard, S. Bernard, R. Belleau, and F. Maltais. 1998. Histochemical and morphological characteristics of the vastus lateralis muscle in patients with chronic obstructive pulmonary disease. Med. Sci. Sports Exercise 30 (10):1467-1474.

51. Satta. A., G.B. Migliori, A. Spanevello, M. Neri, R. Bottinelli, M. Canepari, M.A. Pellegrino, and C. Reggiani. 1997. Fibre types in skeletal muscles of chronic obstructive pulmonary disease patients related to respiratory function and exercise tolerance. Eur. Respir. J. 10:2853-2860.

52. Levine, S., L. Kaiser. J. Leferovich, and B. Tikunov. 1997. Cellular adaptations in the diaphragm in chronic obstructive pulmonary disease. N. Engl. J. Med. 337:1799-1806.

53. Mercadier, J. J.. K. Schwartz, S. Schiaffino, C. Wisnewsky, S. Ausoni, M. Heimburger, R. Marrash, R. Pariente, and M. Aubier. 1998. Myosin heavy chain gene expression changes in the diaphragm of patients with chronic lung hyperinflation. Am. J. Physiol. 274:L527-534.

54. Creutzberg. E.C. and A.M.W.J. Schols. 1999. Anabolic steroids. Curr. Opin. Clin. Nutr. Metah Care 2:243-253.

55. van Balkom. R.H.H.. P.N.R. Dekhuijzen, H.T.M. Folgering, J.H. Vecrkamp, H.T. van Moerkerk, J.A.M. Fransen. and G.L.A. van Herwaarden. 1998. Anabolic steroids in part reverse glucocorticoidinduced alterations in rat diaphragm. $J$. Appl. Physiol. 84 (5): 1492-1499.

56. van Balkom. R.H.. P.N. Dekhuijzen. H.F. van der Heijden, H.T. Folgering, J.A. Fransen, and C.L. van Henvaarden. 1999. Effects of anabolic steroids on diaphragm impairment induced by methylprednisolone in emphy'sematous hamsters. Eur. Respir. J. 13:1062-1069. 


\section{Chapter 7}

Characterization of nonresponse to high caloric oral nutritional therapy in depleted patients with chronic obstructive pulmonary disease

E. C. Creutzberg', A. M. W. J. Schols' ${ }^{1}$ C. A. P. M. Weling-Scheepers ${ }^{2}$, W. A. Buurman ${ }^{3}$, E. F. M. Wouters ${ }^{1}$

Departments of ${ }^{1}$ Pulmonology and ${ }^{3}$ Surgery, University Hospital Maastricht; ${ }^{2}$ Asthma Center Hornerheide, Horn; The Netherlands

American Journal of Respiratory and Critical Care Medicine 2000; 161: $745-752$

The study was supported by Numico Research BV, The Netherlands 


\section{Abstract}

Nutritional support can increase body weight and physiological function in COPD, but there is a proportion of non-responders. The aim of this prospective study was to describe the non-response to eight weeks of oral nutritional supplementation therapy (500-750 kcal/day extra), implemented in an inpatient pulmonary rehabilitation program, with respect to lung function, body composition, energy balance and systemic inflammatory profile in $24\left(16 \sigma^{2}\right)$ depleted patients with COPD. On base of the weight change after eight weeks, patients were divided into three groups (group 1: weight gain $<2 \%$ of baseline body weight, $n=5$; group 2 : $2 \% \leq$ weight gain $<5 \%, n=9$; group 3: weight gain $>5 \%, n=10$ ). While no differences were seen in lung function and body composition, group 1 was characterized by a higher age, a lower baseline dietary intake/resting energy expenditure (REE) ratio and a higher proportion users of continuous supplemental oxygen compared to group 3. In addition, group 1 exhibited higher baseline concentrations of fasting glucose and LPS-binding protein compared to group 2 and 3 . The concentrations of the soluble TNF-receptors 55 and 75 were elevated in group 1 and 2 compared to group 3. Furthermore, a significant, inverse correlation coefficient between baseline dietary intake and soluble ICAM was revealed $(r=-0.50, p=0.016)$. On linear regression analysis, age, baseline intake/REE ratio, sTNF-receptor 55 and extracellular/intracellular water $(\mathrm{ECW} / \mathrm{lCW})$ ratio were selected as independent, significant parameters contributing to a total explained variation of $78 \%$ in weight change after nutritional therapy. In conclusion, non-response to nutritional therapy in COPD is associated with ageing, relative anorexia and an elevated systemic inflammatory response. Further research is needed to investigate whether these factors contribute to eventual disturbances in intermediary metabolism as reflected by the increased glucose concentration and ECW/LCW ratio.

\section{Introduction}

Weight loss is a common feature in patients with chronic obstructive pulmonary disease (COPD) (1). The clinical importance of weight loss, particularly loss of fatfree mass (FFM), has been demonstrated in its adverse effects on physical performance (2) and quality of life (3). Moreover, weight loss and a low body weight are unfavorable prognostic factors in survival, independently of lung function (4).

Weight loss is generally considered as the result of an imbalance between energy intake and expenditure. Nlthough the dietary intake of patients with COPD does not differ from the recommended daily allowances (5), it is insufficient to match energy requirements in weight-losing patients. An increased resting energy expenditure (REE) has been reported in $26^{\circ} \%$ of the patients with COPD (6). Furthermore, also an elevation in total daily energy expenditure (TDEE), independently of REE, was observed in patients with COPD compared to healthy age-matched subjects (7).

Recent data have shown that a systemic inflammatory response is present in patients with COPD, based on elevated concentrations of acute phase proteins, tumor necrosis factor (TNF)- $\alpha$ receptors and soluble adhesion molecules in peripheral blood $(8,9)$. In addition, clear evidence for a relationship between weight loss and plasma TNF- $\alpha$ has been shown in COPD $(10,11)$. Besides the fact that inflammatory cytokines may 
induce anorexia such as observed in experimental studies (12), enhanced levels of acute phase proteins have been related to an increased REE in COPD (8).

In several studies an attempt has been made to reverse the negative energy balance in depleted patients with COPD with nutritional repletion therapy (13-16). A substantial number of patients failed to respond to the nutritional support, i.e., they were not able to gain body weight. The underlying causes of non-response to nutritional therapy are unknown. Non-response be due to factors such as noncompliance to the therapy, an inadequate energy intake relative to energy requirements, the inability of the patient to ingest the extra calories or underlying disease-specific problems leading to inadequate metabolic handling. The clinical relevance of non-response to nutritional therapy was emphasized by a recent nutritional intervention study that revealed weight gain as a significant, independent predictor of the mortality rate in patients with COPD (4).

Because of the huge impact of non-response on functional status and even on survival in COPD, we set out to unravel the underlying mechanisms, hypothesizing that nonresponse is related to biological characteristics. This hypothesis is firstly based on the results of the previous nutritional intervention study of our group in which patients received $420 \mathrm{kcal} /$ day ( $50 \%$ combined with anabolic steroid treatment) during eight weeks; in this study a substantial proportion of non-responders occurred, despite the fact that the study was performed in a controlled, inpatient setting so that factors such as noncompliance to the nutritional supplementation therapy could largely be excluded. Secondly, since weight loss is related to systemic inflammation in a part of the COPD population, we hypothesized that an elevated systemic inflammatory response might play a role in non-response to nutritional intervention therapy.

Therefore the present study aimed to investigate prospectively the non-response to eight weeks of oral nutritional therapy with respect to lung function impairment, body composition, energy balance and systemic inflammatory profile in depleted patients with COPD. The orally administered supplementation therapy consisted of 500-750 $\mathrm{kcal} / \mathrm{day}$ and was implemented as part of an inpatient pulmonary rehabilitation program.

\section{Patients and methods}

Patients

The study group consisted of 24 depleted patients (160, age mean (SD) 63 (8) years) with severe COPD (forced expiratory volume in one second; FEV : 33 (12)\% of predicted) consecutively admitted to a pulmonary rehabilitation center (Asthma Center Hornerheide, Hom, The Netherlands). Depletion was defined as a body mass index (BMI; body weight/height ${ }^{2}$ ) $\leq 23 \mathrm{~kg} / \mathrm{m}^{2}$ and/or a FFM-index (FFMI; FFM/height ${ }^{2}$ ) $\leq 15($ \% $) / 16\left(0^{\pi}\right) \mathrm{kg} / \mathrm{m}^{2}$.

Patients were included if they fulfilled the criteria for COPD according to the ATS guidelines (17). Furthermore, the $\mathrm{FEV}_{1}$ had to be less than $70 \%$ of the reference value and the increase in FEV after inhalation of a $B_{2}$-agonist less than $10 \%$ of the reference value. Patients with concomitant confounding diseases such as malignant disorders, gastrointestinal abnormalities, recent surgery or severe endocrine disorders were 
excluded. Only patients in a clinical stable condition (not suffering from a recent respiratory tract infection) and without clinical signs of edema were included in the study. The study was approved by the medical ethical committee of the University Hospital Maastricht and all subjects gave their informed consent.

\section{Body composition}

Body height was determined to the nearest $0.5 \mathrm{~cm}$ (Lameris, WM 715, Breukelen, The Netherlands) with subjects standing barefoot. Body weight was assessed with a beam scale to the nearest $0.1 \mathrm{~kg}$ (SECA, FRG) with subjects standing barefoot and in light clothing. The patients were asked to report the amount of weight loss in the last three months before admission to the rehabilitation center.

To measure total body water (TBW), each patient received in the late evening around 10 p.m. a weighted $(1 \mathrm{~g} / 1$ estimated TBW) oral dose of deuterium-labeled water $(99.84$ atom percent excess) mixed into $70 \mathrm{ml}$ water. For the estimation of extracellular water (ECW) $60 \mathrm{mg}$ sodium bromide/l predicted TBW was added to the deuterium dose. Just before and approximately $10 \mathrm{~h}$ later, after complete emptying of the bladder, urine and venous blood samples were obtained. Urine was analyzed for deuterium with an isotope ratio mass spectrometer according to the Maastricht protocol (18). Deuterium dilution space was calculated from the quantity of administered deuterium and the urine deuterium concentrations before and after complete distribution. TBW was calculated from deuterium dilution space by applying a conversion factor of 1.04 , which corrects for the exchange of labile hydrogen which occurs in humans during the equilibration period. FFM was calculated assuming a hydration factor of 0.73 . FM was calculated by subtracting FFM from body weight. The ECW compartment was analyzed using bromide detection. ECW was estimated by the corrected bromide space, which was calculated from the quantity of administered bromide and the serum bromide concentrations before and after complete distribution. Bromide concentration in serum ultrafiltrate was determined by HPLC according to the anion exchange chromatographic method (19). Intracellular water (ICW) was calculated by subtracting ECW from TBW.

Body weight and composition were assessed before the nutritional intervention and after eight weeks of treatment.

\section{Resting energy expenditure}

REE was measured in the early morning $(8.30$ a.m. $)$ by an open circuit indirect calorimetry system using a ventilated hood (Oxycon Beta ${ }^{\mathrm{x}}$, Mijnhardt, Bunnik, the Netherlands) before and after eight weeks of nutritional therapy. The system was calibrated daily at the start of the experiment. The accuracy of the system was regularly assessed using a methanol combustion test. Patients were in a fasting state for at least 10 hours and had a period of at least 30 minutes bed rest prior to the measurements. Patients received their maintenance medication 2 hours before measurements started. REE was measured when subjects were comfortably lying on a bed in supine position. REE was calculated from oxygen consumption and carbon dioxide production using the abbreviated Weir formula (20). 


\section{Dietary intake}

Before and in the last week of the nutritional therapy, patients were asked to register their food intake during four consecutive days to assess dietary intake. The obtained information was coded for computer nutrient analysis. The nutrient data base was derived from the Dutch food composition tables (21). Caloric intake was calculated by taking the average intake over four days. Dietary records were used since this method is more valid than the dietary history method; it gives a good representation of the actual consumption of calories because the food intake is averaged over four consecutive days so day-tot-day variations are largely discarded.

\section{Lung function}

$\mathrm{FEV}_{1}$ and inspiratory vital capacity (IVC) were calculated from the flow volume curve using a spirometer (Masterlab ${ }^{\star}$, Jaeger, Würzburg, Germany). Diffusing capacity for carbon monoxide (DLCO) was determined using the single breath method (Masterlab ${ }^{\star}$, Jaeger, Würzburg, Germany). Lung function parameters were expressed as percentage of reference values (22).

Blood was drawn from the brachial artery while the patients were breathing room air. Arterial oxygen tension $\left(\mathrm{PaO}_{2}\right)$ and carbon dioxide tension $\left(\mathrm{PaCO}_{2}\right)$ were analyzed on a blood gas analyzer (Radiometer, ABL 330, Copenhagen, Denmark). In addition the proportion of patients using continuous oxygen supply was assessed.

Lung function and blood gases were measured before and after the nutritional therapy.

\section{Collection and analysis of laboratory and inflammatory parameters}

Before and at eight weeks after nutritional intervention blood was obtained from the patients in the fasting state by venipuncture at $9 \mathrm{a} . \mathrm{m}$. and collected in evacuated blood collection tubes (Sherwood Medical, St Louis, Missouri, USA) containing EDTA. Plasma was separated from blood cells by centrifuging at $1000 \mathrm{G}$ for 10 minutes at $4^{\circ} \mathrm{C}$ within $2 \mathrm{~h}$ after collection. Separated plasma was again centrifuged at $1000 \mathrm{G}$ for 10 minutes at $4^{\circ} \mathrm{C}$. Plasma samples were stored at $-80^{\circ} \mathrm{C}$ until analysis. Most inflammatory markers were measured using sandwich ELISA (enzyme-linked immunosorbent assay) as described previously (23). Soluble tumor necrosis factor receptor 55 (sTNF-R55) and sTNF-R75 were measured using the monoclonal antibodies MR1-1 and MR2-2 for coating on immuno-assay plates (Nunc-Immuno Plate Maxisorp, Roskilde, Denmark). The standards used were recombinant human sTNF-R55 and sTNF-R75. Specific biotin-labeled polyclonal rabbit anti-human-sTNF$\mathrm{R} \operatorname{IgG}$ was used as detector reagens followed by streptavidin peroxidase conjugate (Dako, Glostrup, Denmark). Photospectrometry at $450 \mathrm{~nm}$ was performed using a micro ELISA autoreader. The detection limit of both assays was $100 \mathrm{pg} / \mathrm{ml}$. Polyclonal rabbit anti-rh lipopolysaccharide (LPS) binding protein (LBP) $\operatorname{lgG}$ was used as coating for the LBP ELISA and biotin-labeled polyclonal rabbit anti-rh LBP IgG was used for detection of LBP. The standard used was rh LBP. Washing and dilution was performed in buffer containing $40 \mathrm{mM} \mathrm{MgCl}$ to prevent disturbance by lipopolysaccharide of LBP recovery in the ELISA. The detection limit of the assay was $200 \mathrm{pg} / \mathrm{ml}$. For detection of the adhesion molecules soluble E-selectin and soluble intercellular adhesion molecule (sICAM), the monoclonal mouse antibodies ENA-1 and ENA-2 
were used respectively. Thereafter detection of the adhesion molecules took place by incubation with rabbit-anti-mouse biotin.

In addition, serum concentrations of glucose, albumin, creatinine and C-reactive protein (CRP) were determined by spectrophotometric analysis (Cobas Mira*; Hoffmann-La Roche, Basel, Switzerland).

\section{Nutritional intervention}

After baseline screening, the patients were treated during eight weeks with nutritional therapy consisting of three supplements per day containing 500-750 kcal in total. Patients were allowed to choose from an assortment of products with variable consistency and flavor (Nutridrink ${ }^{\star}$, Fortimel ${ }^{\star}$, Ensini ${ }^{\infty}$, Fortipudding ${ }^{*}$ ). The supplementation consisted for 61 energy percent of carbohydrates, for 19 energy percent of fat and for 20 energy percent of protein. The total protein content of the supplements together with that of the consumed regular meals was more than enough to ensure the amount of protein needed for optimum protein synthesis which is recommended for repletion of malnourished subjects $(1.5-1.7 \mathrm{~g}$ protein $/ \mathrm{kg}$ body weight/day) (24). The supplements were labeled with the name of each individual patient and handout thrice daily in order to have a stringent control on their intake. Patients were, in addition to taking the supplements, encouraged to continue the consumption of their regular meal portions as well.

The nutritional therapy was embedded in an eight weeks, standardized inpatient rehabilitation program, consisting of general physical training with particular attention to exercise in relation to daily activities, cycle ergometry, treadmill walking, swimming, sports and games. In addition, an educational program about the disease and medication use was given. When appropriate, psychologic or ergotherapeutic treatment was implemented. The metabolic cost of the exercise program was tried to be kept at the same level for all patients by adjusting the exercise activities to the physical performance state of each individual patient. For instance, the bicycle training was set at cycling twice daily twenty minutes on $50-70 \%$ of peak workload reached in a symptom-limited incremental bicycle ergometry test, during which workload was increased with $10 \mathrm{~W}$ every minute. The test was performed before, after four and after eight weeks, so the training workload had in general to be adjusted halfway the rehabilitation period. Because the exercise program was offered in an inpatient setting, there was a thorough control on the compliance of the patients to the different aspects of the program. Furthermore, since the patients in general trained together, they exerted an additional control on the compliance of each other.

\section{Statistics}

A computer simulation model on body weight and energy balance, taking into account the patient's age, sex, body composition and REE, was used for the estimation of the weight response after nutritional therapy (25). On base of this model. a mean gain in body weight of $25 \%$ was expected. Patients were divided into the following subgroups: 1) no weight gain, defined as a weight gain less than $2 \%$ of baseline body weight after eight weeks of intervention (group $1 ; n=5,40^{\prime}$ ): 2) expected weight gain, defined as a weight gain of $5 \%$ or more (group $3 ; n=10,4 \sigma^{\circ}$ ) and 3 ) medium weight 
gain defined as a weight gain between $2 \%$ and $5 \%$ (group $2 ; n=9,60^{\circ}$ ).

All parameters (baseline values and changes after the nutritional intervention) were firstly checked on normality of distribution. When variables were normally distributed and equal variances could be assumed, subsequently a Student's t-test for independent samples (in casu one-way analysis of variance (ANOVA) because three groups had to be compared) was applied to compare the differences between the three groups. The ANOVA test was followed by post-hoc analysis to test the least-significant differences between the groups by two-sample t-tests. When variables were not normally distributed, non-parametric analysis (Mann-Whitney $U$ test), was performed. Baseline differences between the three groups were given, when appropriate, after correction for sex and age by analysis of covariance. Differences in dichotomous variables, like sex, were statistically compared using the Chi-square test. Differences within the three groups before and after nutritional therapy were analyzed with the paired Student's ttest. After calculation of Pearson product moment correlation coefficients, a linear model was fitted to the data to enable the variables that contributed to the variation in weight change after nutritional therapy using multiple regression analysis. Significance was determined at the level of $5 \%$. Data are expressed as mean (SD). Data were analyzed according to the guidelines of Altman et al. (26), using SPSS/PC+ (statistical package for the social sciences, version 6.0 for Windows, SPSS Inc., Chicago, IL, U.S.A.).

\section{Results}

\section{Baseline characteristics}

Table 1 shows the baseline characteristics of the three groups with respect to body composition, energy balance and lung function. The extent of weight loss in the last three months was similar for group 1 and 2; group 3 exhibited however significantly more weight loss than group 2 . Although the three groups were not different in body weight, body composition or REE, baseline daily dietary intake was, also after adjustment for REE, significantly lower in group 1 compared to group 3 . This was predominantly associated with significant differences in total protein and fat intake (data not shown). No differences were seen in baseline lung function or arterial blood gases. The proportion users of continuous supplemental oxygen was however significantly higher in group I compared to group $3(2 / 5$ vs $0 / 10, p<0.05)$. In group 2 , 2/9 patients were on continuous supplemental oxygen supply.

In table 2 the baseline laboratory and inflammatory profile of the patients is shown. Fasting glucose was significantly higher in group 1 compared to group 2 and 3 . The concentration of the acute phase protein LBP was significantly higher in group I compared to group 2 and 3 . Group 1 and 2 exhibited significantly higher concentrations of sTNF-R55 and sTNF-R75 compared to group 3. The serum concentrations of creatinine, a relevant renal function parameter, were within the normal range for all subjects, indicating a normal kidney function and thus a normal clearance rate of the TNF-receptors. Therefore the differences in plasma concentrations of the TNF-receptors between the groups could not be attributed to abnormal clearance rates, but to differences in TNF-receptor production. 
Table 1: Baseline characteristics of the three groups: body composition, energy balance and lung function.

\begin{tabular}{|c|c|c|c|c|c|c|c|}
\hline \multirow{3}{*}{$\mathrm{n}$} & \multirow{3}{*}{$(\mathrm{m} / \mathrm{f})$} & \multicolumn{2}{|c|}{ Group 1} & \multicolumn{2}{|c|}{ Group 2} & \multicolumn{2}{|c|}{ Group 3} \\
\hline & & 5 & $(4 / 1)$ & 9 & $(6 / 3)$ & 10 & $(6 / 4)$ \\
\hline & & mean & $(S D)$ & mean & $(S D)$ & mean & $(S D)$ \\
\hline Age & (yrs) & 69 & (2) & 65 & $(8)$ & 59 & $(8)^{* *}$ \\
\hline Body weight & $(\mathrm{kg})$ & 58.6 & $(9.1)$ & 59.0 & (7.8) & 52.3 & $(5.9)$ \\
\hline Fat-free mass & $(\mathrm{kg})$ & 39.9 & $(4.6)$ & 42.9 & $(7.0)$ & 39.6 & $(5.9)$ \\
\hline Fat mass & (kg) & 18.6 & $(7.5)$ & 16.0 & $(6.2)$ & 12.7 & $(5.5)$ \\
\hline Extracellular/intraceliular w & ratio & 0.90 & $(0.16)$ & 0.88 & $(0.08)$ & 0.82 & $(0.14)$ \\
\hline Weight loss in last 3 months & $(\mathrm{kg})$ & -3.2 & $(2.8)$ & -0.2 & $(3.0)$ & -3.7 & $(3.3) \nRightarrow$ \\
\hline Dietary intake & (kcal/24h) & 1735 & (328) & 2143 & $(496)$ & 2365 & $(428)^{*}$ \\
\hline Resting energy expenditure & $(\mathrm{kcal} / 24 \mathrm{~h})$ & 1335 & (125) & 1433 & (174) & 1367 & $(171)$ \\
\hline Intake/resting energy expend & e ratio & 1.31 & $(0.31)$ & 1.50 & $(0.31)$ & 1.77 & $(0.29)^{*}$ \\
\hline Forced expir. volume in $1 \mathrm{~s}$. & (\% pred) & 33.9 & $(17.6)$ & 35.7 & $(12.4)$ & 32.2 & $(8.2)$ \\
\hline Inspiratory vital capacity & (\% pred) & 69.3 & (17.8) & 78.1 & $(17.7)$ & 81.2 & $(15.6)$ \\
\hline Diffusing capacity for $\mathrm{CO}$ & (\% pred) & 31.1 & $(20.8)$ & 45.8 & (15.9) & 46.2 & $(8.2)$ \\
\hline Arterial $\mathrm{O}_{2}$ pressure & $(\mathrm{mm} \mathrm{Hg})$ & 65.3 & $(6.8)$ & 74.3 & (12.8) & 75.0 & $(12.0)$ \\
\hline Arterial $\mathrm{CO}_{2}$ pressure & $(\mathrm{mm} \mathrm{Hg})$ & 39.0 & $(3.8)$ & 41.3 & $(6.0)$ & 42.0 & $(4.5)$ \\
\hline
\end{tabular}

Group 1: weight gain $<2 \%$, group 2: $2 \% \leq$ weight gain $<5 \%$, group 3 : weight gain $\geq 5 \%$.

${ }^{*} p<0.05,{ }^{* *} p<0.01$ versus group $1 ; \# p<0.05$ versus group 2

Data are given after correction for sex and age

Table 2: Baseline characteristics of the three groups: laboratory and inflammatory parameters.

\begin{tabular}{|c|c|c|c|c|c|}
\hline \multirow[b]{2}{*}{ Fasting glucose } & \multirow[b]{2}{*}{$(\mathrm{mmol} / /)$} & $\begin{array}{l}\text { Group 1 } \\
\text { mean (SD) }\end{array}$ & $\begin{array}{l}\text { Group } 2 \\
\text { mean }(S())\end{array}$ & \multicolumn{2}{|c|}{$\begin{array}{l}\text { Group } 3 \\
\text { mean (SD) }\end{array}$} \\
\hline & & $(1.5)$ & $(0.5)^{*}$ & 5.7 & $(0.9)^{*}$ \\
\hline Albumin & $(g / l)$ & $38.4 \quad(2.7)$ & $43.2 \quad(4.7)$ & 40.4 & $(3.7)$ \\
\hline C-reactive protein & $(\mu \mathrm{g} / \mathrm{ml})$ & $15.0(21.1)$ & $(15.6)$ & 9.1 & $(21.2)$ \\
\hline LPS-binding protein & $(\mu \mathrm{g} / \mathrm{ml})$ & $18.5 \quad(7.8)$ & $11.6(2.7)^{*}$ & 11.8 & $(5.5)^{*}$ \\
\hline Soluble E-select in & $(\mathrm{ng} / \mathrm{ml})$ & $24.8 \quad(9.3)$ & $23.5(16.4)$ & 18.6 & $(3.9)$ \\
\hline Soluble ICAM & $(\mathrm{ng} / \mathrm{ml})$ & $80.9(21.5)$ & $66.5 \quad(16.5)$ & 65.5 & $(25.9)$ \\
\hline Soluble TNF-receptor 55 & $(\mathrm{ng} / \mathrm{ml})$ & $0.60 \quad(0.26)$ & $0.59 \quad(0.19)$ & 0.35 & $(0.13)^{* \# \#}$ \\
\hline Soluble TNF-receptor 75 & (ng/ml) & $1.67(0.58)$ & $1.70 \quad(0.44)$ & 1.05 & $(0.36)^{* \# \#}$ \\
\hline
\end{tabular}

Group 1: weight gain $<2 \%$, group 2: $2 \% \leq$ weight gain $<5 \%$. group 3 : weight gain $>5 \%$.

* $p<0.05$ versus group 1 ; \#\# $p<0.01$ versus group 2 .

Data are given after correction for sex and age.

In order to determine whether the tendency towards a higher ECW/ICW ratio as seen in the non-responders was related to tissue depletion, we correlated baseline ECW/ICW ratio with baseline FFMI. Indeed a significant, inverse correlation coefficient was found $(r=-0.54, \mathrm{p}=0.006)$. The proposed link between a systemic inflammatory response and anorexia was investigated by correlation analysis of the inflammatory parameters at baseline with baseline dietary intake. The concentration slC.AM significantly, inversely correlated with dietary intake $(r=-0.50, p=0.016)$. In figure 1 and 2 scatter plots of the respective correlation coefficients are shown. 


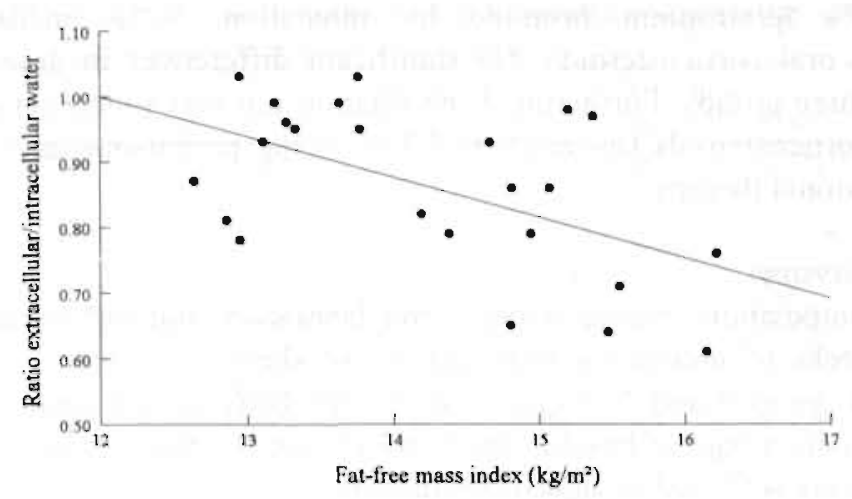

Figure 1: Scatter plot of baseline fat-free mass index (fat-free mass/height ${ }^{2}$ ) and extracellular water/intracellular water ratio. Correlation coefficient: $-0.54, p=0.006$.

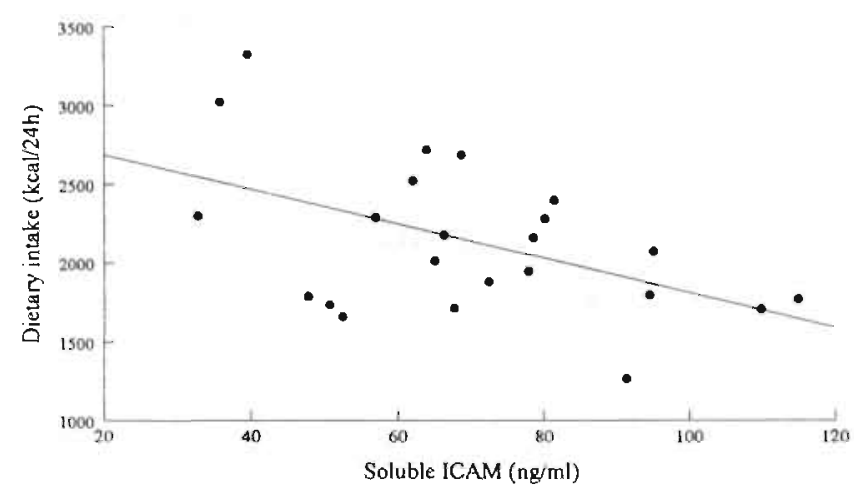

Figure 2: Scatter plot of baseline soluble ICAM and dietary intake. Correlation coefficient: -0.50 , $p=0.016$.

In order to investigate whether non-response was related to the medication that the patients used, the maintenance medication use of the patients was determined. $96 \%$ of the patients were using $\beta_{2}$-sympathicomimetics by inhalation, $67 \%$ oral theophyllines, $83 \%$ ipratropium bromide by inhalation, $92 \%$ inhalation corticosteroids and $54 \%$ oral corticosteroids. No significant differences in drug use were seen between the three groups. Furthermore, no relationship was found between the daily dose of oral corticosteroids (mean (SD) 7.7 (3.0) mg prednisone/day) and weight change after nutritional therapy.In order to investigate whether non-response was related to the medication that the patients used, the maintenance medication use of the patients was determined. $96 \%$ of the patients were using $B_{2}$-sympathicomimetics by inhalation, $67 \%$ 
oral theophyllines, $83 \%$ ipratropium bromide by inhalation, $92 \%$ inhalation corticosteroids and $54 \%$ oral corticosteroids. No significant differences in drug use were seen between the three groups. Furthermore, no relationship was found between the daily dose of oral corticosteroids (mean (SD) 7.7 (3.0) $\mathrm{mg}$ prednisone/day) and weight change after nutritional therapy.

\section{Response to mutritional therapy}

The changes in body composition, energy balance and laboratory and inflammatory mediators after eight weeks of nutritional intervention are shown in table 3 . Body weight increased only in group 2 and 3 . Figure 3 shows the body weight course per two weeks expressed as percentage of baseline body weight for the three groups. The changes in body weight were reflected in significant increases in FFM in group 2 and 3 after eight weeks but not in group 1. Although all groups showed adjustment in the intake of their regular meals, group 2 and 3 significantly elevated their total dietary intake while the net rise in dietary intake in group 1 did not reach significance despite a significant rise in carbohydrate intake (48 (21) g/day, $p<0.05$ ). Only in group $3 \mathrm{REE}$ increased significantly, but this increase was eliminated after correction for the rise in FFM. In group 1, a significant rise in serum albumin was seen after eight weeks. The ratio $\mathrm{ECW} / \mathrm{ICW}$, serum glucose and the inflammatory parameters remained unchanged in all groups after the nutritional intervention.

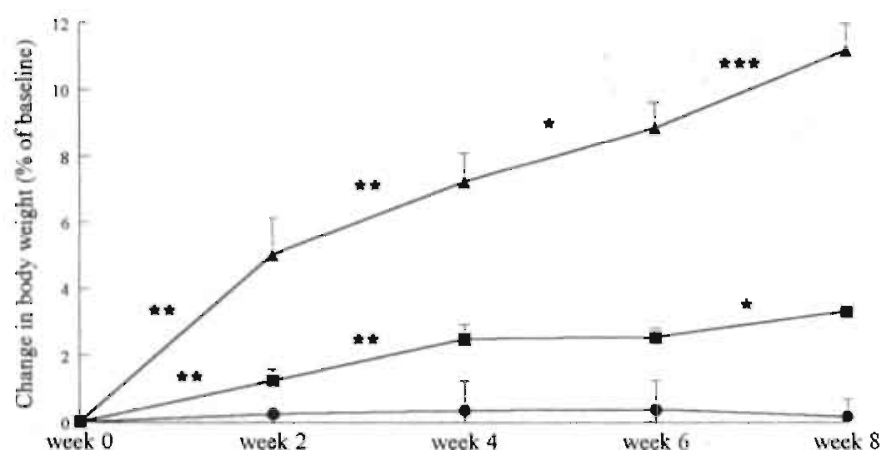

Figure 3: Body weight course per two weeks expressed as percentage of baseline body weight. Circles: group 1 (weight gain $<2 \%$ ), squares: group $2(2 \% \leq$ weight gain $<5 \%)$, triangles: group 3 (weight gain $\geq 5 \%$ ). ${ }^{*} p<0.05,{ }^{* *} p<0.01,{ }^{* * *} p<0.001$. Data are given as mean (SEM) 
Table 3: Changes in body composition, energy balance and laboratory and inflammatory mediators after eight weeks of nutritional intervention.

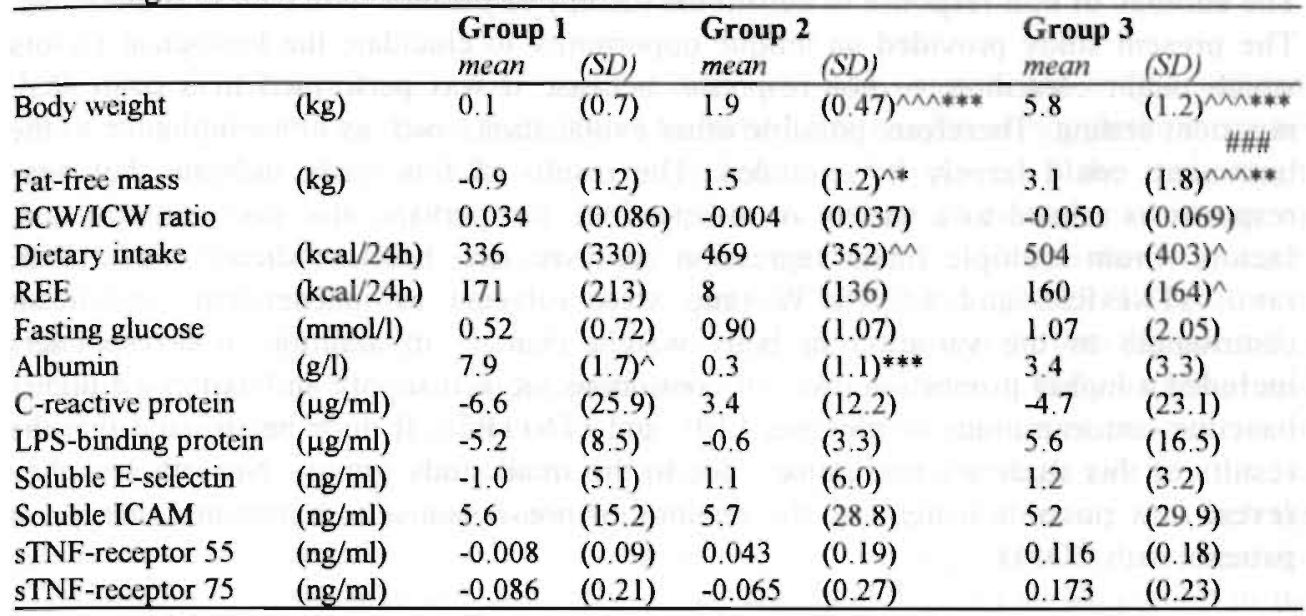

Group l: weight gain $<2 \%$, group $2: 2 \% \leq$ weight gain $<5 \%$, group 3 : weight gain $>5 \%$.

$\mathrm{ECW} / \mathrm{ICW}$ ratio: extracellular/intracellular ratio.

REE: resting energy expenditure.

${ }^{\wedge} p<0.05, \wedge p<0.01, \wedge \wedge p<0.001$ versus baseline.

${ }^{*} p<0.05,{ }^{* *} p<0.01,{ }^{* * *} p<0.001$ versus group 1 .

\#\#\# $\mathrm{p}<0.001$ versus group 2.

To investigate which factors significantly contributed to the variation in body weight change after nutritional therapy, a stepwise multiple linear regression analysis was performed after calculation of the Pearson product moment correlation coefficients. Age and baseline dietary intake/REE ratio, sTNF-R55 and ECW/ICW ratio were selected as independent, significant parameters contributing to a total explained variation of $78 \%$ in weight change after nutritional intervention (table 4 ). The variables weight loss in the last three months, serum glucose, LBP and sTNF-R75 were excluded from the model. Although sTNF-R75 also significantly correlated with weight change, regression analysis without sTNF-R55 (because the concentrations of sTNF-R55 and sTNF-R75 were significantly correlated; $r=0.90, p<0.001$ ) did however not reveal sTNF-R75 as a significant parameter.

Table 4: Multiple linear regression analysis to investigate which baseline parameters significantly contributed to the variation in weight change after nutritional intervention.

\begin{tabular}{lllll}
\hline Prediction variables & B & SE of B & Cumulative $\mathbf{R}^{2}$ & $\overline{\text { p-value }}$ \\
\hline Age & -0.09 & 0.04 & 0.42 & 0.0401 \\
lntaki/resting energy expenditure ratio & 3.49 & 0.85 & 0.57 & 0.0006 \\
Soluble TNF-receptor 55 & -5.09 & 1.38 & 0.67 & 0.0016 \\
Extracellular/intracellular water ratio & -7.16 & 2.49 & 0.78 & 0.0101 \\
Weight loss in the last 3 months & & & & NS \\
Glucose & & & & NS \\
LPS-binding protein & & & & NS \\
Soluble TNF-receptor 75 & & & NS \\
\hline
\end{tabular}




\section{Discussion}

The etiology of non-response to nutritional therapy in patients with COPD is unknown. The present study provided an unique opportunity to elucidate the biological factors which might contribute to non-response, because it was performed in a controlled, inpatient setting. Therefore, possible other explanations such as noncompliance to the treatment, could largely be excluded. The results of this study indicate that nonresponse is related to a variety of independent, but perhaps also partly interrelated, factors. From multiple linear regression analysis, age, baseline dietary intake/REE ratio, STNF-R55 and ECW/ICW ratio were selected as independent, significant contributors to the variation in body weight change. In addition, non-responders included a higher proportion users of continuous oxygen supply and expressed higher baseline concentrations of glucose, LBP, and sTNF-R75. It must be stressed that the results of this study are preliminary due to the small study groups. Nevertheless they reveal new possible insights in the etiology of non-response to nutritional therapy in patients with COPD.

Age contributed for a significant part to the variation in weight change after nutritional therapy and was significantly higher in the non-responders. Ageing is known to be related to decreases in REE and in energy expenditure for activities in healthy subjects, resulting in a lower dietary intake. The lower energy expenditure in the elderly is predominantly related to the decline in FFM due to a reduced physical activity (27), possibly accompanied by an alteration in tissue metabolism and/or an adaptation in REF: due to a lower daily caloric intake (28). However, the lower dietary intake in the non-responders in the present study was independent of age and no differences in REE or in the amount of metabolically active tissue (FFM) were seen between the groups. In addition, instead of an adaptation in REE due to weight loss, an increased REE and TDEE have been reported in patients with $\operatorname{COPD}(6,7)$. Therefore other factors must be involved in the non-response to nutritional therapy.

No differences were seen in baseline body weight or body composition. Despite the comparable REE and the same degree of weight loss, baseline dietary intake was significantly lower in the non-responders compared to the responders, also after adjustment for REE. In animal studies exposure to LPS, TNF- $\alpha$ or interleukin (IL)-l $\alpha$ induces anorexia and weight loss (12). In this study we also showed evidence for a relationship between the relative anorexia seen in the non-responders and an enhanced systemic inflammatory response. In the absence of adequate characterization of systemic inflammation in COPD, a selection of inflammatory parameters was analyzed for the present study. Although one would expect a relationship between dietary intake and the sTNF-receptors, we could not reveal such conclation coefficients. Instead, a significant, inverse correlation between baseline dietary intake and IICAM was found. Soluble adhesion molecules like sICAM and sE-selectin may reflect systemic inflammatory activity and are reported to be elevated in COPD (9). The fact that sICAM conelated with dietary intake and SE-selectin did not, can be possibly explained by the fact that E-selectin is thought to underlie the initial leukocyte rolling on the vessel wall in areas of inflammation, while ICAM is thought to be present in 
tissues throughout the body and may therefore, more than E-selectin, reflect the presence of a systemic inflammatory response (9).

The rise in dietary intake after eight weeks was only significant in the patients exhibiting a weight gain more than $2 \%$ of baseline body weight, although the mean net increase in intake did not differ between the groups. The power of the study might have been insufficient to reveal a significance in the change in dietary intake in group 1. However, on base of the substantial rise in dietary intake of $336 \mathrm{kcal} /$ day in group 1 , which is equivalent to two slices of wheat bread with butter and cheese, and because of the fact that the percentage of patients suffering from recent weight loss did not differ between group 1 and the well-responding group 3 , a higher gain in body weight would be cxpected in group 1. It might easily be concluded that the failure of the patients in group 1 to gain weight, was due to the inability to consume enough calories, i.e., to noncompliance to the therapy. However, because of the inpatient setting in which the study was performed, there was a strict control on the consumption of the supplements. Therefore the lower increase in dietary intake was likely due to an adaptation in the consumption of the regular meals, on which we had less control despite the fact that the patients were encouraged to consume every meal completely. So the gap between the offered $500-750 \mathrm{kcal} /$ day and the rise in dietary intake of $336 \mathrm{kcal} /$ day in group 1, compared with a gap of $\pm 250 \mathrm{kcal} /$ day in group 2 and 3 , was predominantly due to less compliance to the consumption of the regular meals and not to noncompliance to the therapy per se, namely the nutritional supplementation.

Another explanation for the non-response to the nutritional intervention, could be a variation in the metabolic load of the exercise program. It must be noted, however, that the exercise program was standardized for all patients; the training activities were adjusted to the physical performance state of each individual patient. For instance, the bicycle training load was set at $50-70 \%$ of the peak workload reached during an incremental bicycle ergometry test. This test was performed before, after four and after eight weeks, so the training workload had in general to be adjusted halfway the rehabilitation period. The individual adjustment of the exercise program implicates that all patients were trained at the same 'metabolic' intensity level of exercise. Because the exercise program was given in an inpatient setting, there was furthermore a thorough control on the compliance of the patients to the different aspects of the exercise program. In addition, since the patients in general trained together, they exerted an additional control on the compliance of each other.

Another possible covariate of the observed differences in weight response between the three groups, could be an eventual discrepancy regarding the translation from training load intensity to the actual activity-related energy expenditure for each individual patient. In other words, the energy efficiency might have been different between the patients. Indeed in a previous study of our group, an increased TDEE was observed in patients with COPD compared to age-matched control subjects, independently of REE, which was probably related to an increased energy expenditure for activities (7). The fact that the patients in group 1 and 3 were in a state of negative energy balance prior to admission to the pulmonary rehabilitation center, despite a mean dietary intake/RF'E ratio ranging from 1.3 to 1.8 , might be indicative for the presence of an elevated 
wasting of energy. The mechanisms behind this weight loss, however, were probably different for these two groups. The reason for the recent weight loss of the patients in group 3 was likely an inadequate caloric intake relative to increased energy requirements, that could easily be overcome by offering them nutritional supplementation alone. In contrast, the patients in group 1 seemed to be compromised with additional problems related to their decreased dietary intake and/or to inadequate metabolic handling.

Because of the stringent control on the compliance to the nutritional therapy and the standardization of the pulmonary rehabilitation program, other (biological) factors had to be involved in the etiology of non-response to nutritional therapy. In other words, other explanations must be sought for the much lower increase in body weight than would have been expected on base of the change in dietary intake in group 1.

The phenomenon of non-response might be related to the effects of the enhanced systemic inflammatory profile on metabolism. Baseline concentrations of the acute phase protein LBP were elevated, together with a trend towards a higher CRP. The concentrations of STNF-R55 and sTNF-R75 were significantly higher in the patients with a weight gain less than $5 \%$ versus the patients with a weight gain of $5 \%$ or more. Furthermore, sTNF-R55 significantly contributed to the variation in weight change after eight weeks, independently of baseline dietary intake. Previous studies have shown evidence for a relationship between weight loss and the presence of a systemic inflammatory response in patients with COPD. Increased serum concentrations of the inflammatory mediator TNF- $\alpha$ were found in patients with COPD who had involuntarily lost weight in comparison to weight-stable patients and healthy subjects (10). Furthermore, the LPS-induced TNF- $\alpha$ production of monocytes was higher in weight-losing patients with COPD compared to patients not suffering from weight loss and to healthy subjects (11). A previous study of our group reported increased concentrations of the acute phase reactant proteins CRP and LBP in hypermetabolic patients with COPD compared to normometabolic patients. In this hypermetabolic subgroup the patients with an elevated CRP had elevated concentrations of LBP, IL-8, s'INF-R55 and sTNF-R75 and expressed a lower FFM (8).

The presence of an elevated inflammatory state has consequences for the protein need due to an enhanced protein synthesis rate in the liver. Seven days exposure to LPS, TNF- $\alpha$ or IL $-1 \alpha$ in rats produced anorexia and weight loss and accelerated peripheral protein wasting while preserving liver protein content. In contrast, when the animals wcre only pair-fed or starved, loss of liver proteins and relative preservation of skeletal muscle protein occurred (12). It is likely that the patients in our study group, especially thosc with an enhanced inflammatory state, exhibited a protein balance in favor of the liver content. Therefore it is important that protein intake is adequate in order to increase or preserve peripheral muscle tissue. The finding that the concentrations of the acute phase proteins, adhesion molecules and inflammatory cytokines did not change after the nutritional intervention, except for the rise in serum albumin in group I, emphasizes that the increased protein need will stay present. In addition, the fact 
that the concentrations of the inflammatory markers did not change, provides evidence against the hypothesis that anorexia and cachexia are causes of an elevated systemic inflammatory response rather than the consequences (29).

The variation in baseline ECW/ICW ratio significantly contributed for $11 \%$ to the variation in body weight change after nutritional intervention. In line, a tendency towards a higher ECW/ICW ratio was seen in the patients who failed to respond. This shifting in body water compartments can possibly be extrapolated to a decreased cellular hydration state resulting in cellular shrinkage. Cellular shrinkage can be triggered by a variety of factors, such as uremia, inflammatory state and stress conditions resulting in hormonal alterations. In the absence of differences in uremic levels, the reported enhanced inflammatory state of the non-responders could have induced an increase in ECW/ICW ratio. Cellular shrinkage in turn acts as a catabolic signal triggering breakdown of protein and glycogen on the one hand and the expression of gluconeogenic enzymes on the other, together resulting in net protein breakdown (30). This proposed catabolic response can explain the inverse relationship between baseline ECW/ICW ratio and FFMI, the latter as a measure of functional tissue depletion, although one must take into account that the found increase in ECW was relative to $\mathrm{ICW}$.

Non-responders exhibited a significantly higher fasting serum concentration of glucose compared to the responders, possibly reflecting the presence of insulin resistance. The scarce data on insulin and carbohydrate metabolism in patients with COPD are however conflicting. Jacobsson et al. reported a lower skeletal muscle glycogen concentration, assessed by a biopsy of the quadriceps femoris, in hypoxemic patients with COPD compared to a control group; no evidence for insulin resistance of the peripheral tissues was however found in this COPD group (31). Hjalmarsen et al. reported in contrast an altered glucose metabolism in severely hypoxemic patients with COPD (32).

The proportion of patients who were on continuous oxygen support was significantly higher in the non-responding compared to the responding group. (hronic or even intermittent hypoxemia is reported to affect intermediary metabolism (33). Hypoxia is also a stringent depressor of protein synthesis (34). Anorexia, together with a decrease in the growth rate of muscle tissue, was found to be another effect of hypoxia, which could not be attenuated by supplementation of extra protein (35). Hypoxia has furthermore a potentiating effect on the in vitro production of inflammatory cytokines (IL- 1 and TNF- $\alpha$ ) after endotoxin stimulation that was postulated to be due to a decreased anti-inflammatory prostaglandin $\mathrm{PGE}_{2}$ synthesis $(36,37)$.

Further studies are required in order to investigate whether the enhanced glucose levels and the higher use of additional oxygen represent disturbances in intermediary metabolism and hypoxemia respectively, as well as the possible relation with nonresponse to nutritional therapy. Furthermore it must be stressed that the patient population studied in this report was too small to rely on for definitive recommendations. 
In conclusion, despite the overall positive effect of high-caloric nutritional support incorporated in a pulmonary rehabilitation program in depleted patients with COPD, a substantial proportion of non-responders was revealed. Non-response in COPD can be considered as multifactorial problem. Beside the presence of an acute phase response and an elevated systemic inflammatory response, other factors showed to play a role: ageing, relative anorexia an shifting in body water compartments. The findings of this study, although preliminary due to the limited size of the study population, indicate the complexity of metabolic disturbances in patients with COPD characterized by a systemic inflammatory response. The results may have important implications for the treatment of pulmonary cachexia, especially concerning the patients not responding to oral nutritional therapy. Further research is needed to investigate which options will be appropriate in the treatment of depleted patients with COPD not responding to highcaloric nutritional support.

\section{References}

1. Schols AMWJ, PB Soeters, AM Dingemans, R Mostert, PJ Frantzen, EFM Wouters. 1993 Prevalence and characteristics of nutritional depletion in patients with stable COPD eligible for pulmonary rehabilitation. Am. Rev. Respir. Dis. 147: 1151-1156.

2. Wilson DO, RM Rogers, EC Wright, NR Anthonisen. 1989. Body weight in chronic obstructive pulmonary disease. The National Institutes of Health Intermittent Positive-Pressure Breathing Trial. Am. Rev. Respir. Dis. 139: 1435-1438.

3. Shoup R, G Dalsky, S Wamer, M Davies, M Connors, M Khan, F Khan, R ZuWallack. 1997. Body composition and health-related quality of life in patients with obstnuctive airways disease. Eur. Respir. J. 10: 1575-1580.

4. Schols AMWJ, J Slangen, L Volovics, EFM Wouters. 1998. Weight loss is a reversible factor in the prognosis of chronic obstructive pulmonary disease. Am. J. Respir. Crit. Care Med. 157: 1791-1797.

5. Hunter AM, MA Carey, HW Larsh. 1981. The nutritional status of patients with chronic obstructive pulmonary disease. Am. Rev. Respir. Dis. 124: 376-381.

6. Creutzberg EC, AMWJ Schols, FCM Bothmer-Quaedvlieg, EFM Wouters. 1998. Prevalence of an elevated resting energy expenditure in patients with chronic obstructive pulmonary disease in relation to body composition and lung function. Eur. J. Clin. Nutr. 52: 396-401.

7. Baarends EM, AMWJ Schols, DL Pannemans, KR Westerterp, EFM Wouters. 1997. Total free living energy expenditure in patients with severe chronic obstructive pulmonary disease. $A m . J$. Respir. Crit. Care Med. 155: 549-554.

8. Schols AMWJ, WA Buurman, AJ Staal-van den Brekel, MA Dentener, EFM Wouters, 1996. Evidence for a relation between metabolic derangements and increased levels of inflammatory mediators in a subgroup of patients with chronic obstructive pulmonary disease. Thorax 51: 819 824.

9. Riise GC, S Larsson, CG Lofdahl, BA Andersson. 1994. Circulating cell adhesion molecules in bronchial lavage and serum in COPD patients with chronic bronchitis. Eur. Respir. J. 7: 16731677.

10. Di Francia M, D Barbier, JL Mege. J Orehek. 1994. Tumor necrosis factor-alpha levels and weight loss in chronic obstructive pulmonary disease. Am. J. Respir. Crit. Care Med. 150: 14531455.

11. De Godoy I, M Donahoe. WJ Calhoun. J Mancino. RM Rogers. 1996. Elevated TNF-alpha production by peripheral blood monocytes of weight-losing COPD patients. Am. J. Respir. Cril. Care Med. 153: 633-637.

12. Fong Y, LL Moldawer, M Marano, H Wei, A Barber. K Manogue. KJ Tracey, G Kuo. DA Fischman, A Cerami et al. 1989. Cachectin/TNF or IL-I alpha induces cachexia with 
redistribution of body proteins. Am. J. Physiol. 256: R659-R665

13. Lewis MI, MJ Belman, L Dorr Uyemura. 1987. Nutritional supplementation in ambulatory patients with chronic obstructive pulmonary disease. Am. Rev. Respir. Dis. 135: 1062-1068.

14. Efthimiou J, J Fleming, C Gomes, SG Spiro. 1988. The effect of supplementary oral nutrition in poorly nourished patients with chronic obstructive pulmonary disease. Am. Rev. Respir. Dis. 137: 1075-1082.

15. Rogers RM, M Donahoe, J Costantino. 1992. Physiologic effects of oral supplemental feeding in malnourished patients with chronic obstructive pulmonary disease. A randomized control study. Am. Rev. Respir. Dis. 146: 1511-1517.

16. Schols AMWJ, PB Soeters, R Mostert, RJ Pluymers, EFM Wouters. 1995. Physiologic effects of nutritional support and anabolic steroids in patients with chronic obstructive pulmonary disease. A placebo-controlled randomized trial. Am. J. Respir. Crit. Care Med. 152: 1268-1274.

17. American Thoracic Society. 1995. Standards for the diagnosis and care of patients with chronic obstructive pulmonary disease. Am. J. Respir. Crit. Care Med. 152: S77-S121.

18. Westerterp KR, L Wouters, WD van Marken Lichtenbelt. 1995. The Maastricht protocol for the measurement of body composition and energy expenditure with labeled water. Obes. Res. 3 Suppl. 1: $49-57$.

19. Schoeller DA. 1992. Isotope dilution methods. In P Bjömtröp, BN Brodoff, eds. Obesity. JB Lippincott Company Philadelphia. 80-88.

20. Weir JB. 1949. Now methods for calculating metabolic rate with special reference to protein metabolism. J. Phys. 109: 1-9.

21. Stichting Nederlands Voedingsstoffenbestand. 1996. NEVO tabel. Voorlichtingsbureau voor de voeding. Den Haag.

22. Quanjer PH, ed. 1993. Standardized lung function testing. Official statement of the European Respiratory Society. Eur. Respir. J. 6 Suppl. 16: 1-100.

23. Leeuwenberg JF, TM Jeunhomme, WA Buurman. 1994. Slow release of soluble TNF receptors by monocytes in vitro. J. Immunol. 152: 4036-4043.

24. Hopkins BS. BR Bistrian. GL Blackbum. 1983. Protein-calorie management in the hospitalized paticnt. In HA Schncider, ed. Nutritional support in clinical practice. Harper \& Row, Philadelphia. 140-159

25. Westerterp KR. JH Donkers, EW Fredrix, P Boekhoudt. 1995. Energy intake, physical activity and body weight: a simulation model. Br. J. Nuir. 73: 337-347.

26. Altman DG. SM Gore, MJ Gardner, SJ Pocock. 1983. Statistical guidelines for contributors to medical journals. Br. Med. J. (Clin. Res. Ed) 286: 1489-1493.

27. Vaughan L. F Zurlo, E Ravussin. 1991. Aging and energy expenditure. Am. J Clin. Nutr. 53: 821-825.

28. Fukagawa NK. LG Bandini, JB Young. 1990. Effect of age on body composition and resting metabolic rate. Am. J. Physiol. 259: E233-E238.

29. Vaisman N. T Hahn. 1991. Tumor necrosis factor-alpha and anorexia - cause or effect? Metabolism 40: 720-723.

30. Haussinger D, E Roth, F Lang. W Gerok. 1993. Cellular hydration state: an important determinant of protcin catabolism in health and disease. Lancet 341: 1330-1332.

31. Jakobsson P. L Jorfeldt. H von Schenck. 1995. Insulin resistance is not exhibited by advanced chronic obstructive pulmonary disease patients. Clin. Physiol. 15: 547-555.

32. Hjalmarsen A, U Aasebo, K Birkeland, G Sager, R Jorde. 1996. Impaired glucose tolerance in patients with chronic hypoxic puimonary diseasc. Diabetes and Metabolism 22: 37-42.

33. Mimura Y, K Funya. 1995. Mechanisms of adaptation to hypoxia in energy metabolism in rats. J. Am. Coll. Surg. 181: 437-443.

34. Precdy VR, DM Smith, PH Sugden. 1985. The effects of 6 hours of hypoxia on protein synthesis in rat tissues in vivo and in vitro. Biochem. $J .228: 179-185$.

35. Bigard AX. P Douce, D Merino, F Lienhard, CY Guezennec. 1996. Changes in dietary protein intake fail to prevent decrease in muscle growth induced by severe hypoxia in rats. $J$. Appl. 
Physiol. 80: 208-215.

36. Ghezzi P, CA Dinarello, M Bianchi, ME Rosandich, JE Repine, CW White. 1991. Hypoxia increases production of interleukin-1 and tumor necrosis factor by human mononuclear cells. Cytokine 3: 189-194.

37. Hempel SL, MM Monick, GW Hunninghake. 1996. Effect of hypoxia on release of IL-I and TNF by human alveolar macrophages. Am. J. Respir. Cell. Mol. Biol. 14: 170-176. 


\title{
Chapter 8
}

\begin{abstract}
Anabolic steroids
E. C. Creutzberg, A. M. W. J. Schols

Department of Pulmonology, University Hospital Maastricht, The Netherlands
\end{abstract}

Current Opinion in Clinical Nutrition and Metabolic Care 1999:

2: $243-253$ 


\section{Summary}

Anabolic steroids may be an additional mode of intervention to promote anabolism and improve clinical outcome in various acute and chronic wasting diseases. The present review discusses the rationale for anabolic steroid treatment in acute and chronic disease, their mechanistic actions, the available clinical trials in acute and chronic disease and their side-effects.

\section{Introduction}

The sex hormone testosterone has androgenic effects but is also long known for its anabolic characteristics. Despite limited scientific evidence, testosterone and its analogues in the form of anabolic steroids have been supplemented for several decades in sports because of their supposed enhancing effects on muscle mass and muscle performance. In clinical practice, muscle wasting is a frequently observed complication in many acute and chronic disease states adversely affecting clinical outcome. Anabolic steroids have been investigated as treatment alternative to promote anabolism in a variety of wasting diseases characterized by loss of body cell mass. In this review the rationale for anabolic steroid treatment in acute and chronic disease is discussed, their mechanistic actions, the available clinical trials and their side-effects.

\section{Rationale for anabolic steroid treatment}

Acule divease

During the occurrence of acute disease such as polytrauma, sepsis, major burns or in the early postoperative period, patients can rapidly lose body cell mass due to an imbalance between protein synthesis and breakdown. These changes may be (temporarily) tolerated in non-depleted patients, but there is evidence that depleted patients have a higher risk to develop morbidity and mortality $(1,2)$. Under these circumstances catabolic hormones such as epinephrine and cortisol are increased while anabolic hormones like growth hormone and testosterone are decreased. The metabolic changes are mediated by a systemic inflammatory response (3).

Loss of body cell mass cannot be overcome by addition of extra protein or specific amino acids alone. In contrast, administration of high doses of protein may even be deleterious, because the protein cannot always be effectively utilized during the stress response of injury; the excess amino acids need to be oxidized resulting in increased formation of urea and heat (4). Among treatment strategies, anabolic steroid treatment has only been evaluated in a few studies with respect to decrease catabolism during acute illness.

\section{Chronic disease}

Chronic wasting diseases like chronic obstructive pulmonary disease (COPD) and human immunodeficiency virus (HIV) infection may be a target for treatment with testosterone or anabolic steroids for several reasons.

Patients infected with HIV will eventually be subject to a range of multifactorial problems like cachexia, fatigue and weakness which negatively affect quality of life. Since the magnitude of the depletion of body cell mass correlates with the timing of death in patients with the acquired immune deficiency syndrome (AIDS). treatment of weight loss may potentially enhance survival (5). Furthermore, the fact that $25-60 \%$ of the patients 
with HIV-infection have testosterone levels in the hypogonadal range is of interest since this hypogonadism has been shown to be related to weight loss in HIV-infection (6). This is in accordance with the fact that otherwise healthy men with androgen deficiency suffer from long term loss of bone and muscle mass leading to physical frailty, increased fracture risk and inactivity (7). Similarly to HIV-infection, in patients with COPD weight loss associated with muscle wasting and weakness is a well-known phenomenon, having negative consequences on exercise capacity, quality of life and survival. Also in these patients hypogonadism has been reported, especially in relation to body mass depletion (8).

In both diseases several attempts have been made to reverse the weight loss by instituting oral nutritional therapy, but not all patients are able to respond to such treatment. In addition, patients with COPD not responding to oral nutritional therapy were characterized by a higher mortality rate than responding patients $(9)$. For these reasons, anabolic steroid therapy may be an alternative option for the treatment of body cell mass wasting.

In addition to the use of anabolic steroid treatment in the chronic wasting diseases presented above, the use of anabolic steroids may also be of interest related to other clinical conditions because of their stimulating effects on bone and haematopoiesis.

The prevalence of chronic diseases increases dramatically in the elderly population. The aging process per se is accompanied by changes in the hypothalamic-pituitary-gonadal axis resulting in notable declines in testosterone and estrogen. In addition, partly independently of aging, many chronic wasting diseases are characterized by both loss of bone mass $(10)$ as well as below normal testosterone levels as indicated above $(6,8)$.

Anaemia, which is also related to (inflammatory) cachexia, may be another target for anabolic steroid treatment. The anaemia in chronic renal failure is mainly due to erythropoietin (EPO) deficiency, because approximately $90 \%$ of the circulating EPO is made by the kidney (11). Before the availability of recombinant human EPO (rHuEPO), anaemic haemodialysis patients were treated with anabolic steroids because of their erythropoietic effect (directly or via EPO) (12).

\section{Mechanistic sites of action of anabolic steroids}

Human as well as animal and in vitro studies have been performed in order to get insight into the mechanistic effects of anabolic steroids on their different sites of action. At the cellular level, steroid hormones readily pass through the cell membrane of the target tissue, bind with specific steroid receptors, move to the nucleus where they attach to nuclear chromatin and stimulate specific messenger RNA by transcription. Ribosomal DNA then results into new proteins that mediate the hormone's function; the nature and quantities of proteins produced will vary based on the type of tissue and its sensitivity to the hormone (13). Sites of action for anabolic steroids are muscle and bone muscle tissue and haematopoiesis. Anabolic steroids may also have central effects by stimulating athletes to strive for higher training intensity (14).

In this section the effects of anabolic steroids on muscle and bone muscle tissue, their interaction with corticosteroids and the effects on haematopoiesis, acute phase response and immune function are discussed. 


\section{Muscle tissue}

Anabolic steroids act on muscle tissue via two pathways: inducing protein anabolic effects mediated by the androgen receptor and inhibition of protein catabolic processes via interaction with the glucocorticoid receptor by neutralizing the effects of endogenous glucocorticosteroids (15). The mechanisms of body compositional changes and nitrogen accumulation after administration of anabolic steroids are however poorly defined. The increases in muscle mass and performance are attributed to anabolic effects on actin and myosin via somatomedin (14). In a study by Brodsky et al. measurement of muscle protein synthesis by the increment of $\left({ }^{13} \mathrm{C}\right)$ leucine in muscle protein and myosin heavy chain during infusion of $\mathrm{L}-\left(1-{ }^{13} \mathrm{C}\right)$ leucine after six months testosterone replacement in five hypogonadal men showed that the accumulation of muscle was associated with an increase in the fractional synthesis rates of mixed skeletal muscle proteins. Furthermore a trend toward a rise in myosin heavy chain was seen, implicating that testosterone enhances skeletal muscle mass by stimulating the muscle protein synthesis rate rather than by decreasing muscle protein breakdown (16). From muscle biopsy analysis after strength training with or without a course of $100 \mathrm{mg}$ nandrolone decanoate i.m. during eight weeks in 13 experienced male body-builders, a significant but minor increase in the fibre crosssectional area was seen in the treated group and not in the placebo group, while capillary ultrastructure and capillary supply did not change (17).

Several animal studies are performed in order to further elucidate the effects of anabolic steroids on muscle tissue. Nandrolone decanoate has shown to increase type I crosssectional area in the gastrocnemius and type IIx/b cross-sectional area in the gastrocnemius and diaphragm of rats, indicating myocyte hypertrophy. In vitro contractile and fatigue properties of the diaphragm remained unchanged, except for a decrease in twitch kinetics (time to peak tension and half-relaxation time). This finding did not support the hypothesis that anabolic steroids might have more extensive effects on the diaphragm compared to other muscles because its higher cytosol androgen receptor density (18). In contrast, another study showed that testosterone treatment during 2.5 weeks in castrated male rats resulted in increases in specific forces, type II total fibre proportional area and relative expression of all adult diaphragm fast myosin heavy chain (MHC) isoforms, while in normal males only MHC isoform 2B increased (19). So the effects of anabolic steroids on diaphragmatic function may be also dependent on basal circulating androgen levels.

\section{Bone tissue}

Recent data have demonstrated that androgen receptors are not only present in primary human osteoblasts, but also in osteocytes and in mononuclear and endothelial cells in the bone marrow. In vitro, a stimulating effect of androgens on osteoblastic cell proliferation and differentiation have been shown. Recent evidence further suggests that androgens may also affect bone resorption by inhibition of osteoclastic differentiation. Testosterone treatment in hypogonadal men rapidly increases 1.25-dihydroxy vitamin D levels and corrects calcium malabsorption, leading to an improvement in calcium balance and bone formation. In eugonadal men, testosterone treatment has shown to increase spinal bone mass density by reducing the rate of bone resorption rather than increasing bone formation $(20,21)$. 


\section{Interaction with corricosteroids}

Corticosteroids are known to induce respiratory and peripheral muscle weakness. (22). Long-term use of corticosteroids is also a risk factor for developing osteoporosis, presumably due to suppression of testosterone levels (21). Anabolic steroids may be useful in corticosteroid-treated patients because they can interact with the glucocorticoid receptor and neutralize the effects of endogenous glucocorticosteroids, together with the fact that they exert direct anabolic properties via the androgen receptor. A binding competition between androgens and glucocorticosteroids for the same site of the receptor responsible for mediating the catabolic effect of glucocorticosteroids is proposed. Also inhibition of glucocorticoid action at the gene level or down-regulation of the glucocorticoid receptor are reported (22). In rats, treatment with nandrolone decanoate was able to antagonize the loss of diaphragm force induced by long-term low-dose methylprednisolone administration. Furthermore, the $\pm 10 \%$ reduction in force generation by methylprednisolone was completely abolished, as well as the reduction in type Ila and Ilx, but not type I, fibre cross-sectional area. The decrease in glycogenolytic activity and the increase in fatty acid oxidation capacity were however not reversed by nandrolone (22)

The anticatabolic effects of anabolic steroids by blocking or displacing cortisol from glucocorticoid receptors within the cell may also be advantageous in sports. The antagonism prevents cortisol, which is secreted in response to the physical stress of intense and frequent workouts, from exerting its catabolic effect within the tissue. The potential benefit of this is a more rapid recovery time resulting in longer or more intense training sessions (13).

\section{Haematopoiesis}

The hormone EPO binds to specific receptor sites of committed erythroid progenitor cells (colony-forming units-erythroid; CFU-E), causing cells to proliferate and differentiate into nurmoblasts. Anabolic steroids act mainly via stimulation of EPO synthesis but also directly on erythropoiesis; androgens are supposed to enhance erythropoietic stem cell differentiation and to increase the sensitivity of erythroid progenitors, including CFU-E and burst-forming units (BFL-E), to EPO. These two mechanisms result to a synergistic effect of anabolic steroids and EPO $(11,12)$.

\section{Acute phase response and immune function}

Since anabolic steroids increase (muscle) protein synthesis, they might theoretically also enhance the production of acute phase and immune proteins. In patients with alcoholic hepatitis, in whom malnutrition often occurs as a complicating factor in the recovery and as a significant risk factor in survival, short-term treatment with oral oxandrolone and/or parenteral amino acid in dextrose supplementation resulted in marked improvements in negative acute phase proteins like serum albumin and transferrin versus standard therapy alone (abstinence, nutritionally adequate diet and multivitamins) (23). In the same study population there was furthermore evidence that oxandrolone exerted some additional effect, particularly on serum prealbumin levels (24). Another study also reported beneficial effects of oral oxandrolone combined with high caloric supplementation on visceral proteins, but these effects did not differ from treatment with standard care (25). 
In a placebo-controlled, double-blinded randomized trial in 217 patients with COPD, the effects of nutritional intervention alone or combined with nandrolone decanoate (men 50 $\mathrm{mg}$, women $25 \mathrm{mg}$ i.m. every two weeks during eight weeks) were evaluated (26). Not previously published data on the negative acute phase response showed a rise in albumin in the nutrition group after four weeks and after eight weeks in the nandrolone + nutrition group (figure 1). Prealbumin only increased in the group treated with nandrolone after eight weeks (figure 2). A rise in transferrin was seen in both the nutrition and the nutrition + nandrolone group after four and eight weeks. Furthermore, the increase in transferrin after eight weeks was significant higher in the nandrolone group compared to placebo (figure 3).

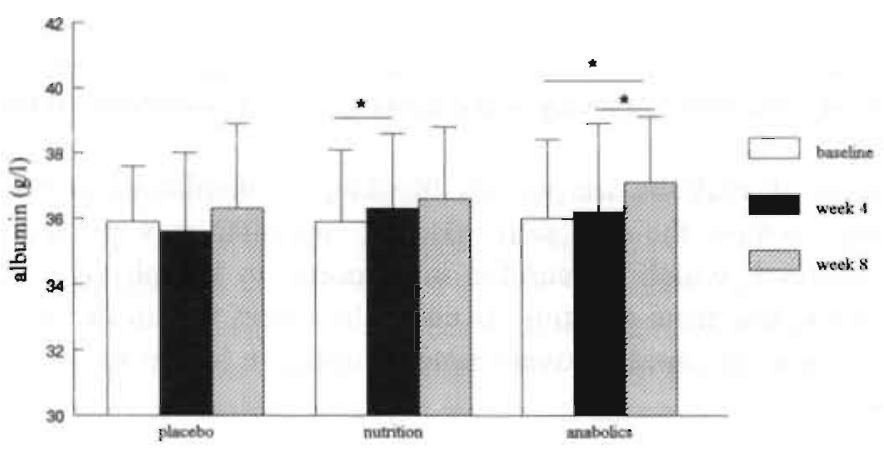

Figure 1: Effects of nandrolone decanoate and nutritional supplementation versus nutritional supplementation alone and placebo in 217 patients with chronic obstructive pulmonary discase on the negative acute phase protein albumin. Previous unpublished data from trial featured in reference 26 .

In a rat model of intra-abdominal sepsis, danazol has shown to increase the hepatic acute phase response ( $\alpha_{1}, \alpha_{2}$ and $\beta_{1}$ globulin serum protein fractions) which may be beneficial in the prophylactic treatment of subjects at increased risk of sepsis (27). On the other hand, it was hypothesized that the immune system plays a substantial role in the origin of side-effects of anabolic steroids, because of the down-regulating effects of glucocorticosteroids by anabolic steroids. Indeed nandrolone decanoate and oxymethenelone inhibited in a murine model the production of antibodies against sheep red blood cells and directly induced the production of the inflammatory cytokines IL-IB and TNF- $\alpha$ but not of $\mathrm{LL}-2$ and $\mathrm{IL}-10$, while testosterone and dehydroepiandrosterone did not. Furthermore, nandrolone inhibited interferon production in a human cell line and the production of corticotropin by human peripheral blood lymphocytes following viral infection (28). 


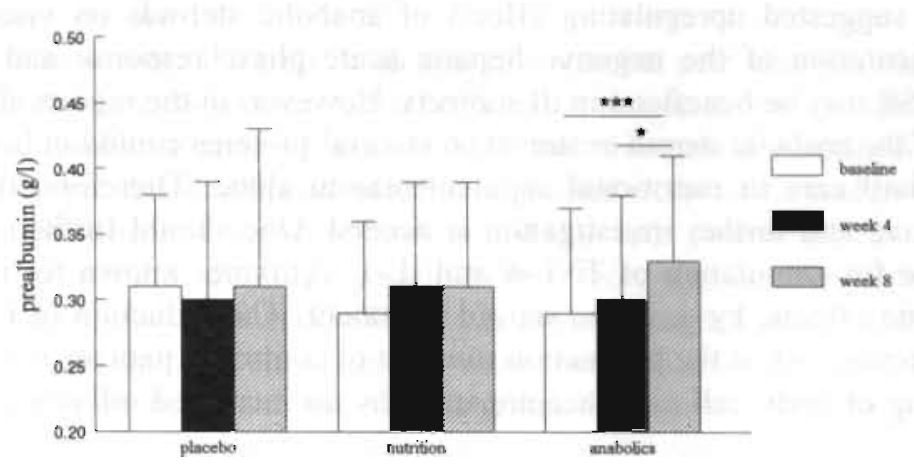

Figure 2: $\quad$ Effects of nandrolone decanoate and nutritional supplementation versus nutritional supplementation alone and placebo in 217 patients with chronic obstructive pulmonary disease on the negative acute phase protein prealbumin. Previous unpublished data from trial featured in reference 26 .

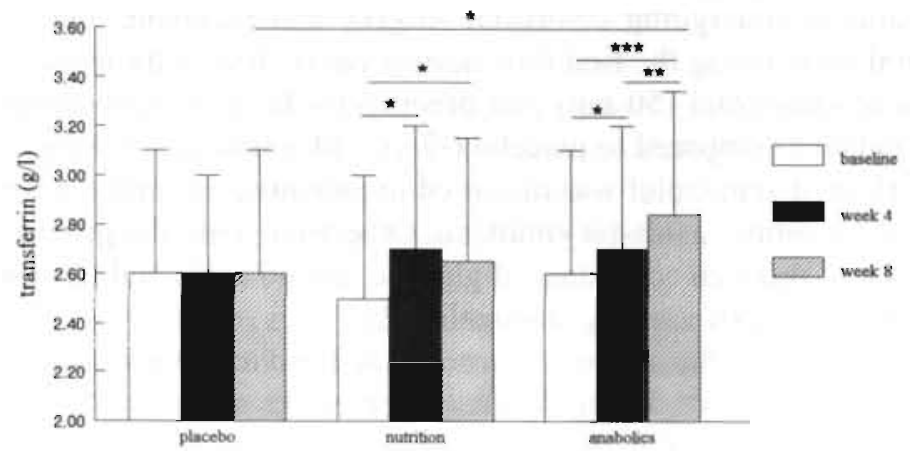

Figure 3: $\quad$ Effects of nandrolone decanoate and nutritional supplementation versus nutritional supplementation alone and placebo in 217 patients with chronic obstructive pulmonary disease on the negative acute phase protein transferrin. Previous unpublished data from trial featured in reference 26.

Little is known about the effects of anabolic steroids on immune function and immune disorders. In patients with the autoimmune disease Primary Sjögren's Syndrome, treatment with nandrolone decanoate revealed a significant decrease in the erythrocyte sedimentation rate (ESR). Another anabolic steroid, stanozolol, has shown to exert fibrinolytic effects in patients with rheumatoid arthritis. which may explain the decrease in ESR in this study (29). 
Taking together, the suggested upregulating effects of anabolic steroids on visceral proteins as an augmentation of the negative hepatic acute phase response and the decreasing effect on ESR may be beneficial in ill subjects. However, in the reports about hepatitis, the effects of the anabolic steroid treatment on visceral proteins could not be not separated from standard care or nutritional supplementation alone. Therefore, these studies are inconclusive and further investigation is needed. One should furthermore consider the evidence for stimulation of TNF- $\alpha$ and IL-1, cytokines known for their cachectic and anorectic effects, by anabolic steroid treatment. The induction of these cytokines may be deleterious when the production runs out of control in patients already suffering from wasting of body cell mass accompanied by an increased inflammatory state.

\section{Clinical trials}

Acute disease

Placebo-controlled treatment with $50 \mathrm{mg}$ nandrolone decanoate on day three and $25 \mathrm{mg}$ on day six in 20 polytrauma patients together with parenteral and enteral nutrition resulted in a diminished negative nitrogen balance and 3-methyl-histidine excretion during the first seven days after the polytrauma event. The plasma amino acid levels were higher in the treated group compared to the control group and renal losses of amino acids as well as the cumulative nitrogen excretion over ten days were reduced (1)

In a study with 60 patients undergoing colorectal surgery and receiving amino acid infusions via a peripheral vein during the first four postoperative days, administration of a single i.m. injection of stanozolol $(50 \mathrm{mg}) 24 \mathrm{~h}$ preoperatively improved cumulative postoperative nitrogen balance compared to placebo ( $-7 \mathrm{vs} .-14 \mathrm{~g} /$ four days). Little or no additional beneficial effect of stanozolol was observed in patients receiving a dextrosesaline regimen or a glucose-amino acids-fat emulsion. Otherwise, only the provision of a more complete nutritional regimen consisting of glucose, amino acids and fat resulted in a positive nitrogen balance unaffected by stanozolol (2).

Placebo-controlled treatment with the anabolic steroid oxandrolone $(10 \mathrm{mg}$ orally twice daily) was investigated in 13 patients during the first three weeks of the recovery phase after major burn injury (30-50\% of total body surface area) combined with a high calorie and protein diet ( $2 \mathrm{~g}$ protein $/ \mathrm{kg} /$ day). All patients participated in a strength and endurance training program. While total dietary intake was the same, the treated group showed a higher average weight gain $(7 \mathrm{~kg})$ and a greater improvement in muscle function quantified by the physical therapy index compared to placebo (weight gain: $3.8 \mathrm{~kg}$ ) (3). These studies indicate that small doses before and/or during acute illness have a positivic effect on the nitrogen balance. The disadvantage of these studies is that the study groups are heterogenous and that the findings nuay be partly ascribed to effects of nutrition and/or training alone. Furthermore, outcome parameters such as nitrogen balance and 3-methylhistidine excretion are not very sensitive and can therefore not be used to draw definitive conclusions. So whether these short-acting beneficial effects of anabolic steroids on nitrogen retention for the benefit of protein synthesis can be translated into an amelioration of clinical outcome requires further investigation. 


\section{Chronic disease}

Before describing the trials with anabolic steroids performed in chronic disease, a study in healthy subjects is presented in order to get insight into the effects of supraphysiologic doses of testosterone on muscle size and strength in health. Bhasin et al. set up a randomized, double-blinded, placebo-controlled study in 43 healthy men with experience in weight-lifting. They were randomized into four groups: placebo-no strength training, placebo-strength training (weight-lifting three times daily), testosterone (600 $\mathrm{mg}$ intramuscularly (i.m.) weekly for 10 weeks)-no strength training and testosterone-strength training. Protein and energy intake were standardized.

of the men in the no-strength training group, those with testosterone treatment had greater increases in fat-free mass ( $3.2 \mathrm{~kg}$, ns vs. $0.8 \mathrm{~kg}$, ns) and triceps and quadriceps muscle size and muscle strength. The men in the testosterone-strength training group had greater increases in fat-free mass $(6.1 \mathrm{~kg}, \mathbf{p}<0.001)$, muscle size and muscle strength than those in the two no-strength training groups. The men in the placebo-strength training group achieved an increase in fat-free mass of $2.1 \mathrm{~kg}(\mathrm{p}=0.017)$. See figure 4 for the changes in fat-free mass and muscle size and strength. It can be concluded from this well-designed study that supraphysiologic doses of testosterone, especially when combined with strength training, are at least able to increase fat-free mass and muscle size and strength in healthy men (30).

\section{Human immunodeficiency virus infection}

In a study $41 \mathrm{HIV}$-infected men with low testosterone levels were randomly assigned to placebo or treatment with transdermal testosterone patches designed to release $5 \mathrm{mg} /$ day testosterone for 12 weeks. Serum testosterone increased together with an increase in lean body mass, while no change in body weight was seen. Overall health related quality of life did not change, while role limitation due to emotional problems improved in the treated group (6).

The effects of oral oxandrolone therapy were evaluated in a double-blinded, placebocontrolled study in 63 weight-losing HIV-infected patients with established muscle weakness. Patients were randomized to receive placebo, $5 \mathrm{mg} /$ day oxandrolone or 15 $\mathrm{mg} /$ day oxandrolone during 16 weeks. Body weight decreased in the control group, remained stable in the $5 \mathrm{mg} /$ day group and increased in the $15 \mathrm{mg} /$ day group. Significantly more patients in the $15 \mathrm{mg} /$ day group reported improvements in appetite and activity compared to placebo, while muscle strength and weakness did not improve (31).

The treatment with oxymetholone (three times daily $50 \mathrm{mg}$; in half the patients combined with the TNF- $\alpha$ blocking drug ketotifen) was evaluated in a non-blinded study during 30 weeks in 30 chronically weight-losing. otherwise stable patients with HIV infection compared to 30 control patients. All patients received protein and vitamin supplements besides their regular medication. Body weight showed a dramatic increase $(7.1 \mathrm{~kg})$. irrespectively of ketotifen addition, compared to a decrease of $1.8 \mathrm{~kg}$ in the control group The mean time to peak weight was 20 weeks. The Karnofski index, which indicates the ability to perform activities of daily life, improved with $11^{\circ} \%$ after 20 weeks. Quality of life improved in $80 \%$ of the patients (5) 

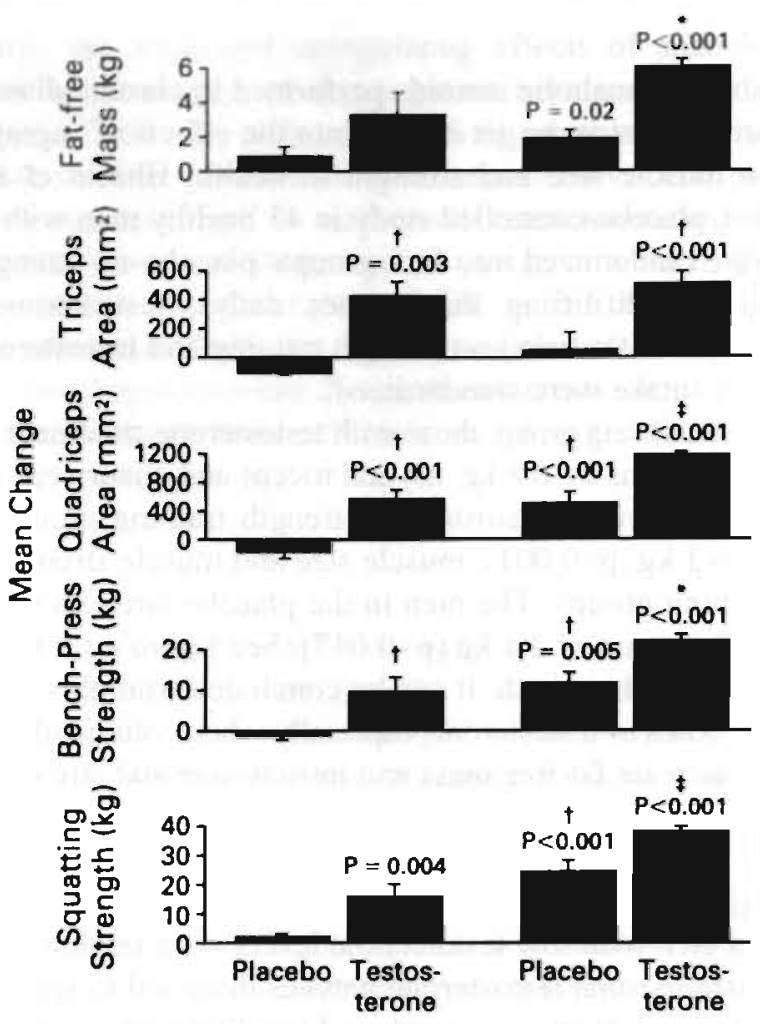

No Exercise

Exercise

Figure 4: $\quad$ Changes from baseline in mean $\pm S E M$ in fat-free mass, triceps and quadriceps crosssectional areas and muscle strength in the bench-press and squatting exercises over 10 weeks of treatment. The p-values shown are for the comparison between the change indicated and a change of zero. The asterisks indicate $p<0.05$ for the comparison between the change indicated and that in either no-excrcise group; the daggers $p<0.05$ for the comparison between the change indicated and that in the group assigned to placebo with no exercise and the double daggers $p<0.05$ for the comparison between the change indicated and the changes in all three other groups.

In another non-blinded trial the effects of 16 weeks treatment with nandrolone decanoate ( $100 \mathrm{mg} / \mathrm{ml} \mathrm{i.m.} \mathrm{every} \mathrm{two} \mathrm{weeks)} \mathrm{were} \mathrm{investigated} \mathrm{in} 24$ male weight-losing patients with HIV infection resistant to nutritional intervention therapy. The treatment was combined with a specific exercise program aimed at increasing muscle mass. Mean body weight increased $(0.14 \mathrm{~kg} /$ week), as well as lean body mass $(3 \mathrm{~kg})$ and quality of life parameters (especially functionality) (32).

\section{Chronic obstructive pulmonary disease}

In a placebo-controlled, double-blinded randomized trial in 217 patients with $\mathrm{COPD}$, the effects of nutritional intervention alone or combined with nandrolone decanoate (men 50 $\mathrm{mg}$, women $25 \mathrm{mg}$ i.m. every two weeks during eight weeks) incorporated in a pulmonary rehabilitation program were evaluated. The depleted patients showed increases in body 
weight $(2.6 \mathrm{~kg})$, fat-free mass $(1.9 \mathrm{~kg}$ ) and maximal inspiratory mouth pressure (PI-max) after both treatments, but only in the nandrolone group the rise in fat-free mass and PImax was higher compared to placebo. The changes in body composition are shown in figure 5 (26).
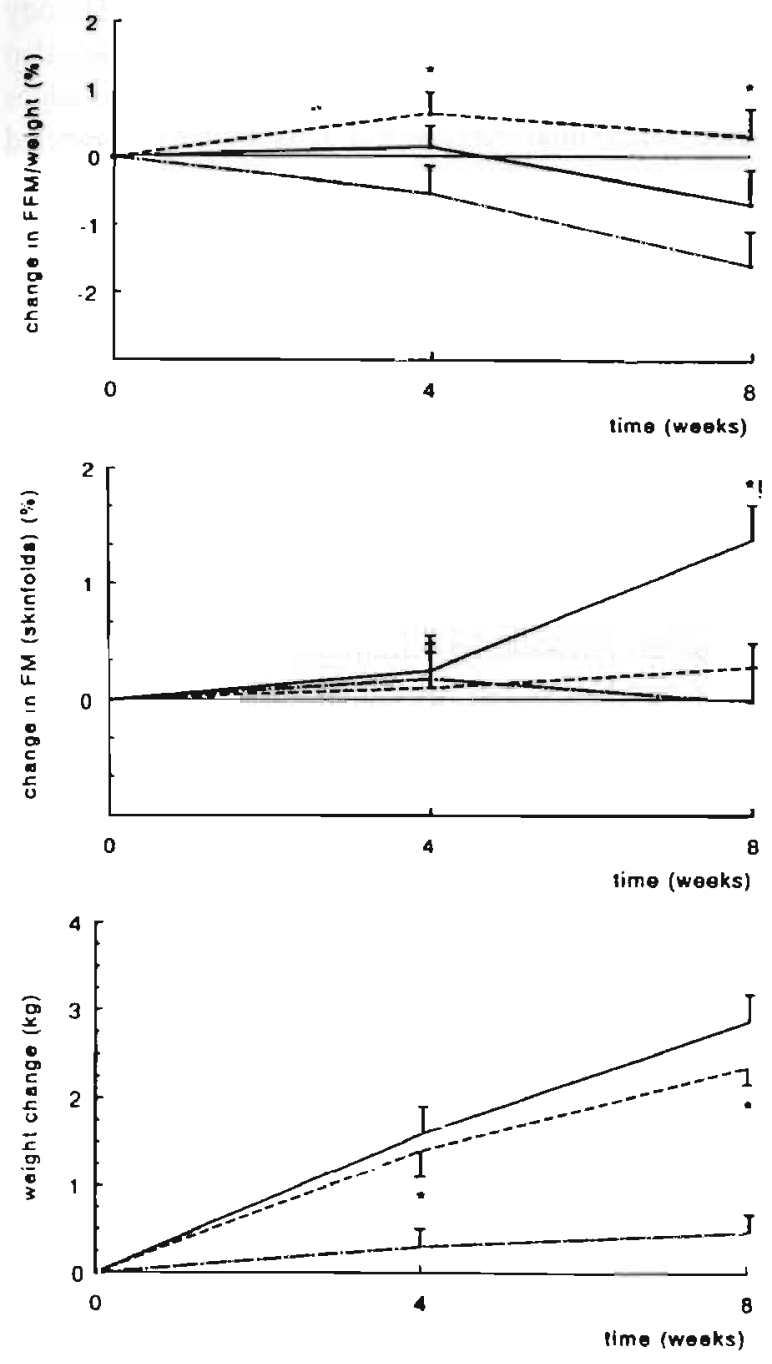

Figure 5: $\quad$ Fat-free mass (FFM) (top panel) and subcutaneous assessed fat mass (FM) (middlc pancl) changes in relation to the weight gain (bottom panel) in depleted COPD patients. Dashed/dotted line: placebo: solid line: nutrition, dashed line: nutrition and anabolic steroids. ${ }^{*}$ Indicates a significant $(\mathrm{p}<0.03)$ difference between nutrition or nutrition and anabolic steroids and placebo. ! Indicates a significant $(p<0.03)$ difference between nutrition and nutrition and nutrition and anabolic steroids. 
Besides this short-term study, a long-term placebo-controlled, double-blinded randomized trial was performed evaluating the effects of oral stanozolol treatment $(12 \mathrm{mg})$ during six months in 23 male depleted patients with COPD with a low PI-max. The treatment was preceded by an i.m. injection with testosterone $(250 \mathrm{mg})$. All patients received inspiratory muscle and cycle ergometer training but no nutritional supplementation was offered. Body weight increased with $1.8 \mathrm{~kg}$, while the control group lost weight. Lean body mass also increased, as well as arm muscle and thy circumference. However, no significant changes in PI-max, the 6 minutes walking distance or maximal exercise capacity could be detected (14).

In summary, the available studies in HIV-infection and COPD reveal that treatment with anabolic steroids has substantial effects on body composition, but the functional effects are still to be precisely defined. Furthermore, the effects of anabolic steroids in chronic wasting seem also dependent on supportive treatment like nutritional supplementation and exercise.

Besides the comprehensive experience of anabolic steroid treatment in HIV infection and COPD described above, very few recent studies have been performed in other diseases leading to body cell mass depletion. An uncontrolled study in ten boys with Duchenne's muscular dystrophy (6-9 years) treated with oral oxandrolone $(0.1 \mathrm{mg} / \mathrm{kg} /$ day during three months) showed an improvement in average functional muscle score of 34 while from natural history data a decrease during this period would have been expected (33). There are few uncontrolled studies in which the effects of testosterone replacement in hypogonadal men are evaluated. Positive effects on fat-free mass, muscle size and strength and bone resorption were demonstrated, but it should be emphasized that they were uncontrolled $(7,34)$.

\section{Osteoporosis}

Several long-term studies (ranging from 6-24 months) are performed investigating the efficts of anabolic steroid treatment (nandrolone decanoate) in osteoporotic elderly women. These studies showed in general increases in bone mineral content probably due to inhilition of bone resorption accompanied by an increase in bone density and in one study a reduction in bone pain complaints (35-37).

\section{Renal failure}

In order to investigate whether anabolic steroids can enhance the effect of EPO on haematopoiesis versus EPO alone in renal anaemia, a few studies are performed. The results are somewhat inconclusive; one study showed no beneficial effect on top of rHuEPO (12) while two other studies reported higher increases in haematocrit and a reduction in the number of blood transfusions and in the rHuEPO dose needed after additive treatment with anabolic steroids $(11,38)$ 


\section{Side-effects of anabolic steroids}

Anabolic steroids are often discredited due to negative publicity about abuse by athletes. Treatment with anabolic steroids as therapy during acute disease has minimal chance of complications due to the generally short treatment time. However, Hausmann et al. stated that anabolic therapy may be a contraindication in surgical patients because of water retention (1).

The detrimental side-effects of anabolic steroids in health and chronic disease reported in the literature are highly dose-dependent and it must be emphasized that they only appear after long-term treatment (like in osteoporosis).

The virilizing effects of androgens like hirsutism, acne, voice change and alopecia generally abate with dose reduction or discontinuation of treatment; no clinical sequelae or irreversible pathophysiologic effects have been associated with this masculinization (39). Anecdotal reports of 'roid rage' by androgenic steroid users have brought attention to the relationship between anabolic steroid use and angry outbursts. However, a placebocontrolled trial in healthy men did not show evidence for an increase in angry behaviour after testosterone treatment reported by the subjects themselves and by close relatives (40).

Anabolic steroids are primarily excreted in the urine, so hepatotoxicity is negligible. Therefore reports of jaundice, peliosis hepatis and hepatocellular carcinoma are extremely rare at the dose levels of anabolic steroids used in hormone replacement therapy (39).

Due to the haematopoietic effects of anabolic steroids, an increased haematocrit together with a tendency towards thrombosis is reported (41). Furthermore, anabolic steroids are known to induce vasodilation and thereby increase blood pressure which is a risk factor for cardiovascular disease $(39,42)$. Water retention may eventually result in oedema (41). Changes in lipoprotein profile typically accompanying the administration of androgens include reduced high-density lipoprotein cholesterol, with marginal effects on low-density lipoprotein cholesterol and triglyceride levels (42). These alterations may increase the risk for coronary heart disease (43) but seem to be reversible and to be more related to the treatment dose than to the duration (39).

\section{Conclusions}

A short-term course of anabolic steroids may be an additional mode of intervention to enhance the increase in body cell mass and physical performance in frailty and in chronic wasting diseases such as HIV-infection and COPD because of their effects on muscle and bone tissue and their antagonism with corticosteroids. An adequate calorie and especially protein intake is however required in order to optimize the anabolic effects of these drugs. In view of the potential side effects, treatment duration and dose should be limited. Furthermore, one should consider whether the additional effects on haematopoiesis are desirable or not. The available study designs in acute disease, characterized by heterogeneity of study populations and poor sensitivity of outcome measures, don't however allow a positive advise yet for use of anabolic steroids during acute tissue depletion. 


\section{References}

1. Hausmann DF, Nutz V, Rommelsheim K, Caspari R, Mosebach KO. Anabolic steroids in polytrauma patients. Influence on renal nitrogen and amino acid losses: a double-blind study. JPEN $1990 ; 14(2): 111-4$

2. Hansell DT, Davies JW, Shenkin A, Garden OJ, Bums HJ, Carter DC. The effects of an anabolic steroid and peripherally administered intravenous nutrition in the early postoperative period. JPEN $1989 ; 13(4): 349-58$.

3. Demling $\mathrm{RH}$, DeSanti $\mathrm{L}$. Oxandrolone, an anabolic steroid, significantly increases the rate of weight gain in the recovery phase after major burns. J Trauma 1997; 43(1):47-5 I

4. Chang DW, DeSanti L, Demling RH. Anticatabolic and anabolic strategies in critical illness: A review of current treatment modalities. Shock 1998; 10 (3):155-160.

5. Hengge UR, Baumann M, Maleba R, Brockmeyer NH, Goos M. Oxymetholone promotes weight gain in patients with advanced human immunodeficiency virus (HIV-1) infection. Br J Nurr 1996; 75(1): 129-38.

6. Bhasin S, Storer TW, Asbel Sethi N, Kilbourne A, Hays R, Sinha Hikim I, Shen R. Arver S, Beall G. Effects of testosterone replacement with a nongenital, transdermal system, Androderm, in human immunodeficiency virus-infected men with low testosterone levels. J Clin Endocrinol Metab 1998; 83(9):3155-62.

7. Wang C, Eyre DR, Clark R, Kleinberg D, Newman C, Iranmanesh A, Veldhuis J. Dudley RE. Berman N, Davidson T, Barstow TJ. Sinow R, Alexander G. Swerdloff RS. Sublingual testosterone replacement improves muscle mass and strength. decreases bone resorption, and incrcases bone formation markers in hypogonadal men--a clinical rescarch center study. J Clin Fndocrinol Metab 1996; 81(10):3654-62.

8. Kamischke A, Kemper DE. Castel MA. Luthke M. Rolf C, Bchre HM, Magnussen H, Nieschlag E. Testosterone levels in men with chronic obstructive pulmonary disease with or without glucocorticoid therapy. Eur Respir.J 1998: 11 (1):41-5.

9. Schols A. Slangen J, Volovics L. Wouters EFM. Weight loss is a rcversible factor in the prognosis of chronic obstructive pulmonary disease. Am J Respir ('ril ('are Med 1998; 157 (6): 1791-1797.

10. Engelen M, Schols A, Heidendal GAK, Wouters EFM. Dual-energy X-ray absorptiometry in the clinical evaluation of body composition and bone mineral density in patients with chronic obstructive pulmonary disease. Am J Clin Nutr 1998; 68 (6): 1298-1303

I1. Ballal SH, Domoto DT, Polack DC, Marciulonis P, Martin KJ. Androgens potentiate the effects of erythropoietin in the treatment of anemia of end-stage renal disease. Am J Kidney Dis 1991; 17(1):29-33.

12. Berns JS, Rudnick MR. Cohen RM. A controlled trial of recombinant human erythropoietin and nandrolone decanoate in the treatment of anemia in patients on chronic hemodialysis. Clin Nephrol 1992; 37(5):264-7.

13. Sturmi JE, Diorio DJ. Anabolic agents. Clin Sports Med 1998: 17(2):261-82

14. Ferreira IM, Verreschi IT. Nury LE. Goldstein RS, Zamul N. Brooks D. Jardim JR. The influence of 6 months of oral anabolic steroids on body mass and respiratory muscles in undernourished COPD patients. Chest 1998; 114(1): 19-28.

15. Bartsch W. Anabolic steroids-action on cellular level. Wien Med Wochenschr 1993; 143(1415):363-6

16. Brodsky IG, Balagopal P, Nair KS. Efficts of testosterone replacement on musclc mass and muscle protein synthesis in hypogonadal men--a clinical research center study. J Clin Endocrinol Metab 1996; $\left.81(10): 346^{\circ}\right)-7.5$

Kuipers H, Peeze Binkhorst FM, Hartgens F, Wijnen JA, Keizer HA. Muscle ultrastructure after strength training with placebo or anabolic stcroid. Can J Appl Physiol 1993; 18(2): 189-96.

Bisschop A, GayanRamirez G. Rollier H, Dekhuijzen PNR, Dom R. DeBock V. Decramer M Effects of nandrolone decanoate on respiratory and peripheral muscles in male and female rats. Journal of Applied Physiology 1997; 82 (4):1112-1118. 
effects of testosterone on diaphragm in castrated and normal male rats. J Appl Physiol 1997; 82(1):134-43.

20. Vanderschueren D, Boonen S. Androgen exposure and the maintenance of skeletal integrity in aging men. The Aging Male 1998; 1:180-7.

21. Eastell R, Boyle IT, Compston J, Cooper C, Fogelman I, Francis RM, Hosking DJ, Purdie DW, Ralston S, Reeve J, Reid DM, Russell RG, Stevenson JC. Management of male osteoporosis: report of the UK Consensus Group. Qjm 1998; $91(2) ; 71-92$.

22. van Balkom RHH, Dekhuijzen PNR, Folgerging HTM, Veerkamp JH, van Moerkerk HT, Fransen JAM, van Herwaarden GLA. Anabolic steroids in part reverse glucocorticoid-induced alterations in rat diaphragm. Journal of Applied Physiology 1998; 84 (5):1492-1499.

23. Bonkovsky HL, Fiellin DA, Smith GS, Slaker DP, Simon D, Galambos JT. A randomized, controlled trial of treatment of alcoholic hepatitis with parenteral nutrition and oxandrolone. I. Short-term effects on liver function. Am J Gastroenterol 1991; 86(9):1200-8.

24. Bonkovsky HL, Singh RH, Jafri IH, Fiellin DA, Smith GS, Simon D, Cotsonis GA, Slaker DP A randomized, controlled trial of treatment of alcoholic hepatitis with parenteral nutrition and oxandrolone. II. Short-term effects on nitrogen metabolism, metabolic balance, and nutrition. Am J Gastroenterol 1991; 86(9): 1209-18.

25. Mendenhall CL, Moritz TE, Roselle GA. Morgan TR. Nemchausky BA. Tamburro CH, Schiff ER, McClain CJ, Marsano LS, Allen JI, et al. Protein energy malnutrition in severe alcoholic hepatitis: diagnosis and response to treatment. The VA Cooperative Study Group \#275. JPEN 1995; 19(4):258-65.

26. Schols AMWJ, Soeters PB, Mostert R, Pluymers RJ, Wouters EFM. Physiologic effects of nutritional support and anabolic steroids in patients with chronic obstructive pulmonary disease. A placebo-controlled randomized trial. Am J Respir Crit Care Med 1995; 152(4 Pt 1): 1268-74. Mealy K, Clooney A, Marks P, Hennessy T, Jackson J. Effects of anabolic steroids on acute phase responses in intra-abdominal sepsis. Mediators of Inflammation 1997; 6 (1):69-72.

28. Hughes TK, Fulep E, Juelich T, Smith EM, Stanton GJ. Modulation of immune responses by anabolic androgenic steroids. Int J Immunopharmacol 1995; 17(11):857-63.

29. Drosos AA, van Vliet Dascalopoulou E, Andonopoulos AP, Galanopoulou V, Skopouli FN, Moutsopoulos HM. Nandrolone decanoate (deca-durabolin) in primary Sjogren's syndrome: a double blind pilot study. Clin Exp Rheumatol 1988; 6(1):53-7.

30. Bhasin S, Storer TW, Berman N, Callegari C, Clevenger B, Phillips J, Bunnell TJ, Tricker R, Shirazi A. Casaburi R. The effects of supraphysiological doses of testosterone on muscle size and strength in normal men. N Eng JMed 1996: 335(1): 1-7

31. Berger JR. Pall L. Hall CD. Simpson DM. Berry PS, Dudley R. Oxandrolone in AIDS-wasting myopathy Aids 1996; 10(14):1657-62.

32. Gold J, High HA, Li Y, Michelmore H, Bodsworth NJ, Finlayson R, Fumer VL, Allen BJ, Oliver CJ. Safety and efficacy of nandrolone decanoate for treatment of wasting in patients with HIV infection. Aids 1996; 10(7):745-52.

33. Fenichel G. Pestronk A. Florence J, Robison V. Hemelt V. A beneficial effect of oxandrolone in the treatment of Duchenne muscular dystrophy: a pilot study. Neurology 1997; 48(5):1225-6.

34. Bhasin S, Storer TW. Berman N, Yarasheski KE, Clevenger B, Phillips J, Lee WP, Bunnell TJ, Casaburi R. Testosterone replacement increases fat-free mass and muscle size in hypogonadal men. J Clin Lindocrinol Metab 1997: 82(2):407-13.

35 Nied AG. Nordin BE. Chatterton BE. Double-blind placebo-controlled trial of treatment of osteoporosis with the anabolic nandrolone decanoate. Osteoporos Int 1993; 3 Suppl 1:218-22.

36. Passeri M. Pedrazzoni M. Pioli G, Butturini L. Ruys AH, Cortenraad MG. Effects of nandrolone decanoatc on bone mass in established osteoporosis. Maturitas 1993; 17(3):211-9.

37. Flicker L, Hopper JL. Larkins RG. Lichtenstein M, Buirski G, Wark JD. Nandrolone decanoate and intranasal calcitonin as therapy in established osteoporosis. Osteoporos Int 1997; 7(1):29-35

38. Gaughan WJ, Liss KA, Dunn SR. Mangold AM, Buhsmer JP, Michael B, Burke JF. A 6-month study of low-dose recombinant human erythropoietin alone and in combination with androgens for 
the treatment of anemia in chronic hemodialysis patients. Am J Kidney Dis 1997: 30(4):495-500

39. Gelfand MM, Wiita B. Androgen and estrogen-androgen hormone replacement therapy: a review of the safety literature, 1941 to 1996. Clin Ther 1997; 19(3):383-404.

40. Tricker R, Casaburi R, Storer TW, Clevenger B, Berman N, Shirazi A, Bhasin S. The effects of supraphysiological doses of testosterone on angry behavior in healthy eugonadal men--a clinical research center study. J Clin Endocrinol Metab 1996; 81(10):3754-8.

41. Bhasin S, Bagatell CJ, Bremner WJ, Plymate SR. Tenover JL, Korenman SG, Nieschlag E. Therapeutic Perspective: Issues in testosterone replacement in older men. Journal of Clinical Endocrinology and Metabolism 1998; 83 (10):3435-3448.

42. Kuipers H, Wijnen JA, Hartgens F, Willems SM. Influence of anabolic steroids on body composition, blood pressure, lipid profile and liver functions in body builders. Int J Sports Med 1991; 12(4):413-8.

43. Kouri EM, Pope HG, Jr., Oliva PS. Changes in lipoprotein-lipid levels in normal men following administration of increasing doses of testosterone cypionate. Clin J Sport Med 1996; 6(3):152-7. 


\section{Chapter 9}

A role for anabolic steroids in the rehabilitation of patients with chronic obstructive pulmonary disease? A double-blind, placebo-controlled, randomized trial

E. C. Creutzberg' ${ }^{1}$, E. F.M. Wouters' ${ }^{1}$ R. Mostert ${ }^{2}$, R. J. Pluymers ${ }^{3}$, A. M.W. J. Schols'

'Department of Pulmonology, University Hospital Maastricht; ${ }^{2}$ Asthma Center Hornerheide, Horn; 'NV Organon, Oss; The Netherlands

\section{Submitted}

The study was supported by NV Organon, The Netherlands 


\section{Abstract \\ Background}

Muscle wasting commonly occurs in patients with chronic obstructive pulmonary disease (COPD), negatively affecting muscle function, exercise capacity and health status. Chronic use of systemic glucocorticosteroids (GCs) further contributes to muscle weakness and wasting. Anabolic steroids could be an additional mode of intervention for the treatment of muscle weakness in COPD.

\section{Methods}

We randomly assigned 63 male patients with severe COPD to receive on day $1,15,29$ and 43 a deep i.m. injection in the $\mathrm{m}$. gluteus maximus with $50 \mathrm{mg}$ nandrolone decanoate (ND; Deca-Durabolin", NV Organon, Oss, The Netherlands) in $1 \mathrm{ml}$ arachis oil or $1 \mathrm{ml}$ arachis oil alone (placebo) in a doubly-blinded design. Outcome measures were fat-free mass by deuterium dilution, respiratory and peripheral muscle function. exercise capacity (incremental bicycle ergometry) and health status (St. George's Respiratory Questionnaire; SGRQ).

\section{Results}

Treatment with ND relative to placebo resulted in higher increases in fat-free mass (mean (SD) $1.7(2.5)$ vs. $0.3(1.9) \mathrm{kg}, \mathrm{p}=0.010)$, peak oxygen pulse (1.2(1.4) vs. 0.5 (1.3) ml, $\mathrm{p}=0.034$ ) and the SGRQ symptom score ( 18 (19) vs. $6(16) \%, p=0.027) .49 \%$ Of the patients were treated with long-term, low-dose oral GCs $(7.5(2.4) \mathrm{mg} / 24 \mathrm{~h})$. In users of oral GCs, Pl-max only increased after $\mathrm{ND}\left(6.0(8.8) \mathrm{cm} \mathrm{H}_{2} \mathrm{O}, \mathrm{p}=0.032\right.$ ) but not after placebo $\left(-2.2(11.1) \mathrm{cm} \mathrm{H}_{2} \mathrm{O}, \mathrm{NS}\right)$. In addition, treatment with $\mathrm{ND}$ relative to placebo in users of oral GCs lead to higher improvements in peak work load (20 (20) vs 5 (8) W, $\mathrm{p}=0.010)$ and peak lactate/peak work load ratio $\left(-0.02(0.03) \mathrm{vs} 0.0(0.02) \mathrm{mmol} / \mathrm{W}^{*} \mathrm{l}\right.$, $\mathrm{p}=0.046$ ).

\section{Conclusions}

A short course of ND had an overall positive efficacy relative to pulmonary rehabilitation alone on body composition, peak oxygen pulse and health status in patients with severe COPD. The use of oral GCs as maintenance medication significantly attenuated the response to pulmonary rehabilitation with respect to respiratory muscle function and exercise capacity, which could be restored by ND treatment.

\section{Introduction}

Chronic obstructive pulmonary disease (COPD) is characterized by chronic airflow limitation that progresses slowly over time and is, by definition, largely irreversible (1). In addition to the deteriorating lung function, COPD is associated with multi-factorially caused impaiments in skeletal muscle function. resulting in a decreased exercise capacity. Fat-free mass (FFM) is an important determinant of physical capacity. Tissue depletion commonly occurs in COPD, its prevalence increasing from $20^{\circ} \circ$ in clinically stable outpatients (2) up to $35 \%$ in patients eligible for pulmonary rehabilitation (3). Loss of fatfree mass (FFM), as an indirect measure of muscle mass, adversely affects respiratory and peripheral muscle function (2) exercise capacity (3) and health status (4). In addition. selective wasting of FFM, despite relative preservation of fat mass (FM), has been reported (5), indicating the presence of underlying disturbances in energy or intermediary metabolism. 
In patients with COPD there is indeed evidence for a relationship between an enhanced systemic inflammatory response on the one hand and FFM depletion (6) and relative anorexia on the other $(7,8)$. Furthermore, decreased levels of anabolic hormones may further aggravate the failure of generating an anabolic response needed for muscle anabolism. Indeed low levels of testosterone were reported in COPD, which were even more pronounced in patients on oral glucocorticosteroid (GC) therapy (9). Long-term, low-dose systemic GCs are prescribed as maintenance antiinflammatory medication in a substantial number of patients. Chronic use of oral GCs further contributes to weakness and wasting of both the respiratory and peripheral muscles in patients with COPD (10). The COPD population comprises mainly elderly subjects. Aging per se is already accompanied by a decline in the size of muscle fibers and thereby in muscle function (11). Furthermore, many patients with COPD reduce their level of exercise dramatically in response to exertional dyspnea. The resulting sedentary lifestyle leads to muscle deconditioning (12).

Because of the negative consequences of muscle weakness and wasting in patients with COPD, anabolic stimuli such as training or anabolic steroids might be considered as treatment in these patients. Only a few controlled studies on anabolic steroid supplementation have been performed in COPD. Our group previously investigated the effects of nandrolone decanoate (ND) combined with nutritional support versus nutrition alone or placebo, as an integrated part of an eight-week pulmonary rehabilitation program. In the patients depleted in body mass, both treatment regimens resulted in improvements in body weight. FFM and maximal inspiratory mouth pressure (PI-max). Only in the group treated with ND however, the rises in FFM and PI-max were significantly higher than in the control group (13). Besides this short-term study, others have evaluated the effects of six months of oral stanozolol treatment in male patients with COPD depleted in body mass and with a low PI-max. The treatment was combined with inspiratory muscle training and cycling. Body weight, lean body mass as well as arm muscle and thigh circumference increased. However, the changes in PI-max, six minute walking distance and maximal exercise capacity were not different from the control group (14).

These previous studies with anabolic steroids have predominantly evaluated their efficacy in the treatment of weight loss. However, imposition of anabolic stimuli may be indicated as an additional mode of intervention to improve muscle mass and function in COPD, irrespective of weight loss. Furthermore, the effects on physical performance and health status are still to be precisely defined. As another application for therapy in COPD, anabolic steroids might be effective in patients using oral GCs as maintenance medication. In experimental animal models, ND was able to reverse the diaphragmatic muscle weakness and wasting specifically induced by systemically administered GCs $(15,16)$.

The present study aimed to investigate the effects of ND treatment embedded into an eight-week pulmonary rehabilitation program on body composition, respiratory and peripheral muscle function, exercise performance and health status in male patients with COPD. The treatment consisted of $50 \mathrm{mg}$ ND (Deca-Durabolin ${ }^{\text {is }}$, NV Organon. Oss. The Netherlands) given i.m. every two weeks in a randomized, placebo-controlled, doublyblinded study design. The patients were post-stratified by maintenance oral GC' use in 
order to evalıate whether the patients on oral GCs would respond differently to the ND) therapy.

\section{Patients and methods}

\section{l'atients}

The patients were consecutively admitted to a pulmonary rehabilitation center and were included if they fulfilled the criteria for COPD according to the ATS guidelines (17). The $\mathrm{FEV}_{1}$ had to be less than $70 \%$ of the reference value and the increase in $\mathrm{FEV}_{1}$ after inhalation of a $\beta_{2}$-agonist less than $10 \%$ of the reference value. Obese patients (body mass index (BMI); body weight/height $\mathrm{t}^{2}>30 \mathrm{~kg} / \mathrm{m}^{2}$ ) and subjects younger than 18 years were excluded from the study. Other criteria for exclusion were malignancies, cardiac failure, chronic hypoxemia at rest requiring continuous oxygen support $\left(\mathrm{PaO}_{2}<7.3 \mathrm{kPa}\right)$, gastrointestinal abnormalities such as inflammatory bowel disease and severe endocrine disorders such as insulin-dependent diabetes mellitus. Only patients in a clinically stable condition (not suffering from a recent respiratory tract infection) and without clinical signs of edema were included. The final intent-to-treat study group consisted of 63 male patients (age mean (SI)) $66(8)$ years) with severe COPD (forced expiratory volume in one second; $\mathrm{FEV}_{1}: 36$ (14)\% of predicted). The study was approved by the medical ethical committee of the University Hospital Maastricht and all subjects gave their informed consent in writing.

\section{Assessments}

\section{Lung function}

At baseline, $\mathrm{FEV}_{1}$ and inspiratory vital capacity (IVC) were calculated from the flow

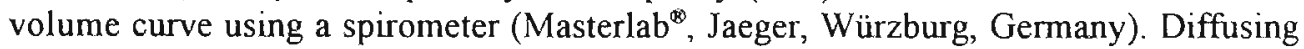
capacity for carbon monoxide (DLco) was determined using the single breath method (Masterlab ${ }^{\$}$, Jaeger, Würzburg, Germany) and was corrected for alveolar volume (K.co). Lung function parameters were expressed as percentage of reference values (18). Blood was drawn from the brachial artery while the patients were breathing room air. Arterial oxygen tension $\left(\mathrm{PaO}_{2}\right)$ and carbon dioxide tension $\left(\mathrm{PaCO}_{2}\right)$ were analyzed on a blood gas analyzer (Radiometer, ABL 330, Copenhagen, Denmark).

The following measurements were performed at baseline and after eight weeks of treatment.

\section{Laboratory parameters}

For safety analysis. standard laboratory parameters were assessed. The patients were in the fasting state for at least $10 \mathrm{~h}$. Biochemistry included measurements of serum sodium, potassium, calcium, creatinine, glucose, ASAT, ALAT, $\gamma$-GT, total bilirubin, total protein, albumin, urea and lactate dehydrogenase (LDH) by spectrophotometric analysis (Cobas Mira ; Hoffmann-La Roche, Basel, Switzerland). In whole blood, the hematological parameters hemoglobin, hematocrit, erythrocyte sedimentation rate (ESR) were measured, as well as erythrocyte, leukocyte and thrombocyte counts. Leukocytes were differentiated into neutrophils, lymphocytes, eosinophils, basophils and monocytes (Cobas Micro"; Hoffmann-La Roche, Basel, Switzerland). 


\section{Body composition}

Body height was determined to the nearest $0.5 \mathrm{~cm}$ (WM 715, Lameris, Breukelen, The Netherlands) with subjects standing barefoot. Body weight was assessed with a beanr scale to the nearest $0.1 \mathrm{~kg}$ (SECA, Hamburg, Germany) with subjects standing barefoot and in light clothing. To measure total body water (TBW), each patient received in the late evening around 10 p.m. a weighted $(1 \mathrm{~g} / \mathrm{l}$ estimated TBW) oral dose of deuteriumlabeled water ( 99.84 atom percent excess) mixed into $70 \mathrm{ml}$ water. For the estimation of extracellular water (ECW) $60 \mathrm{mg}$ sodium bromide/l predicted TBW was added to the deuterium dose. Just before and approximately $10 \mathrm{~h}$ later, after complete emptying of the bladder, urine and venous blood samples were obtained. Urine was analyzed for deuterium with an isotope ratio mass spectrometer according to the Maastricht protocol (19). Deuterium dilution space was calculated from the quantity of administered deuterium and the urine deuterium concentrations before and after complete distribution. TBW was calculated from deuterium dilution space by applying a conversion factor of 1.04 , which corrects for the exchange of labile hydrogen which occurs in humans during the equilibration period. The ECW compartment was analyzed using bromide detection. ECW was estimated by the corrected bromide space, which was calculated from the quantity of administered bromide and the serum bromide concentrations before and after complete distribution. Bromide concentration in serum ultrafiltrate was determined by HPLC according to the anion exchange chromatographic method (20). Intracellular water (ICW) was calculated by subtracting ECW from TBW. FFM, extracellular mass (ECM) and intracellular mass (ICM) were calculated assuming a hydration factor of 0.73 . FM was calculated by subtracting FFM from body weight.

\section{Muscle function}

Respiratory muscle function was assessed by measuring Pl-max according to the method of Black and Hyatt (21). The best of three attempts was taken for analysis. PI-max values were noted as positive values. Skeletal muscle function of the upper extremities was assessed with use of a Harpenden handgrip dynamometer (Yamar ${ }^{\infty}$, Preston, Jackson, MI, U.S.A.). The isometric grasp was determined by measuring the maximally developed strength of the flexors of the fingers of both hands. The highest value of three maneuvers was used. The average of the maximal left and right handgrip strength was taken for analysis. Isometric strength of the lower extremities was measured with a 'multi-joint' dynamometer device (Aristokin ${ }^{*}$. LODE. Groningen, The Netherlands). The feet were attached against a fixed support while seated with knees bent at a $120^{\circ}$ angle. The patients generated their maximal isometric force of the legs against an applied resistance of 2200 $\mathrm{N}$ while their seat was fixed. The best of three performed repetitions was used in the analysis. Using the same equipment, linear isokinetic muscle function of the lower limbs was assessed. While seated with knees bent at a $90^{\circ}$ angle, the feet were attached against a fixed support. leaving the ankles free to rotate. The patients performed maximal isokinetic extension of the legs against an applied resistance of $250 \mathrm{~N}$. The rate at which the seat shifted backwards was set at $60 \mathrm{~cm} / \mathrm{s}$ (preload: $150 \mathrm{~N}$ during $0.3 \mathrm{~s}$.): the velocity of the contraction thus remained constant. At this isokinetic rate, the maximal energy generated by the legs mainly determined the outcome of the performance. The highest power value from five repetitive attempts was taken for analysis. During all muscle 
function tests, the patients were encouraged to perform as optimally as they could.

\section{Exercise capacity}

An incremental bicycle ergometry test was performed on an electromagnetic brakes ergometer (Corival $400^{\circ}$, Lode, Groningen, The Netherlands) to investigate maximal leg exercise capacity. After a two minute resting period and one minute unloaded cycling, power was increased every minute by $10 \mathrm{~W}$. The load cycled was unknown to the patients who were encouraged to cycle for as long as possible. Peak work load was compared with the predicted values (22). During the exercise test, heart rate was monitored (Sport-tester ${ }^{8}$, Polar electro $\mathrm{Cy}$, Kempele, Finland). Oxygen consumption $\left(\mathrm{V}^{\prime} \mathrm{O}_{2}\right)$ was measured and calculated from breath by breath analysis using a breathing mask (Oxycon Beta ${ }^{\infty}$, Jaeger, Würzburg, Germany). The equipment was calibrated before the tests and the accuracy of the system was regularly assessed using a methanol combustion test. Immediately before and two minutes after reaching the peak work load, a venous blood sample was taken to measure the concentration of lactate. The blood samples were stored on ice $\left(4{ }^{\circ} \mathrm{C}\right)$ and centrifuged for 5 minutes at $3000 \mathrm{rpm}$ (Sigma 2-15\%, Lameris, Breukelen, The Netherlands). Plasma lactate was determined enzymatically using an automated system (Cobas Mira ${ }^{\circledR}$, Roche, Basel, Switzerland). Peak work load, peak $\mathrm{V}^{\prime} \mathrm{O}_{2}$ the ratio between peak $\mathrm{V}^{\prime} \mathrm{O}_{2}$ and peak heart rate (peak oxygen pulse) and the ratio between peak lactate and peak work load (peak lactate/peak work load) were used in the analyses.

\section{Health status}

Health status was measured by the St. George's Respiratory Questionnaire (SGRQ). a standardized, sensitive and reproducible questionnaire specific for patients with lung diseases (23). The SGRQ consists of 76 items and is designed to allow direct comparisons of the health gain to be obtained with different types of interventions. After it was filled out by the patients themselves, subscores ranging from 0 to $100 \%$ for the categories symptoms (distress due to respiratory symptoms), activity (disturbance of physical activity) and impact (overall impact on daily life and well-being) were calculated, as well as the total score (mean of the three scores). A high score means greater impairment in health status thus a reduction in score implies an improvement in health status. The Cronbach $\alpha$ (a measure of homogeneity of the items within each category) is 0.60 for symptoms, 0.82 for activity and 0.71 for impact. A change from baseline score of four points or more after treatment is considered as clinically significant. This was based on a multivariate model in which the SGRQ score was related to clinically appropriate changes in a range of disease-related variables. In addition, minimum subjective efficacy of therapy corresponded with a change in SGRQ of four points (23).

\section{Study design and intervention}

After inclusion, the patients were randomly allocated to receive ND or placebo. When all baseline measurements were performed, the patients received on day one, fifteen, twentynine and forty-three in a double-blind fashion a deep i.m. injection in the $\mathrm{m}$. gluteus maximus with $50 \mathrm{mg} \mathrm{ND}$ in $1 \mathrm{ml}$ arachis oil or $1 \mathrm{ml}$ arachis oil alone (placebo). Patients were post-stratified by oral GC use as maintenance medication. Further analyses were done with the subgroup of patients long-term treated with low-dose oral GCs. 
The intervention was incorporated into an eight-week, standardized inpatient pulmonary rehabilitation program, consisting of general physical training with particular attention to exercise in relation to daily activities, cycle ergometry (load depending on the maximal load during an incremental bicycle ergometry test), treadmill walking, swimming, sports and games. No strength training was offered. In addition, an educational program about the disease and medication use was implemented. When appropriate, psychologic or occupational therapy was given. The diet that was offered to the patients was standardized because of the inpatient setting. In addition, patients who were depleted in body mass or in FFM or were weight-losing received nutritional supplementation therapy (500-750 $\mathrm{kcal} / 24 \mathrm{~h}$ extra), in order to bring all patients in an as optimal as possible nutritional state. The total protein content of the diet was more than enough to ensure optimal protein synthesis. This was based on the available data in the literature that protein synthesis is optimally stimulated during administration of $1.5 \mathrm{~g}$ protein $/ \mathrm{kg}$ body weight $/ 24 \mathrm{~h}(24)$.

\section{Data handling}

The intent-to-treat group consisted of 63 subjects (ND: $n=33$, placebo: $n=30$ ). One patient in the ND treated group discontinued because he accidentally received an ampule with Deca-Durabolin instead of study medication, one patient was not willing to cooperate further with the study (placebo group), one patient resigned from the rehabilitation center because of familial problems (placebo group) and one patient was to weak to fulfill the exercise tests anymore (ND treated group). As determined by an independent chest physician, three patients in the ND treated group discontinued because of a serious adverse event, i.c. intubation for mechanical ventilation due to respiratory insufficiency during a respiratory tract infection. Two of the three patients suffering from respiratory insufficiency died during the study period. Four of the above mentioned seven subjects were excluded from the per-protocol group that consisted of all subjects who had at least one post-baseline assessment of at least one of the primary efficacy parameters ( $\mathrm{n}=59$; ND: $n=30$, placebo: $n=29$ ). 52 Patients completed the study (ND: $n=28$, placebo: $n=28$ ) No differences in the number of patients dropping out from the study were seen between the treated and the placebo group. No side effects during ND treatment were noted.

\section{Statistical analysis}

Statistical analysis on the efficacy parameters was performed in the per-protocol group. Differences between the groups were non-parametrically analyzed by the Mann Whitney $U$ test for independent samples. Changes within the groups between baseline and week eight were tested by applying Wilcoxon's rank sum test. Significance was determined at the level of 5\%. Data are expressed as mean (SD) in the text and as mean (SEM) in the bar graphs. Data were analyzed according to the guidelines of Altman et al. (25), using SPSS$/ \mathrm{PC}+$ (statistical package for the social sciences, version 9.0 for Windows, SPSS Inc., Chicago, IL, U.S.A.).

\section{Results}

\section{Baseline characteristics of the patients}

The baseline characteristics of the intent-to-treat group are shown in table 1. Lung function and exercise capacity were severely compromised when compared with the 
predicted values. About half of the patients were using oral GCs as maintenance antiinflammatory medication. No differences in (safety or efficacy) parameters at baseline were seen between the patients treated with ND versus placebo, nor between patients who were using oral GCs as maintenance medication versus patients who were not. Other maintenance respiratory medication included: B2-sympathicomimetics $(97 \%$ of the patients in both groups), theophyllines (53\% in the treated group and $79 \%$ in the placebo group ( $\mathrm{p}=0.033$ ), ipratropium bromide ( $87 \%$ and $91 \%$ respectively, NS) and inhalation glucocorticosteroids ( $77 \%$ and $85 \%$ respectively, NS).

Table 1: Baseline characteristics of the intent-to-treat group.

\begin{tabular}{|c|c|c|c|c|c|c|}
\hline $\mathrm{n}$ & & $\begin{array}{l}\text { Nand } \\
\text { Deca } \\
33 \\
\text { mean }\end{array}$ & $\begin{array}{l}\text { rolone } \\
\text { noate } \\
\text { (SD) }\end{array}$ & $\begin{array}{l}\text { Place } \\
30 \\
\text { mean }\end{array}$ & $\begin{array}{l}\text { bo } \\
\text { (SD) }\end{array}$ & $\begin{array}{l}\text { N vs } \mathbf{P} \\
\text { p-value }\end{array}$ \\
\hline$\overline{\text { Age }}$ & (yrs) & $6 \overline{6}$ & (8) & 67 & (7) & NS \\
\hline Forced expiratory volume in $1 \mathrm{~s}$. & (\%pred) & 38 & (17) & 33 & $(10)$ & NS \\
\hline Inspiratory vital capacity & (\%pred) & 87 & (17) & 81 & (14) & NS \\
\hline Diffusing capacity/alveolar volume & (\%pred) & 65 & (25) & 59 & (26) & NS \\
\hline Arterial $\mathrm{O}_{2}$ pressure & $(\mathrm{kPa})$ & 9.9 & $(1.4)$ & 9.3 & $(1.1)$ & NS \\
\hline Arterial $\mathrm{CO}_{2}$ pressure & $(\mathrm{kPa})$ & 5.6 & $(0.8)$ & 5.6 & $(0.7)$ & NS \\
\hline Body mass index & $\left(\mathrm{kg} / \mathrm{m}^{2}\right)$ & 21.4 & $(3.6)$ & 21.7 & $(3.5)$ & NS \\
\hline Fat-free mass index & $\left(\mathrm{kg} / \mathrm{m}^{2}\right)$ & 15.9 & $(1.8)$ & 15.7 & (1.4) & NS \\
\hline Peak work load & (\%pred) & 37 & $(17)$ & 40 & $(15)$ & NS \\
\hline Oral glucocorticosteroids & $(\mathrm{mg} / 24 \mathrm{~h})$ & 7.6 & $(2.5)$ & 7.3 & $(2.5)$ & NS \\
\hline
\end{tabular}

Mean dose in patients using oral glucocorticosteroids: $19 / 33$ patients in the nandrolone decanoate treated group and $12 / 30$ patients in the placibo group.

\section{Efficacy analysis of nandrolone decanoate treatment}

Differences in treatment response between the groups given below were independent of baseline values. No differences in treatment response were seen between patients depleted in body mass or FFM and non-depleted patients.

\section{Body composition}

Treatment with ND incorporated into an eight-week inpatient pulmonary rehabilitation program resulted in a significantly higher rise in FFM and ICM compared with placebo. No expansion of ECM was noted in either group. FM increased only in the placebo group. The changes in body composition are presented in figure 1.

\section{Muscle function and exercise capacity}

In table 2, the effects of treatment with ND versus placebo on respiratory and peripheral muscle function and exercise capacity are presented. Only in the patients treated with ND, significant improvements in PI-max and in maximal isokinetic power of the lower extremities were revealed. In both ND and placebo treated patients, maximal isometric handgrip and lower extremities strength increased. Significant improvements in peak work load, peak $\mathrm{V}^{\prime} \mathrm{O}_{2}$ and peak oxygen pulse during the incremental bicycle ergometry test were seen in both groups. The rise in peak oxygen pulse was however higher in the ND treated patients. Peak lactate/peak work load improved only after treatment with ND. 


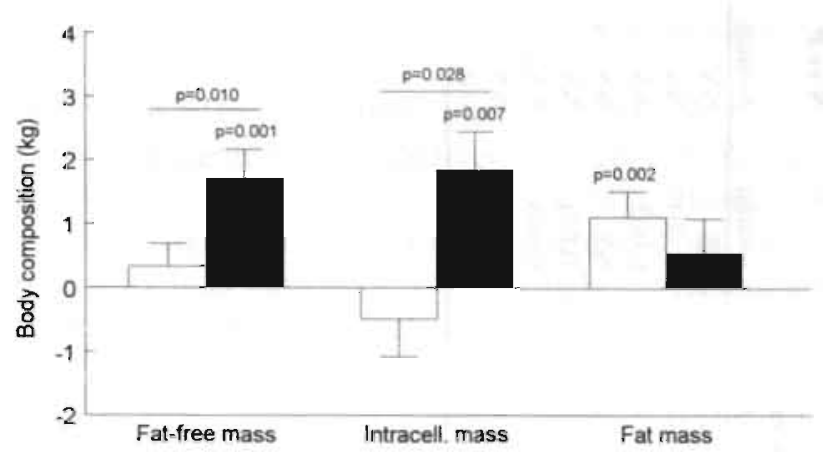

Figure 1: Higher increases in fat-free mass and intracellular mass after eight weeks of treatment with nandrolone decanoate versus placebo combined with an inpatient pulmonary rehabilitation program. Data are presented as mean (SEM). Open bars: change in the placebo group; closed bars: change in the nandrolone decanoate treated group.

\section{Health status}

The changes in health status are shown in figure 2 . In both groups, the symptom score improved, but the improvement was significantly higher in the patients treated with ND compared with placebo. In addition, the impact score and total score (mean symptom, activity and impact score) only improved in the ND treated group. Activity score did not change in either group. Improvements in health status can be considered as clinically significant, since the changes comprised more than four points.

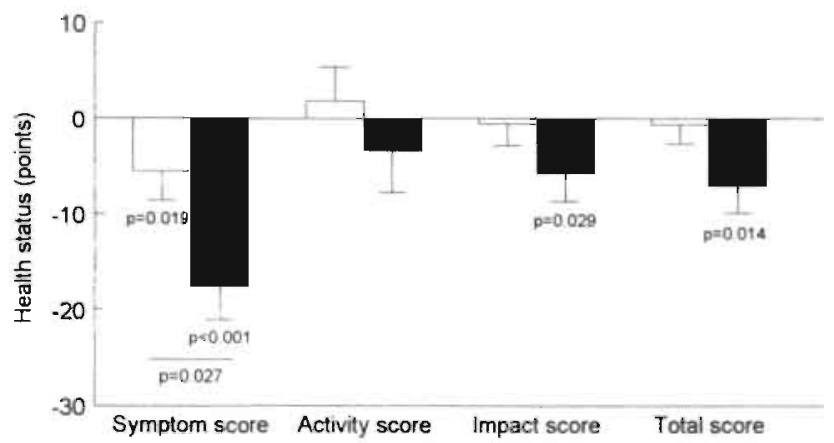

Figure 2: Greater improvement in health status as assessed by the St. George's Respiratory Questionnaire after eight weeks of nandrolone decanoate treatment versus placebo combined with an inpatient pulmonary rehabilitation program. Total score is mean symptom, activity and impact score. Data are presented as mean (SEM). Open bars: change in the placebo group: closed bars: change in the nandrolone decanoate treated group. 
Table 2: Changes in muscle function and exercise capacity after treatment with nandrolone decanoate versus placebo combined with an cight-week inpatient pulmonary rehabilitation program.

\begin{tabular}{|c|c|c|c|c|c|c|c|c|c|c|}
\hline & \multicolumn{4}{|c|}{ Nandrolone decanoate $(n=30)$} & \multicolumn{5}{|c|}{ Placebo $(n=29)$} & \multirow{2}{*}{$\begin{array}{l}\mathbf{N} \text { ys } \mathbf{P} \\
\text { p-value }\end{array}$} \\
\hline & $\begin{array}{l}\text { Baseline } \\
\operatorname{mean}(S D)\end{array}$ & $\begin{array}{l}\text { Weel } \\
\text { mean }\end{array}$ & $\begin{array}{l}\text { eight } \\
\text { (SD) }\end{array}$ & $p$-value & $\begin{array}{l}\text { Base } \\
\text { mean }\end{array}$ & $\begin{array}{l}\text { ine } \\
(S D)\end{array}$ & $\begin{array}{l}\text { Weel } \\
\text { meam }\end{array}$ & $\begin{array}{l}\text { eight } \\
S D)\end{array}$ & p-value & \\
\hline Max. inspiratory muscle strength $\left(\mathrm{cm} \mathrm{H}_{2} \mathrm{O}\right)$ & (19) & 92 & $(20)$ & 0.033 & 76 & $(20)$ & 78 & (20) & NS & NS \\
\hline Max. isometric handgrip strength $(\mathrm{kg})$ & $36.4(6.2)$ & 38.3 & $(7.0)$ & 0.001 & 35.3 & (6.9) & 37.4 & $(7.7)$ & $<0.001$ & NS \\
\hline Max isometric leg strength $\quad(N)$ & 1927 (398) & 2108 & (258) & 0.017 & 1751 & (474) & 1975 & $(425)$ & 0.002 . & NS \\
\hline Max. isokinetic leg power & $811 \quad(278)$ & 914 & $(286)$ & 0.010 & 796 & $(195)$ & 871 & $(266)$ & NS & NS \\
\hline Peak work load & $(27)$ & 74 & (35) & $<0.001$ & 57 & $(22)$ & 67 & (26) & $<0.001$ & NS \\
\hline Peak oxygen consumption & $945 \quad(282)$ & 1145 & $(448)$ & $<0.001$ & 893 & (223) & 992 & $(320)$ & 0.006 & NS \\
\hline Peak lactate/peak work load & $0.08 \quad(0.04)$ & 0.06 & $(0.02)$ & 0.006 & 0.07 & $(0.04)$ & 0.07 & $(0.03)$ & NS & NS \\
\hline Peak oxygen pulse & $(1.8)$ & 8.6 & $(2.3)$ & 0.001 & 7.6 & $(2.4)$ & 8.1 & $(2.7)$ & 0.040 & 0.034 \\
\hline
\end{tabular}


Efficacy analysis of nandrolone decanoate treatment stratified by oral glucocorticosteroid use

In figures 3-5, the differences in treatment response after ND versus placebo in users of oral GCs are presented. The differences between the groups given below were independent of baseline values. In users of oral GCs, PI-max only increased after ND but not after placebo (figure 3). Furthermore, in users of oral GCs, peak work load and peak lactate/peak work load ratio improved to a higher extent after treatment with ND versus placebo (figure 4 and 5 respectively).

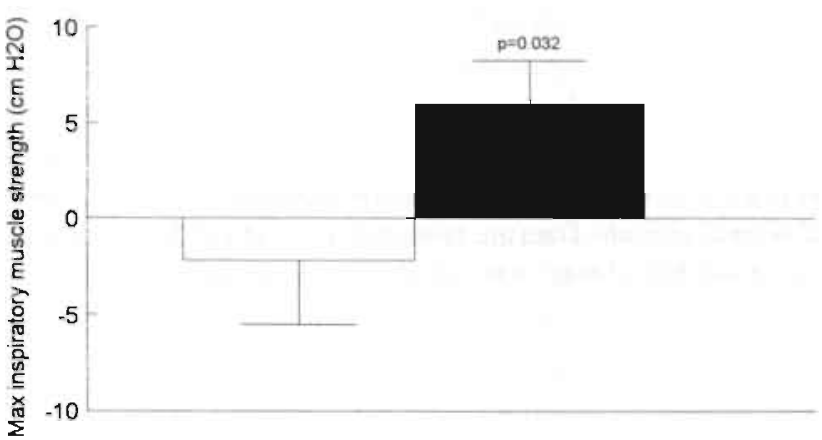

Figure 3: Improvement in maximal inspiratory muscle strength after eight weeks of treatment with nandrolone decanoate. but not placebo, combined with an inpatient pulmonary rehabilitation program in users of oral glucocorticosteroids. Data are presented as mean (SEM). Open bar: change in the placebo group; closed bar: change in the nandrolone decanoate treated group.

Safety analysis of nandrolone decanoate treatment

\section{Laboratory parameters}

Shifts in laboratory parameters from baseline till week eight after treatment with ND are given below. Increases in LDH (305.4 (39.1) to 361.0 (43.2) U/1, p<0.001), ALAT (18 (13) to 21 (10) U/, p=0.022), ASAT ( 16 (5) to 22 (8) U/, p=0.001) and creatinin (91 (13) to $98(17) \mu \mathrm{mol} / \mathrm{l}, \mathrm{p}=0.001$ ) were found. In addition, rises in erythrocyte count (4.55 (0.34) to $\left.4.74(0.47) * 10^{12} / 1, p=0.019\right)$, hematocrit $(42.2(3.5)$ to $43.6(4.5) \%, p=0.028)$ and hemoglobin $(8.6(0.7)$ to $8.9(0.9) \mathrm{mmol} / \mathrm{l}, \mathrm{p}=0.034)$ were seen. ESR decreased from 26.1 (20.9) to $19.1(13.6) \mathrm{mm} / \mathrm{h}(\mathrm{p}=0.012)$. In the placebo group, rises in ALAT (15 (6) to $23(21) \mathrm{U} / \mathrm{l}, \mathrm{p}=0.009)$, urea $(6.0(1.4)$ to $7.2(1.8) \mathrm{mmol} / \mathrm{l}, \mathrm{p}=0.001)$, leukocyte count $\left(8.0(2.9)\right.$ to $\left.8.7(2.8) * 10^{9} / 1, p=0.045\right)$, thrombocyte count $\left(244(57)\right.$ to $270(78) * 10^{9} / 1$, $\mathrm{p}=0.048)$ and in proportion segmented neutrophils $(60(8)$ to $65(10) \%, \mathrm{p}=0.011)$ were revealed. Bilirubin dropped from 12 (4) to 8 (3) $\mu \mathrm{mol} / \mathrm{l}(\mathrm{p}<0.001)$. Serum sodium, potassium, calcium, $\gamma$-GT, glucose, albumin and protein did not change in either group. 


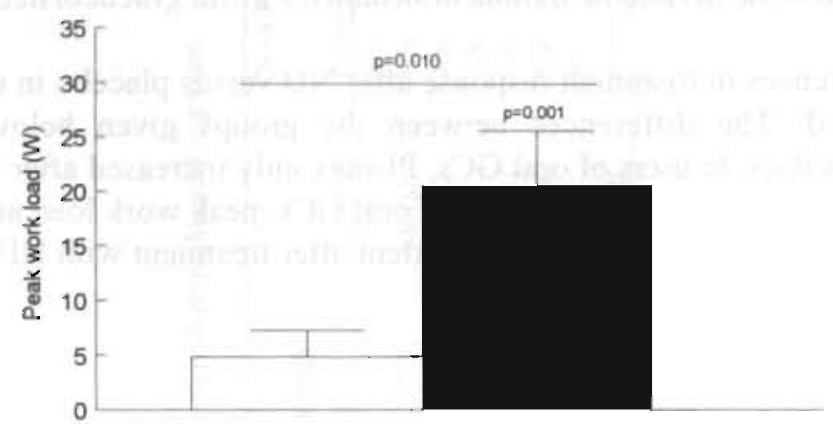

Figure 4: Greater improvement in peak work load after eight weeks of treatment with nandrolone decanoate versus placebo combined with an inpatient pulmonary rehabilitation program in users of oral glucocorticosteroids. Data are presented as mean (SEM). Open bar: change in the placebo group; closed bar: change in the nandrolone decanoate treated group.

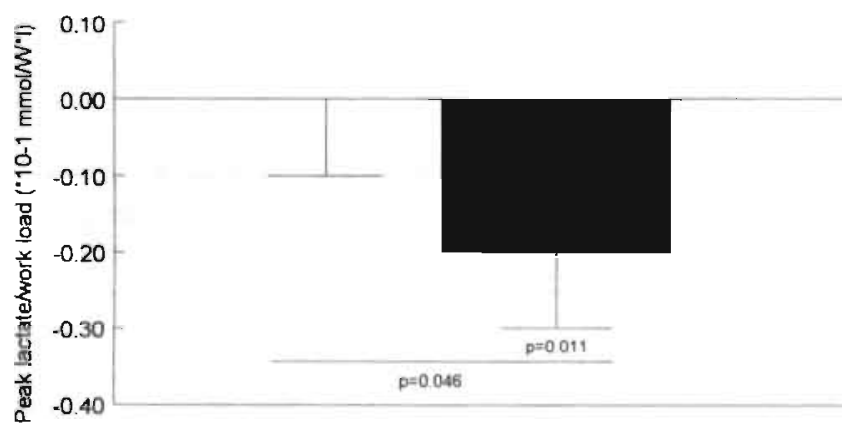

Figure 5: Greater improvement in peak lactate/peak work load after eight weeks of treatment with nandrolone decanoate versus placebo combined with an inpatient pulmonary rehabilitation program in users of oral glucocorticosteroids. Data are presented as mean (SEM). Open bar: change in the placebo group: closed bar: change in the nandrolone decanoate treated group.

\section{Discussion}

Efficacy of nandrolone decanoate treatment

The present study revealed that a short course of ND implemented in an inpatient rehabilitation program resulted in higher increases in FFM, ICM, peak oxygen pulse and health status relative to placebo in stable patients with severe COPD. Furthermore, PImax, peripheral muscle endurance and peak lactate/peak work load ratio only improved in the ND treated patients. Irrespective of ND addition, pulmonary rehabilitation resulted 
in improvements in peripheral muscle strength and exercise capacity. The use of oral GCs as maintenance medication significantly impaired the response to pulmonary rehabilitation with respect to PI-max and exercise capacity, which could be restored by ND treatment.

\section{Effects of nandrolone decanoate on body composition}

The higher increases in FFM after ND treatment were in agreement with the results seen after short- and long-term treatment with anabolic steroids in COPD as previously published $(13,14)$. The increase in FFM was completely attributable to a rise in ICM and thus to an increase in metabolically active body cell mass. Although anabolic steroids are known to induce water retention (26), in the present study no expansion of ECM was seen. The stimulating effects of anabolic steroids on muscle tissue are mediated by the androgen receptor and can be attributed to increases in the fractional synthesis rates of actin and myosin heavy chains (27), resulting in fiber hypertrophy (28). On the other hand, inhibition of protein catabolic processes by neutralizing the effects of endogenous GCs via interaction with the GC receptor is proposed (29). Recent work favors the hypothesis of anabolic steroids stimulating skeletal muscle anabolism, in the presence of sufficient amino acids, rather than attenuating muscle protein breakdown $(30,31)$.

Differential effects of nandrolone decanoate on respiratory muscle function versus peripheral muscle function and exercise capacity

In the present study, PI-max, peripheral muscle endurance and peak lactate/peak work load ratio only improved after ND treatment and not after pulmonary rehabilitation alone. These findings might be explained by combining the pathology underlying muscle weakness and wasting in COPD with the specific effects of ND on muscle tissue.

Experimental animal studies have shown that in the respiratory muscles, anabolic steroids preferably stimulate the glycolytic, fast-twitch, type II fibers. As a result, diaphragm muscle strength relative to endurance will be enhanced (32). ND treatment in rats resulted in increases in type IIb/x cross-sectional area (CSA) in the diaphragm (33) and in decreases in the more oxidative, slow-twitch, fiber type I CSA (34). Lewis et al. reported after treatment with ND an enhanced velocity of shortening as well as higher peak twitch and tetanic forces in the diaphragm of rats (35). In castrated male rats, testosterone treatment resulted in increases in specific forces, type Il total fiber proportional area and relative expression of all diaphragm fast $\mathrm{MHC}$ isoforms, while in intact males only MHC isoform IIb increased (36). Therefore the effects of anabolic steroids on diaphragmatic function appear to be dependent on basal circulating androgen levels. This is an important issue, since in a substantial proportion of patients with COPD reduced concentrations of free testosterone are reported (9). In the peripheral muscles, anabolic steroids mostly stimulate the oxidative, slow-twitch, type 1 fibers, but also to some extent the type II fibers. ND treatment in addition to exercise training in rats induced a relative increase in MHC isoform I and a decrease in MHC isoforms lla in the $\mathrm{m}$. soleus (37). In the $\mathrm{m}$. gastrocnemius. ND increased type I CSA as well as type Ilb/x CSA (33).

The affinity of anabolic steroids for specific fiber types is interesting in the light that fiber type shifts are reported in patients with COPD. In the peripheral muscles, a decrease in the proportion of type I fibers corresponding with a relative increase in type II fibers was 
seen, indicating a shift from endurance towards more strength function $(38,39)$. Concerning the respiratory muscles, there is evidence that the diaphragm of patients with severe COPD has undergone adaptations resulting in relative resistance to fatigue. The physiological alterations were accompanied by increases in fiber type I proportions and in slow isoforms of myofibrillar proteins (40). These adaptations are probably the result of the chronic activity of the diaphragm due to increasing lung hyperinflation (41).

The increase in PI-max after treatment with ND in the present study could therefore likely be explained by a partial restoration of the force relative to fatiguability function of the diaphragm. Furthermore, only in the ND treated group peripheral muscle endurance as well as peak lactate/peak work load ratio, the latter as an indirect measure of oxidative capacity, improved, while in both groups an increase in peripheral muscle strength and exercise capacity was seen. This finding might indicate a counteraction on the shift from oxidative to more glycolytic fiber type in the peripheral muscles described in COPD. Furthermore, the higher increase in peak oxygen pulse in the ND treated group probably reflected an improved oxygen delivery, owing to the rise in hemoglobin. Indeed anabolic steroids are reported to stimulate erythropoiesis, predominantly by enhancing the activity of erythropoietin (42). These effects were probably superposed on the suggested improvements in intrinsic muscle oxidative capacity after ND treatment. The fact that in the placebo group improvements in peripheral muscle strength and exercise capacity were achieved despite no rise in FFM, is quite likely the result of intrinsic alterations in muscle energy metabolism, induced by the pulmonary rehabilitation program, as described previously (43).

\section{Efficacy of nandrolone decanoate on health status}

This is the first study evaluating the effects of anabolic steroids on health status in COPD. In both groups, improvements in the symptom score of the SGRQ were achieved. It is indeed reported that pulmonary rehabilitation per se results in improvements in health status $(44,45)$. The change in symptom score was however significantly higher in the ND treated group compared with placebo. Furthermore, impact score and total score improved only after ND. Since the changes in health status were all four points or more, they can be considered as clinically significant improvements (23).

It has been previously reported that patients with COPD with severe dyspnea exhibited a worse activity, impact and total score of the SGRQ compared with those with moderate dyspnea (46). Hypothetically, the positive effects of ND treatment on respiratory muscle function lead to decreases in the sensation of dyspnea, by giving better resistance to airway hyperinflation. This would ultimately result in an improved perception of health status, since dynamic lung hyperinflation contributes importantly to the perception of breathlessness in patients with COPD (47). Altematively, central, adrenergic effects of anabolic steroids, like better mood and less depression (48), might have attributed to the higher improvement in health status in the ND treated group, independently of the suggested decrease in dyspnea.

Differential effects of nandrolone decanoate on users and non-users of long-term, lowdose oral glucocorticosteroids

In the present study, striking differences were seen in the response to treatment with ND 
versus placebo in patients to whom oral GCs were prescribed as maintenance medication. In users of oral GCs, PI-max only improved with additional ND treatment. Furthermore, in users of oral GCs, peak work load and peak lactate/peak work load ratio improved to a higher extent after treatment with ND compared with placebo. This implies that in users of oral GC's, additional ND treatment was a conditio sine qua non to achieve improvements in functional performance.

Oral GCs are often prescribed as maintenance medication to treat the inflammation in patients with COPD, despite insufficient evidence regarding their efficacy at this time. Instead, adverse effects of GC use are reported (49). GC-induced muscle wasting is associated with a negative nitrogen balance due to increased protein catabolism as well as reduced protein synthesis. Decramer et al. reported that the average daily dose of oral GCs was inversely correlated with respiratory and peripheral muscle strength in patients with COPD or asthma (10). Experimental studies indicate that especially the glycolytic, type II fibers are susceptible to the deleterious effects of GCs in terms of muscle wasting (50). Short- and long-term methylprednisolone treatment resulted in selective atrophy of type IIx and IIb but not type I and Ila fibers in the diaphragm of rats, together with a reduction in force generation. As a result, endurance to repeated isotonic contractions improved $(51,52)$. Dexamethasone treatment in hamsters significantly reduced the type II fiber CSA in the diaphragm and the type I and II fiber CSA in the $\mathrm{m}$. gastrocnemius (53).

The positive effect of ND treatment in oral GC users could be explained by competitive binding of anabolic steroids and GC's to the GC receptor, neutralizing the deleterious effects of GCs (48). Our results are in line with two animal experimental studies. In a rat model, treatment with ND was able to antagonize the loss of diaphragm force induced by long-term low-dose methylprednisolone administration. Methylprednisolone-induced reductions in type Ila and Ilx, but not type I, fiber CSA were abolished by ND administration (15). A subsequent study investigated whether ND was able to antagonize the loss of diaphragmatic function in emphysematous hamsters treated with long-term low-dose methylprednisolone. ND significantly improved the force-generating capacity. The fiber type IIa and IIx atrophy in the diaphragm was completely reversed to the level of non-emphysematous hamsters (16).

\section{Safety of nandrolone decanoate treatment}

In both groups changes in laboratory parameters occurred. It seemed therefore unlikely that they could be attributed to the ND treatment. Furthermore, anabolic steroids are predominantly excreted by the kidneys, so hepatotoxicity is negligible (54). The increases in hematological parameters after ND treatment were attributed to the erythropoietic action of anabolic steroids (42) and positively affected exercise capacity in the present investigation. To our best knowledge. no drug-related side-effects occurred during the study period. Three patients in the ND group, of whom two died, discontinued because of a serious adverse event. The serious adverse events were presumably disease-related; the patients discontinued because of respiratory insufficiency after a respiratory tract infection leading to intubation for mechanical ventilation. 


\section{Conclusions}

In conclusion, a short-term course of ND implemented into an eight-week pulmonary rehabilitation program had an overall positive efficacy relative to placebo on body composition, peak oxygen pulse and health status in patients with severe COPD, without revelation of significant adverse effects. Furthermore, respiratory muscle strength, peripheral muscle endurance and peak lactate/peak work load ratio only improved in the ND treated patients. No additional effects of ND on peripheral muscle strength and exercise capacity were revealed. The use of oral GCs as maintenance medication significantly impaired the response to pulmonary rehabilitation with respect to respiratory muscle strength and exercise capacity, which could be restored by ND treatment.

\section{References}

1. Siafakas N.M., Vermeire P., Pride N.B. et al. Optimal assessment and management of chronic obstructive pulmonary disease (COPD). The European Respiratory Society Task Force. Eur. Respir. J. $1995 ; 8: 1398-420$.

2. Engelen M.P.K.J., Schols A.M.W.J., Baken W.C., Wesseling G.J., Wouters E.F.M.. Nutritional depletion in relation to respiratory and peripheral skeletal muscle function in out-patients with COPD. Eur. Respir. J. 1994;7:1793-7.

3. Schols A.M.W.J., Soeters P.B., Dingemans A.M., Mostert R., Frantzen P.J., Wouters E.F.M Prevalence and characteristics of nutritional depletion in patients with stable COPD eligible for pulmonary rehabilitation. Am. Rev. Respir. Dis. 1993;147:1151-6.

4. Shoup R., Dalsky G., Wamer S., et al. Body composition and health-related quality of life in patients with obstructive airways disease. Eur. Respir. J. 1997;10:1575-80.

5. Engelen M.P.K.J, Schols A.M.W.J., Lamers R.J.S., Wouters E.F.M. Different patterns of chronic tissue wasting among patients with chronic obstructive pulmonary disease. Clin. Nurr. 1999:18:27580.

6. Schols A.M.W.J., Buurman W.A., Staal van den Brekel A.J., Dentener M.A., Wouters E.F.M Evidence for a relation between metabolic derangements and increased levels of inflammaton mediators in a subgroup of patients with chronic obstructive pulmonary discase. Thorax 1996:51:819-24

7. Creutzberg E.C., Schols A.M.W.J. Weling-Scheepers C.A.P.M., Buurman W.A., Wouters E.F.M Characterization of nonresponse to high caloric oral nutritional therapy in depleted patients with chronic obstructive pulmonary disease. Am. J. Respir. Crit. Care Med. 2000:161:745-52

8. Schols A.M.W.J.. Creutzberg E.C.. Buurman W.A.. Campfield L.A., Saris W.H.M.. Wouters E.F.M. Plasma leptin is related to proinflammatory status and dietary intake in patients with chronic obstructive pulmonary disease. Am. J Respir. Crit. Care Med 1999:160:1220-6.

9. Kamischke A., Kemper D.E., Castel M.A., et al. Testosterone levels in men with chronic obstructive pulmonary disease with or without glucocorticoid therapy. Eur. Respir. J. 1998;11:41-5.

10. Decramer M. Lacquet L.M., Fagard R., Rogiers P. Corticosteroids contribute to muscle weakness in chronic airflow obstruction. Am. J Respir. Cril Care Med 1994:150:11-6.

11. Klitgaard H.. Mantoni M. Schiaffino S. et al. Function. morphology and protein expression of ageing skeletal muscle: a cross-sectional study of elderly men with different training backgrounds. Acta. Physiol. Scand 1990:140:41-54

12. Casaburi R. Anabolic therapies in chronic obstructive pulmonary disease, Monaldi Arch. Chest Dis. 1998:53:454-9

13. Schols A M.W J., Soeters P.B., Moster R., Pluymers R.J., Wouters E.F.M. Physiologic effects of nutritional support and anabolic steroids in patients with chronic obstructive pulmonary discase. A placebo-controlled randomized trial. Am. J. Respir. Crit. Care Med. 1995:152:1268-74

14. Ferreira I.M., Verreschi I.T., Nery L.E., et al. The influence of 6 months of oral anabolic steroids on body mass and respiratory muscles in undernourished COPD patients. Chest 1998:114:19-28. 
van Balkom R.H.H., Dekhuijzen P.N.R., Folgering H.T.M., et al. Anabolic steroids in part reverse glucocorticoid-induced alterations in rat diaphragm. J. Appl. Physiol. 1998;84 (5):1492-9.

16. van Balkom R.H.H., Dekhuijzen P.N., van der Heijden H.F., Folgering H.T., Fransen J.A., van Henwaarden C.L. Effects of anabolic steroids on diaphragm impairment induced by methylprednisolone in emphysematous hamsters. Eur. Respir. J. 1999;13:1062-9.

17. American Thoracic Society. Standards for the diagnosis and care of patients with chronic obstructive pulmonary disease. Am. J. Respir. Crit. Care Med. 1995;152 (suppl.):S77-121.

18. Quanjer P.H. (ed.) Standardized lung function testing. Official statement of the European Respiratory Society. Eur. Respir. J. 1993;6 (suppl. 16): 1-100.

19. Westerterp K.R., Wouters L., van Marken Lichtenbelt W.D. The Maastricht protocol for the measurement of body composition and energy expenditure with labeled water. Obes. Res. 1995;3 Suppl 1:49-57.

20. Vaisman N.. Pencharz P.B., Koren G., Johnson J.K. Comparison of oral and intravenous administration of sodium bromide for extracellular water measurements. Am. $J$. Clin. Nutr. 1987:46:1-4.

21. Black L.F., Hyatt R.E. Maximal respiratory pressures: normal values and relationship to age and sex. Am. Rev. Respir. Dis. 1969;99:696-702.

22. Jones N.L. In Clinical exercise testing. Philadelphia: Saunders, 1988: 158-85.

23. Jones P.W. Issues concerning health-related quality of life in COPD. Chest 1995; 107: 187S-93S.

24. Sauerwein H.P., Romijn JA. More consideration to dietary protein in the nutrition of chronically ill adults with tendency to weight loss. Ned. Tijdschr. Geneeskd. 1999;143:886-9.

25. Altman D.G., Gore S.M., Gardner M J., Pocock S.J. Statistical guidelines for contributors to medical journals. Br. Med. J. (Clin. Res. Ed.) 1983;286:1489-93.

26. Bhasin S., Bagatell C.J., Bremner W.J., et al. Therapeutic Perspective: Issues in testosterone replacement in older men. J. Clin. Endocrinol Metab. 1998;83 (10):3435-48.

27. Brodsky I.G., Balagopal P., Nair K.S. Effects of testosterone replacement on muscle mass and muscle protein synthesis in hypogonadal men--a clinical research center study. J. Clin. Endocrinol. Metab. 1996:81:3469-75.

28. Kuipers H., Peeze Binkhorst F.M., Hartgens F., Wijnen J.A., Keizer H.A. Muscle ultrastructure after strength training with placebo or anabolic steroid. Can. J. Appl. Physiol. 1993;18:189-96.

29. Bartsch W. Anabolic steroids-action on cellular level. Wien. Med. Wochenschr. 1993;143:363-6.

30. Ferrando A.A., Tipton K.D., Doyle D., Phillips S.M., Cortiella J., Wolfe R.R. Testosterone injection stimulates net protein synthesis but not tissue amino acid transport. Am. J. Physiol. 1998;275:E86471

31. Sheffield-Moore M., Wolfe R.R.. Gore D.C., Wolf S.E., Ferrer D.M.. Ferrando A.A. Combined effects of hyperaminoacidemia and oxandrolone on skeletal muscle protein synthesis. Am. J. Physiol. Endocrinol. Metab. 2000:278:E273-9.

32. Dekhuijzen P.N., Machiels H.A., Heunks L.M., van der Heijden H.F., van Balkom R.H. Athletes and doping: effects of drugs on the respiratory system. Thorax 1999;54:1041-6.

33. Bisschop A. GayanRamirez G., Rollier H., et al. Effects of nandrolone decanoate on respiratory and peripheral muscles in male and female rats. J. Appl. Physiol. 1997;82 (4):1112-8.

34. Gayan-Ramirez G., Rollier H., Vanderhoydonc F., Verhoeven G., Gosselink R., Decramer M. Nandrolone decanoate does not enhance training effects but increases IGF-I mRNA in rat diaphragm. J. Appl. Physiol. 2000;88:26-34.

35. Lewis M.I., Foumier M.. Yeh A.Y.. Micevych P.E., Sieck G.C. Alterations in diaphragm contractility after nandrolone administration: an analysis of potential mechanisms. J Appl. Physiol. 1999:86:985-92

36. Prezant D.J., Karwa M.L. Kim H.H. Maggiore D. Chung V., Valentine D.E. Short- and long-term effects of testosterone on diaphragm in castrated and normal male rats. J. Appl. Physiol. 1997:82:134-43

37. Noirez P., Ferry A. Effect of anabolic/androgenic steroids on myosin heavy chain expression in hindlimb muscles of male rats. Eur. J. Appl. Physiol. 2000;81:155-8. 
38. Whittom F., Jobin J., Simard P.M., et al. Histochemical and morphological characteristics of the vastus lateralis muscle in patients with chronic obstructive pulmonary disease. Med. Sci. Sports Exercise 1998;30 (10):1467-74.

39. Satta A., Migliori G.B., Spanevello A., et al. Fibre types in skeictal muscles of chronic obstructive pulmonary disease patients related to respiratory function and exercise tolerance. Eur. Respir. J. 1997; 10:2853-60.

40. Levine S., Kaiser L., Leferovich J., Tikunov B. Cellular adaptations in the diaphragm in chronic obstructive puimonary disease. N. Engl. J. Med. 1997;337:1799-806.

41. Mercadier J J., Schwartz: K., Schiaffino S., et al. Myosin heavy chain gene expression changes in the diaphragm of patients with chronic lung hyperinflation. Am. J. Physiol. 1998:274:L.527-34.

42. Bems J.S. Rudnick M.R., Cohen R.M. A controlled trial of recombinant human erythropoietin and nandrolone decanoate in the treatment of anemia in patients on chronic hemodialysis. Clin. Nephrol. 1992;37:264-7.

43. Maltais F., LeBlanc P., Simard C., et. al. Skeletal muscle adaptation to endurance training in patients with chronic obstructive pulmonary disease. Am. J. Respir. Crit. Care Med. 1996;154:442-7.

44. Berry M.J., Rejeski W.J., Adair N.E., Zaccaro D. Exercise rehabilitation and chronic obstructive pulmonary disease stage. Am. J. Respir. Crit. Care Med. 1999;160:1248-53.

45. Bernard S., Whittom F., LeBlanc $\mathrm{P}$., et al. Aerobic and strength training in patients with chronic obstructive pulmonary disease. Am. J. Respir. Crit. Care Med. 1999;159 (3):896-901.

46. Hajiro T., Nishimura K., Tsukino M. Ikeda A., Oga T., Izumi T. A. Comparison of the level of dyspnea vs disease severity in indicating the health-related quality of life of patients with COPD. Chest 1999;116:1632-7.

47. O. Donnell D., Webb K.A. Exertional breathlessness in patients with chronic airflow limitation. The role of lung hyperinflation. Am. Rev. Respir. Dis. 1993:148:1351-7.

48. Creutzberg E.C., Schols A.M.W.J. Anabolic steroids. Curr. Opin. Clin. Nutr. Metab. Care $1999 ; 2: 243-53$.

49. McEvoy C.E., Ensrud K.E., Bender E., et al. Association between corticosteroid use and vertebral fractures in older men with chronic obstructive pulmonary disease. Am. J. Respir. Crit. Care Med. $1998 ; 157$ (3):704-9.

50. Wang Y.M., Zintel T., Vasquez A., Gallagher C.G. Corticosteroid therapy and respiratory muscle function in humans. Am. Rev. Respir. Dis. 1991;144:108-12.

5i. Van Balkom R.H., Zhan W.Z., Prakash Y.S., Dekhuijzen P.N., Sieck G.C. Corticosteroid effects on isotonic contractile properties of rat diaphragm muscle. J. Appl. Physiol. 1997:83:1062-7.

52. van Balkom R.H., Dekhuijzen P.N., Folgering H.T., Veerkamp J.H., Fransen J.A., van Herwaarden C.L. Effects of long-term low-dose methylprednisolone on rat diaphragm function and structure. Muscle Nerve 1997:20:983-90.

53. Lewis M.I., Monn S.A., Sieck G.C. Effect of corticosteroids on diaphragm fatigue, SDH activity. and muscle fiber size. J. Appl. Physiol. 1992:72:293-301.

54. Gelfand M.M. Wiita B. Androgen and estrogen-androgen hormone replacement therapy: a review of the safety literature, 1941 to 1996. Clin. Ther. 1997:19:383-404. 


\section{Chapter 10}

General discussion 
The two major domains investigated in the present thesis, were several components of the energy balance in stable and acute chronic obstructive pulmonary disease (COPD) as well as the efficacy of nutritional and anabolic intervention strategies for the treatment of weight loss and muscle wasting in COPD. Directions towards further research on the regulation of the energy balance as well as future therapeutic implications will be discussed below.

\section{Regulation of the energy balance}

In this thesis, it was clearly shown that several components of the energy balance were disturbed in part of the patients with stable COPD and to a higher extent in patients suffering from an acute disease exacerbation. Leptin was proposed as one of the factors responsible for the decreased dietary intake relative to resting energy expenditure; plasma leptin concentrations were inversely correlated with dietary intake in chronic and acute COPD, as well as with the degree of weight change after eight weeks of nutritional supplementation in patients with stable COPD. This is in accordance with the results of experimental animal studies in which administration of leptin resulted in a reduction in food intake (1). During an acute disease exacerbation, systemic leptin concentrations were high and the normal feedback regulation of leptin by fat mass (FM) seemed to be disrupted.

In both stable and acute disease, plasma leptin was associated with the systemic inflammatory response. In patients with emphysema as well as in patients suffering from acute exacerbation of COPD, leptin was found to be positively correlated with soluble TNF-receptor 55, independently of the amount of FM. Experimental animal studies have provided evidence for a link between pro-inflammatory cytokines and leptin. Treatment of fasted hamsters with the cytokines TNF- $\alpha$ and interleukin 1 increased leptin messenger RNA (mRNA) in adipose tissue and the circulating concentrations of leptin. Circulating leptin was in turn correlated with a decrease in food intake (2). The hypothesis that cytokine induction of leptin may play a significant role in the anorexia and cachexia of inflammatory diseases was further illustrated by Sarraf showing that administration of the pro-inflammatory cytokines TNF- $\alpha$ and interleukin 1 produced a prompt and dosedependent increase in serum leptin and leptin mRNA expression in the adipose tissue of mice. In contrast, interleukin 4 and 10 , cytokines not known to induce anorexia, did not affect leptin gene expression or serum leptin concentrations (3). Data in humans confirm this influence of systemic inflammation on leptin. In patients with solid tumors, infusion of TNF- $\alpha$ resulted in a transient increase in serum leptin concentration (4). Administration of recombinant human interleukin $1 \alpha$ to cancer patients also increased leptin concentration dose-dependently, accompanied by a decrease in appetite in the majority of the patients (5).

On the opposite end of the energy balance spectrum, recent data have suggested a key role for TNF- $\alpha$ in the insulin resistance of obesity and of non-insulin dependent diabetes mellitus (6). In humans, a strong positive correlation was found between the degree of obesity based on the body mass index, hyperinsulinemia and relative TNF- $\alpha$ mRNA concentrations in adipose tissue (7). Another recent study did however not reveal a significant relationship between individual insulin sensitivity on the one hand and 
circulating concentrations of TNF- $\alpha$ and leptin on the other in patients with offspring NIDDM (8). Although it was reported that insulin resistance was not exhibited by patients with advanced COPD compared to healthy subjects (9), an influence of alterations in insulin sensitivity on the observed relationship between STNF-receptors and leptin in patients with stable COPD can however not be excluded. In this thesis, in stable COPD no relation was revealed between the systemic TNF-receptors and glucose concentrations. In contrast, on day seven of an acute exacerbation of COPD, plasma glucose was positively correlated with plasma soluble TNF-receptor 55 , independently of the influences of sex, age and fat mass. TNF- $\alpha$ is able to decrease the expression of the glucose transporter Glut 4 . Furthermore, expression of TNF- $\alpha$ in the $m$. vastus lateralis was found to be fourfold higher in patients with insulin resistance or non-insulindependent diabetes mellitus (NIDDM) than in insulin-sensitive subjects (10).

Reports concerning the effects of oral corticosteroid use on leptin are contradictory. Two days of oral corticosteroid administration in healthy subjects resulted in significantly increased serum concentrations of leptin and insulin (11). Another study reported that administration of dexamethasone during four days to healthy lean and obese subjects induced a significant increase in plasma leptin concentrations (12). In lean healthy male volunteers, Tataranni investigated whether acute intravenous administration of glucocorticosteroids or prolonged oral treatment affected plasma leptin concentrations. Acute administration had no effects on insulin, free fatty acids or leptin concentrations as compared to placebo, while prolonged administration significantly increased fasting concentrations of insulin, but not of glucose, FFA or leptin (13). In this thesis, no effects of prolonged oral glucocorticosteroid treatment on systemic leptin was found in stable COPD. During an acute exacerbation of COPD, the (high) plasma leptin concentrations might have been (in part) the result of high-dose systemic glucocorticosteroid treatment; the course of plasma leptin seemed to have mimicked the scheme of prednisolone administration.

The supposed action of glucocorticosteroids on leptin concentrations can furthermore be mediated by insulin resistance (13), since glucose and insulin are also able to induce leptin expression. In lean mice, glucose injection resulted in an increase in plasma glucose and in an upregulation of leptin mRNA, independently of age, nutritional state and plasma insulin (14). Also injection of insulin in fasted rats induced leptin gene expression (15). At the level of adipose tissue and muscle, glucocorticosteroids antagonize insulinmediated uptake and utilization of glucose and also exert a permissive effect on lipolysis by promoting the activation of the cAMP-dependent hormone-sensitive lipase, a key enzyme inhibited by insulin (16). On base of the present thesis, in contrast to in stable COPD, insulin resistance seemed indeed to be present during an acute disease exacerbation, predominantly based on the high insulin concentrations and to a lesser extent on base of the temporary increased glucose concentrations.

In the studies described in this thesis, only circulating leptin was measured. Leptin is predominantly synthesized in the adipose tissue, but also other organs and tissues are known to produce leptin. For instance, the kidney is an organ with substantial leptin receptor mRNA expression. Also the lung, the liver as well as muscle tissue express leptin 
receptor mRNA (17). In addition, TNF- $\alpha$ is known to be produced in several tissues, like adipose tissue (18), muscle tissue (19) and in the lungs (20). No information on leptin concentrations and production in local tissues, like adipose, muscle and lung tissue, is available yet in COPD. Furthermore, it is not known if the suggested association between the systemic inflammatory response and systemic leptin concentrations is the reflection of a (TNF- $\alpha$-induced) leptin expression in local tissues. In addition, in other disease states, like obesity and diabetes mellitus, a central insensitivity for leptin, besides a disproportionate leptin production, is proposed $(7,21)$.

Besides the factors influencing leptin metabolism mentioned in this thesis, on base of experimental studies other regulators of leptin are proposed. For instance, hypoxia is suggested as a potent inducer of leptin expression. In healthy subjects, hypobaric hypoxia induced a rise in circulating leptin, associated with a decrease in appetite (22). Since a subgroup of patients with COPD suffers from chronic or intermittent hypoxemia, which worsens during eating (23), increases in leptin mediated by oxygen desaturation possibly contribute to less appetite and a limited dietary intake. In addition, hypoxia is reported to induce the production of inflammatory mediators like tumor necrosis factor- $\alpha$ (TNF- $\alpha$ ) and interleukin-1 ( $\mathrm{L}-1)(24,25)$. This pathway might be responsible for a further increase in leptin, such as reported in experimental animal studies $(2,3)$ and a corresponding further decrease in appetite and dietary intake.

In this thesis, it was found that a substantial part of the patients with COPD exhibited an increased resting energy expenditure (REE). Hypermetabolism at rest was associated with less hyperinflation compared with normometabolism at rest, in contrast to the suggested contribution of an elevated oxygen cost of breathing to an elevated REE. In contrast, independently of REE, the higher hyperinflation in FFM-depleted patients suggested a higher oxygen cost of breathing during activities, which might contribute to the elevated total daily energy expenditure reported in $\operatorname{COPD}(26,27)$. From these results, probably other factors are responsible for the hypermetabolism at rest in COPD. For instance, an elevated systemic inflammatory response is earlier reported in relation with an increased REE in COPD (28).

In experimental animal studies, energy expenditure was found to be increased after administration of leptin (29). The pathway through which this effect is mediated is unknown. Recent attention has been payed to uncoupling protein (UCP)s. These proteins can uncouple the production of ATP from the respiratory chain, dissipating energy in the form of heat while the efficiency of energy metabolism decreases (30). In genetically obese mice, leptin administration increased oxygen consumption as well as UCP mRNA concentrations in brown adipose tissue (31). Chronically intracerebroventricular infusion of leptin in lean rats also resulted in an upregulation of the mRNA of all UCPs in brown and white adipose tissue, liver and muscle tissue (30). Whether leptin-induced UCP formation is indeed involved in the resting and/or activity-related compartments of the elevated energy expenditure reported in COPD, remains to be studied. 
In summary, future attention has to be given to the supposed relationship between leptin, the systemic inflammatory response, hypoxia, glucose and insulin metabolism and treatment with systemic glucocorticosteroids with respect to the (dys-) regulation of the energy balance in patients with stable and acute COPD.

Besides its function in weight homeostasis, leptin may also play a protective role in severe stress states. In leptin-defective mice, in which the T-cell mediated immunity is decreased for unknown reasons, administration of leptin resulted in a complete reversion of the immunosuppressive effects of acute starvation. This might be explained by the fact that leptin, which is low during starvation, can induce proliferation, differentiation and functional activation of hematopoietic cells and enhances the production and phagocytic activity of macrophages (32). This protective effect of leptin was confirmed in two studies in acute sepsis, in which surviving patients were characterized by higher leptin concentrations than non-survivors $(33,34)$.

Furthermore, a relationship between leptin and the central regulation of respiration has been suggested. The respiratory depression of which leptin-deficient, obese mice were suffering from, was easily restored by administration of leptin (35).

In addition, a role for leptin in the anabolic hormonal system has been proposed. In healthy men, leptin inversely correlated with circulating growth hormone and testosterone concentrations (36). Independently of testosterone, leptin has an important function in stimulating the reproductive system $(37,38)$. Whether the low leptin concentrations found in stable COPD $(39,40)$ are (in part) related to the sexual disturbances reported in a part of the COPD population (41), remains to be studied.

\section{Anabolic management}

Because of the deleterious effects of body weight loss and muscle wasting on morbidity and mortality in COPD, the rationale for nutritional repletion therapy is well established. In the present thesis, nutritional supplementation therapy, containing a sufficient amount of protein and implemented in an inpatient pulmonary rehabilitation program, was found to be effective in depleted or weight-losing patients with COPD. Eight weeks of treatment resulted in improvements in body composition, respiratory and peripheral muscle function, exercise capacity and health status. The pulmonary rehabilitation program in which both intervention studies described in this thesis were embedded, was controlled and standardized. Further improvement in outcome might be obtained by optimizing training programs. For instance, adjusted pulmonary rehabilitation programs are probably indicated for patients characterized by weight loss or depletion of muscle mass.

The results of the nutritional intervention study described in this thesis were in contrast with the conclusions of a recent meta-analysis, that concluded that nutritional supplementation therapy had no effect on improving anthropometric measures, lung function or functional exercise capacity among stable patients with COPD (42). Some remarks must however be placed at the conclusions of this meta-analysis. At first, interventions studies with a duration of two or more weeks were included. It is likely that two weeks of nutritional supplementation is probably too short to achieve substantially changes in body composition and physiological function. Secondly, most of the nutritional intervention trials were not combined with exercise training. It can be expected that 
nutritional supplementation without an anabolic stimulus will only result in an expansion of FM. Physiological function will likewise not improve on nutrition alone, since FFM is an important determinant of functional performance. Thirdly, in several studies, the offered nutritional supplementation therapy consisted of an inadequate energy intake, relatively to energy requirements, needed for body weight gain. So the possibility exists that the nutritional interventions themselves were not of sufficient magnitude to sort an effect. In other words, the failure of intervention instead of the failure to intervene might have been responsible for the nonresponse found in several nutritional intervention trials. Nonresponse can furthermore be due to noncompliance to the therapy or to the inability of the patient to ingest the extra calories. In addition, underlying disease-specific problems leading to inadequate metabolic handling could be present. Indeed we revealed that patients not responding to optimized nutritional supplementation therapy in terms of weight gain, were characterized by, besides a higher age and relative anorexia, an elevated systemic inflammatory response. The clinical relevance of nonresponse to nutritional therapy was emphasized by the survival analysis of Schols et al., in which weight gain was identified as a significant, independent predictor of the mortality rate in patients with COPD (43).

Because in (part of) the patients with COPD tissue depletion was not simply solved by restoring the impaired energy intake relatively to energy expenditure, anabolic endocrinological therapeutic options are worth to take into account for the treatment of wasting in COPD. A second argument for this might be the fact that low circulating anabolic hormones are reported in a part of the patients with COPD (44).

The efficacy of anabolic steroid supplementation for the enhancement of physical functioning was investigated in this thesis. As described, the efficacy of a short course of nandrolone decanoate was significantly higher relative to pulmonary rehabilitation alone with respect to body composition and health status, while muscle function and exercise capacity improved to an equal extent. An additional indication for anabolic steroid treatment in COPD might be stimulation of the erythropoiesis, as suggested by the increases in hematological parameters after nandrolone decanoate. Anabolic steroids are known for their effects on erythropoiesis, predominantly by enhancing the activity of erythropoietin. In the past, anabolic steroids were indeed used for the treatment of anemia in chronic renal failure $(45,46)$. Although erythropoietin is reported to be increased in a part of the patients with COPD (47), an (extra) rise in erythropoietin might be beneficial for the improvement of oxygen delivery.

In both intervention studies described in this thesis, it was found that long-term treatment with low-dose oral glucocorticosteroids as maintenance medication significantly impaired the response to pulmonary rehabilitation and nutritional supplementation, with respect to respiratory muscle strength and exercise capacity. Since imposing anabolic steroid treatment completely reversed these deleterious effects of systemic glucocorticosteroids, a clear role for the implementation of anabolic steroid treatment in the rehabilitation of patients long-term treated with systemic glucocorticosteroids is indicated. A possible explanation for this effect is binding competition of anabolic steroids and glucocorticosteroids on the glucocorticosteroid receptor, thereby neutralizing the deleterious effects of glucocorticosteroids (48). 
In clinical practice, anabolic steroids are used because of their high anabolic/androgenic ratio. Nandrolone decanoate for instance has an anabolic/androgenic ratio of 10:1 relative to testosterone (49). However, stimulating the androgenic together with the anabolic pathways by means of testosterone supplementation might be indicated in COPD for the following reasons.

Decreased concentrations of anabolic hormones, like testosterone, might aggravate the failure of generating an anabolic response needed for muscle anabolism. Indeed low concentrations of testosterone are reported in COPD, which were even more pronounced in patients on oral glucocorticosteroid therapy (44). The prevalence of hypogonadism, i.e. low testosterone concentrations, as well as the relationship with lung function, oral glucocorticosteroid use, body composition, functional performance and health status in COPD is however unknown yet.

Other anabolic hormones to be evaluated for the treatment of wasting in COPD are growth hormone and insulin-like growth factors (IGFs). The main rationale for supplementation of these hormones in acute and chronic disease, is to improve the nitrogen balance. Aging per se already leads to a decrease in growth hormone and IGF concentrations. Studies in healthy, elderly subjects indicated positive effects of growth hormone therapy on muscle strength and immune function. Although it is not known yet if growth hormone, IGFs and/or IGF binding proteins are reduced in patients with COPD, to date two studies on growth hormone supplementation in COPD are published. An uncontrolled study suggested positive effects on body weight, nitrogen balance and inspiratory muscle function (50). However, three weeks of growth hormone administration in underweight patients with COPD in a placebo-controlled design increased lean body mass but did not improve muscle strength or exercise tolerance relatively to pulmonary rehabilitation alone (51). Further studies are needed to make a conclusive statement on growth hormone supplementation in COPD.

\section{Anticatabolic management}

From the present thesis, evidence arose that the systemic inflammatory response was prominently involved in the decreased dietary intake in stable and acute COPD. In patients with stable COPD. plasma concentrations of soluble TVF-receptor 55, as a measure of the systemic inflammatory response, were positively correlated with plasma leptin, independently of FM. In turn, plasma leptin as well as plasma soluble intercellular adhesion molecule-l were inversely associated with dietary intake in depleted, emphysematous patients with COPD. During an acute exacerbation of COPD, dietary intake was severely depressed. At day seven of hospitalization, dietary intake relative to REE was inversely correlated with plasma soluble lNF-receptor 55 and with plasma leptin.

Besides evidence for the involvement of the systemic inflammatory response in the energy intake in stable and acute COPD, it was found that systemic inflammation was also associated with non-response to nutritional supplementation therapy. Despite of the overall positive effects of nutritional supplementation therapy combined with pulmonary rehabilitation in patients with COPD, not all subjects responded to the nutritional therapy in terms of weight gain. Since the treatment was standardized and optimized, factors such 
as noncompliance could be excluded as determinants of nonresponse. Instead, elevated circulating concentrations of soluble TNF-receptor 55 and of leptin were found to be independently associated with non-response to nutritional supplementation therapy. The clinical relevance of nonresponse to nutritional supplementation was illustrated by the fact that it was revealed as an independent predictor of mortality in COPD (43).

From other work, it has become clear that, besides a local upregulation of inflammatory processes in the lungs (20), an elevated systemic inflammatory response is present in patients with COPD. This was based on elevated concentrations of acute phase proteins, TNF- $\alpha$ receptors and soluble adhesion molecules in peripheral blood $(28,52)$. In addition, their is clear evidence for a relationship between weight loss and plasma TNF- $\alpha(53,54)$. Furthermore, the decreased FFM found in hypermetabolic patients with an increased Creactive protein was found to be accompanied by raised plasma concentrations of LPSbinding protein, interleukin 8 and soluble TNF- $\alpha$ receptors 55 and 75 compared with patients with normal CRP concentrations (28). The proposed cytokine involvement in pulmonary cachexia needs an appropriate approach to combate this significant comorbidity in COPD.

The present antiinflammatory therapeutic strategy in COPD concerns mainly controlling the local inflammatory processes. Inhaled glucocorticosteroids are often prescribed as maintenance antiinflammatory medication, despite insufficient evidence regarding their efficacy on local inflammation at this time (55). Sometimes prescription of inhaled glucocorticosteroids is accompanied by orally administered glucocorticosteroids. However, it was suggested that the local inflammatory processes were resistant to the antiinflammatory properties of systemically administered glucocorticosteroids (55). In contrast, in this thesis it was revealed that long-term treatment with oral glucocorticosteroids adversely affected the clinical outcome of optimized nutritional supplementation therapy implemented in a pulmonary rehabilitation program. For these reasons, other, non-steroidal antiinflammatory modulation options, either nutritional or pharmacological, might be indicated for (a subgroup of) patients with COPD.

Increasing attention is being payed to the supposed positive effects of $n-3$ polyunsaturated fatty acids, as such in fish oil, on inflammatory processes. The possible mechanisms involve suppression of excessive endothelial activity and thereby decreased production of pro-inflammatory mediators like prostaglandins and leukotrienes. After ingestion, n-3 fatty acids will be preferentially incorporated in the cell membrane and inhibit the metabolizing of arachidonic acid to prostaglandin E2 by cyclooxygenase. Instead, less inflammatory prostaglandins are produced. In line, lipooxygenase converts $n-3$ fatty acids to leukotriene B5, which has only a fraction of the chemotactic activity of the normally, from arachidonic acid, synthesized leukotriene B4 (56). In healthy subjects, dietary supplementation with the $n-3$ fatty acid gamma-linolenic acid resulted indeed in increased fractions of this n-3 polyunsaturated acid in neutrophil phospholipids. This change in phospholipid composition within inflammatory cells such as the neutrophil might attenuate the biosynthesis of arachidonic acid, thereby representing a mechanism by which dietary polyunsaturated fatty acids exert their action (57). 
Encouraging effects of n-3 fatty acid supplementation with respect to improved imnnune function, decreased systemic inflammatory response and body weight are observed in patients suffering from cancer cachexia (58-60). Studies on supplementation of $n-3$ fatty acids in chronic disease, like inflammatory bowel disease, indicate a potential effectiveness on systemic inflammatory response (for instance, decreases in neutrophil leukotriene B4 production) and disease activity (61). Whether n-3 fatty acid supplementation in COPD will exert positive effects on systemic inflammatory processes and, secondly, clinical outcome, is still to be unraveled.

Polyunsaturated fatty acids might have additional effects in lung disease. As already mentioned, the $n-3$ and $n-6$ fatty acids shunt eicosanoid production away from the arachidonic acid pathway, and hence decrease the production of bronchoconstrictive leukotrienes. Animal studies showed that eicosapentaenoic acid or gamma-linolenic acid supplementation of animals, exposed to endotoxins, results in decreased effects on thromboxane $\mathrm{B} 2$ and pulmonary vascular resistance. Hence, a protective effect of such fatty acids in lung disease is biologically plausible (62). In chronic hypoxic rats with pulmonary hypertension, supplementation with dietary fish oil resulted in a decrease in lung thromboxane B2 and 6-ketoprostaglandin F1 $\alpha$ as well as in lower mortality rates compared to non-treated rats (63).

In addition to nutritional inflammatory modulation options, the possibilities with regard to antiinflammatory modulation by means of pharmacological intervention in COPD are growing. These involve among others interleukin 10, transcription factor inhibitors and phosphodiesterase inhibitors. Also antagonists against inflammatory mediators like leukotriene B4, TNF- $\alpha$ and prostaglandins are under investigation (64).

In summary, for the subgroup of patients not responding to oral nutritional therapy and characterized by an increased systemic inflammatory response, nutritional or pharmacological antiinflammatory modulation is worth to be taken into account in addition to optimized nutritional supplementation therapy. Furthermore, investigating the consequences of an elevated systemic inflammatory response on muscle fibers per se, may open further and more direct approaches towards novel antiinflammatory treatment strategies in patients with COPD.

\section{References}

1. Scelcy R.J., van Dijk G., Campfield L.A., Smith F.J., Bum P., Nelligan J.A., Bell S.M., Baskin D.G., Woods S.C., Schwartz M.W. Intraventricular leptin reduces food intake and body weight of lean rats but not obese Zucker rats. Horm Metab Res 1996;28:664-668

2. Grunfeld C., Zhao C. Fuller J., Pollack A., Moser A.. Fricdman J.. Fingold K.R. Endotoxin and cytokines induce expression of leptin, the ob gene product, in hamsturs. I Clin Invest 1996;97:2152-2157

3. Sarraf P., Frederich R.C., Tumer E.M., Ma G., Jaskowiak N.T., Rivet D.J., 3rd, Flier J.S., Lowell B.B., Fraker D.L., Alexander H.R. Multiple cytokines and acute inflammation raise mouse leptin levels: potential role in inflammatory anorexia. $J$ Exp Med 1997:185:171-175.

4. Zumbach M.S.. Boehme M.W., Wahl P.. Stremmel W., Zicgler R., Nawroth P.P. Tumor necrosis factor increases serum leptin levels in humans. J Clin Endocrinol Metab 1997;82:4080-4082.

5. Janik J.E. Curti B.D., Considine R. V., Rager H.C., Powers G.C., Alvord W.G., Smith J.W., 2nd, Gause B.L. Kopp W.C. Interleukin I alpha increases serum leptin concentrations in humans. $J$ ('lin Endocrinol Melab 1997:82:3084-3086.

6. Hotamisligil G.S. Spiegelman B.M. Tumor necrosis factor alpha: a key component of the obesity- 
diabetes link. Diabetes 1994:43:1271-1278.

7. Kern P.A., Saghizadeh M., Ong J.M., Bosch R.J., Deem R., Simsolo R B. The expression of tumor necrosis factor in human adipose tissue. Regulation by obesity, weight loss, and relationship to lipoprotein lipase. J Clin Invest 1995;95:2111-2119.

8. Kellerer M., Rett K., Renn W., Groop L., Haring H.U. Circulating TNF-alpha and leptin levels in offspring of NIDDM patients do not correlate to individual insulin sensitivity. Horm Metab Res 1996;28:737-743.

9. Jakobsson P., Jorfeldt L., von Schenck H. Insulin resistance is not exhibited by advanced chronic obstructive pulmonary disease patients. Clin Physiol 1995:15:547-555.

10. Saghizadeh M., Ong J.M., Garvey W.T., Henry R.R., Kern P.A. The expression of TNF alpha by human muscle. Relationship to insulin resistance. JClin Invest 1996:97:1111-1116.

11. Papaspyrou Rao S., Schneider S.H., Petersen R.N., Fried S.K. Dexamethasone increases leptin expression in humans in vivo. J Clin Endocrinol Metab 1997:82:1635-1637.

12. Dagogo Jack S., Selke G., Melson A.K., Newcomer J.W. Robust leptin secretory responses to dexamethasone in obese subjects. J Clin Endocrinol Metab 1997:82:3230-3233.

13. Tataranni P.A., Pratley R., Maffei M., Ravussin E. Acute and prolonged administration of glucocorticoids (methylprednisolone) does not affect plasma leptin concentration in humans. Int J Obes Relat Metab Disord 1997;21:327-330.

14. Mizuno T., Bergen H., Kleopoulos S., Bauman W.A., Mobbs C.V. Effects of nutritional status and aging on leptin gene expression in mice: importance of glucose. Horm Melab Res 1996:28:679684.

15. Saladin R., Staels B., Auwerx J., Briggs M. Regulation of ob gene expression in rodents and humans. Horm Metab Res 1996:28:638-641.

16. Folli F., Saad M.J., Kahn C.R. Insulin receptor/IRS-1/PI 3-kinase signaling system in corticosteroid-induced insulin resistance. Acta Diabetol 1996:33:185-192.

17. Jensen M.D., Moller N., Nair K.S., Eisenberg P., Landt M., Klein S. Regional leptin kinetics in humans. Am J Clin Nutr 1999;69:18-21

18. Hotamisligil G.S., Amer P., Caro J.F., Atkinson R.L., Spiegelman B.M. Increased adipose tissue expression of tumor necrosis factor-alpha in human obesity and insulin resistance. $J$ Clin Invest 1995:95:2409-2415.

19. Shindoh C., Hida W., Ohkawara Y., Yamauchi K., Ohno I., Takishima T, Shirato K. TNF-alpha mRNA expression in diaphragm muscle after endotoxin administration. Am J Respir Crit Care Med 1995;152:1690-1696.

20. Keatings V.M., Collins P.D., Scott D.M., Barnes P.J. Differences in interleukin-8 and tumor necrosis factor-alpha in induced sputum from patients with chronic obstructive pulmonary disease or asthma. Am J Respir Cril Care Med 1996;153:530-534.

21. Mantzoros C.S., Moschos S., Avramopoulos I., Kaklamani V.. Liolios A., Doulgerakis D.E.. Griveas I.. Katsilambros N.. Flier J.S. Leptin concentrations in relation to body mass index and the tumor necrosis factor-alpha system in humans. J Clin Endocrinol Melab 1997:82:3408-3413.

22. Tschop M., Strasburger C.J., Hartmann G., Biollaz J., Bartsch P. Raised leptin concentrations at high altitude associated with loss of appetite [letter]. Lancet 1998:352:1119-1120.

23. Schols A.M.W.J., Mostert R., Cobben N., Soeters P., Wouters E.F.M. Transcutaneous oxygen saturation and carbon dioxide tension during meals in patients with chronic obstructive pulmonary discase. Chest 1991:100:1287-1292.

24. Hempel S.L., Monick M.M., Hunninghake G.W. Effect of hypoxia on release of IL-I and TNF by human alveolar macrophages. Am J Respir Cell Mol Biol 1996:14:170-176.

25. Ghezzi P., Dinarello C.A., Bianchi M., Rosandich M.E., Repine J.E., White C.W. Hypoxia increases production of interleukin- 1 and tumor necrosis factor by human mononuclear cells. Cytokine 1991:3:189-194.

26. Baarends E.M., Schols A.M.W.J., Pannemans D. L.. Westerterp K.R., Wouters E.F.M. Total free living energy expenditure in patients with severe chronic obstructive pulmonary disease. $A m J$ Respir Crit Care Med 1997:155:549-554 
Baarends E.M., Schols A.M.W.J. Westerterp K.R., Wouters E.F.M. Total daily energy expenditure relative to resting energy expenditure in clinically stable patients with COPD. Thorax 1997:52 (9):780-785.

28. Schols A.M.W.J., Buurman W.A., Staal van den Brekel A.J., Dentener M.A., Wouters E.F.M. Evidence for a relation between metabolic derangements and increased levels of inflammatory mediators in a subgroup of patients with chronic obstructive pulmonary disease. Thorax 1996:51:819-824

Hwa J J.. Ghibaudi L., Compton D., Fawzi A.B., Strader C.D. Intracerebroventricular injection of leptin increases thermogenesis and mobilizes fat metabolism in ob/ob mice. Horm Metab Res 1996:28:659-663

30. Cusin I., Zakrzewska K.E., Boss O., Muzzin P., Giacobino J.P., Ricquier D., Jeanrenaud B., Rohner Jeanrenaud F. Chronic central leptin infusion enhances insulin-stimulated glucose metabolism and favors the expression of uncoupling proteins. Diabetes 1998;47:1014-1019.

31. Scarpace P.J., Matheny M., Pollock B.H., Tumer N Leptin increases uncoupling protein expression and energy expenditure. Am J Physiol 1997;273 E226-230.

32. Lord G.M., Matarese G. Howard L.K., Baker R.J., Bloom S. R., Lechler R.I. Leptin modulates the T-cell immune response and reverses starvation-induced immunosuppression. Nature 1998:394 (6696):897-901.

33. Torpy D.J., Bornstein S.R. Chrousos G.P. Leptin and interleukin-6 in sepsis. Horm Metab Res 1998:30 (12):726-729.

34. Bornstein S.R.. Licinio J.. Tauchnitz R. Engelmann L., Negrao A. B., Gold P., Chrousos G.P. Plasma leptin levels are increased in survivors of acute sepsis: associated loss of diumal rhythm. in cortisol and leptin secretion. J Clin Endocrinol Metab 1998:83:280-283.

35. O. Donnell C.P., Schaub C.D. Haines A.S., Berkowitz D.E., Tankersley C.G., Schwartz A.R. Smith P.L. Leptin prevents respiratory depression in obesity. Am $J$ Respir Crit Care Med 1999:159:1477-1484

36. Nystrom F. Ekman B.. Osterlund M. Lindstrom T., Ohman K.P. Arnquist H.J. Serum leptin concentrations in a normal population and in $\mathrm{GH}$ deficiency: negative correlation with testosterone in men and effects of GH treatment. Clin Endocrinol Oxf 1997:47:191-198. Auwerx J., Staels B. Leptin. Lancel 1998:351:737-742

38. Flier J.S. Leptin expression and action: New experimental paradigms. Proceedings of the National Academy of Sciences of the United S Tates of America 1997:94 (9):4242-4245.

39. Schols A. Creutzberg E.C. Buunnan W.A. Campfield L.A.. Saris W.H.M., Wouters E.F.M Plasma leptin is related to proinflammatory status and dietary intake in patients with chronic obstructive pulmonary disease. Am J Respir Crit Care Med 1999:160:1220-1226.

Takabatake N. Nakamura H., Abe S. Hino T., Saito H., Yuki H.. Káto S. Tomoike H Circulating leptin in patients with chronic obstructive pulmonary disease. Am.J Respir Crit Care Med 1999:159(4):1215-1219

41. Fletcher E.C.. Martin R.J. Sexual dysfunction and erectile impotence in chronic obstructive pulmonary disease. Chest 1982:81:413-421

42. Ferreira I.M.. Brooks D.. Lacasse Y. Goldstein R.S. Nutritional Support for Individuals With COPD: A Meta-analysis. Chest 2000:117:672-678

43. Schols A.M.W.J.. Slangen J.. Volovics L.. Wouters E.F.M. Weight loss is a reversible factor in the prognosis of chronic obstructive pulmonary disease. Am.J Respir Crit Care Med 1998:157 (6): $1791-1797$.

44. Kamischke A.. Kemper D.E., Castel M.A., Luthke M., Rolf C., Behre H.M.. Magnussen H. Nieschlag $\mathrm{E}$. Testosterone levels in men with chronic obstructive pulmonary disease with or without glucocorticoid therapy. Eur Respir J 1998:11:41-45.

45. Ballal S.H.. Domoto D.T., Polack D.C. Marciulonis P., Martin K.J. Androgens potentrate the effects of enthropoietin in the treatment of anemia of end-stage renal disease |see comments|. $\mathrm{Am}$ J Kidney Dis 1991:17:29-33.

46. Berns J.S.. Rudnick M.R. Cohen R.M. A controlled trial of recombinant human erythropoietin and 
nandrolone decanoate in the treatment of anemia in patients on chronic hemodialysis. Clin Nephrol 1992:37:264-267.

47. Casale R., Pasqualetti P. Diurnal rhythm of serum erythropoietin circulating levels in chronic obstructive pulmonary disease. Panminerva Med 1997;39: 183-185.

48. Sturmi J.E., Diorio D.J. Anabolic agents. Clin Sports Med 1998;17:261-282.

49. Hansell D.T., Davies J.W., Shenkin A., Garden O.J., Burns H.J., Carter D.C. The effects of an anabolic steroid and peripherally administered intravenous nutrition in the early postoperative period J Parenter Enteral Nutr 1989; 13:349-358.

50. Pape G.S., Friedman M., Underwood L.E., Clemmons D.R. The effect of growth hormone on weight gain and pulmonary function in patients with chronic obstructive lung disease. Chest 1991:99:1495-1500

51. Burdet L., de Muralt B., Schutz Y., Pichard C., Fitting J.W. Administration of growth hormone to underweight patients with chronic obstructive pulmonary disease. A prospective, randomized. controlled study. Am J Respir Cril Care Med 1997;156:1800-1806.

52. Riise G.C., Larsson S., Lofdahl C.G., Andersson B.A. Circulating cell adhesion molecules in bronchial lavage and serum in COPD patients with chronic bronchitis. Eur Respir $J$ 1994:7:16731677.

53. Di Francia M., Barbier D., Mege J.L., Orehek J. Tumor necrosis factor-alpha levels and weight loss in chronic obstructive pulmonary disease. Am J Respir Crit Care Med 1994;150: 1453-1455.

54. De Godoy I., Donahoe M., Calhoun W.J., Mancino J., Rogers R.M. Elevated TNF-alpha production by peripheral blood monocytes of weight-losing COPD patients. Am J Respir Crit Care Med 1996; 153:633-637.

55. Keatings V.M. Jatakanon A., Worsdell Y.M., Barnes P.J. Effects of inhaled and oral glucocorticoids on inflammatory indices in asthma and COPD. Am J Respir Crit Care Med 1997; 155:542-548.

56. Furst P., Kuhn K.S. Fish oil emulsions: what benefits can they bring? Clin Nutr 2000:19:7-14.

57. Johnson M.M., Swan D.D., Surette M.E., Stegner J., Chilton T., Fonteh A.N., Chilton F.H. Dietary supplementation with gamma-linolenic acid alters fatty acid content and eicosanoid production in healthy humans. $J$ Nutr 1997: 127:1435-1444.

58. Falconer J.S., Fearon K C., Ross J.A., Carter D.C. Polyunsaturated fatty acids in the treatment of weight-losing patients with pancreatic cancer. World Rev Nutr Diet 1994:76:74-76.

59 Wigmore S.J., Ross J.A., Falconer J.S., Plester C.E.. Tisdale M.J.. Carter D.C., Fearon K.C. The effect of polyunsaturated fatty acids on the progress of cachexia in patients with pancreatic cancer. Nutrinon 1996:12:S27-30.

60. Wigmore S.J., Fearon K.C., Maingay J.P., Ross J.A. Down-regulation of the acute-phase response in patients with pancreatic cancer cachexia receiving oral eicosapentaenoic acid is mediated via suppression of interleukin-6. Clin Sci Colch 1997:92:215-221.

61. Belluzzi A., Boschi S., Brignola C.. Munarini A., Cariani G. Miglio F. Polyunsaturated fatty acids and inflammatory bowel disease. Am J Clin Nutr 2000:71:339S-342S.

62. Schwartz J. Role of polyunsaturated fatty acids in lung disease. Am J Clin Nutr 2000:71:393S$396 \mathrm{~S}$

63. Archer S.L., Johnson G.J., Gebhard R.L. Castleman W.L., Levine A.S., Westcott J.Y., Voelkel N.F.. Nelson D.P., Weir E.K. Effect of dietary fish oil on lung lipid profile and hypoxic pulmonan hypertension. J Appl Physiol 1989;66:1662-1673

64. Barnes P J. Novel approaches and targets for treatment of chronic obstructive pulmonary disease. Am. Respir Crit Care Med 1999:160:S72-S79. 
Chapter 11

Summary 
In the present thesis, the following topics were studied:

1. The prevalence of and the contributing factors to an increased resting energy expenditure (REE) in patients with chronic obstructive pulmonary disease (COPD).

2. The role of leptin in the energy (im-)balance in patients with stable COPD and during acute disease exacerbations.

3. The efficacy of nutritional supplementation and anabolic steroid therapy implemented in a pulmonary rehabilitation program in patients with COPD. In addition, determinants of nonresponse to these anabolic management strategies were investigated.

Below, the results of the studies on these three domains of investigation are shortly summarized.

\section{Resting energy expenditure}

The commonly occurring weight loss in patients with COPD is the result of an imbalance between energy expenditure and energy intake. Besides an increased total daily energy expenditure (TDEE), an elevated REE is often reported. However, the prevalence of hypermetabolism at rest and its contributing factors are still unknown. In chapter 2 , the prevalence of an elevated REE in patients with COPD, in relationship with body composition and lung function, was studied. Fat-free mass (FFM) is the major determinant of REE in healthy subjects and FFM is decreased in a substantial proportion of patients with COPD. Therefore the prevalence of hypermetabolism was determined on base of the relationship between FFM and REE in a healthy, elderly control group. On the base of the generated equations, the prevalence of an increased REE in COPD amounted up to $26 \%$. Hypermetabolic patients were characterized by a lower age and a lower total lung capacity (TLC) compared to normometabolic patients. The latter finding was in contrast to the suggested contribution of an elevated oxygen cost of breathing (OCB) to an increased REE in COPD. The patients depleted in FFM were characterized by a higher residual volume/TLC ratio and a lower maximal inspiratory mouth pressure (PI-max) compared to non-depleted patients, independently of hypermetabolism. This finding suggested a higher OCB during activities, independently of REE, contributing to the elevated TDEE previously reported in COPD. The usually applied Harris and Benedict equations, that do not consider body composition but only global body weight, overestimated the prevalence of hypermetabolism at rest and linked hypermetabolism incorrectly to aging and FFM depletion in COPD.

As one of the possible contributors to hypermetabolism at rest. in chapter 3 the acute effects of nebulized salbutamol, a commonly used $\beta_{2}$-sympathicomimetic bronchodilating drug, on REE was investigated in patients with COPD in comparison with a group of younger and elderly healthy subjects. A single dose $(5 \mathrm{mg})$ of nebulized salbutamol induced an increase in REE of $4 \%$ in patients with COPD, which was lower than the increase in younger healthy subjects $\left(11^{\circ} \%\right)$. but comparable to the increase in healthy elderly control subjects $(6 \%)$. It was concluded that the contribution of a single dose of salbutamol to REE could not fully explain hypermetabolism at rest in patients with COPD. 


\section{Leptin}

The potential role of the hormone leptin in the regulation of the energy balance in patients with stable COPD, in relationship with the systemic inflammatory response, was investigated in chapter 4. Male patients with the COPD-subtype emphysema exhibited lower (detectable) leptin concentrations in comparison with male patients with the COPD. subtype chronic bronchitis. This was due to a lower fat mass (FM), which is the tissue in which leptin is predominantly produced, in emphysema. In emplyysematous patients, leptin was positively correlated with the inflammatory marker soluble TNF-receptor 55 (STNE-R55), after adjustment for the influences of FM and oral glucocorticosteroid (GC) use. Leptin divided by FM was in tum inversely correlated with dietary intake in depleted, predominantly emphysematous, male patients with COPD, as well as with the degree of weight change after eight weeks of nutritional supplementation therapy. This proposed cytokine-leptin link in pulmonary cachexia might explain the poor response to nutritional support in a part of the patients with COPD.

In chapter 5 , the role of leptin in the energy balance of patients with COPD during the first seven days of hospitalization for an acute disease exacerbation was investigated. On admission to the hospital, the dietary intake/REE ratio was severely disturbed, but gradually restored until day seven. Also temporary increases in the acute phase protein response and in the systemic concentrations of glucose and insulin were seen. Plasma leptin divided by the amount of FM dropped during the course of the exacerbation, but remained elevated compared to the concentration in healthy, elderly subjects. On day seven of the exacerbation, sTNF-R55 was, independently of FM, correlated with the natural logarithm (LN) of leptin as well as with plasma glucose. In turn, LN leptin, but also sTNF-R55, were inversely correlated with the dietary intake/REE ratio on day seven. The temporarily disturbed energy balance during the first days of an acute exacerbation of COPD was related to increased plasma leptin concentrations as well as to the systemic inflammatory response. Evidence was found that leptin was in turn under control of the systemic inflammatory response and, presumably, the high-dose systemic GC treatment.

\section{Therapeutic options}

Since body mass and FFM depletion adversely affect functional performance, health status and survival rates in patients with COPD, nutritional support can be considered as an appropriate treatment option. In chapter 6 , the efficacy of eight weeks of oral nutritional supplementation therapy $(500-750 \mathrm{kcal} /$ day extra) implemented in a standardized pulmonary rehabilitation program in depleted and weight-losing patients with COPD was investigated. Overall, significant increases in body weight, fat-free mass, respiratory and peripheral muscle strength, exercise capacity and health status were achieved. About half of the patients was long-term treated with low-dose oral GCs as maintenance antiinflammatory medication. The use of systemic GCs significantly attenuated the response to nutritional support with respect to PI-max, exercise capacity and health status. In general, optimized nutritional supplementation therapy was effective in depleted and in weight-losing patients with COPD, but for the subgroup long-term treated with oral GCs, additional modes of intervention must be taken into investigation.

Not all depleted patients with COPD respond to nutritional therapy in terms of body weight gain. Therefore we have investigated in chapter 7 the possible causes of 
nonresponse to eight weeks of optimized nutritional supplementation therapy (500-750 $\mathrm{kcal} /$ day extra) embedded in a pulmonary rehabilitation program. The subgroup of patients that exhibited a body weight gain $<2 \%$ were characterized by older age and, at baseline, a lower dietary intake/REE ratio and higher circulating concentrations of fasting glucose, LPS-binding protein and sTNF-R55 and R75 compared to patients with a body weight gain $z 5 \%$. Also the number of users of continuous oxygen supply was higher in nonresponders. On regression analysis, age, baseline dietary intake/REE ratio, sTNF-R55 and extracellular/intracellular water ratio significantly and independently explained $78 \%$ of the variation in body weight change after nutritional therapy. For depleted patients characterized by an elevated systemic inflammatory response, additional treatment options must be considered to enhance the response to nutritional therapy.

In chapter 8, the rationale for anabolic steroid therapy, the available clinical trials in acute and chronic disease and the side-effects of anabolic steroids were reviewed. Also the supposed mechanisms of action of anabolic steroids on muscle tissue, bone tissue, the hematopoietic system, the acute phase response and immune function and their interaction with glucocorticosteroids were discussed.

The efficacy of anabolic steroid treatment in the rehabilitation of male patients with COPD was studied in chapter 9. Eight weeks of treatment with nandrolone decanoate relative to placebo implemented in a pulmonary rehabilitation program resulted in higher increases in FFM, intracellular mass and health status, without revelation of significant side-effects. Furthermore, PI-max and peripheral muscle endurance only improved in the nandrolone decanoate treated patients. Irrespective of anabolic steroid addition, pulmonary rehabilitation lead to improvements in peripheral muscle strength and exercise capacity. About half of the patients was long-term treated with low-dose oral GCs as maintenance anti-inflammatory medication. Maintenance oral GC treatment significantly impaired the response to pulmonary rehabilitation with respect to PI-max and exercise capacity, unless nandrolone decanoate was given.

Chapter 10 comprised the general discussion of the thesis and suggests implications for future investigations. 


\title{
Chapter 12
}

\author{
Samenvatting
}


In dit proefschrift werden de volgende onderwerpen bestudeerd:

1. De prevalentie van en de bijdragende factoren aan een verhoogd energiegebruik in rust bij patiënten met chronisch obstructief longlijden ("chronic obstructive pulmonary disease'; COPD).

2. The rol van leptine in de energiebalans bij patiënten met COPD in de stabiele fase en tijdens acute ziekte-exacerbaties.

3. De effectiviteit van behandeling met voedingssupplementen c.q. anabole steroïden geïmplementeerd in een longrevalidatieprogramma bij patiënten met COPD. Ook zijn de determinanten van het niet reageren op deze anabole behandelingsstrategieen onderzocht.

Hieronder worden de resultaten van de studies op deze drie onderzoeksterreinen kort samengevat.

\section{Rustenergiegebruik}

Gewichtsverlies komt vaak voor bij patiënten met COPD. Gewichtsverlies is de resultante van een verstoorde balans tussen energieopname en energiegebruik. Naast een verhoogd totaal dagelijks energiegebruik, wordt een verhoogd rustenergiegebruik vaak gerapporteerd bij patiënten met COPD. De prevalentie van hypermetabolisme in rust en de factoren die ervoor verantwoordelijk zijn, zijn echter nog onbekend. In hoofdstuk 2 is de prevalentie van een verhoogd rustenergiegebruik bij patiënten met COPD bestudeerd, in relatie tot lichaamssamenstelling en longfunctie. De vetvrije massa is de belangrijkste determinant van het rustenergiegebruik bij gezonde individuen. In een behoorlijk deel van de COPDpopulatie is de vetvrije massa verlaagd. Om deze redenen hebben we de prevalentie van hypermetabolisme in rust bij patiënten met COPD bepaald aan de hand van de relatie tussen vetvrije massa en rustenergiegebruik in een gezonde, oudere controlegroep. Op basis van de gegenereerde vergelijkingen bedroeg de prevalentie van een verhoogd rustenergiegebruik bij COPD $26 \%$. Hypermetabole patiënten werden gekarakteriseerd door een lagere leeftijd en een lagere totale longcapaciteit vergeleken met normometabole patiënten. De laatste bevinding was in tegenspraak met de gesuggereerde bijdrage van een verhoogde ademarbeid aan het verhoogde rustenergiegebruik bij COPD. De patiënten die leden aan depletie van vetvrije massa werden gekarakteriseerd door een hogere ratio residuaal volume/totale longcapaciteit en een lagere ademhalingsspierkracht vergeleken met niet-gedepleerde patiënten, onafhankelijk van hypermetabolisme in rust. Deze bevinding suggereerde een verhoogde ademarbeid tijdens activiteiten, onafhankelijk van het rustenergiegebruik, bijdragend aan het verhoogde totaal dagelijks energiegebruik eerder gerapporteerd bij COPD. De in het algemeen gebruikte Harris en Benedict vergelijkingen, die geen rekening houden met de lichaamssamenstelling maar alleen met het globale lichaamsgewicht, overgeschatten de prevalentie van hypermetabolisme in rust bij COPD. Verder relateren ze hypermetabolisme in rust onterecht aan een hogere leeftijd en aan depletie van vetvrije massa.

Eén van de mogelijke oorzaken van hypermetabolisme in rust bij patiënten met COPD is het gebruik van luchtwegverwijdende medicatie zoals het $B_{2}$-sympathicomimeticum salbutamol. In hoofdstuk 3 werden de acute effecten van verneveld salbutamol op het rustenergicgebruik bij patiënten met COPD onderzocht, in vergelijking met een groep jongere en oudere gezonde individuen. Verneveling van $5 \mathrm{mg}$ salbutamol induceerde een 
stijging in het rustenergiegebruik van $4 \%$ bij patiënten met COPD. Deze stijging was lager dan die bij gezonde jongeren (11\%), maar vergelijkbaar aan die bij gezonde ouderen $(6 \%)$. Geconcludeerd werd dat de bijdrage van een enkele dosis salbutamol aan het rustenergiegebruik niet het hypermetabolisme in rust bij patiënten met COPD volledig kon verklaren.

\section{Leptine}

De mogelijke rol van het hormoon leptine in de regulatie van de energiebalans bij patiënten met stabiel COPD, in relatie tot de systemisch inflammatoire respons, is onderzocht in hoofdstuk 4. Mannelijke patiënten met het COPD-subtype emfyseem vertoonden lagere (detecteerbare) leptineconcentraties dan mannelijke patiënten met het COPD-subtype chronische bronchitis. Dit kwam door de lagere vetmassa, het weefsel waarin leptine voornamelijk geproduceerd wordt, bij emfyseempatiënten. Leptine was positief gecorreleerd aan de circulerende inflammatoire merker TNF-receptor 55 bij patiënten met emfyseem, rekening houdend met de invloeden van vetmassa en oraal glucocorticosteroïdgebruik. Leptine gedeeld door de vetmassa was negatief gecorreleerd aan de voedselinname bij gedepleerde, voornamelijk emfysemateuze, mannelijke patiënten met COPD, evenals aan de gewichtsverandering na acht weken voedingssuppletie. Deze correlaties tussen cytokines en leptine bij pulmonaire cachexie verklaren wellicht de slechte respons op voedingstherapie bij een deel van de patiënten met COPD.

In hoofdstuk 5 werd de rol van leptine in de energiebalans van patiënten met COPD tijdens de eerste zeven dagen van ziekenhuisopname wegens een acute ziekte-exacerbatie onderzocht. Bij opname was de ratio voedselinname/rustenergiegebruik ernstig verstoord, maar herstelde geleidelijk tot aan dag 7. Ook waren er tijdelijke verhogingen van de acute fase respons en van de plasmaconcentraties van glucose en insuline. De concentratie leptine gecorrigeerd voor de vetmassa daalde tijdens de exacerbatie, maar bleef verhoogd ten opzichte van de concentratie bij gezonde, oudere individuen. Op dag zeven van de exacerbatie was de circulerende TNF-receptor 55, onafhankelijk van de vetmassa, gecorreleerd aan de concentraties leptine en glucose. Leptine en de circulerende TNFreceptor 55 waren op dag zeven van de exacerbatie negatief gecorreleerd aan de ratio voedselinname/rustenergiegebruik. De tijdelijk verstoorde energiebalans tijdens een acute exacerbatie van COPD was geassocieerd met verhoogde leptineconcentraties en met de systemisch inflammatoire respons. Er waren aanwijzingen dat leptine onder controle stond van de systemisch inflammatoire respons en waarschijnlijk de hoge doses systemische glucocorticosteroïden.

\section{Behandelingsopties}

Omdat depletie van lichaamsgewicht en vetvrije massa een negatieve invloed hebben op de functionele capaciteit, de gezondheidsstatus en de mortaliteit bij patiënten met COPD, is voedingssuppletie een passende behandelingsoptie. In hoofdstuk 6 werd de effectiviteit van orale voedingstherapie in de vorm van supplementen (500-750 kcal/dag extra) bij gedepleerde en gewichtsverliezende patiënten met COPD onderzocht. De voedingstherapie was geïplementeerd in een gestandaardiseerd longrevalidatieprogramma. Er werden significante toenamen in lichaamsgewicht, vetvrije massa, ademhalings- en perifere spierfunctie, inspanningscapaciteit en gezondheidsstatus bereikt. Ongeveer de helft van de patiënten werd behandeld met lage doses orale glucocorticosteroïden als onderhouds- 
medicatie. Patiënten die systemische glucocorticosteroïden gebruikten, vertoonden een significant lagere respons op voedingstherapie wat betreft ademhalingsspierfunctie, inspanningscapaciteit en gezondheidsstatus dan patiënten die geen systemische glucocorticosteroïden gebruikten. In het algemeen was geoptimaliseerde voedingssuppletie effectief bij gedepleerde en gewichtsverliezende patiënten met COPD. Echter voor de subgroep die langdurig behandeld werd met orale glucocorticosteroïden, moeten additionele interventiestrategieën in overweging genomen worden.

Niet alle gedepleerde patiënten met COPD reageren op voedingstherapie met gewichtstoename. Daarom hebben we in hoofdstuk 7 de mogelijke oorzaken van non-respons op acht weken geoptimaliseerde voedingssuppletie (500-750 kcal/dag extra), geïmplementeerd in een longrevalidatieprogramma, onderzocht. De subgroep van patiënten die minder dan $2 \%$ aankwam in gewicht, werd gekarakteriseerd door een hogere leeftijd, een lagere ratio voedselinname/rustenergiegebruik en hogere concentraties glucose, LPS-bindend eiwit en de circulerende TNF-receptoren 55 en 75 vergeleken met patiënten die 5\% of meer aankwamen in gewicht. Ook waren er meer patiënten die continu zuurstof gebruikten in de groep die niet goed reageerde op voedingssuppletie. Een regressieanalyse liet zien dat de factoren leeftijd, de ratio voedselinname/rustenergiegebruik, de concentratie circulerende TNF-receptor 55 en de ratio extracellulair/intracellulair water de variatie in gewichtsverandering na voedingstherapie voor $78 \%$ konden verklaren. Voor gedepleerde patiënten gekarakteriseerd door een verhoogde systemisch inflammatoire respons moeten additionele therapieën ontwikkeld worden, om de respons op voedingstherapie te vergroten.

Hoofdstuk acht geeft een overzicht over de rationele voor therapie met anabole steroïden, de beschikbare klinische onderzoeken bij acute en chronische ziekten en de bijwerkingen van anabole steroïden. Ook worden de veronderstelde werkingsmechanismen van anabole steroïden besproken wat betreft spierweefsel, botweefsel, het bloedbereidende systeem, de acute fase respons, de immuunfunctie en de interactie met glucocorticosteroïden.

De effectiviteit van anabole steroïdenbehandeling, geïntegreerd in de revalidatie van mannelijke patiënten met COPD, werd onderzocht in hoofdstuk 9. Acht weken behandeling met het anabool steroïde nandrolon decanoaat resulteerde in sterkere toenamen in de vetvrije massa, de intracellulaire massa en de gezondheidsstatus vergeleken met placebo. Er werden geen noemenswaardige bijwerkingen gerapporteerd. De ademhalingsspierfunctie en het uithoudingsvermogen van de perifere spieren verbeterden alleen bij de met nandrolon decanoaat behandelde patiënten. De kracht van de perifere spieren en de inspanningscapaciteit verbeterden onafhankelijk van behandeling met nandrolon decanoaat. Ongeveer de helft van de patiënten kreeg lage doses orale glucocorticosteroïden als onderhoudsbehandeling. In deze groep patiënten waren de verbeteringen in de ademhalingsspierfunctie en de inspanningscapaciteit significant groter na behandeling met nandrolon decanoaat vergeleken met placebo.

Hoofdstuk 10 behelsde de algemene discussie van het proefschrift en deed suggesties voor verder onderzoek. 
Abbreviations 


\begin{tabular}{|c|c|}
\hline$\% \mathrm{FM}$ & fat mass as percentage of body weight \\
\hline \%pred & percentage of predicted \\
\hline $12 \mathrm{MWD}$ & 12 minute walking distance \\
\hline AIDS & acquired immunodeficiency syndrome \\
\hline ANOVA & analysis of variance \\
\hline APPR & acute phase protein response \\
\hline BFU-E & burst-forming unit-erythroid \\
\hline BIA & bioelectrical impedance analysis \\
\hline BMI & body mass index \\
\hline CFU-E & colony-forming unit-erythroid \\
\hline $\mathrm{Cl}$ & confidence interval \\
\hline COPD & chronic obstructive pulmonary disease \\
\hline CRP & $C$-reactive protein \\
\hline $\operatorname{CSA}$ & cross-sectional area \\
\hline $\mathrm{D}_{2} \mathrm{O}$ & deuterium-labeled water \\
\hline Dico & diffusing capacity for $\mathrm{CO}$ \\
\hline DXA & dual-energy $x$-ray absorptiometry \\
\hline $\mathrm{ECM}$ & extracellular mass \\
\hline $\mathrm{ECW}$ & extracellular water \\
\hline ECW/ICW ratio & extracellular/intracellular water ratio \\
\hline EDTA & ethylene-diamine-tetraacetic acid \\
\hline ELISA & enzyme-linked immunosorbent assay \\
\hline EPO & erythropoietin \\
\hline ESR & erythrocyte sedimentation rate \\
\hline $\mathrm{FEV}_{1}$ & forced expiratory volume in one second \\
\hline FFA & free fatty acid \\
\hline FFM & fat-free mass \\
\hline FFMI & tat-free mass index \\
\hline FM & fat mass \\
\hline $\mathrm{FVC}$ & forced vital capacity \\
\hline GC & glucocorticosteroid \\
\hline $\mathrm{HB}$ & Harris and Benedict \\
\hline HIV & human immunodeficiency virus \\
\hline HR & heart rate \\
\hline HRCT & high-resolution computed tomography \\
\hline HRP & horseradish peroxidase \\
\hline i.m. & intramuscular \\
\hline $\mathrm{ICM}$ & intracellular mass \\
\hline $\mathrm{ICW}$ & intracellular water \\
\hline IGF & insulin-like growth factor \\
\hline IL & interleukin \\
\hline ITGV & intrathoracic gas volume \\
\hline IVC & inspiratory vital capacity \\
\hline Kco & diffusing capacity corrected for alveolar space \\
\hline LBP & LPS-binding protein \\
\hline
\end{tabular}




\begin{tabular}{|c|c|}
\hline LDH & lactate dehydrogenase \\
\hline LN leptin & natural logarhythm of leptin \\
\hline LPS & lipopolysaccharide \\
\hline MHC & myosin heavy chain \\
\hline MIP & mean inspiratory pressure \\
\hline mRNA & messenger RNA \\
\hline ND & nandrolone decanoate \\
\hline NIDDM & non-insulin-dependent diabetes mellitus \\
\hline NS & not significant \\
\hline OCB & oxygen cost of breathing \\
\hline$p(-v a l u e)$ & statistical significance \\
\hline $\mathrm{PaCO}_{2}$ & arterial carbon dioxide tension \\
\hline $\mathrm{PaO}_{2}$ & arterial oxygen tension \\
\hline PE-max & maximal expiratory pressure \\
\hline PEF & peak expiratory flow \\
\hline PG & prostaglandin \\
\hline PI-max & maximal inspiratory mouth pressure \\
\hline I & correlation coefficient \\
\hline $\mathrm{R}^{2}$ & explained variance \\
\hline Raw & airway resistance \\
\hline REE & resting energy expenditure \\
\hline REEFFM & predicted REE adjusted for FFM \\
\hline REEHB & predicted REE on the base of the Harris and Benedict equations \\
\hline rHuEPO & recombinant human erythropoietin \\
\hline RQ & respiratory quotient \\
\hline RV & residual volume \\
\hline $\mathrm{SaO}_{2}$ & arterial oxygen saturation \\
\hline $\mathrm{SD}$ & standard deviation \\
\hline SEM & standard error of the mean \\
\hline SGRQ & St. George`s Respiratory Questionnaire \\
\hline SICAM & soluble intercellular adhesion molecule \\
\hline SPSS & statistical package for the social sciences \\
\hline sTNF-R55 & soluble TNF-receptor 55 \\
\hline sTNF-R75 & soluble TNF-receptor 75 \\
\hline TBW & total body water \\
\hline TDEE & total daily energy expenditure \\
\hline TLC & total lung capacity \\
\hline TNF $\alpha$ & tumor necrosis factor $\alpha$ \\
\hline UCP & uncoupling protein \\
\hline VAS & visual analogue scale \\
\hline $\mathrm{V}^{\prime} \mathrm{CO}_{2}$ & carbon dioxide production \\
\hline $\mathrm{VO}_{2}$ & oxygen consumption \\
\hline
\end{tabular}


Naschrift 
Dit naschrift geeft me de gelegenheid de mensen te bedanken, zonder wier hulp dit proefschrift niet tot stand zou zijn gekomen.

Allereerst natuurlijk mijn co-promotor Dr. ir. Annemie Schols. Je kritische werkwijze heeft voor een groot deel bijgedragen aan mijn vorming tot onderzoeker. Je enthousiasme en betrokkenheid heb ik zeer gewaardeerd! Prof. dr. E. Wouters, door uw overkoepelende visie over de materie heeft $u$ uw waarde voor mij vooral getoond tijdens het schijven van de artikelen, dank hiervoor.

Het onderzoek dat in dit proefschrift beschreven is, is uitgevoerd binnen de Universiteit Maastricht c.q. het Academisch Ziekenhuis Maastricht en voor een groot deel binnen het Astmacentrum Hornerheide. Omdat ik op beide plaatsen met veel plezier heb gewerkt, wil ik de desbetreffende medewerkers van de afzonderlijke centra hieronder noemen.

Erica Baarends, bedankt voor al je hulp en de leuke samenwerking tijdens de onderzoekstijd! Francine Bothmer, vooral tijdens mijn begintijd bij Longziekten heb ik veel praktische zaken van je geleerd, bedankt! Mieke Dentener, jou wil ik bedanken voor je kundige hulp en kritische blik met betrekking tot het inflammatoire deel van het onderzoek. Marja Vermeeren, bedankt voor de prettige samenwerking op voedingsgebied. Geertjan Wesseling wil ik bedanken voor de hulp tijdens de salbutamolstudie. Ook het longfunctieteam onder leiding van Ingrid Vanderhoven en verpleegafdeling A3 bedankt voor de medewerking.

De onderzoeksgroep van de capaciteitsgroep Pulmonologie en de vakgroep Longziekten is de laatste jaren flink gegroeid. ik wil alle (oud-) collega's bedankt voor de collegialiteit en gezelligheid: Roelinka Broekhuizen, Mariëlle Engelen, Frits Franssen, Harry Gosker, Karin Groenewegen, Esther Koerts, Solange Korn, Mehmet Küçükaycan, Ramon Langen, Lotte Nelissen, André Tinga en Juanita Vernooy. Ook de artsen en het secretariaat van de afdeling Longziekten: bedankt voor de prettige werkomgeving.

Wim Buurman van de capaciteitsgroep Algemene Heelkunde wil ik bedanken voor de kritische adviezen met betrekking tot de artikelen over inflammatie. François van Dielen van Algemene Heelkunde, bedankt voor de hulp bij de analyse van leptine. Annelies Goris van de capaciteitsgroep Humane Biologie, bedankt voor je hulp bij de voedingsstudie tijdens je stage op Homerheide. Klaas Westerterp en Wouter van Marken Lichtenbelt van de capaciteitsgroep Humane Biologie, hartelijk dank voor de samenwerking op het gebied van de lichaamssamenstelling.

In het algemeen wil ik alle medewerkers van het Astmacentrum Hornerheide bedanken voor hun bereidwillige medewerking aan het onderzoek. In het bijzonder: Clarie Weling. bedankt voor je enthousiaste inzet voor het onderzoek. Je hebt me enorm geholpen door veel praktische taken binnen de verschillende studies op je te nemen! De (long-) artsen Rob Mostert en Joan Does en later ook Herman-Jan Pennings en Jean Simons wil ik bedanken voor het soepel laten verlopen van het onderzoek in het astmacentrum. Ook de inzet van het verpleegkundig team heb ik zeer gewaardeerd. 
De voedingsassistenten, vooral Alda Hendriks en Truus Hoebergen, wil ik bedanken voor het uitdelen van wel heel veel pakjes bijvoeding. Bewegingsagogen Marco Akkermans en Jérôme Janssen: bedankt voor het goed laten veriopen van alle inspanningsonderzoeken en trainingen van de patiënten. Annelies Derks, Peggy Dzaak, Monique Peulen en Gonny Vervuurt: bedankt voor de hulp en de gezelligheid tijdens alle uurtjes die ik op het laboratorium heb vertoeft. Ook een bedankje aan de longfunctieassistenten Kitty Coenen en Marianne Kerckhoffs, het team fysiotherapie onder leiding van Paul Janssen en de secretaresses Annemiek Bergh en Gerry Janssen voor alle medewerking.

De beoordelingscommissie onder leiding van Prof. dr. R. Stockbrügger en verder bestaande uit Prof. dr. P. Calverley, Prof. dr. G. Ramsay, Prof. dr. H. Sauerwein en Prof. dr. K. Westerterp wil ik hartelijk danken voor het kritisch beoordelen van het proefschrift. Prof. Calverley, thank you for your critical evaluation of the thesis.

Het grootste gedeelte van het in dit proefschrift beschreven onderzoek werd uitgevoerd met financiële steun van Numico Research BV en NV Organon, waarvoor dank. De rol van het 'anabool management' in de behandeling van patiënten met COPD is groeiende! Het anabole steroïdenonderzoek in samenwerking met NV Organon had een prominente plaats in mijn AIO-tijd. Gerrit van de Laar, regelmatig kwam je op Hornerheide voor een werkbezoek dat altijd onderbroken werd voor een gezellige lunch. Jou en ook Rob Pluymers wil ik hartelijk bedanken voor de prettige samenwerking.

Tenslotte: respect heb ik voor de longpatiënten, die belangenloos hebben meegewerkt aan het onderzoek. Ondanks hun ziekte hadden ze vaak nog 'lucht' voor een aardige opmerking of grapje. 


\section{Publications}


- Creutzberg EC, Schols AMWJ, Bothmer-Quaedvlieg FCM, Wouters EFM. Prevalence of an elevated resting energy expenditure in patients with chronic obstructive pulmonary disease in relation to body composition and lung function. Eur. J. Clin. Nutr. 1998; 52 (6): 396-401.

- Creutzberg EC, Schols AMWJ, Bothmer-Quaedvlieg FCM, Wesseling G, Wouters EFM. Acute effects of nebulized salbutamol on resting energy expenditure in patients with chronic obstructive pulmonary disease and in healthy subjects. Respiration 1998; 65 (5): $375-380$.

- Creutzberg EC, Schols AMWJ. Anabolic steroids. Curr. Opin. Clin. Nutr. Metab. Care 1999; 2: 243-253.

- Schols AMWJ, Creutzberg EC, Buurman WA, Campfield LA, Saris WHM, Wouters EFM. Plasma leptin is related to proinflammatory status and dietary intake in patients with chronic obstructive pulmonary disease. Am. J. Respir. Crit. Care Med. 1999; 160: 1220-1226.

- Creutzberg EC, Schols AMWJ, Weling-Scheepers CAPM, Buurman WA, Wouters EFM. Characterization of nonresponse to high caloric oral nutritional therapy in depleted patients with chronic obstructive pulmonary disease. Am. J. Respir. Crit. Care Med. 2000; 161: 745-752.

- Creutyberg EC. Wouters EFM, Vanderhoven-Augustin IML, Dentener MA, Schols AMWJ. Disturbances in leptin metabolism are related to energy imbalance during acute cxacerbations of chronic obstructive pulmonary disease. Am. J. Respir. Crit. Care Med. 2000 ; in press.

- Creutzberg E(: Wouters EFM, Mostert R. Weling-Scheepers CAPM, Schols AMWJ. lifficacy of nutritional supplementation therapy implemented in a pulmonary rehabilitation program in depleted patients with COPD. 2000. Submitted.

- Creutzberg EC, Wouters EFM. Mostert R, Pluymers RJ, Schols AMWJ. A role for anabolic steroids in the rehabilitation of patients with chronic obstructive pulmonary disease? A double-blind, placebo-controlled, randomized trial. 2000. Submitted.

- Dentener MA, Creutzberg EC, Schols AMWJ, Veer C van 't. Buurman WA, Wouters EFM. Enhancement of anti-inflammatory mediator soluble interleukin-I receptor ii (sil1rii) during treatment of exacerbation of chronic obstructive pulmonary disease. 2000 . Submitted. 


\section{Curriculum vitae}


Eva Creutzberg was born on July 1, 1971 in Heiloo, The Netherlands. After she finished secondary school (gymnasium beta; Murmellius Gymnasium, Alkmaar, The Netherlands) in 1989, she attended the one-year education at the 'Vrije Hogeschool' (Driebergen, The Netherlands). In 1990 she started the study 'Health Sciences' at the University of Maastricht, The Netherlands and specialized in 'Biological Health Sciences'. She graduated in 1995 on a research project performed at the Department of Pulmonology, University Hospital Maastricht.

From March 1995 until October 2000 she worked as a PhD student c.q. research assistant at the Department of Pulmonology of the University Hospital Maastricht. Her project concerned energy metabolism and inflammation in relation to tissue depletion in COPD, as well as therapeutic options for the treatment of the systemic impairments in patients with COPD. 
